Self-management support using mHealth in patients with COPD

From promise to proof
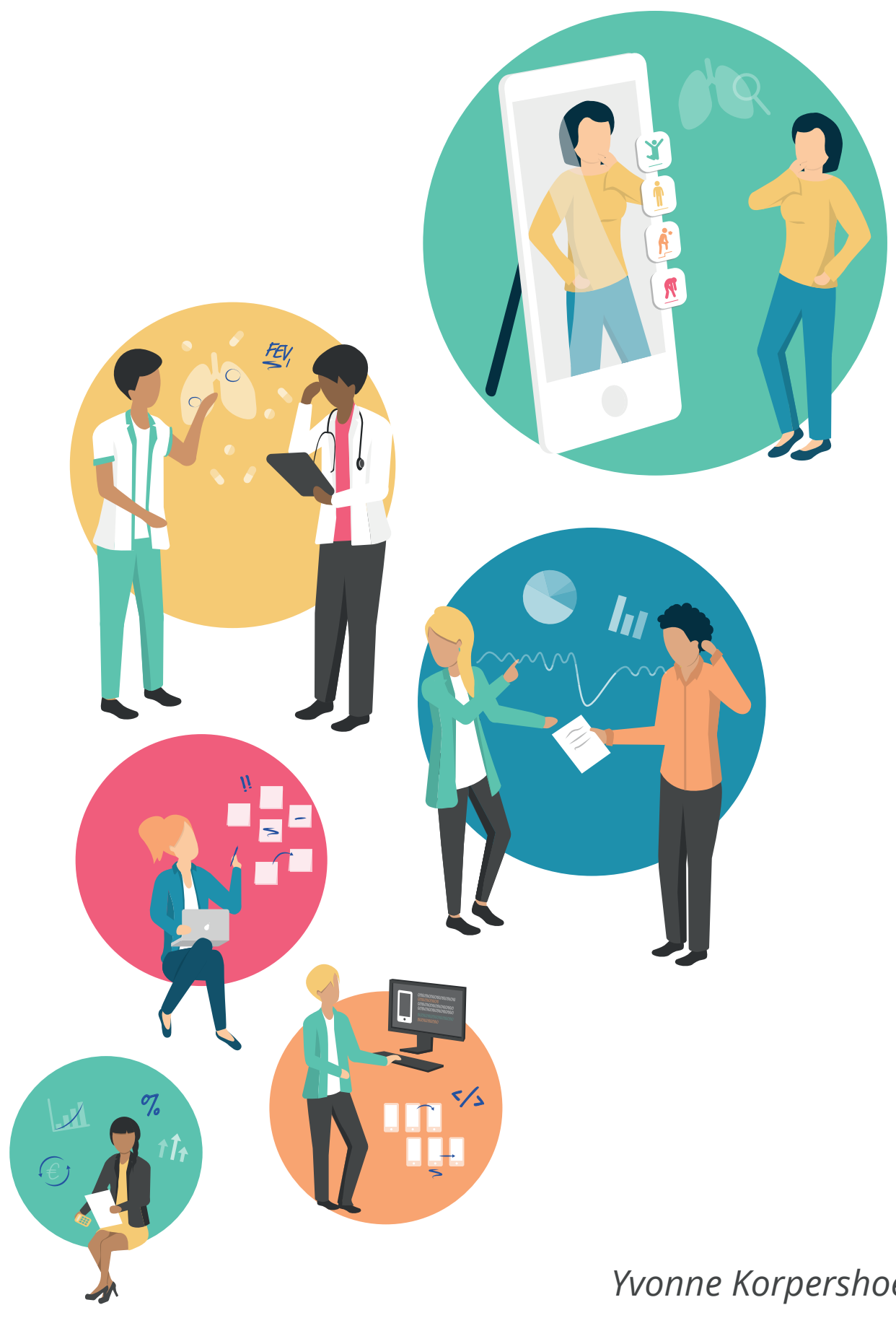

Yvonne Korpershoek 


\title{
Self-management support using mHealth in patients with COPD
}

\author{
From promise to proof
}

Yvonne Korpershoek 


\section{Self-management support using mHealth in patients with COPD}

From promise to proof

ISBN: 978-90-831117-9-7

Cover design: Beatrijs Van Hoof, Panton BV

Printed by: Print Service Ede

(C2021, Yvonne Korpershoek

All rights reserved. No part of this thesis may be reproduced or transmitted in any form or by any means, without permission of the author. 


\title{
Self-management support using mHealth in patients with COPD
}

\author{
From promise to proof
}

Zelfmanagementondersteuning door middel van mHealth

bij patiënten met COPD

Van belofte tot bewijs

(met een samenvatting in het Nederlands)

\section{Proefschrift}

ter verkrijging van de graad van doctor aan de Universiteit Utrecht op gezag van de rector magnificus, prof.dr. H.R.B.M. Kummeling, ingevolge het besluit van het college voor promoties

in het openbaar te verdedigen op

donderdag 4 maart 2021 des middags te 2.30 uur

door

Yvonne Johanna Gerarda Korpershoek

geboren op 30 mei 1986

te Veenendaal 
Promotoren:

Prof. dr. L. Schoonhoven

Prof. dr. M.J. Schuurmans

Copromotor:

Dr. J.C.A. Trappenburg

The studies in this thesis were financially supported by the University of Applied Sciences Utrecht and the Netherlands Organisation for Health Research and Development, ZonMw (grant number 520001002).

The development of the Copilot app was funded by a grant received for winning the Ureka Mega Challenge 2017 at the University Medical Center Utrecht. 



\section{CONTENT}

Chapter 1 General introduction

Part $1 \quad$ Self-management and the potential of mHealth in patients with COPD

Chapter 2 Determinants of activation for self-management in patients with COPD

Chapter 3 Factors influencing exacerbation-related self-

management in patients with COPD: a qualitative study

Chapter 4 Self-management behaviors to reduce exacerbation impact in COPD patients: a Delphi study

Chapter 5 Perceptions of patients with chronic obstructive pulmonary disease and their health care providers towards using mHealth for self-management of exacerbations: a qualitative study 
Part 2 A new mHealth intervention to enhance selfmanagement in patients with COPD

Chapter 6 User-centered design of a mobile health intervention to enhance exacerbation-related self-management in patients with chronic obstructive pulmonary disease (Copilot): mixed methods study

Chapter 7 Early-stage feasibility of a mobile health intervention (Copilot) to enhance exacerbation-related selfmanagement in patients with chronic obstructive pulmonary disease: multimethods approach

Chapter 8 General discussion

Summary

Samenvatting

List of publications and presentations

Dankwoord

Curriculum Vitae 


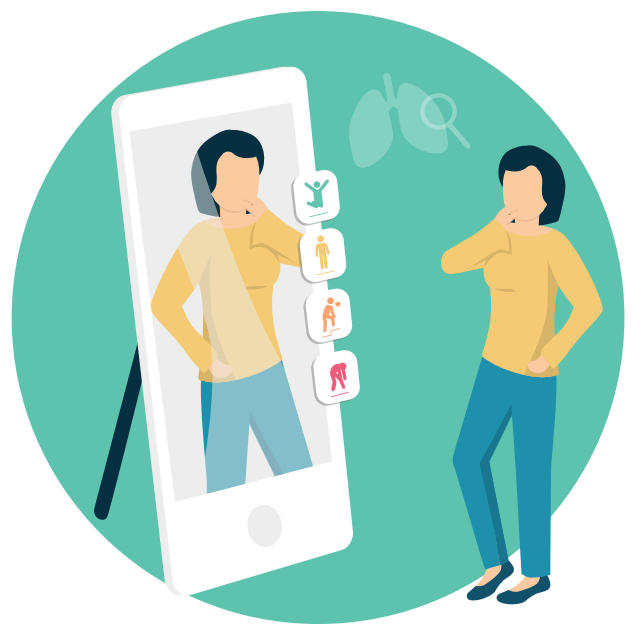




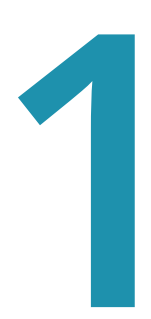

General Introduction 
Chapter 1 
Patients with COPD about their experiences with exacerbations:

"Symptoms of an exacerbation are so different, you can't put your finger on it" (chapter 3)

"Afterwards you can say: 'Oh, the symptoms were already present for a few days' " (chapter 3)

"I am someone who thinks 'then my doctor is wasting time for nothing', so I wait with contacting my doctor until I am sick to death" (chapter 3)

"I wish I would have had the information at that time about how I could recognize that I am not doing well and how I can manage a threating attack" (chapter 5)

"Sometimes when you are so short of breath, you forget things because of that. For me, it would be useful to have the correct steps clear for myself in case I am short of breath: What is it? What to do? How to breathe? Is there anyone I should contact? Who to contact? And what kind of medicine should I take?" (chapter 5)

\section{Can mobile health be used to enhance self-management in patients with COPD and thereby reduce the impact of exacerbations?}




\section{COPD and exacerbations}

Worldwide, Chronic Obstructive Pulmonary Disease (COPD) is one of the most common chronic diseases and currently the fourth leading cause of mortality. ${ }^{1,2}$ COPD is a progressive life-threatening lung disease that is characterized by a persistent reduction of airflow. ${ }^{3}$ The most common symptoms of COPD are dyspnea, chronic cough and sputum production and these symptoms vary from day to day in individual patients. ${ }^{3}$ The natural course of COPD is interrupted by exacerbations characterized by a sustained worsening of patients' respiratory symptoms, which are beyond normal day-to-day variability and may warrant medical treatment. ${ }^{4,5}$ These exacerbations are serious events in the course of COPD as they accelerate the decline in lung function, ${ }^{6}$ negatively affect the quality of life ${ }^{7,8}$ and lead to increased mortality ${ }^{9}$ and high socio-economic costs. ${ }^{10}$ Selfmanagement is widely recognized to be important to reduce the impact of COPD exacerbations on both patients and society. ${ }^{3}$ Patients can influence the frequency, severity and recovery of COPD exacerbations themselves by performing adequate self-management behavior before, during and after exacerbations.,11-13 Thus far, the management of COPD exacerbations is mostly reactive, with a main focus on medical treatment of exacerbations and less on prevention and early detection of exacerbations. A shift towards more pro-active exacerbation management is needed to further reduce the impact of exacerbations. This requires a more clear focus on self-management. ${ }^{14}$

\section{The concept of self-management}

In the past decades, increased attention has been paid to self-management to improve health outcomes and reduce health care costs associated with chronic conditions. ${ }^{15,16}$ This is in accordance with a paradigm shift in health care from traditional professional driven care towards more patient-centered care. ${ }^{17}$ The focus on self-management requires repositioning of the role of the patient and health care provider. Patients are nowadays expected to have an active role and to take responsibility in decisions affecting their chronic disease. ${ }^{17,18}$ Health care providers should focus on enabling patients to become active members in their own care and therefore have a major role in providing self-management support. ${ }^{15}$

Despite the widely recognized importance of self-management in chronic care, there is no consensus on the definition of self-management. Self-management is a broad term and in literature various definitions and concepts of self-management are used interchangeably. The definition used in this thesis is the widely applied definition by Barlow et al. (2002) who define self-management as "an individual's 
ability to detect and manage symptoms, treatment, physical and psychosocial consequences, and lifestyle changes inherent in living with a chronic condition". ${ }^{17}$ The introduction of various definitions and concepts leads to confusion in both the scientific, clinical and public domain. It remains unclear what self-management entails and what the exact role of patients and their health care providers should be. Subsequently, different understandings of self-management by health care providers lead to different ways of providing self-management support. ${ }^{17,19,20}$ The pivotal objective of self-management support is to change health behaviors and to equip patients with skills to actively participate in the management of their chronic disease. $14,21,22$ To date, patient education is often recognized as a way of providing self-management support. ${ }^{23}$ However, self-management support should go beyond educational approaches as education in itself does not change behavior or motivate patients. ${ }^{3,24,25}$ Adequate positioning of the concept of selfmanagement in health care is an ongoing challenge.

\section{Self-management in patients with COPD: a need for adequate support}

The quotes at the beginning of this chapter illustrate that self-management can be difficult for patients with COPD. Previous research showed that patients with COPD have difficulties with both detecting exacerbations and taking prompt actions. ${ }^{26-28}$ Approximately $50 \%$ of exacerbations are not reported to a health care professional and subsequently do not receive adequate treatment. ${ }^{28-31}$ The majority of patients with COPD is willing to respond promptly when experiencing symptom deterioration, but generally refrain from contacting a healthcare provider. ${ }^{28}$ Although considerable research has provided insight into patients perceptions and experiences regarding exacerbations, the underlying process of exacerbation-related self-management behavior is relatively unexplored. ${ }^{32-36} \mathrm{Also}$, little is known about which self-management behaviors have the highest potential to reduce exacerbation impact and are feasible to influence. Understanding selfmanagement behavior is however essential to provide adequate self-management support. ${ }^{25}$

\section{Effectiveness of COPD self-management interventions}

In the past decades, various self-management interventions have been developed for patients with COPD. Systematic reviews have reported positive results of selfmanagement interventions on hospital admissions, quality of life and health care use. ${ }^{11,12,37,38}$ The large heterogeneity in interventions, however, makes it hard to draw conclusions on the effective components and on what works for whom. ${ }^{38,39}$ Self-management interventions that include an action plan have shown positive 
outcomes on quality of life and hospital admissions ${ }^{12,37}$ and are recommended in international guidelines for the prevention of exacerbation complications. ${ }^{3}$ In the Netherlands, a written COPD action plan developed by Trappenburg et al (2011) is recommended to support patients in early detection of exacerbations and teaching self-management skills. ${ }^{40,41}$ However, despite the evidence that self-management is effective in patients with COPD, supporting patients in the development of self-management skills is complex and often unsuccessful. A substantial proportion of patients does not respond to self-management interventions. 12,37,38 This might be explained by the 'one size fits all' and static approach regarding design, intensity and mode of delivery without a focus on individual exacerbation patterns and behaviors. To further reduce the impact of exacerbations, more comprehensive, dynamic and individualized strategies are needed to improve exacerbation-related self-management behavior that meet patient's needs, perceptions and capabilities.

\section{mHealth as a solution for future self-management support}

The rapidly evolving nature and increased uptake of mobile health (mHealth) will influence the accessibility and the way self-management support will be provided in the future, also in patients with COPD. ${ }^{42-44}$ Mhealth is a component of eHealth, which is defined as "the use of information and communication technologies for health". ${ }^{42}$ To date, there is no standardized definition of mHealth. Given the current trends in internet access and mobile device use, it could be expected that the use of mHealth will become more and more relevant for a growing number of patients with COPD in the upcoming decades. ${ }^{42,45}$ The use of mobile health (mHealth) has the potential to engage patients in managing their own health, to support them in gradually developing self-management skills over time and to change health behaviors by using relevant behavior change techniques, such as action planning and providing feedback. ${ }^{44,46-48}$ Mhealth creates opportunities to individualize self-management interventions and to provide more dynamic and intensive therapeutic stimuli that fit with real-time health status and individual exacerbation patterns. Since mobile devices are carried on the person, tailored self-management support could be provided anytime and anywhere.

Over the past decade, a considerable number of mHealth interventions for patients with COPD have been developed worldwide aiming at reducing the negative impact of COPD. ${ }^{43,44,49,50}$ When starting this thesis, mHealth was upcoming in COPD care. A rapid growth in mHealth interventions has been observed over the past five years while working on this thesis, also in the Netherlands. ${ }^{51,52}$ Currently, numerous health applications for COPD are available in app stores and 
also used by patients with COPD, although scientific evidence for a large number of these apps is unclear or not present at all. ${ }^{47,51,52}$ Furthermore, most mHealth interventions lack a specific focus on developing self-management skills or are in our opinion incorrectly classified as self-management support because they focus on providing COPD information only or on tele-monitoring. ${ }^{43,49,50,53-55}$ Given the proven effectiveness of self-management in patients with COPD, 11,12,37 it could be expected that mHealth interventions supporting patients in self-management of exacerbations will be effective in reducing exacerbation impact. When starting this thesis, there were no evidence-based mHealth interventions available for patients with COPD that focus specifically on the development of exacerbationrelated self-management skills over time.

Although the use of mHealth has potential for future exacerbation-related selfmanagement support, patient and health care provider perspectives towards using mHealth for self-management are relatively unexplored. Little is known about their willingness to use mHealth for self-management of exacerbations, their perceptions on benefits and barriers of using mHealth and their preferences regarding the content of mHealth interventions. This knowledge is essential to determine if mHealth is indeed a solution for exacerbation-related selfmanagement support and, if so, how self-management support should be provided with mHealth to enhance the development of mHealth interventions with optimal usability and feasibility in daily practice.

\section{Aims of this thesis}

This thesis contains two parts. In part one, we aim to generate a better understanding of self-management behavior of patients with COPD and explore whether the use of mHealth is promising in enhancing exacerbation-related selfmanagement. In part two, we aim to develop an evidence-driven, attractive and usable mHealth intervention to enhance exacerbation-related self-management in patients with COPD and to describe this development process transparently.

\section{Outline of this thesis}

The first part of this thesis provides insight into current self-management behavior of patients with COPD and the potential of mHealth to enhance exacerbation-related self-management. In chapter $\mathbf{2}$ we provide insight into activation for self-management in patients with COPD and key determinants of activation for self-management. In chapter $\mathbf{3}$ the underlying process of exacerbation-related self-management behavior in patients with COPD is further explained. Chapter $\mathbf{4}$ describes the most relevant set of self-management 
behaviors that can be targeted and influenced to maximally reduce the impact of exacerbations. To determine whether the use of mHealth is promising for exacerbation-related self-management support, perceptions of patients and their health care providers towards the use of mHealth for self-management of exacerbations are qualitatively explored in chapter $\mathbf{5}$. The chapters in the first part of this thesis provided building blocks for the development of a new evidencedriven mHealth intervention (the Copilot app) to enhance exacerbation-related self-management in patients with COPD. The second part of this thesis describes the development and early-stage feasibility evaluation of the Copilot app. The full user-centered design and development process of the Copilot app including the design, iterative software development and usability testing, is described in detail in chapter 6. The perceived feasibility of the Copilot app in health care providers' daily practice is evaluated in chapter 7. Finally, chapter 8 presents the main findings of this thesis, reflects on important outcomes of this thesis and provides recommendations for clinical practice, research and education. 


\section{References}

1. Lozano R, Naghavi M, Foreman K, et al. Global and regional mortality from 235 causes of death for 20 age groups in 1990 and 2010: A systematic analysis for the global burden of disease study 2010. Lancet. 2012;380(9859):2095-2128.

2. Mathers CD, Loncar D. Projections of global mortality and burden of disease from 2002 to 2030. PLoS Med. 2006;3(11):e442.

3. Global Initiative for Chronic Obstructive Lung Disease (GOLD). Global strategy for the diagnosis, management, and prevention of chronic obstructive pulmonary disease [updated 2020]. Available from: https://goldcopd.org/wp-content/uploads/2019/11/GOLD-2020-REPORT-ver1.0wms.pdf. Accessed June 2, 2020.

4. Rodriguez-Roisin R. Toward a consensus definition for COPD exacerbations. Chest. 2000;117(5 Suppl 2):398S-401S.

5. Burge S, Wedzicha JA. COPD exacerbations: Definitions and classifications. Eur Respir J Suppl. 2003;41:46s-53s.

6. Donaldson GC, Seemungal TA, Bhowmik A, Wedzicha JA. Relationship between exacerbation frequency and lung function decline in chronic obstructive pulmonary disease. Thorax. 2002;57(10):847-852.

7. Miravitlles M, Ferrer M, Pont A, et al. Effect of exacerbations on quality of life in patients with chronic obstructive pulmonary disease: A 2 year follow up study. Thorax. 2004;59(5):387-395.

8. Seemungal TA, Donaldson GC, Paul EA, Bestall JC, Jeffries DJ, Wedzicha JA. Effect of exacerbation on quality of life in patients with chronic obstructive pulmonary disease. Am J Respir Crit Care Med. 1998;157(5 Pt 1):1418-1422.

9. Soler-Cataluna J, Martinez-Garcia MA, Roman Sanchez P, Salcedo E, Navarro M, Ochando R. Severe acute exacerbations and mortality in patients with chronic obstructive pulmonary disease. Thorax. 2005;60(11):925-931.

10. Toy EL, Gallagher KF, Stanley EL, Swensen AR, Duh MS. The economic impact of exacerbations of chronic obstructive pulmonary disease and exacerbation definition: A review. COPD. 2010;7(3):214-228.

11. Zwerink M, Brusse-Keizer M, van der Valk, $P$ D, et al. Self-management for patients with chronic obstructive pulmonary disease. Cochrane Database Syst Rev. 2014;3:CD002990.

12. Howcroft M, Walters EH, Wood-Baker R, Walters JA. Action plans with brief patient education for exacerbations in chronic obstructive pulmonary disease. Cochrane Database Syst Rev. 2016;12:CD005074.

13. Harrison SL, Goldstein R, Desveaux L, Tulloch V, Brooks D. Optimizing nonpharmacological management following an acute exacerbation of chronic obstructive pulmonary disease. Int J Chron Obstruct Pulmon Dis. 2014;9:1197-1205.

14. Effing TW, Vercoulen JH, Bourbeau J, et al. Definition of a COPD self-management intervention: International expert group consensus. Eur Respir J. 2016;48(1):46-54.

15. Wagner EH, Austin BT, Von Korff M. Organizing care for patients with chronic illness. Milbank Q. 1996;74(4):511-544.

16. Bodenheimer T, Lorig K, Holman H, Grumbach K. Patient self-management of chronic disease in primary care. JAMA. 2002;288(19):2469-2475.

17. Barlow J, Wright C, Sheasby J, Turner A, Hainsworth J. Self-management approaches for people with chronic conditions: A review. Patient Educ Couns. 2002;48(2):177-187.

18. Lorig KR, Holman H. Self-management education: History, definition, outcomes, and mechanisms. Ann Behav Med. 2003;26(1):1-7. 
19. Sadler E, Wolfe CD, McKevitt C. Lay and health care professional understandings of self-management: A systematic review and narrative synthesis. SAGE Open Med. 2014;2:2050312114544493.

20. Westland H, Schröder CD, de Wit J, Frings J, Trappenburg JCA, Schuurmans MJ. Self-management support in routine primary care by nurses. Br J Health Psychol. 2018;23(1):88-107.

21. Trappenburg J, Jonkman N, Jaarsma T, et al. Self-management: One size does not fit all. Patient Educ Couns. 2013;92(1):134-137.

22. Bourbeau J, Nault D, Dang-Tan T. Self-management and behaviour modification in COPD. Patient Educ Couns. 2004;52(3):271-277.

23. Elissen A, Nolte E, Knai C, et al. Is europe putting theory into practice? A qualitative study of the level of self-management support in chronic care management approaches. BMC Health Serv Res. 2013;13:117-6963.

24. Michie S, Johnston M, Abraham C, et al. Making psychological theory useful for implementing evidence based practice: A consensus approach. Qual Saf Health Care. 2005;14(1):26-33.

25. Michie S, van Stralen MM, West R. The behaviour change wheel: A new method for characterising and designing behaviour change interventions. Implement Sci. 2011;6:42-5908.

26. Bucknall CE, Miller G, Lloyd SM, et al. Glasgow supported self-management trial (GSuST) for patients with moderate to severe COPD: Randomised controlled trial. BMJ. 2012;344:e1060.

27. Bischoff EW, Hamd DH, Sedeno M, et al. Effects of written action plan adherence on COPD exacerbation recovery. Thorax. 2011;66(1):26-31.

28. Trappenburg JC, Schaap D, Monninkhof EM, et al. How do COPD patients respond to exacerbations? BMC Pulm Med. 2011;11:43-2466.

29. Wilkinson TM, Donaldson GC, Hurst JR, Seemungal TA, Wedzicha JA. Early therapy improves outcomes of exacerbations of chronic obstructive pulmonary disease. Am J Respir Crit Care Med. 2004;169(12):1298-1303.

30. Langsetmo L, Platt RW, Ernst P, Bourbeau J. Underreporting exacerbation of chronic obstructive pulmonary disease in a longitudinal cohort. Am J Respir Crit Care Med. 2008;177(4):396-401.

31. Xu W, Collet JP, Shapiro S, et al. Negative impacts of unreported COPD exacerbations on healthrelated quality of life at 1 year. Eur Respir J. 2010;35(5):1022-1030.

32. Adams R, Chavannes N, Jones K, Ostergaard MS, Price D. Exacerbations of chronic obstructive pulmonary disease--a patients' perspective. Prim Care Respir J. 2006;15(2):102-109.

33. Barnes N, Calverley PM, Kaplan A, Rabe KF. Chronic obstructive pulmonary disease and exacerbations: Patient insights from the global hidden depths of COPD survey. BMC Pulm Med. 2013;13:54-2466.

34. Kessler R, Stahl E, Vogelmeier C, et al. Patient understanding, detection, and experience of COPD exacerbations: An observational, interview-based study. Chest. 2006;130(1):133-142.

35. Harrison SL, Apps L, Singh SJ, Steiner MC, Morgan MD, Robertson N. 'Consumed by breathing' - a critical interpretive meta-synthesis of the qualitative literature. Chronic IIIn. 2014;10(1):31-49.

36. Williams V, Hardinge M, Ryan S, Farmer A. Patients' experience of identifying and managing exacerbations in COPD: A qualitative study. NPJ Prim Care Respir Med. 2014;24:14062.

37. Lenferink A, Brusse-Keizer M, van der Valk, P D, et al. Self-management interventions including action plans for exacerbations versus usual care in patients with chronic obstructive pulmonary disease. Cochrane Database Syst Rev. 2017;8:CD011682.

38. Jonkman $\mathrm{NH}$, Westland $\mathrm{H}$, Trappenburg JC, et al. Characteristics of effective self-management interventions in patients with COPD: Individual patient data meta-analysis. Eur Respir J. 2016;48(1):55-68.

39. Jonkman NH, Westland $\mathrm{H}$, Trappenburg JC, et al. Do self-management interventions in COPD patients work and which patients benefit most? an individual patient data meta-analysis. Int J Chron Obstruct Pulmon Dis. 2016;11:2063-2074. 
40. Trappenburg JC, Monninkhof EM, Bourbeau J, et al. Effect of an action plan with ongoing support by a case manager on exacerbation-related outcome in patients with COPD: A multicentre randomised controlled trial. Thorax. 2011;66(11):977-984.

41. Long Alliantie Nederland (LAN). Landelijk zorgpad COPD-longaanval met ziekenhuisopname. Available from: http://www.longalliantie.nl/files/4714/8422/5897/landelijk_zorgpad_v1.0_def. pdf. Updated 2017. Accessed Jun 1, 2017.

42. World Health Organisation. Mhealth. New horizons for health through mobile technologies. Second global survey on eHealth. Available from: http://www.who.int/goe/publications/goe_mhealth_ web.pdf. Updated 2011. Accessed August 3, 2018.

43. McLean S, Nurmatov U, Liu JL, Pagliari C, Car J, Sheikh A. Telehealthcare for chronic obstructive pulmonary disease: Cochrane review and meta-analysis. BrJ Gen Pract. 2012;62(604):e739-49.

44. McCabe C, McCann M, Brady AM. Computer and mobile technology interventions for self-management in chronic obstructive pulmonary disease. Cochrane Database Syst Rev. 2017;5:CD011425.

45. Centraal Bureau Statistiek. 75-plussers sterkst groeiende groep internetters. Available from: https:// www.cbs.nl/nl-nl/nieuws/2016/52/75-plussers-sterkst-groeiende-groep-internetters. Updated 2016. Accessed June 19, 2020.

46. Schnall R, Rojas M, Bakken $\mathrm{S}$, et al. A user-centered model for designing consumer mobile health (mHealth) applications (apps). J Biomed Inform. 2016;60:243-251.

47. Kumar S, Nilsen WJ, Abernethy A, et al. Mobile health technology evaluation: The mHealth evidence workshop. Am J Prev Med. 2013;45(2):228-236.

48. West R, Michie S. A guide to development and evaluation of digital behavior change interventions in health care. London: Silverback Publishing; 2016.

49. Alwashmi M, Hawboldt J, Davis E, Marra C, Gamble JM, Abu Ashour W. The effect of smartphone interventions on patients with chronic obstructive pulmonary disease exacerbations: A systematic review and meta-analysis. JMIR Mhealth Uhealth. 2016;4(3):e105.

50. Goldstein RS, O'Hoski S. Telemedicine in COPD: Time to pause. Chest. 2014;145(5):945-949.

51. Hallensleben C, van Luenen S, Rolink E, Ossebaard HC, Chavannes NH. eHealth for people with COPD in the Netherlands: A scoping review. Int J Chron Obstruct Pulmon Dis. 2019;14:1681-1690.

52. Zorginstituut Nederland. Rapport digitale COPD zorg in Nederland. Available from: https://www. zorginstituutnederland.nl/publicaties/rapport/2019/06/03/zinnige-zorg---rapport-digitale-copdzorg-in-nederland. Updated 2019. Accessed September 14, 2020.

53. Sul AR, Lyu DH, Park DA. Effectiveness of telemonitoring versus usual care for chronic obstructive pulmonary disease: A systematic review and meta-analysis. J Telemed Telecare. 2020;26(4):189199.

54. McKinstry B. The use of remote monitoring technologies in managing chronic obstructive pulmonary disease. QJM. 2013;106(10):883-885.

55. Bolton CE, Waters CS, Peirce S, Elwyn G, EPSRC and MRC Grand Challenge Team. Insufficient evidence of benefit: A systematic review of home telemonitoring for COPD. J Eval Clin Pract. 2011;17(6):1216-1222. stylefix 


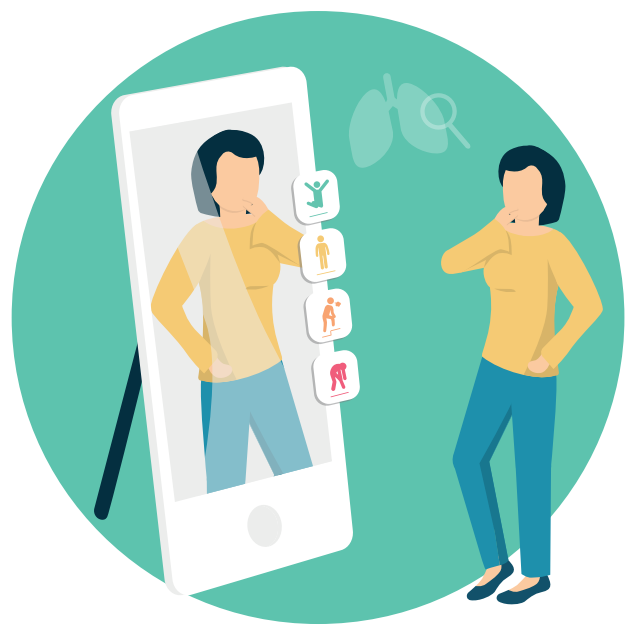




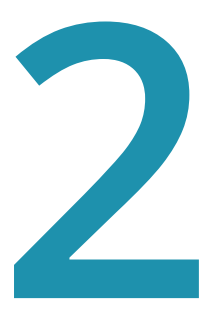

\section{Determinants of activation for self-management in patients with COPD}

Yvonne JG Korpershoek, Irene D Bos-Touwen, Janneke M de Man-van Ginkel, Jan-Willem J Lammers, Marieke J Schuurmans, Jaap CA Trappenburg 


\section{Abstract}

Background: COPD self-management is a complex behavior influenced by many factors. Despite scientific evidence that better disease outcomes can be achieved by enhancing self-management, many COPD patients do not respond to selfmanagement interventions. To move toward more effective self-management interventions, knowledge of characteristics associated with activation for selfmanagement is needed. The purpose of this study was to identify key patient and disease characteristics of activation for self-management.

Methods: An explorative cross-sectional study was conducted in primary and secondary care in patients with COPD. Data were collected through questionnaires and chart reviews. The main outcome was activation for selfmanagement, measured with the 13-item Patient Activation Measure (PAM). Independent variables were sociodemographic variables, self-reported health status, depression, anxiety, illness perception, social support, disease severity, and comorbidities.

Results: A total of 290 participants (age: $67.2 \pm 10.3$; forced expiratory volume in 1 second predicted: $63.6 \pm 19.2)$ were eligible for analysis. While poor activation for self-management (PAM-1) was observed in $23 \%$ of the participants, only $15 \%$ was activated for self-management (PAM-4). Multiple linear regression analysis revealed six explanatory determinants of activation for self-management $(P<0.2)$ : anxiety ( $\beta$ : $-0.35 ;-0.6$ to -0.1 ), illness perception ( $\beta$ : $-0.2 ;-0.3$ to -0.1$)$, body mass index (BMI) ( $\beta$ : $-0.4 ;-0.7$ to -0.2 ), age $(\beta$ : $-0.1 ;-0.3$ to -0.01 ), Global Initiative for Chronic Obstructive Lung Disease stage ( 2 vs $1 \beta$ : $-3.2 ;-5.8$ to $-0.5 ; 3$ vs $1 \beta$ : -3.4 ; -7.1 to 0.3 ), and comorbidities ( $\beta$ : $0.8 ;-0.2$ to 1.8 ), explaining $17 \%$ of the variance.

Conclusion: This study showed that only a minority of COPD patients is activated for self-management. Although only a limited part of the variance could be explained, anxiety, illness perception, BMI, age, disease severity, and comorbidities were identified as key determinants of activation for self-management. This knowledge enables health care professionals to identify patients at risk of inadequate self-management, which is essential to move toward targeting and tailoring of self-management interventions. Future studies are needed to understand the complex causal mechanisms toward change in self-management. 


\section{Introduction}

COPD is one of the most prevalent chronic diseases worldwide and the fourth leading cause of mortality. ${ }^{1,2}$ Increased burden of COPD is expected due to aging of the population and continued exposure to COPD risk factors. ${ }^{1,3}$ To address the burden on both patients and society self-management has become increasingly important. ${ }^{4-6}$ Self-management is defined as 'an individual's ability to detect and manage symptoms, treatment, physical and psychosocial consequences, and lifestyle changes inherent in living with a chronic condition'.7 Self-management can support COPD patients to manage their symptoms, prevent complications and to make adequate decisions on medication, exercise, breathing techniques, diet and contacting healthcare providers. ${ }^{48,9}$

The pivotal objective of self-management interventions is to change health behaviors and to equip patients with skills to actively participate in the management of their disease. ${ }^{4,10}$ Previous research has shown that self-management interventions have positive effects on disease outcomes, health-related quality of life and healthcare costs.5,11,12 A substantial proportion of COPD patients, however, does not respond or comply with self-management interventions., , 10,13 $^{-13}$ The large variance in effectiveness between patients presumes that it is unlikely that one intervention fits all patients..$^{10,13}$ Health care professionals play a major role in providing self-management support, but patients' initial self-management capabilities are often not determined by these professionals, frequently resulting in a "one size fit all approach". 10,14

To identify COPD patients who are more engaged in self-management and patients who encounter difficulties in performing adequate self-management, more insight into patient and disease characteristics associated with self-management behavior is needed. 8,10 The process toward adequate self-management requires an increase in knowledge, skills and confidence for self-management, which is defined as the level of activation for self-management. ${ }^{14}$ Higher levels of activation reflect better capacity to self-manage one's disease. ${ }^{14,15}$ In a recent study, we investigated factors associated with activation for self-management in a large population of patients with various chronic diseases (eg, diabetes mellitus type II, chronic heart failure, chronic renal disease and COPD). ${ }^{16}$ This study identified age, $\mathrm{BMI}$, educational level, financial distress, physical health status, depression, illness perception, social support and underlying disease as important determinants, explaining $16 \%$ of the variance in activation for self-management. ${ }^{16}$ These associations were disease transcending except for social support. More specific, 
the association between COPD and activation was dependent on social support while this was not observed for other conditions. ${ }^{16}$ In this study, no specific COPD related factors were taken into account and, therefore, factors explaining variance in activation for self-management in COPD patients specifically remain unclear. Previous studies have shown that COPD-specific characteristics such as dyspnea and disease severity may also be related to self-management behavior. ${ }^{8,17,18}$ Investigating the association between COPD-specific determinants and activation for self-management, combined with previously investigated determinants, may contribute to a thorough understanding of factors influencing self-management behavior in COPD patients.

To move toward the development of targeted and tailored self-management interventions with improved efficiency and (cost-) effectiveness, knowledge on key patient and disease characteristics of activation for self-management in COPD patients specifically is needed. Therefore, the objective of this study was to identify key determinants of activation for self-management in patients with COPD.

\section{Methods}

\section{Study design}

A descriptive study was performed with a cross-sectional research design. The study was conducted in one secondary and two primary care settings in the Netherlands and was part of a larger study..$^{16}$ The study was approved by the Medical Research Ethics Committee of the University Medical Centre of Utrecht.

\section{Study population and recruitment}

Patients diagnosed with mild-to-very severe COPD were selected by the attending physician according to the following inclusion criteria: a clinical diagnosis of COPD meaning a post-bronchodilator forced expiratory volume in 1 second $\left(\mathrm{FEV}_{1}\right) /$ forced vital capacity (FVC) ratio $<70 \%$ and age above 40 years. In secondary care, patients should have visited the outpatient clinic in the past 6 months to reduce the risk of including patients who are deceased or are no longer under treatment. Exclusion criteria were a diagnosis of lung cancer, cognitive impairments, language or communication problems and a life expectancy of less than 3 months. 
The sample size was calculated to allow sufficient power for a multiple linear regression analysis using 20 variables. According to the ratio number of predictor variables to number of participants (1:10), a sample size of at least 200 participants was required. ${ }^{19}$ Patients were selected by chart review according to the in- and exclusion criteria. Patients received an invitation letter from their attending physician to participate in this study. Attached with the invitation letter, patients also received a letter with study information, an informed consent form, a questionnaire, and a pre-addressed return envelope. To enhance recruitment rates, patients were sent a reminder after three weeks if the IC form was not returned. By signing the IC form, patients gave consent to consult their medical chart to obtain additional information.

\section{Data collection}

Data were collected by means of administering a questionnaire and medical chart review. The questionnaire was a composition of Dutch-validated questionnaires and a set of questions to determine sociodemographic characteristics.

The primary outcome activation for self-management was measured by the Patient Activation Measure (PAM-13), a 13-item instrument that assesses self-reported knowledge, skills and confidence for self-management. ${ }^{14,20,21} \mathrm{~A}$ positive change in activation has shown to be associated with positive changes in various selfmanagement behaviors..$^{15}$ Items are scored on a five-point scale. The sum of these scores is converted in a 0-100 point scale.20,22 Based on cut-off points for the four levels of activation: level 1 ( $\leq 47.0$ points), level 2 (47.1-55.1 points), level 3 (55.2-67 points) and level 4 ( $\geq 67.1$ points) - the individual patients' level of activation can be determined. ${ }^{20,22} \mathrm{~A}$ higher level refers to higher activations scores. ${ }^{14}$ Patients in level 1 are often passive and lack confidence for self-management resulting in low self-management engagement. Patients in level 2 become aware that they should be involved in their care, although there remain gaps in knowledge and skills. Patients in level 3 gain confidence for self-management and start to take action. The fourth, and highest, level of activation includes patients who have adopted new behaviors and are challenged to maintain these behaviors over time. Therefore, patients with higher levels of activation are considered to be better self-managers. ${ }^{14,15,23}$ The PAM-13 is translated in Dutch and validated in COPD patients showing good internal consistency $(a=0.88)$. Item-rest correlations were moderate-to-strong and test-retest reliability was moderate. ${ }^{21}$ 
Determinants of activation for self-management were measured using the following instruments. Health status was measured by the Short Form-12 Health Survey (SF-12), a short version of the Short Form-36 (SF-36). ${ }^{24} 25$ The 12-item SF-12 measures both physical and mental health. ${ }^{26}$ Item scores result in two summary scores on a 0-100 point scale. Higher scores refer to a better health status. Presence of anxiety or depression was measured by the Dutch-validated Hospital Anxiety and Depression Scale (HADS). ${ }^{27,28}$ The HADS includes two seven-item subscales (anxiety and depression) both with a score range of $0-21 .{ }^{28} \mathrm{Higher}$ scores refer to a higher state of anxiety or depression, with cut-off point $\geq 11$ indicating a depression or anxiety disorder. The Brief IIIness Perception Questionnaire (B-IPQ) was used to measure illness perception. ${ }^{29}$ The B-IPQ consists of eight items, each scored on a scale from 1-10, resulting in an overall score (range 0-80). Higher scores indicate a more negative illness-perception. Assessment of reproducibility was performed with Dutch COPD patients and showed moderate to good reliability. ${ }^{29}$ The 12-item Multidimensional Scale of Perceived Social Support (MSPSS) was used to assess social support. ${ }^{30,31}$ Items were scored on a seven-point scale. Higher scores indicate higher perceived support. ${ }^{30,31}$ Validity and reliability were confirmed by Dutch cardiac patients and their partners..$^{32}$

Sociodemographic characteristics included age, gender, BMI, ethnicity, socioeconomic status, living situation and smoking habits. Socioeconomic status was operationalized in three separate variables: educational level, financial distress, and care allowance as a proxy for income. Operationalization of these determinants is detailed in Table 1. Disease characteristics included COPD severity, COPD duration, current exacerbation and comorbidities. Severity of COPD was obtained from the medical chart and classified into four stages of Global Initiative for Chronic Obstructive Lung Disease (GOLD), which were determined using $\mathrm{FEV}_{1} / \mathrm{FVC}$ and $\mathrm{FEV}_{1} \%$ predicted data. ${ }^{1}$ In case of missing lung function data, GOLD stage as reported by the physician was used. To complement $\mathrm{FEV}_{1} \%$ predicted in the classification of COPD severity, dyspnea was measured by the five-point Medical Research Council (MRC) scale. A higher score indicates a higher degree of perceived breathlessness. ${ }^{33}$ COPD duration was determined by number of years since diagnosis. Current exacerbation at the time of the measurement was examined by asking whether patients currently used a course of antibiotics and/ or prednisolone. Furthermore, comorbidities obtained from chart review were assessed by the Charlson Comorbidity Index (CCl). ${ }^{34,35}$ The $\mathrm{CCl}$ is based on ICD10 (International Classification of Diseases - tenth revision) codes and defines 19 comorbidities. A weighted score, based on the relative risk of mortality at 1 year, was assigned to each comorbidity with a total range of $0-37.35$ 


\section{Data analysis}

Statistical analysis was performed using SPSS 21.0 (IBM Corporation, Armonk, NY, USA). ${ }^{36}$ Descriptive statistics were used to describe baseline characteristics. Means and standard deviations were used to describe continuous variables whereas frequencies and percentages were used for categorical variables.

Patients were excluded when all 13 questions of the PAM-13 were answered identically or showed more than seven missing. ${ }^{21,22}$ Analysis of missing values of all determinants was performed and showed $2 \%$ missing variables, distributed among $31 \%$ of the cases. Multiple imputation was used to deal with missing data, since this may reduce bias when data is missing at random. ${ }^{37}$ Data analysis was performed in ten imputed data sets.

Univariate linear regression analysis was used to analyze the association between single determinants and activation for self-management, rather as a method for selecting candidate predictors. Pooled estimates of the association, derived from the estimates per imputed dataset as created by SPSS, are used in the "Results" section.

A stepwise backward multiple linear regression analysis was performed in order to identify explanatory variables of activation for self-management. Variables were excluded in order of the highest $P$-value. A significance level of $20 \%$ was used to keep a variable in the model. This method was applied to each of the ten imputation data sets separately and resulted in ten sets of selected variables. The majority method was used to keep variables in the final model, which consisted of variables that were selected in $50 \%$ or more of the 10 data sets. ${ }^{38}$ To calculate pooled $R^{2}$ statistics, Fisher's $r$ to $z$ transformation was used. ${ }^{39}$ Assumptions of linearity, multicollinearity $(R>0.8)$ and homoscedasticity were checked and approved. Some continuous variables did not completely meet the assumption for normal distribution. Therefore, generalized linear models were used with robust standard errors in the linear regression analysis. 


\section{Results}

In total, 607 eligible COPD patients were invited in this study, of which 315 patients (52\%) agreed to participate. A total of 42 patients were excluded during the process of recruitment and data collection. Finally, 290 participants were eligible for analysis (Figure 1).

The mean age of participants was 67.2 (SD 10.3) and $63.4 \%$ were males. The majority of participants were Dutch (92.4\%), married (66.2\%), unemployed (81.7\%), non-smokers (68.3\%) and had a low-to-medium education level (81,7\%). Most participants had moderate COPD as mean $\mathrm{FEV}_{1} \%$ predicted was 63.6 (GOLD stage 2). In addition, a majority of $63.1 \%$ of the participants had a MRC score below three. Nearly half of the population was diagnosed with COPD for more than 5 years (46,6\%). Other patients' characteristics are detailed in Table 1.

\section{Activation for self-management}

The mean activation score (PAM-13) was 54.7 (SD 10.4). Figure 2 shows the prevalence of different levels of activation for self-management among the study population and details that participants were almost equally distributed in PAM13 level 2 and 3 (29.7 vs 33.1, respectively). Poor activation for self-management (level 1 ) was observed among $22.8 \%$ of the participants. A minority of $14.5 \%$ of the participants was activated for self-management and scored on level 4 (Figure 2).

\section{Determinants associated with activation for self-management}

Univariate associations between determinants and activation for self-management are presented in Table 2. Physical health status, mental health status, anxiety, depression, illness perception, BMI, education level, dyspnea and GOLD stage were significantly associated with activation for self-management $(P<0.05)$. Multiple linear regression analysis revealed six explanatory determinants of activation for self-management: Anxiety, illness perception, BMI, age, GOLD stage and comorbidities (Table 2 ). Increased level of anxiety ( $\beta$ :-0.35; $\mathrm{Cl}-0.64$ to -0.06 ), a more negative illness perception $(-0.17 ;-0.28$ to -0.06$)$, increased BMI $(-0.42 ;-0.65$ to -0.19$)$, increased age $(-0.14 ;-0.26$ to -0.01$)$, increased GOLD stage ( 2 vs 1: -3.15 ; -5.77 to $-0.54,3$ vs $1:-3.37 ;-7.07$ to 0.32$)$ and less comorbidities $(0.79 ;-0.19$ to 1.77) were associated with a decrease in activation for self-management $(P<0.2)$. For GOLD stage, a statistical significant association was observed specifically in GOLD stage 2 versus $1(P<0.5)$. The explained variance $\left(R^{2}\right)$ of the multivariable model was 0.17 . High correlations were observed between mental and physical health $(R=0.76)$ and anxiety and depression $(R=0.73)$. 


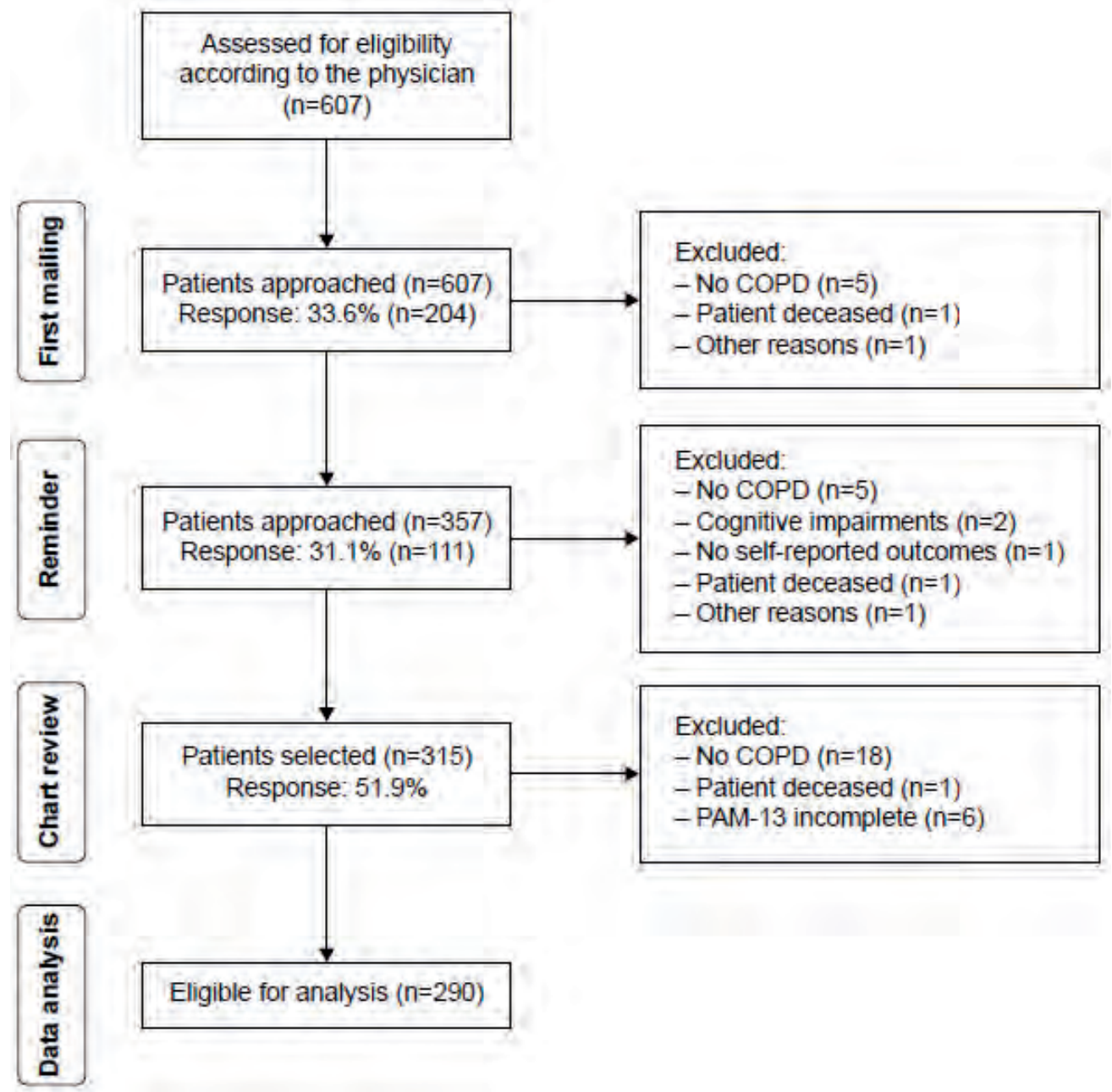

Figure 1. Flow chart of recruitment

Abbreviation: PAM, Patient Activation Measure. 
Table 1. Baseline characteristics of the study population

Gender

Male

$184(63.4 \%)$

Female

$105(36.2 \%)$

Age (mean $\pm S D)$

$67.2 \pm 10.3$

BMI (mean \pm SD)

$26.6 \pm 4.7$

Ethnicity

Dutch

$268(92.4 \%)$

Other

$19(6.6 \%)$

Marital status a

Married

$192(66,2 \%)$

Not married

$98(33,8 \%)$

Living situation

Living alone

$72(24.8 \%)$

Not living alone

213 (73.4\%)

Education level ${ }^{b}$

Low

$126(43.4 \%)$

Medium

$111(38.3 \%)$

High

$46(15.9 \%)$

Current working

Yes

$48(16.6 \%)$

No

$237(81.7 \%)$

Financial distress

None

$121(41.7 \%)$

Low

$129(44.5 \%)$

High

$33(11.4 \%)$

Care allowance ${ }^{c}$

Received

$119(41.0 \%)$

Not received

$159(54.8 \%)$

Smoking

Never

Former

$173(59.7 \%)$

Current

$89(30.7 \%)$

Average smoking (pack-years) (mean \pm SD)

$36.6 \pm 24.6$

Social support (MSPSS) (mean \pm SD)

$60.6 \pm 17.4$

HADS

Depression (mean \pm SD)

$5.6 \pm 4.1$

Anxiety (mean $\pm \mathrm{SD}$ )

$5.7 \pm 4.3$

Health status (SF-12)

Physical component (mean \pm SD)

$45.6 \pm 24.5$

Mental component (mean \pm SD)

$61.7 \pm 23.4$ 
Table 1. (Continued)

\begin{tabular}{|c|c|}
\hline Illness perception (B-IPQ) (mean \pm SD) & $40.1 \pm 12.0$ \\
\hline Activation (PAM) (mean \pm SD) & $54.7 \pm 10.4$ \\
\hline \multicolumn{2}{|l|}{ Illness duration } \\
\hline$\leq 2 \mathrm{yrs}$ & $42(14.5 \%)$ \\
\hline $2-5$ yrs & $69(23.8 \%)$ \\
\hline$>5$ yrs & $135(46.6 \%)$ \\
\hline $\mathrm{FEV}_{1} \%$ predicted (mean $\pm \mathrm{SD}$ ) & $63.6 \pm 19.2$ \\
\hline \multicolumn{2}{|l|}{ GOLD stage $^{d}$} \\
\hline I (mild) & $93(32.1 \%)$ \\
\hline II (moderate) & $133(45.9 \%)$ \\
\hline III (severe) & $40(13.8 \%)$ \\
\hline IV (very severe) & $14(4.8 \%)$ \\
\hline \multicolumn{2}{|l|}{ MRC score } \\
\hline$\leq 3$ & $183(63.1 \%)$ \\
\hline$>3$ & $105(36.2 \%)$ \\
\hline Charlson comorbidity index (mean \pm SD) ${ }^{\mathrm{e}}$ & $2.5 \pm 1.5$ \\
\hline \multicolumn{2}{|l|}{ Current exacerbation } \\
\hline No & $224(77.2 \%)$ \\
\hline Yes & $60(20.7 \%)$ \\
\hline
\end{tabular}

Notes: Data are presented in $\mathrm{n}(\%)$ unless specified otherwise. ${ }^{a}$ Marital status: married, widow, divorced or unmarried people were included; b education level: low (primary school through vocational training), medium (secondary school or vocational training) and high (college or university degree); ' care allowance received by single people making an annual living <€30.939 or a combined annual living <€42.438; d GOLD stage: I (FEV1 $\geq 80 \%)$, II

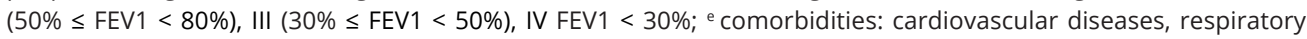
diseases, diabetes, kidney diseases, liver diseases, cancer, connective tissue disorders, paraplegia, osteoporosis and arthrosis, gastrointestinal disorders, anxiety and depression, Parkinson's disease and multiple sclerosis, eczema, dementia and HIV; ${ }^{\mathrm{f}}$ current exacerbation: no (no course of antibiotics and/or prednisolone in the past 3 weeks), yes (course of antibiotics and/or prednisolone in the past 3 weeks).

Abbreviations: BMI, body mass index; FEV1, forced expiratory volume in 1 second; MSPSS, Multidimensional Scale of Perceived Social Support; B-IPQ, Brief Illness Perception Questionnaire; PAM, Patient Activation Measure; SD, standard deviation; HADS, Hospital Anxiety and Depression Scale; GOLD, Global Initiative for Chronic Obstructive Lung Disease; MRC, Medical Research Council; SF-12, Short-Form-12 Health Survey. 


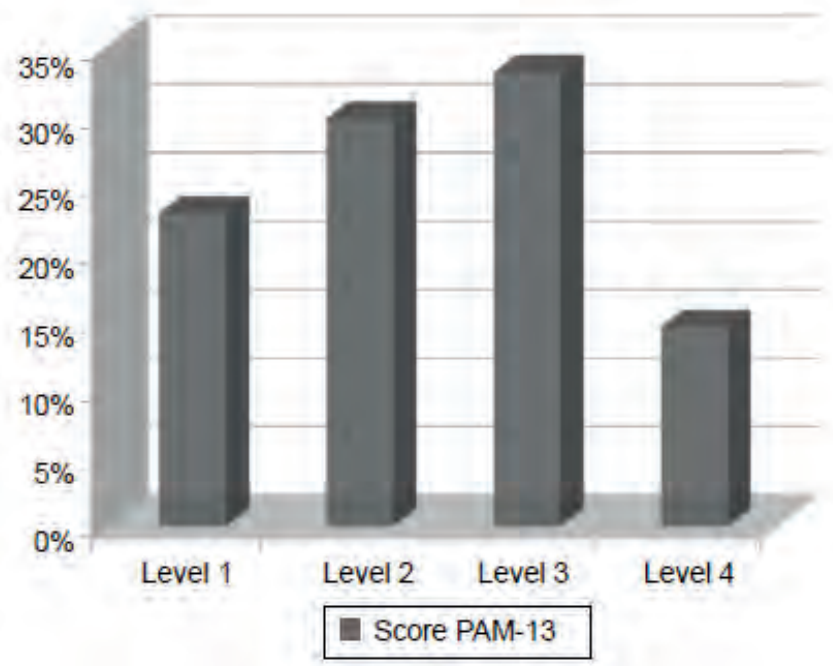

Figure 2. Distribution of different PAM levels

Notes: Level 1 ( $\leq 47.0)$ : Disengaged and overwhelmed: Individuals are passive and lack confidence. Knowledge is low, goal-orientation is weak, and adherence is poor. Level 2 (47.1-55.1): Becoming aware, but still struggling: Individuals have some knowledge, but large gaps remain. They believe health is largely out of their control, but can get simple goals. Level 3 (55.2-67.0): Taking action: Individuals have the key facts and are building selfmanagement skills. They strive for the best practice behaviors and are goal-oriented. Level 4 ( $\geq 67.1)$ : Maintaining behaviors and pushing further: Individuals have adopted new behaviors, but may struggle in times of stress or change. Maintaining a healthy lifestyle is a key focus. Description of PAM levels is cited from http://www. insigniahealth.com. ${ }^{23}$ Abbreviation: PAM, Patient Activation Measure. 
Table 2. Univariate linear regression and multiple linear regression to analyze the association between multiple determinants and activation for self-management

\begin{tabular}{|c|c|c|c|c|c|c|}
\hline \multirow{2}{*}{$\begin{array}{l}\text { Determinants association } \\
\text { with self-management } \\
\text { capacity (PAM-13) }\end{array}$} & \multicolumn{3}{|c|}{ Univariate linear regression } & \multicolumn{3}{|c|}{ Multiple linear regression $\S$} \\
\hline & $\beta$ & $95 \% \mathrm{Cl}$ & P-value $t$ & $\beta$ & $95 \% \mathrm{Cl}$ & P-value $t$ \\
\hline $\begin{array}{l}\text { Health status physical } \\
\text { component (SF-12) }\end{array}$ & 0.12 & $0.08 / 0.17$ & 0.00 & & NA & \\
\hline $\begin{array}{l}\text { Health status mental } \\
\text { component (SF-12) }\end{array}$ & 0.11 & $0.06 / 0.16$ & 0.00 & & NA & \\
\hline Anxiety (HADS) & -0.54 & $-0.81 /-0.27$ & 0.00 & -0.35 & $-0.64 /-0.06$ & 0.02 \\
\hline Depression (HADS) & -0.69 & $-0.97 /-0.41$ & 0.00 & & NA & \\
\hline Illness perception (B-IPQ) & -0.26 & $-0.36 /-0.17$ & 0.00 & -0.17 & $-0.28 /-0.06$ & 0.00 \\
\hline Social support (MSPSS) & 0.05 & $-0.01 / 0.12$ & 0.12 & & NA & \\
\hline Age (years) & -0.11 & $-0.22 / 0.01$ & 0.07 & -0.14 & $-0.26 /-0.01$ & 0.03 \\
\hline Gender (female vs male) & 0.25 & $-2.26 / 2.76$ & 0.85 & & NA & \\
\hline $\mathrm{BMI}\left(\mathrm{kg} / \mathrm{m}^{2}\right)$ & -0.38 & $-0.64 /-0.13$ & 0.00 & -0.42 & $-0.65 /-0.19$ & 0.00 \\
\hline Ethnicity (other vs Dutch) & -4.14 & $-8.96 / 0.69$ & 0.09 & & NA & \\
\hline $\begin{array}{l}\text { Living situation } \\
\text { (not alone vs alone) }\end{array}$ & -1.27 & $-4.05 / 1.50$ & 0.37 & & NA & \\
\hline $\begin{array}{l}\text { Education level } \\
\text { (low, medium, high) }\end{array}$ & & & & & NA & \\
\hline Moderate vs low & 2.30 & $-0.32 / 4.92$ & 0.09 & & & \\
\hline High vs low & 4.85 & $1.40 / 8.31$ & 0.01 & & & \\
\hline $\begin{array}{l}\text { Financial distress } \\
\text { (none, low, high) }\end{array}$ & & & & & NA & \\
\hline $\begin{array}{l}\text { Low vs none } \\
\text { High vs none }\end{array}$ & $\begin{array}{l}-0.91 \\
-2.30\end{array}$ & $\begin{array}{l}-3.50 / 1.68 \\
-6.32 / 1.71\end{array}$ & $\begin{array}{l}0.49 \\
0.26\end{array}$ & & & \\
\hline $\begin{array}{l}\text { Care allowance } \\
\text { (received vs not received) }\end{array}$ & 0.23 & $-2.25 / 2.71$ & 0.86 & & NA & \\
\hline $\begin{array}{l}\text { Current smoking } \\
\text { (never, former, current) }\end{array}$ & & & & & NA & \\
\hline Former vs never & 3.78 & $-0.56 / 8.13$ & 0.09 & & & \\
\hline Current vs never & 3.98 & $-0.62 / 8.59$ & 0.09 & & & \\
\hline Dyspnea (MRC) $(>3$ of $\leq 3)$ & -3.69 & $-6.17 /-1.21$ & 0.00 & & NA & \\
\hline $\begin{array}{l}\text { GOLD stage } \\
\text { GOLD } 2 \text { vs } 1 \\
\text { GOLD } 3 \text { vs } 1 \\
\text { GOLD } 4 \text { vs } 1\end{array}$ & $\begin{array}{l}-3.65 \\
-4.89 \\
-4.02\end{array}$ & $\begin{array}{l}-6.37 /-0.93 \\
-8.70 /-1.08 \\
-9.70 / 1.67\end{array}$ & $\begin{array}{l}0.01 \\
0.01 \\
0.17\end{array}$ & $\begin{array}{l}-3.15 \\
-3.37 \\
-2.48\end{array}$ & $\begin{array}{l}-5.77 /-0.54 \\
-7.07 / 0.32 \\
-7.62 / 2.67\end{array}$ & $\begin{array}{l}0.02 \\
0.07 \\
0.35\end{array}$ \\
\hline $\begin{array}{l}\text { Illness duration } \\
\begin{array}{c}(\leq 2 \text { yrs, } 2-5 \text { yrs, }>5 \text { yrs }) \\
2-5 \text { yrs vs } \leq 2 \text { yrs, } \\
>5 \text { yrs vs } \leq 2 \text { yrs }\end{array}\end{array}$ & $\begin{array}{r}1.25 \\
-0.44\end{array}$ & $\begin{array}{l}-2.60 / 5.09 \\
-4.07 / 3.20\end{array}$ & $\begin{array}{l}0.53 \\
0.81\end{array}$ & & NA & \\
\hline $\begin{array}{l}\text { Current exacerbation } \\
\text { (no vs yes) }\end{array}$ & 2.40 & $-0.56 / 5.35$ & 0.11 & & NA & \\
\hline Comorbidity $(\mathrm{CCl})$ & 0.42 & $-0.38 / 1.21$ & 0.30 & 0.79 & $-0.19 / 1.77$ & 0.11 \\
\hline
\end{tabular}

Explained variance of the model $R^{2}=0.172(\mathrm{n}=290)$

Abbreviations: MSPSS, Multidimensional Scale of Perceived Social Support; B-IPQ, Brief Illness Perception Questionnaire; PAM, Patient Activation Measure; HADS, Hospital Anxiety and Depression Scale; GOLD, Global Initiative for Chronic Obstructive Lung Disease; MRC, Medical Research Council; BMI, body mass index; CCl, Charlson comorbidity index; $\mathrm{Cl}$, confidence interval; NA, not applicable; SF-12, Short-Form-12 Health Survey. 


\section{Discussion}

This study has provided insight into the prevalence of different levels of activation for self-management and identified patient and disease characteristics associated with activation for self-management in COPD patients. Only a minority of COPD patients was activated for self-management. The main finding was that increased anxiety, a more negative illness perception, higher BMI, higher age, more disease severity and less comorbidities were associated with a lower activation for self-management. These variables explained $17 \%$ of the variance in activation for self-management.

Activation for self-management in the study population, represented by the mean activation score, was lower compared to a previous Dutch study including COPD patients. ${ }^{21}$ This might be explained by the fact that this study focused on various chronic disease patients who were younger (58.7 vs. 67.2 years). ${ }^{21}$ In our study, only a minority of participants was activated for self-management (level 4) which indicates major room for improvement. Slightly more than half of the participants were in level 2 and 3 and nearly a quarter was considered to be a poor self-manager (level 1). In contrast, another Dutch study focusing on activation for self-management in COPD patients showed that most patients were in level 3 and $4 .{ }^{40}$ Since both other Dutch studies sampled patients from a national panel, this may have positively affected the outcome as these patients might be more activated for self-management.

This study identified anxiety, illness perception, BMI, age, GOLD stage and comorbidities as explanatory determinants of activation for self-management. This is partly in line with previous studies focusing on self-management in COPD patients. A previous literature review identified anxiety, illness perception and dyspnea as factors influencing self-management. ${ }^{8}$ In addition, associations with age and disease severity were observed in another study focusing on selfmanagement. ${ }^{18}$ On the contrary, socioeconomic status and social support were expected to be related with self-management, ${ }^{8}$ although no significant association with activation for self-management was observed in our study. This might be due to the large heterogeneity in self-management outcome parameters used in previous studies and our specific focus on activation for self-management. Remarkably, comorbidities and BMI were identified as key determinants in our study, while this has not been reported in previous studies to our knowledge. A previous study using the PAM-13 in COPD patients identified no associations with age and presence of comorbidities, although a small association with 
dyspnea was found. ${ }^{40}$ In our study, age and comorbidities were identified as key determinants of activation for self-management which may be explained by the fact that we included multiple determinants in our model, investigating the relative influence of each individual determinant, and the fact that patients in our study had relatively more comorbidities.

The identified determinants were partly in line with findings from our larger study focusing on determinants for self-management in various chronic diseases. ${ }^{16}$ In line with that study, the age, BMI and illness perception were identified as key determinants. On the contrary, education level, financial distress, physical health status, depression, and social support were not identified as key determinants in this current study. In this study, anxiety was identified as a key determinant. It is important to note that anxiety was highly correlated with depression and mental health status. This may indicate that emotional distress in general is an important determinant of self-management behavior. Furthermore, contrasting was that disease severity emerged as a key determinant in this study, though not in the larger study. This might be explained by the fact that disease severity was standardized for various chronic diseases in the larger study, leading to broader categories of severity. Finally, comorbidity was a key determinant in this study, indicating that COPD patients with several comorbidities seem more activated for self-management. This might be due to the fact that these patients already have more experience with healthcare and know how to cope with their disease. The results of this study indicate that anxiety, disease severity and comorbidity were more important in identifying the level of activation in COPD patients, than they were in the mixed group of patients with various chronic conditions.

The explained variance was $17 \%$, which is lower compared to previous studies on explanatory variables of self-management in COPD patients (varying from $31 \%$ to $34 \%) .{ }^{18,41}$ The identified key determinants could only explain the variance of activation for self-management to a limited extent. The remaining variance may be explained by other types of factors influencing activation for self-management, for example, self-efficacy or received self-management support from healthcare professionals. Self-efficacy was not included in this study since the PAM-13 already includes items focusing on self-efficacy. However, in social cognitive theory, self-efficacy is considered to be a an important intermediate in the causal chain toward adoption of self-management skills and behavior change. ${ }^{42,43}$ 
An important strength of this study was that a wide range of determinants was analyzed simultaneously in a relatively large study population. Inclusion from both primary and secondary care had a positive impact on the generalizability of the results since this maximizes variation in COPD severity. Finally, the response rate of more than $50 \%$ was higher than the expected rate of $40 \%$, which strengthens the external validity of this study. A limitation of this study was that patients were recruited by physicians in different settings, which may have resulted in selection bias. In primary care, a few patients were considered eligible by their physician based on GOLD stage, while lung function data were missing. Those participants were included in the analysis when GOLD stage was explicitly listed in the chart and patients received active treatment for their COPD. Furthermore, in this study less non-native patients were included than expected based on data of the Dutch population, ${ }^{44}$ which might have been due to language barriers.

The acquired knowledge on explanatory determinants of activation for selfmanagement is important for all healthcare professionals supporting COPD patients in self-management, as it allows them to make a risk assessment of inadequate engagement in self-management based on an individual patient profile. Based on the study results, specific attention should be paid to relatively older patients, with a relatively high weight, a more negative illness perception, more severe COPD, less comorbidities, and emotional disturbances. This stresses the need for adequate assessment on patient related factors that can be influenced such as illness perception, anxiety, and BMI, as improving these factors may lead to increased quality of life or health status. ${ }^{4546}$ For example, healthcare professionals should pay more attention to identifying negative illness perceptions by asking patients how they experience their COPD and how COPD symptoms influence their daily lives, ${ }^{46}$ so that they can anticipate on these perceptions in future consultations.

For patients at risk for inadequate engagement in self-management, intensifying self-management support seems important to increase the likelihood of engagement in self-management. First, adequate assessment by healthcare professionals on patient knowledge, skills and confidence is needed to identify problem areas allowing them to anticipate on these individual problem areas with tailored strategies. Intensifying self-management support may then consist of spending more time on education or to provide additional materials to increase patients knowledge, to amplify action planning and decision support to increase patients skills, or to add reinforcement consultations to increase patients confidence for self-management. 
The knowledge on determinants of activation for self-management may help healthcare professionals to make a first step in targeting and tailoring their interventions. Assessment on engagement in self-management based on patient profiles, and identifying behavioral needs, may contribute to individualizing self-management interventions. Dose, content, and modus of self-management interventions should then be tailored to individual patient needs and capabilities.

More research is needed to investigate barriers and facilitators of activation for self-management in COPD patients including a focus on other patientrelated factors, such as self-efficacy, but also on provider and healthcare system characteristics. These studies should focus on identifying causal relationships between determinants and activation for self-management. Longitudinal studies are required to determine key determinants of change in activation for selfmanagement. This knowledge is essential to eliminate barriers of activation for self-management and will contribute to targeting and tailoring of selfmanagement interventions.

\section{Conclusion}

This study showed that only a minority of COPD patients is activated for selfmanagement, which implies that there is great potential for improvement in self-management and subsequently in health outcomes. This study found that increased anxiety, a more negative illness perception, increased BMI, increased age, increased disease severity and less comorbidities were associated with a decrease in activation for self-management in COPD patients. This knowledge contributes to identification of patients at risk of inadequate engagement in selfmanagement activities, which is an essential first step towards targeting and tailoring individualized self-management interventions in the future. To be able to thoroughly understand the complex causal mechanisms towards change in selfmanagement behavior, future research is needed. 


\section{References}

1. Global Initiative for Chronic Obstructive Lung Disease (GOLD). Global strategy for the diagnosis, management, and prevention of chronic obstructive pulmonary disease. [Updated 2016]. Available from: http://www.goldcopd.org/uploads/users/files/GOLD_Report\%202016.pdf. Accessed February 2, 2016.

2. World Health Organization. The global burden of disease. Updated 2004. Available from: http://www.who.int/healthinfo/global_burden_disease/GBD_report_2004update_full.pdf?ua=1. Accessed October 28, 2015.

3. Mathers CD, Loncar D. Projections of global mortality and burden of disease from 2002 to 2030 . PLoS Med. 2006;3(11):e442.

4. Bourbeau J, van der Palen J. Promoting effective self-management programmes to improve COPD. Eur Respir J. 2009;33(3):461-463.

5. Zwerink M, Brusse-Keizer M, van der Valk PD, et al. Self-management for patients with chronic obstructive pulmonary disease. Cochrane Database Syst Rev. 2014;3:CD002990.

6. Spruit MA, Singh SJ, Garvey C, et al. An official American Thoracic Society/European Respiratory Society statement: key concepts and advances in pulmonary rehabilitation. Am J Respir Crit Care Med. 2013;188(8):e13-e64.

7. Barlow J, Wright C, Sheasby J, Turner A, Hainsworth J. Self-management approaches for people with chronic conditions: a review. Patient Educ Couns. 2002;48(2):177-187.

8. Disler RT, Gallagher RD, Davidson PM. Factors influencing self-management in chronic obstructive pulmonary disease: an integrative review. Int J Nurs Stud. 2012;49(2):230-242.

9. Bourbeau J, Nault D. Self-management strategies in chronic obstructive pulmonary disease. Clin Chest Med. 2007;28(3):617-628, vii.

10. Effing TW, Bourbeau J, Vercoulen J, et al. Self-management programmes for COPD: moving forward. Chron Respir Dis. 2012;9(1):27-35.

11. Adams SG, Smith PK, Allan PF, Anzueto A, Pugh JA, Cornell JE. Systematic review of the chronic care model in chronic obstructive pulmonary disease prevention and management. Arch Intern Med. 2007;167(6):551-561.

12. Bourbeau J, Julien M, Maltais F, et al. Reduction of hospital utilization in patients with chronic obstructive pulmonary disease: a disease-specific self-management intervention. Arch Intern Med. 2003;163(5):585-591.

13. Trappenburg J, Jonkman N, Jaarsma T, et al. Self-management: one size does not fit all. Patient Educ Couns. 2013;92(1):134-137.

14. Hibbard JH, Mahoney ER, Stockard J, Tusler M. Development and testing of a short form of the patient activation measure. Health Serv Res. 2005;40(6 Pt 1):1918-1930.

15. Hibbard JH, Mahoney ER, Stock R, Tusler M. Do increases in patient activation result in improved self-management behaviors? Health Serv Res. 2007;42(4):1443-1463.

16. Bos-Touwen I, Schuurmans M, Monninkhof EM, et al. Patient and disease characteristics associated with activation for self-management in patients with diabetes, chronic obstructive pulmonary disease, chronic heart failure and chronic renal disease: a cross-sectional survey study. PLoS One. 2015;10(5):e0126400.

17. Cramm JM, Nieboer AP. Self-management abilities, physical health and depressive symptoms among patients with cardiovascular diseases, chronic obstructive pulmonary disease, and diabetes. Patient Educ Couns. 2012;87(3):411-415.

18. Warwick M, Gallagher R, Chenoweth L, Stein-Parbury J. Self-management and symptom monitoring among older adults with chronic obstructive pulmonary disease. J Adv Nurs. 2010;66(4):784-793. 
19. Peduzzi P, Concato J, Kemper E, Holford TR, Feinstein AR. A simulation study of the number of events per variable in logistic regression analysis. J Clin Epidemiol. 1996;49(12):1373-1379.

20. Hibbard JH, Stockard J, Mahoney ER, Tusler M. Development of the Patient Activation Measure (PAM): conceptualizing and measuring activation in patients and consumers. Health Serv Res. 2004;39(4 Pt 1):1005-1026.

21. Rademakers J, Nijman J, van der Hoek L, Heijmans M, Rijken M. Measuring patient activation in the Netherlands: translation and validation of the American short form Patient Activation Measure (PAM13). BMC Public Health. 2012;12(1):577.

22. Insignia Health. Patient Activation Measure (PAM) 13, licence materials. 2011.

23. Insignia Health. Patient Activation Measure (PAM) Survey levels. Available from: http://www. insigniahealth.com/products/pam-survey. Accessed March 10, 2016.

24. Ware J Jr, Kosinski M, Keller SD. A 12-Item Short-Form Health Survey: construction of scales and preliminary tests of reliability and validity. Med Care. 1996;34(3):220-233.

25. Aaronson NK, Muller M, Cohen PD, et al. Translation, validation, and norming of the Dutch language version of the SF-36 Health Survey in community and chronic disease populations. J Clin Epidemiol. 1998;51(11):1055-1068.

26. Mols F, Pelle AJ, Kupper N. Normative data of the SF-12 health survey with validation using postmyocardial infarction patients in the Dutch population. Qual Life Res. 2009;18(4):403-414.

27. Zigmond AS, Snaith RP. The hospital anxiety and depression scale. Acta Psychiatr Scand. 1983;67(6):361-370.

28. Spinhoven P, Ormel J, Sloekers PP, Kempen Gl, Speckens AE, Van Hemert AM. A validation study of the Hospital Anxiety and Depression Scale (HADS) in different groups of Dutch subjects. Psychol Med. 1997;27(2):363-370.

29. De Raaij EJ, Schroder C, Maissan FJ, Pool JJ, Wittink H. Cross-cultural adaptation and measurement properties of the Brief Illness Perception Questionnaire-Dutch Language Version. Man Ther. 2012;17(4):330-335.

30. Zimet GD, Dahlem NW, Zimet SG, Farley GK. The Multidimensional Scale of Perceived Social Support. J Pers Assess. 1988(52):30-41.

31. Zimet GD, Powell SS, Farley GK, Werkman S, Berkoff KA. Psychometric characteristics of the Multidimensional Scale of Perceived Social Support. J Pers Assess. 1990;55(3-4):610-617.

32. Pedersen SS, Spinder H, Erdman RA, Denollet J. Poor perceived social support in implantable cardioverter defibrillator (ICD) patients and their partners: cross-validation of the multidimensional scale of perceived social support. Psychosomatics. 2009;50(5):461-467.

33. Bestall JC, Paul EA, Garrod R, Garnham R, Jones PW, Wedzicha JA. Usefulness of the Medical Research Council (MRC) dyspnoea scale as a measure of disability in patients with chronic obstructive pulmonary disease. Thorax. 1999;54(7):581-586.

34. Charlson ME, Pompei $\mathrm{P}$, Ales $\mathrm{KL}$, MacKenzie CR. A new method of classifying prognostic comorbidity in longitudinal studies: development and validation. J Chronic Dis. 1987;40(5): 373-383.

35. Sundararajan V, Henderson T, Perry C, Muggivan A, Quan H, Ghali WA. New ICD-10 version of the Charlson comorbidity index predicted in-hospital mortality. J Clin Epidemiol. 2004;57(12): 1288-1294.

36. IBM Corp. IBM SPSS Statistics for Windows, Version 21.0. Armonk, NY: IBM Corp.; 2012.

37. Donders AR, van der Heijden GJ, Stijnen T, Moons KG. Review: a gentle introduction to imputation of missing values. J Clin Epidemiol. 2006;59(10):1087-1091.

38. Vergouwe $Y$, Royston $P$, Moons KG, Altman DG. Development and validation of a prediction model with missing predictor data: a practical approach. J Clin Epidemiol. 2010;63(2):205-214. 
39. Harel $\mathrm{O}$. The estimation of $\mathrm{R} 2$ and adjusted $\mathrm{R} 2$ in incomplete data sets using multiple imputation. Journal of Applied Statistics. 2009; 36(10):1109-1118.

40. Baan D, Heijmans M, Spreeuwenberg P, Rijken M. Zelfmanagement vanuit het perspectief van mensen met astma of COPD. Available from: http://www.nivel.nl/sites/default/files/bestanden/ Rapport-Zelfmanagement-mensen-met-COPD-of-Astma.pdf. Accessed March 21, 2016.

41. Wang KY, Sung PY, Yang ST, Chiang CH, Perng WC. Influence of family caregiver caring behavior on COPD patients' self-care behavior in Taiwan. Respir Care. 2012;57(2):263-272.

42. Bourbeau J. Self-management interventions to improve outcomes in patients suffering from COPD. Expert Rev Pharmacoecon Outcomes Res. 2004;4(1):71-77.

43. Bandura A. Self-efficacy: toward a unifying theory of behavioral change. Psychol Rev. 1977;84(2):191-215.

44. Sanderse C, Verweij A, Beer J de. Etniciteit: Wat is de huidige situatie? Available from: http:// www.nationaalkompas.nl/bevolking/etniciteit/huidig/. Accessed March 1, 2016.

45. Tsiligianni I, Kocks J, Tzanakis N, Siafakas N, van der Molen T. Factors that influence diseasespecific quality of life or health status in patients with COPD: a review and meta-analysis of Pearson correlations. Prim Care Respir J. 2011;20(3):257-268.

46. Weldam SW, Lammers JW, Heijmans MJ, Schuurmans MJ. Perceived quality of life in chronic obstructive pulmonary disease patients: a cross-sectional study in primary care on the role of illness perceptions. BMC Fam Pract. 2014;15:140. 
Determinants of activation for self-management 


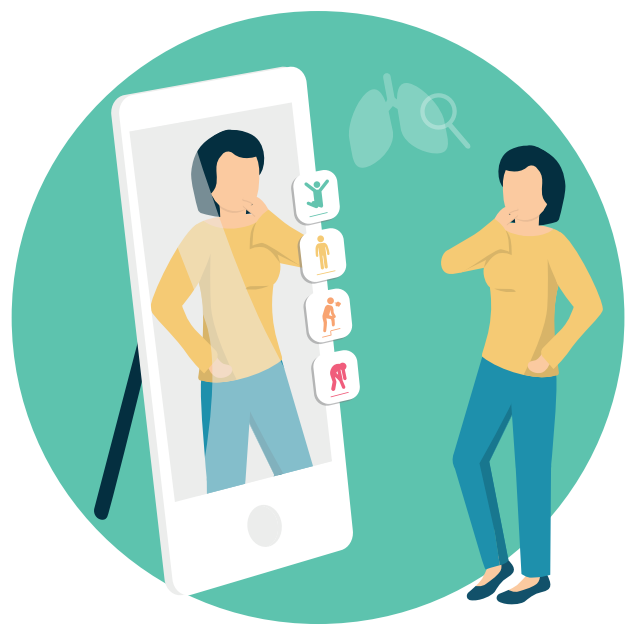




\section{Factors influencing exacerbation-related self- management in patients with COPD: a qualitative study}

Yvonne JG Korpershoek, Sigrid CJM Vervoort, Lisa NT Nijssen, Jaap CA Trappenburg, Marieke J Schuurmans International Journal of COPD. 2016; 11, 2977-2990 


\section{Abstract}

Background: In patients with COPD, self-management skills are important to reduce the impact of exacerbations. However, both detection and adequate response to exacerbations appear to be difficult for some patients. Little is known about the underlying process of exacerbation-related self-management. Therefore, the objective of this study was to identify and explain the underlying process of exacerbation-related self-management behavior.

Methods: A qualitative study using semi-structured in-depth interviews was performed according to the grounded theory approach, following a cyclic process in which data collection and data analysis alternated. Fifteen patients (male $\mathrm{n}=8$; age range 59-88 years) with mild to very severe COPD were recruited from primary and secondary care settings in the Netherlands, in 2015.

Results: Several patterns in exacerbation-related self-management behavior were identified, and a conceptual model describing factors influencing exacerbationrelated self-management was developed. Acceptance, knowledge, experiences with exacerbations, perceived severity of symptoms and social support were important factors influencing exacerbation-related self-management. Specific factors influencing recognition of exacerbations were heterogeneity of exacerbations and habituation to symptoms. Feelings of fear, perceived influence on exacerbation course, patient beliefs, ambivalence toward treatment, trust in health care providers and self-empowerment were identified as specific factors influencing self-management actions.

Conclusion: This study provided insight into factors influencing exacerbationrelated self-management behavior in COPD patients. The conceptual model can be used as a framework for health care professionals providing self-management support. In the development of future self-management interventions, factors influencing the process of exacerbation-related self-management should be taken into account. 


\section{Introduction}

COPD is a highly prevalent chronic disease and a major cause of mortality worldwide. ${ }^{1}$ The natural course of COPD is interrupted by exacerbations characterized by a sustained worsening of patients' respiratory symptoms, which are beyond normal day-to-day variability and may warrant medical treatment..$^{1-3}$ These exacerbations have a serious negative impact on the quality of life $\mathrm{e}^{4,5}$ and are associated with accelerated lung function decline and increased mortality. ${ }^{6,7}$ To address the burden of exacerbations, self-management has become increasingly important. ${ }^{8,9}$ Self-management skills are important to detect exacerbations early and to take prompt action to reduce the impact. ${ }^{10}$ However, both detecting exacerbations and taking prompt action appear to be difficult for patients. ${ }^{11-13}$ Previous studies have shown that approximately $50 \%$ of exacerbations are not reported to a health care professional and subsequently do not receive adequate treatment. ${ }^{10,14,15}$

Supporting patients in early detection of an exacerbation and teaching selfmanagement skills using a written action plan have been shown to accelerate recovery time and decrease the acute impact of exacerbations on health status. However, no effects on the quality of life, exacerbation frequency and health care utilization have been observed. ${ }^{16}$ This may be explained by the sole focus on exacerbation onset and the "one size fits all" approach regarding the design, intensity and mode of delivery in different types of patients. ${ }^{17}$ Individualized and tailored strategies aimed at changing behavior across the full spectrum of exacerbation-related self-management are expected to result in a higher effect size. ${ }^{17,18}$ To be able to develop self-management interventions that are acceptable, valued by and effective in patients, more in-depth knowledge is needed on how patients perceive these events and behave accordingly. ${ }^{19}$

Previous research has shown that patients' perceptions toward exacerbations are complex and diverse. ${ }^{20-22} \mathrm{~A}$ recent meta-synthesis of qualitative studies has provided an improved understanding of patients' responses and appraisals of exacerbations. ${ }^{23}$ Furthermore, a recent study investigated patients' assessment and management of exacerbations at home and showed that they identified exacerbations by visible and invisible symptoms and that health care contact usually occurred when patients no longer felt able to manage their symptoms by themselves. ${ }^{24}$ Although considerable research has provided insight into patients' perceptions and experiences regarding exacerbations, the underlying process of exacerbation-related self-management behavior is relatively unexplored. This lack 
of knowledge subsequently hampers the development of future exacerbationrelated self-management interventions with higher effect sizes that fit patients' needs and requests for care. The objective of this study was to identify and explain the underlying process of exacerbation-related self-management behavior in COPD patients necessary for the development of future targeted and tailored self-management interventions.

\section{Methods}

\section{Study design}

A qualitative study was performed according to the principles of the grounded theory approach to generate a theory to explain COPD patients' exacerbationrelated self-management behavior. ${ }^{25,26}$ The study was approved by the Medical Ethics Research Committee of the University Medical Center Utrecht (15-134/C).

\section{Sample and setting}

Initially, a purposive sample of Dutch patients with a clinical diagnosis of COPD, who had experienced at least one exacerbation in the past 12 months, was selected by health care providers (HCPs) from four general practices, one physiotherapy practice and one hospital in or near the city of Utrecht during the period of March-October 2015. Patients were eligible to participate if they met the inclusion and exclusion criteria described in Table 1. To increase the likelihood of reflecting different perspectives in the findings and ensuring representativeness, maximum variation sampling was used to create a large diversity in patients' age, sex, COPD severity and time since the last exacerbation. After the initial sampling, the data collection and analysis were alternated following a cyclic process, and theoretical sampling was used to select patients who could enrich the theory as it emerged. Theoretical sampling was continued as much as possible until saturation was reached. ${ }^{26}$

\section{Recruitment and informed consent}

Patients were informed about the study by their HCP. If a patient was willing to participate, patient's permission was asked to share contact details with the researcher. Subsequently, the patient received written study information and was contacted by the researcher to make an appointment for the interview. Written informed consent was obtained from all patients. Patients provided consent to consult their medical charts to obtain additional information on several predetermined characteristics. Twenty patients were approached for this study. In 
total, fifteen patients agreed to participate. Four patients declined to participate, and one patient could not participate due to hospitalization.

Table 1. Inclusion and exclusion criteria

\begin{tabular}{ll}
\hline Patients with a clinical diagnosis of COPD & \\
\hline Inclusion & Exclusion \\
\hline Age $>40$ years & Diagnosed with cognitive impairments \\
\hline $\mathrm{FEV}_{1} / \mathrm{FVC}$ ratio $<70 \%$ & $\begin{array}{l}\text { Primary diagnosis of asthma, cardiac disease or } \\
\text { other major functionally limiting diseases }\end{array}$ \\
\hline GOLD stage $\geq 2$, spirometry FEV $<80 \%$ predicted & Life expectancy $\leq 3$ months \\
\hline Adequate communication skills & \\
\hline $\begin{array}{l}\geq 1 \text { reported exacerbation* in the past } 12 \\
\text { months prior to entering this study } \\
\text { (to ensure adequate recall of their experience } \\
\text { of an exacerbation) }\end{array}$ & \\
\hline
\end{tabular}

Notes: *An exacerbation was defined as a period of symptom deterioration in which use of a course of corticosteroids and/or antibiotics was required or hospitalization was necessary. Data from Global Initiative for Chronic Obstructive Lung Disease (GOLD). ${ }^{1}$

Abbreviations: GOLD, Global Initiative for Chronic Obstructive Lung Disease; FEV1, forced expiratory volume in 1 second; FVC, forced vital capacity.

\section{Data collection}

Semi-structured in-depth individual interviews were performed to investigate patients' perspectives toward exacerbation-related self-management. Each patient was interviewed once. A topic list was used as a framework for formulating open questions. The topics included perceived symptoms of COPD, perceptions toward exacerbations, performed actions, perceptions toward one's own role in exacerbation management and needs regarding self-management (Appendix 1). To clarify the meaning of an exacerbation, patients were asked specifically if they could remember a period of symptom deterioration for which a course of prednisolone and/or antibiotics had been prescribed (Appendix 1). The topic list was adapted during the process based on emerging theoretical ideas. All interviews started with the same opening question: "How do you experience having a lung disease in your daily life?".

The interviews were conducted by a nurse scientist with a nursing degree (YK) and health scientist in training (LN). An expert on qualitative research with a nursing background was involved in the process of data collection to ensure methodological quality (SV). The interviews were held in patients' homes $(n=13)$ or at the hospital $(n=2)$. In three interviews, a partner was present. The duration of the interviews ranged from 45 to 90 minutes. The interview focus shifted to specific topics that 
were identified through the data analysis. In thirteen interviews, both researchers (YK and LN) were present, and they alternated between the interviewer and observer roles. All interviews were audiotaped. During and directly after the interviews, memos were created to describe observations, reflect on methodological issues and capture initial thoughts related to theoretical concepts.

Baseline characteristics were collected after the interviews through questionnaires. In addition, medical chart reviews were performed to obtain information on the recorded time period since the last exacerbation, lung function and comorbidities. Patient data were encoded and analyzed anonymously.

\section{Data analysis}

Data were analyzed according to the grounded theory approach by two independent researchers (YK and LN) and were discussed with a third researcher (SV). All interviews were transcribed verbatim. Data analysis was supported by NVivo 10.0 software (QSR International Pty Ltd, Version 10, 2012). The analysis took place in a cyclic process through open coding, axial coding and selective coding and was alternated with data collection. ${ }^{26,27}$ Using constant comparison, the identified themes were reviewed for differences and similarities in interview fragments. ${ }^{26,28}$ Memo writing supported the process of analysis.

First, two researchers (YK and LN) read an interview in its entirety to get an overall picture and then summarized the interview by reflecting on the interview course and information obtained related to the research objective. Second, the interview was reread in more detail, and meaningful paragraphs were open coded independently by both researchers and discussed afterward to reach consensus. Using open coding, the interview data were segmented and an initial list of codes emerged. After five interviews, the analysis shifted toward axial coding, in which codes were categorized according to similarity and organized under main themes. ${ }^{26,27}$ After axial coding, new data were collected to support initial ideas on connections between categories. Analytic induction was performed after the analysis of ten interviews by testing initial theoretical ideas in new cases. Finally, through selective coding, the categories were refined and connections between the categories were integrated to identify the process of exacerbationrelated self-management behavior, leading to a conceptual model explaining this process. Connections between categories were confirmed with the last two interviews leading to saturation. ${ }^{26}$ The third researcher's (SV) role in this process included coding a selection of interview data and participating in discussions on the data analysis. 
The credibility of the study was enhanced by emphasizing the aim to learn from patients and the researchers' non-judgmental approach during the interviews. The potential for bias was diminished through the transcription of interviews and the use of researcher triangulation in all phases of the study. ${ }^{29}$ To further enhance the credibility of the study, the process of data analysis and interpretation was systematically discussed in our research team, comprising experts in the fields of nursing science, qualitative research, self-management and COPD (MS, SV, JT). ${ }^{29}$ In addition, an external expert on qualitative research performed a peer review on our methodological quality, and a clinical nurse specialist was consulted for a peer review on the interpretation of our conceptual model.

\section{Results}

Baseline characteristics of the study population are presented in Table 2 . Maximum variation was achieved for disease severity (mild to very severe COPD), age (range 59-88 years), sex (almost equally distributed) and time since the last exacerbation ( $<1-12$ months). Prescriptions for self-medication (antibiotics and/ or prednisolone) were lacking in the study population, except some patients who received prescriptions during the holidays.

\section{Patient perceptions toward exacerbations}

When answering our first question, almost all patients started talking about their daily symptoms and functional limitations. Most experienced symptoms were breathlessness, sputum production and fatigue. Hence, symptoms varied widely per individual. Functional limitations were mostly related to exercising, walking and talking. With the exception of two patients, all patients were familiar with the name COPD for their disease.

When asking patients about their experiences with periods of symptom deterioration for which medical treatment was indicated, two patients could not remember having such a period in the past year. Most patients had a clear memory of this period and perceived it as a very unpleasant experience sometimes invoking feelings of fear and anxiety. Only four patients were familiar with the term "exacerbation" or "lung attack" as terms to describe these periods of symptom deterioration. Other patients related these periods to pneumonia, infection or the flu. A few patients did not refer to a certain term since their HCP, in their opinion, had not explicitly mentioned a certain term. Several patients believed that some internal factors, such as emotions, stress and pushing the 
boundaries regarding activities, could influence exacerbation onset. Other patients attributed exacerbation onset to external factors, such as seasonal influences and air pollution.

Table 2. Baseline characteristics of the study population $(\mathrm{N}=15)$

\begin{tabular}{|c|c|c|c|c|c|c|c|c|}
\hline ID & Sex & Age $^{a}$ & $\begin{array}{c}\text { Living } \\
\text { situation }^{\mathrm{b}}\end{array}$ & $\begin{array}{c}\text { Education } \\
\text { levelc }\end{array}$ & Smoking & $\begin{array}{l}\text { GOLD } \\
\text { stage }^{\text {d }}\end{array}$ & $\begin{array}{c}\text { Self-reported } \\
\text { exacerbations } \\
\text { per year }\end{array}$ & $\begin{array}{c}\text { Time period } \\
\text { from last } \\
\text { exacerbation } \\
\text { in months }\end{array}$ \\
\hline R01 & $F$ & 66 & A & Medium & Former & 1 & 1 & $1-3$ \\
\hline R02 & M & 59 & LPC & Medium & Current & 3 & 3 & $1-3$ \\
\hline R03 & $\mathrm{F}$ & 64 & A & Medium & Current & 1 & 1 & $>12 *$ \\
\hline R04 & $\mathrm{F}$ & 74 & LP & Low & Former & 2 & 0 & $6-12$ \\
\hline R05 & $\mathrm{F}$ & 74 & LP & Medium & Current & 3 & 1 & $1-3$ \\
\hline R06 & M & 73 & A & Low & Current & 2 & 3 & $6-12$ \\
\hline R07 & $\mathrm{F}$ & 81 & A & Medium & Former & 3 & 2 & $<1$ \\
\hline R08 & $\mathrm{F}$ & 74 & A & High & Current & 2 & 1 & $1-3$ \\
\hline R09 & M & 67 & LP & Low & Former & 2 & 3 & $<1$ \\
\hline R10 & M & 88 & A & Medium & Former & 3 & 1 & $<1$ \\
\hline R11 & M & 76 & LP & Low & Former & 4 & 5 & $<1$ \\
\hline R12 & M & 64 & LP & Medium & Current & 3 & 2 & $<1$ \\
\hline R13 & $\mathrm{F}$ & 59 & LP & Low & Former & 2 & 5 & $1-3$ \\
\hline R14 & M & 64 & LC & High & Former & 3 & 1 & $6-12$ \\
\hline R15 & $M$ & 68 & LP & High & Former & 3 & 4 & $<1$ \\
\hline
\end{tabular}

Notes: ${ }^{a}$ Age at time of interview. ${ }^{b}$ A, living alone; LP, living with life partner; LPC, living with life partner and children; LC, living without a partner and with children. 'Low, primary school through vocational training; medium, secondary school or vocational training; high, college or university degree. ${ }^{\mathrm{d} A c c o r d i n g}$ to GOLD classification in medical chart. eAmount of exacerbations determined by amount of prescriptions of prednisone and/or antibiotics for worsening of lung symptoms, estimated by patients themselves. *Last exacerbation was 16 months ago.

Abbreviation: GOLD, Global Initiative for Chronic Obstructive Lung Disease. 


\section{Patterns in patients' exacerbation-related self-management behavior}

Based on patients' stories, a conceptual model describing factors influencing exacerbation-related self-management was developed (Figure 1). Our conceptual model presents the underlying process of exacerbation-related self-management behavior by explaining its influencing factors. We identified several patterns in exacerbation-related behavior based on two important self-management skills: recognition of an exacerbation and performance of self-management actions. The results are presented by first explaining these patterns in patients' behavior followed by a description of factors that influence these patterns. The patterns in recognition serve as a starting point. With regard to recognition, three different patterns in patients were identified and detailed in our conceptual model: 1) early recognition, 2) late recognition and 3) difficulties with recognition. Subsequently, these patients showed different types of self-management actions, which were subdivided into "absence of self-management actions", "self-management actions to reduce symptoms", and "contacting an HCP", as explained in Table 3.

\section{Patients early recognizing exacerbations}

In general, patients who recognized an exacerbation often had experienced more than one exacerbation and perceived these events as a part of their COPD. Symptoms perceived as the onset of an exacerbation were increased fatigue, increased respiratory symptoms (eg, coughing, sputum production and breathlessness), specific pain and fever.

Patients who explained that they were able to recognize an exacerbation at an early stage were generally aware of the importance of early detection and prompt action. They had a pro-active attitude. By closely monitoring symptoms, they felt able to anticipate possible problems. R12: "I try to anticipate on that moment ... because I don't want to let things get that far that I will get a pneumonia". These patients often performed adequate self-management actions to reduce their symptoms and consulted their HCP on time. Some of these patients monitored their symptoms for 2 or 3 days when they felt able to manage the symptoms by themselves to ensure that the symptoms would not diminish on their own without prescription of medication. If their situation did not improve during this time, they contacted their HCP, or they contacted their HCP immediately in cases of sudden symptom increases. Some of these patients expressed a desire for selftreatment at home since they believed that this arrangement would allow them to take faster action. However, some patients who recognized exacerbations early postponed contacting their HCP. 


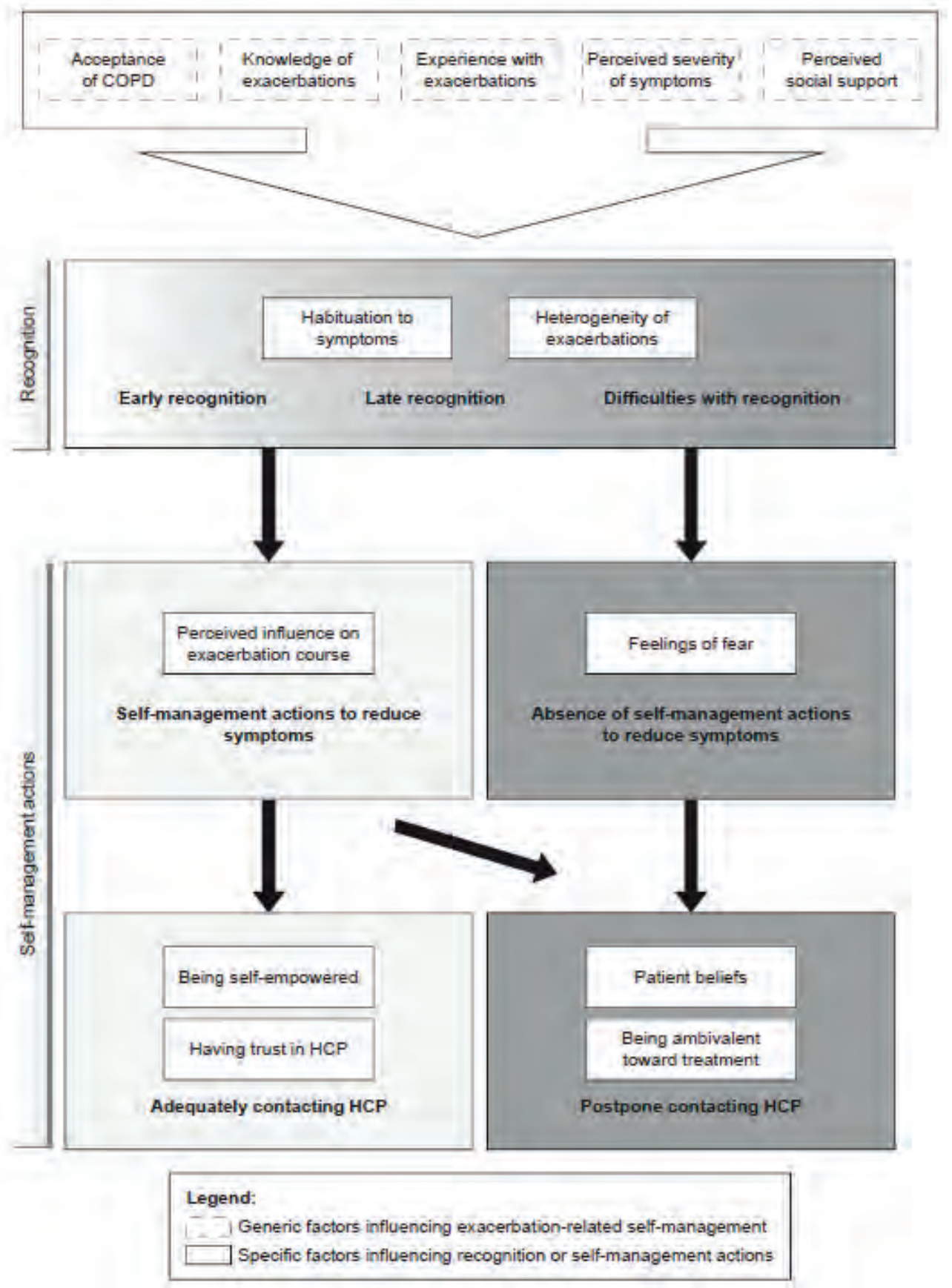

Figure 1. Conceptual model describing factors influencing recognition of exacerbations and performance of self-management actions

Abbreviation: $\mathrm{HCP}$, health care provider. 
Table 3. Operationalization types of self-management actions

\begin{tabular}{ll}
\hline $\begin{array}{l}\text { Type of self- } \\
\text { management actions }\end{array}$ & Explanation \\
\hline $\begin{array}{l}\text { Absence of self- } \\
\text { management actions to } \\
\text { reduce symptoms }\end{array}$ & $\begin{array}{l}\text { Performed actions were similar to self-management actions in the } \\
\text { stable phase (not experiencing an exacerbation). Increasing inhalation } \\
\text { medication was sometimes performed as patients are used to do when } \\
\text { experiencing daily fluctuations in symptoms. }\end{array}$ \\
$\begin{array}{l}\text { Self-management } \\
\text { actions to reduce } \\
\text { symptoms }\end{array}$ & $\begin{array}{l}\text { Taking rest, performing breathing or sputum exploration techniques } \\
\text { and increasing inhalation medication/using an extra dosage of } \\
\text { antibiotics and/or prednisolone. }\end{array}$ \\
Contacting a HCP & $\begin{array}{l}\text { Adequately contacting HCP: Patients directly contacted an HCP in } \\
\text { case of symptom deterioration or monitored symptoms carefully } \\
\text { and contacted an HCP when crossing the mutual agreed threshold in } \\
\text { symptoms. } \\
\text { Postpone contacting HCP: Patients postponed to contact an HCP or } \\
\text { mentioned that their HCP advised them to contact earlier in the future. }\end{array}$ \\
\hline
\end{tabular}

Abbreviation: $\mathrm{HCP}$, health care provider.

\section{Patients recognizing exacerbations late}

Several patients recognized an exacerbation, but the recognition occurred late, when symptoms had already significantly increased over a number of days. These patients explained having difficulties interpreting their symptoms in a timely manner. Some of these patients realized afterward that symptoms had already been present before they recognized them. R11: "Well, afterwards you can say ... oh ... that was already present for a few days". Most of these patients continued their normal daily activities and performed various actions to minimize their symptoms. Several patients adequately contacted their HCP, although most patients postponed seeking medical help until they felt a strong urgency to do so. As a result, some patients reached a point of crisis leading to hospitalization. R02: "I often kept on going way too long. And then, at a certain moment, your blood is out of oxygen. The last time in the hospital I only had 78\% oxygen in my blood. So I kept on going way too long".

\section{Patients having difficulties recognizing exacerbations}

Patients having difficulties recognizing an exacerbation did not remember having an exacerbation or remembered receiving antibiotics and/or prednisolone for a temporary increase in symptoms but associated this period with the flu or with other problems dominating during that specific period. These patients did not seem to relate their temporary illness to their COPD. R05: “... and then my husband called the doctor. I said that is not necessary. It will resolve by itself. 
Everyone experiences flu sometimes". These patients generally performed little self-management actions. Their self-management actions were similar to their behavior in the stable phase, such as taking short-acting inhalation medication as they were used to doing. Overall, these patients postponed contacting an HCP and followed a wait-and-see approach. These patients expressed having little needs with regard to self-management support.

\section{Factors influencing exacerbation-related self-management behavior}

Figure 1 shows that we identified five generic factors influencing both recognition of exacerbations and performance of self-management actions either positively or negatively. In addition, specific factors influencing the ability to recognize an exacerbation or influencing the performance of self-management actions were identified. It is important to note that these factors mutually influenced each other as well. Details of these influencing factors are described in the following paragraphs and further illustrated by quotes in Table 4 (Q references in the text refer to specific quotes in Table 4).

Table 4. Illustrative quotes related to identified factors influencing exacerbation-related selfmanagement

\begin{tabular}{|c|c|}
\hline $\begin{array}{l}\text { Influencing } \\
\text { factors }\end{array}$ & Quotes \\
\hline \multirow[t]{3}{*}{$\begin{array}{l}\text { Acceptance of } \\
\text { COPD }\end{array}$} & $\begin{array}{l}\text { Q1: "You can put on the brave face and say 'I got nothing' but that is nonsense of } \\
\text { course. (...) You can better say 'it is this way'. Okay. And then you can react on it } \\
\text { yourself" (R08). }\end{array}$ \\
\hline & $\begin{array}{l}\text { Q2: “I mean. I have accepted that. I know that at some point it's not going to } \\
\text { resolve so eh ehm ... In the beginning I would have had eh ehm ... a difficult time } \\
\text { with it, but at the point where you accept it isn't going to go away, those lungs } \\
\text { have been affected, the only thing possible is for it to be stable, that's my starting } \\
\text { point" (R14). }\end{array}$ \\
\hline & $\begin{array}{l}\text { Q3: “I am someone who doesn't want to admit it at all, so you just keep doing } \\
\text { everything” (R02). }\end{array}$ \\
\hline \multirow[t]{3}{*}{$\begin{array}{l}\text { Perceived } \\
\text { severity of } \\
\text { symptoms }\end{array}$} & $\begin{array}{l}\text { Q4: "Yeah, then you start to wheeze a bit, but apart from that it it is not too bad" } \\
\text { (R10). (I: "yes ... but so ... you say it's not too bad ... but is it really alright then?") } \\
\text { R10: "Well ... not always ...". }\end{array}$ \\
\hline & $\begin{array}{l}\text { Q5: "I don't think it bothers me that much. (...) My children say it does, but they } \\
\text { look at it differently" (R08). }\end{array}$ \\
\hline & $\begin{array}{l}\text { Q6: "I have seen it with my dad, he didn't go outside anymore, he just sat on a } \\
\text { chair, kept on going but didn't do anything. But well, that's looking back, I never } \\
\text { thought that I would also be such a COPD patient. But it did happen to me and } \\
\text { now I think I have to stay physically active ... If you would like to resist those } \\
\text { infections every time" (R12). }\end{array}$ \\
\hline $\begin{array}{l}\text { Knowledge of } \\
\text { exacerbations }\end{array}$ & $\begin{array}{l}\text { Q7: "The sooner I contact my general practitioner, the sooner the medication is } \\
\text { successful and the sooner I get rid of it again" (R12). }\end{array}$ \\
\hline
\end{tabular}


Table 4 (Continued)

\begin{tabular}{|c|c|}
\hline \multirow[t]{3}{*}{$\begin{array}{l}\text { Experience } \\
\text { with } \\
\text { exacerbations }\end{array}$} & $\begin{array}{l}\text { Q8: "But then the symptoms will not resolve themselves ... you learn quite quickly } \\
\text { that you should call immediately and eh (...) But at some point you learn that: ok, } \\
\text { this is a cough so you have to watch out ..." (R15). }\end{array}$ \\
\hline & $\begin{array}{l}\text { Q9: "At some point it will not pass and I've learned that if I feel something is } \\
\text { coming up, I will call the general practitioner immediately" (R02). }\end{array}$ \\
\hline & $\begin{array}{l}\text { Q10: "I don't want to let it get that far that I will get a pneumonia ... a heavy } \\
\text { pneumonia ... I've had that before, and I was seriously shocked by that. I think it } \\
\text { had also been bothering me for a couple of days then, and I waited too long ... } \\
\text { now I think, I should raise the alarm sooner" (R12). }\end{array}$ \\
\hline
\end{tabular}

Perceived Q11: "Mum, you are short of breath ... Oh am I? And then I'm wheezing without social support even noticing it ..." (R08) (I: "But so then perhaps they recognize it sooner than you?") R08: "Yes".

Q12: ("I: When you decide to call your HCP, what influences that decision? Does your environment influence that decision as well?") "Well ... very little ... that's just eh ... purely my own feeling" (R15).

Heterogeneity Q13: (“I: Do you feel like there is a difference between a gradual or sudden of $\quad$ onset?") "Both are also possible (...) Symptoms are so different, you can't put your exacerbations finger on it. That's too bad right, such a shame ..." (R13).

Habituation Q14: (Partner and patient speaking about perceived symptoms) Partner of R11: to symptoms “He also turn bluish quickly (...) but I often don't even notice because I'm so used to seeing that (...) but yeah, you experience it from the beginning you know? And see things slowly getting worse. And then it's difficult ... I think that's also why you notice it less". R11 adds: "Because the onset is gradually" (...) (R11).

Q15: "Yeah, look, because you always have it ... you learn to live with it. And when it gets worse, you know you have to warn, but because you are so used to it, you learn to live with it and you do everything with it" (R10).

Perceived Q16: (I: “And why do you think it is important to take action on time?") "Well ... I influence on think it will heal faster or something ... If I act sooner on it" (R06).

exacerbation Q17: (I: “And what do you do when you feel more breathless?") “Well nothing. You course can't do anything" (R11).

Feelings of Q18: "At some point it's mainly fear, and well, I start hyperventilating and then I fear can't solve it anymore" (R02).

Being self- $\quad$ Q19: “When I feel terrible and I call the general practitioner, like the last time that empowered I felt a pneumonia was emerging, and the assistant tells me I can visit the general practitioner next week I say: I am sick know, I want to see the doctor right now" (R06). Q20: "So when I go to the general practitioner I know exactly what I want and I eh ... try to direct the general practitioner in that direction. If there are plausible reasons not to do that that's fine too, but before I go into the room I know for myself what I would like to accomplish" (R14).

Q21: "And the assistants were not always that nice to me, they said the doctor doesn't have time today. And then I said: 'Yes, but' ... 'No, no time today, come in on Friday'. But then I visited the doctor and he asked me why I didn't come in earlier? Well ..." (R13).

Having trust Q22: "When something goes wrong I will call that lung nurse because the in HCP pulmonologist isn't always available, you don't get to talk to him on the phone directly, but she can quickly pass on the information so that communication is pretty good" (R15).

Q23: "Actually, the most important thing is recognition, early recognition of a pneumonia and that someone listens to you at the moment you think something is wrong" (R13). (I: "Is that important to you, to take action?") R13: "Yes, absolutely". 
Table 4 (Continued)

\begin{tabular}{|c|c|}
\hline \multirow[t]{4}{*}{ Patient beliefs } & $\begin{array}{l}\text { Q24: (A patient mentioned that his doctor told him a few times to contact earlier } \\
\text { and we asked the patient why the doctor gave this advice in the patients opinion. } \\
\text { The patient answered:) "so you can have it treated sooner ... and then maybe it } \\
\text { will recover sooner as well ... but, I am a bit stubborn" (R10). }\end{array}$ \\
\hline & $\begin{array}{l}\text { Q25: "Pushing through is what I learned back in the days (...) It is all mentality, if } \\
\text { you feel mentally well, the rest will follow, because you feel responsible for the } \\
\text { things that need to happen" (R10). }\end{array}$ \\
\hline & $\begin{array}{l}\text { Q26: "I am someone who thinks 'then my doctor is wasting time for nothing', so I } \\
\text { wait until I am sick to death" (R13). }\end{array}$ \\
\hline & $\begin{array}{l}\text { Q27: “That is how we were raised. Back in the day, you could not be sick (...) It is } \\
\text { very hard to break that habit when you were raised like that (...)" (R08). }\end{array}$ \\
\hline \multirow{2}{*}{$\begin{array}{l}\text { Being } \\
\text { ambivalent } \\
\text { toward } \\
\text { treatment }\end{array}$} & $\begin{array}{l}\text { Q28: "You are not looking forward to going to the hospital. Although I actually } \\
\text { know in advance that it will happen anyway" (R11). }\end{array}$ \\
\hline & $\begin{array}{l}\text { Q29: "Well, that you think: I would not call yet. I will wait a while (...) Prednisolone } \\
\text { is an unpleasant medicine (...) I would rather take nothing but well ... it is a } \\
\text { necessary evil I say" (R15). }\end{array}$ \\
\hline
\end{tabular}

Abbreviations: HCP, health care provider; R, respondent; I, Interviewer; Q, quote.

\section{Generic factors influencing exacerbation-related self-management (both recognition and self-management actions) Acceptance of COPD}

Acceptance of COPD was identified as an important factor influencing patients' perceptions toward COPD and exacerbations, which subsequently affected exacerbation-related self-management. A wide variety of acceptance was found ranging from difficulties with acceptance to full acceptance. Patients who accepted their COPD perceived exacerbations as events they have to deal with and were therefore more likely to recognize an exacerbation early and to adapt their behavior to their current health status by taking prompt actions (Q1 and Q2). The level of acceptance varied in patients showing late recognition. Some patients acknowledged their symptom deterioration but neglected it and were unable to anticipate on these symptoms as they solely wanted to continue on with their normal lives (Q3). Patients having difficulties with acceptance preferred to avoid confronting their disease and often tried to hide it from others; in some cases, they did so because they felt ashamed. Some of these patients did not attribute an increase in symptoms to their COPD and therefore had difficulties with recognizing an exacerbation and taking prompt actions.

\section{Perceived severity of symptoms}

The perceived severity of symptoms varied widely from hardly noticing any symptom deterioration to taking symptom deterioration seriously. Patients who were aware of the gravity of their situation, perceiving exacerbations as 
hazardous events, often recognized exacerbations early. Furthermore, they explained that their situation would worsen if they postponed their actions. Perceived severity of symptoms varied in patients showing late recognition or difficulties with recognition. Some of them trivialized their situation by describing their symptoms as less serious than they actually were (Q4 and Q5). These patients often recognized an increase in symptoms but took a risk in postponing adequate self-management actions. To interpret their own severity, a substantial group of patients compared themselves to other patients with more severe COPD. These comparisons could influence patients' perceptions toward the severity of their symptoms in two different ways. On one hand, some patients trivialized their current condition by comparing themselves to others and therefore saw no reason to adapt their behaviors. On the other hand, the comparison led to patients' recognition of the gravity of their situation and created awareness about the progressive development of COPD, resulting in stronger intentions to perform adequate exacerbation-related self-management (Q6).

\section{Knowledge of exacerbations}

Patients with adequate knowledge of exacerbations often recognized exacerbations early and took prompt actions. Patients who were aware of the importance of taking prompt action were convinced that doing so could help them reduce exacerbation severity and recovery time (Q7). However, some of these patients postponed taking action as other influencing factors overruled. Patients having difficulties with recognition had little understanding of exacerbations and explained having little insight into actions they could perform to feel better.

\section{Experience with exacerbations}

Patients explained that their former experiences with exacerbations led to their increased confidence in recognizing future exacerbations, which was initiated by having a feeling when something is wrong or by recognizing a pattern of symptoms indicating that an exacerbation is imminent (Q8). Furthermore, patients who had experienced benefits from their past actions were more likely to perform adequate self-management actions (Q9). Negative experiences contributed to the learning curve as well. For example, patients who experienced hospitalization due to postponing their actions often recognized their boundaries better. Moreover, previously experienced feelings of fear and anxiety positively influenced patients' intentions to perform self-management actions, as they had learned to try to prevent situations that might invoke these feelings by contacting their HCP earlier (Q10). 


\section{Perceived social support}

Several patients expressed the importance of social support from family and personal relationships, as well as support from HCPs, in self-managing exacerbations. The influence of social support seemed to be highest for patients having difficulties recognizing exacerbations, as they often needed support from family or personal relationships to realize that symptoms were worsening and to stimulate health care contact (Q11). Social support seemed to be less important for patients who recognized exacerbations, although these patients sometimes needed others' support as well to take symptoms seriously and to take prompt actions. Patients who recognized exacerbations early and took prompt action often felt that they were able to manage exacerbations themselves (Q12). However, when these patients nonetheless postponed contacting an HCP, social support was an influencing factor in the decision to contact an HCP as well.

\section{Factors influencing recognition of exacerbation Heterogeneity of exacerbations}

Heterogeneity of exacerbations was identified as a key factor in distinguishing patients showing late recognition from patients showing early recognition. Some patients felt very capable of recognizing an increase in symptoms but perceived the heterogeneity of exacerbations as a barrier. These patients found it difficult to distinguish an exacerbation from normal day-to-day symptom variations, as the onset of an exacerbation could vary from gradual to sudden, and the types and severity of symptoms were not always consistent (Q13).

\section{Habituation to symptoms}

Recognition of an exacerbation was complicated by habituation to the progression of perceived daily symptoms. Patients who experienced habituation to symptoms explained that it became more difficult to determine a significant increase in symptoms, since they had learned to cope with the severity of their symptoms (Q14 and Q15).

\section{Factors influencing self-management actions Perceived influence on exacerbation course}

Patients' perceived influence on the course of an exacerbation varied widely and was identified as a factor influencing self-management actions. Patients who felt able to influence the course of an exacerbation had a greater internal locus of control and were more likely to take self-management actions to reduce the severity of an exacerbation (Q16). In contrast, patients who felt that they could not influence the course of an exacerbation often postponed taking action (Q17). 


\section{Feelings of fear and anxiety}

Some patients expressed feelings of fear and anxiety that limited their ability to perform adequate self-management actions to reduce symptoms. They stated that feelings of fear and anxiety were present at the time of acute symptom deterioration and included a fear of dying due to increased breathlessness and feelings of choking. These patients were often aware of strategies to reduce these perceived symptoms (such as breathing techniques and relaxation); yet, these feelings of fear and anxiety interfered with performing these strategies (Q18).

\section{Factors influencing contacting an HCP Being self-empowered}

Being self-empowered was identified as a factor that differentiated patients who contacted their HCP early from patients who postponed contact with their HCP. Self-empowerment refers to the extent to which patients are able to take action based on their own thoughts, believing that they know what is best for themselves. Self-empowered patients in the study prioritized their own health and were able to stand up for themselves (Q19 and Q20). Patients who postponed contact with their HCP were less self-empowered and mostly influenced by a threshold that they perceived. Some of these patients experienced organizational issues as a barrier to contacting their HCP, such as not getting an opportunity to talk with their HCP. These patients were not able to stand up for themselves, resulting in a delay of action with occasionally serious consequences (Q21).

\section{Having trust in HCP}

Having trust in an HCP was identified as a factor that influenced patients contacting their HCP as patients described the importance of adequate coaching from their HCP in their self-management actions. Patients who took prompt action often had agreements with their HCP on how to act in response to exacerbations and expressed having confidence in their HCP (Q22). Some patients learned what to do in case of symptom deterioration but felt that they were not taken seriously by their HCP when they felt a need to contact their HCP, leading to postponed health care contact. In addition, some patients experienced difficulties with explaining the seriousness of their symptoms to their HCP. Patients explained that being heard by an HCP contributed to their performance of self-management actions (Q23).

\section{Patient beliefs}

For a number of patients, the threshold for contacting an HCP was influenced by their beliefs. Some patients explained that they postponed contacting an HCP out of stubbornness despite knowing better (Q24). Some patients explained having 
hope that their symptoms would resolve themselves and therefore postponed contacting their HCP. Other patients believed that their social responsibilities (eg, housekeeping, work) were more important than listening to their own feelings (Q25). Finally, some patients explained that they did not want to bother their HCP and therefore postponed health care contact (Q26). A few people explained that this belief was influenced by how they were raised (Q27). Patients who adequately contacted their HCP were sometimes familiar with these beliefs, but having learned from their earlier negative experiences, they were able to adapt their beliefs and consider their own health to be most important.

\section{Being ambivalent toward treatment}

Many patients were ambivalent toward taking medication, especially with regard to prednisolone, due to its negative side effects. Consequently, some of these patients postponed contacting their HCP as they preferred not to admit that they needed treatment, although they were aware of its importance. Furthermore, ambivalence toward treatment was reflected by patients who tried to avoid hospitalization and therefore postponed contacting their HCP (Q28). Conversely, patients who were convinced that they needed treatment were more likely to contact their HCP (Q29).

\section{Discussion}

This study resulted in a conceptual model explaining factors influencing exacerbation-related self-management. Based on patients' stories, several patterns in exacerbation-related self-management were identified based on two important self-management skills: recognition of an exacerbation and performance of selfmanagement actions. The identified patterns were dynamic in nature and could change in individual patients over time due to variability in influencing factors and disease progression. Our conceptual model shows that exacerbation-related self-management was influenced by acceptance of COPD, perceived severity of symptoms, knowledge of exacerbations, former experiences with exacerbations and social support. In addition, specific factors influencing the ability to recognize an exacerbation or the performance of self-management actions were identified.

Several of the findings of this study were in line with other studies. Corresponding with previous research, we found that patients often had difficulties understanding the term "exacerbation"22,24 and that patients reported both personal and environmental factors that may cause exacerbations. ${ }^{30}$ Our finding that exacerbation-related self- 
management behavior was determined by personal beliefs, perceptions regarding seriousness of the disease, knowledge of exacerbations and former experiences with exacerbations is consistent with the Health Belief Model. ${ }^{31-33}$ Furthermore, in line with previous research, acceptance was considered to be important for behavior change toward self-management, 34,35 and the importance of social support was strengthened by previous research emphasizing the need to involve others in self-management support to change behavior. ${ }^{36}$ Consistent with previous research focusing on self-management actions, our study found that feelings of fear and anxiety resulted in perceived powerlessness in response to symptoms ${ }^{23}$ and perceived control on exacerbation course influenced self-management actions. ${ }^{37-40}$ Previous studies have also observed differences between patients who pro-actively monitored the course of an exacerbation and contacted their HCP on time and patients who postponed health care contact until feeling an urgency for medical care..$^{21,24,30,41}$ Finally, regarding smoking in relation to self-management, our study concurred with earlier studies in showing that smoking was not an explanatory factor for self-management behavior. ${ }^{42,43}$

Our findings expand upon prior work by identifying patient beliefs, ambivalence toward treatment, self-empowerment and trust in HCPs as specific factors influencing health care contact. Patient belief was identified as a barrier for seeking medical help since various patients felt that they "bothered" their HCP. As patients explicitly mentioned their upbringing as influencing factor, this finding might be due to this older population of COPD patients being raised not to bother other people with personal problems. ${ }^{21,41}$ Furthermore, some patients who postponed health care contact did so because they felt that they were "not being heard" by their HCP. This finding might be explained by previous research showing that patients sometimes feel that they do not have legitimized reasons to seek help. ${ }^{21,23}$ The identified ambivalence toward treatment can be explained by the Health Belief Model and by previous work showing that considering the side effects of medication was related to medication adherence..$^{24,31}$

To date, the literature has been inconclusive regarding patients' skills toward recognition of exacerbations. Williams et al ${ }^{24}$ showed that patients "just know" when they are experiencing exacerbations and that the majority of patients feel capable of distinguishing "bad days" from exacerbations, while our study identified patients showing early recognition, late recognition and patients having difficulties with recognition. These differences could be due to the recruitment strategies in the study of Williams et al. As it was part of a trial evaluating a self-management support intervention, the sample of patients may have had more engagement in self- 
management. ${ }^{24}$ However, in line with our study, Adams et $a^{21}$ showed that patients did not immediately remember exacerbations and described them as "forgotten events". Furthermore, we identified the heterogeneity of exacerbations as an important barrier that differentiated patients recognizing exacerbations late from patients early recognizing exacerbations. However, previous studies have reported that most patients had predictable symptoms and could easily identify consistent warning signs, which may have been due to the inclusion of patients with more exacerbation experiences in those studies. ${ }^{22,24}$ Moreover, we found that recognition was complicated by patients' habituation to their stable symptom severity and daily fluctuations, which has not been described in previous research to our knowledge.

An important strength of this study was that data were independently analyzed by two researchers and discussed with an expert on qualitative research during the entire process. Furthermore, both credibility and confirmability were enhanced by systematically discussing the interpretation of data with experts in the field. Although the results of this study were based on fifteen patients, maximum variation sampling increased the likelihood of diversity in our data collected from a representative selection of patients, which contributed to the transferability of the study. However, this study had a few limitations. Medical chart reviews showed afterward that the inclusion and exclusion criteria were not fully met in two patients with GOLD stage 1. Their charts showed conflicting data with regard to lung function and GOLD stage, and one patient had experienced an exacerbation 12 months ago. Nonetheless, these patients were not excluded from the study since they were considered to be eligible by their HCPs and were able to share their experiences regarding exacerbations. Furthermore, the interpretation of data was based on patients' perceptions regarding exacerbations. This might have affected the credibility of our study since previous research has shown that some patients show little understanding regarding exacerbations. ${ }^{21,22}$ To address this potential limitation, we clarified the term exacerbation by asking patients specifically if they could remember a period of symptom deterioration for which medical treatment was indicated.

The conceptual model provided insight into different patterns of exacerbationrelated self-management and factors influencing this behavior. Since needs and requests for care flowed naturally from the problems perceived by patients, ${ }^{19}$ the identified influencing factors guided our implications for practice and future research. The conceptual model provides a framework for HCPs to identify patterns in patients' exacerbation-related self-management and stresses the need for better assessment on influencing factors to enhance self-management by 
eliminating identified barriers. When an HCP identifies poor exacerbation-related self-management, self-management support should be intensified, which may consist of teaching self-monitoring skills and exacerbation education supported by an action plan. ${ }^{16,44} \mathrm{HCPs}$ should be aware that these patients might express limited needs regarding self-management support themselves. Patients who recognize exacerbations, and show adequate self-management skills, may benefit from continued education and decision support. HCPs should notice that patients who postpone health care contact might be experiencing barriers in the patient-HCP relationship. For this subgroup of patients, it is important that they are being heard by their HCP and that HCPs listen carefully and take their patient' expertise seriously. Finally, patients who show adequate exacerbation-related self-management may benefit from continued self-management support and possibly self-treatment.

Moreover, the conceptual model is important for future development of selfmanagement interventions since it shows which influencing factors should be taken into account during the development and delivery of interventions. Based on this model, special attention should be paid to the elimination of barriers in the process of self-management to be able to develop effective self-management interventions that fit patients' perceptions, capabilities, needs and request for care. Future research should focus on the development of targeted and tailored interventions to improve the full spectrum of exacerbation-related self-management and, subsequently, reduce the impact of exacerbations.

\section{Conclusion}

This study provided in-depth insight into factors influencing exacerbationrelated self-management in COPD patients. Several patterns in exacerbationrelated self-management behavior were identified based on two important selfmanagement skills: recognition of an exacerbation and performance of selfmanagement actions. This study confirmed that recognition of exacerbations can be challenging and that self-management actions are often inadequate. The conceptual model explaining factors that influence exacerbation-related self-management can be used as a framework for health care professionals providing self-management support and as a guide for the development of future individualized and tailored exacerbation-related self-management interventions. 


\section{References}

1. Global Initiative for Chronic Obstructive Lung Disease (GOLD). Global Strategy for the Diagnosis, Management, and Prevention of Chronic Obstructive Pulmonary Disease [updated 2016]. Available from: http://goldcopd.org/global-strategy-diagnosis-management-prevention-copd-2016/. Accessed February 2, 2016.

2. Rodriguez-Roisin R. Toward a consensus definition for COPD exacerbations. Chest. 2000;117(5 suppl 2):398S-401S.

3. Burge S, Wedzicha JA. COPD exacerbations: definitions and classifications. Eur Respir J Suppl. 2003;41:46s-53s.

4. Miravitlles M, Ferrer M, Pont A, et al; IMPAC Study Group. Effect of exacerbations on quality of life in patients with chronic obstructive pulmonary disease: a 2 year follow up study. Thorax. 2004;59(5):387-395.

5. Seemungal TA, Donaldson GC, Paul EA, Bestall JC, Jeffries DJ, Wedzicha JA. Effect of exacerbation on quality of life in patients with chronic obstructive pulmonary disease. Am J Respir Crit Care Med. 1998;157(5 pt 1):1418-1422.

6. Donaldson GC, Seemungal TA, Bhowmik A, Wedzicha JA. Relationship between exacerbation frequency and lung function decline in chronic obstructive pulmonary disease. Thorax. 2002;57(10):847-852.

7. Soler-Cataluna JJ, Martinez-Garcia MA, Roman Sanchez P, Salcedo E, Navarro M, Ochando R. Severe acute exacerbations and mortality in patients with chronic obstructive pulmonary disease. Thorax. 2005;60(11):925-931.

8. Bourbeau J, van der Palen J. Promoting effective self-management programmes to improve COPD. Eur Respir J. 2009;33(3):461-463.

9. Effing TW, Vercoulen JH, Bourbeau J, et al. Definition of a COPD self-management intervention: International expert group consensus. Eur Respir J. 2016;48(1):46-54.

10. Wilkinson TM, Donaldson GC, Hurst JR, Seemungal TA, Wedzicha JA. Early therapy improves outcomes of exacerbations of chronic obstructive pulmonary disease. Am J Respir Crit Care Med. 2004;169(12):1298-1303.

11. Bucknall CE, Miller G, Lloyd SM, et al. Glasgow supported self-management trial (GSuST) for patients with moderate to severe COPD: randomised controlled trial. BMJ. 2012;344:e1060.

12. Trappenburg JC, Schaap D, Monninkhof EM, et al. How do COPD patients respond to exacerbations? BMC Pulm Med. 2011;11:43.

13. Bischoff EW, Hamd DH, Sedeno M, et al. Effects of written action plan adherence on COPD exacerbation recovery. Thorax. 2011;66(1):26-31.

14. Xu W, Collet JP, Shapiro S, et al. Negative impacts of unreported COPD exacerbations on healthrelated quality of life at 1 year. Eur Respir J. 2010;35(5):1022-1030.

15. Langsetmo L, Platt RW, Ernst P, Bourbeau J. Underreporting exacerbation of chronic obstructive pulmonary disease in a longitudinal cohort. Am J Respir Crit Care Med. 2008;177(4):396-401.

16. Trappenburg JC, Monninkhof EM, Bourbeau J, et al. Effect of an action plan with ongoing support by a case manager on exacerbation-related outcome in patients with COPD: a multicentre randomised controlled trial. Thorax. 2011;66(11):977-984.

17. Trappenburg J, Jonkman N, Jaarsma T, et al. Self-management: one size does not fit all. Patient Educ Couns. 2013;92(1):134-137.

18. Spruit MA, Franssen FM, Rutten EP, Wopereis S, Wouters EF, Vanfleteren LE. A new perspective on COPD exacerbations: Monitoring impact by measuring physical, psychological and social resilience. Eur Respir J. 2016;47(4):1024-1027. 
19. van Meijel B, Gamel C, van Swieten-Duijfjes B, Grypdonck MH. The development of evidencebased nursing interventions: methodological considerations. J Adv Nurs. 2004;48(1):84-92.

20. Barnes N, Calverley PM, Kaplan A, Rabe KF. Chronic obstructive pulmonary disease and exacerbations: patient insights from the global hidden depths of COPD survey. BMC Pulm Med. 2013;13:54.

21. Adams R, Chavannes N, Jones K, Ostergaard MS, Price D. Exacerbations of chronic obstructive pulmonary disease - a patients' perspective. Prim Care Respir J. 2006;15(2):102-109.

22. Kessler R, Stahl E, Vogelmeier C, et al. Patient understanding, detection, and experience of COPD exacerbations: an observational, interview-based study. Chest. 2006;130(1):133-142.

23. Harrison SL, Apps L, Singh SJ, Steiner MC, Morgan MD, Robertson N. 'Consumed by breathing' - a critical interpretive meta-synthesis of the qualitative literature. Chronic IIIn. 2014;10(1):31-49.

24. Williams $V$, Hardinge $M$, Ryan $S$, Farmer A. Patients' experience of identifying and managing exacerbations in COPD: a qualitative study. NPJ Prim Care Respir Med. 2014;24:14062.

25. Glaser BG, Strauss AL. The Discovery of Grounded Theory: Strategies for Qualitative Research. 7th ed. Elmer, NJ: Aldine; 1967.

26. Boeije H. Analysis in Qualitative Research. 1st ed. London: Sage Publications; 2010.

27. Strauss AL, Corbin J. Basics of Qualitative Research. Techniques and Procedures for Developing Grounded Theory. 3rd ed. Thousand Oaks, CA: Sage Publications; 2007.

28. Wester F. Strategieën voor kwalitatief onderzoek. [Strategies for Qualitative Research]. 3rd ed. Muiderberg: Coutinho; 1995.

29. Lincoln YS, Guba EG. Naturalistic Inquiry. Newbury Park, CA: Sage Publications; 1985.

30. Hernandez P, Balter M, Bourbeau J, Hodder R. Living with chronic obstructive pulmonary disease: a survey of patients' knowledge and attitudes. Respir Med. 2009;103(7):1004-1012.

31. Rosenstock IM, Strecher VJ, Becker MH. Social learning theory and the health belief model. Health Educ Q. 1988;15(2):175-183.

32. Bandura A. Self-efficacy: toward a unifying theory of behavioral change. Psychol Rev. 1977;84(2):191-215.

33. Bandura A. Self-efficacy. In: Ramachaudran VS, editor. Encyclopedia of Human Behavior. Vol. 4. New York, NY: Academic Press; 1994:71-81.

34. Vercoulen $\mathrm{JH}$. A simple method to enable patient-tailored treatment and to motivate the patient to change behaviour. Chron Respir Dis. 2012;9(4):259-268.

35. Boer LM, Daudey L, Peters JB, Molema J, Prins JB, Vercoulen JH. Assessing the stages of the grieving process in chronic obstructive pulmonary disease (COPD): validation of the acceptance of disease and impairments questionnaire (ADIQ). Int J Behav Med. 2014;21(3):561-570.

36. Cicutto L, Brooks D, Henderson K. Self-care issues from the perspective of individuals with chronic obstructive pulmonary disease. Patient Educ Couns. 2004;55(2):168-176.

37. Disler RT, Gallagher RD, Davidson PM. Factors influencing self-management in chronic obstructive pulmonary disease: an integrative review. Int J Nurs Stud. 2012;49(2):230-242.

38. Dowson CA, Town GI, Frampton C, Mulder RT. Psychopathology and illness beliefs influence COPD self-management. J Psychosom Res. 2004;56(3):333-340.

39. Bourbeau J. Clinical decision processes and patient engagement in self-management. Dis Manage Health Outcomes. 2008;16(5):327-333.

40. Glanz K, Rimer B, Viswanath K. Theory of reasoned action, theory of planned behaviour, and the integrated behavioral model. Health Behaviour and Health Education. Theory, Research and Practice. 4th ed. San Fransisco, CA: Yossey-Bass; 2008:67-96.

41. Gruffydd-Jones K, Langley-Johnson C, Dyer C, Badlan K, Ward S. What are the needs of patients following discharge from hospital after an acute exacerbation of chronic obstructive pulmonary disease (COPD)? Prim Care Respir J. 2007;16(6):363-368. 
42. Korpershoek Y, Bos-Touwen ID, de Man-van Ginkel JM, Lammers JW, Schuurmans MJ, Trappenburg J. Determinants of activation for self-management in patients with COPD. Int J Chron Obstruct Pulmon Dis. 2016;11:1757-1766.

43. Bos-Touwen I, Schuurmans M, Monninkhof EM, et al. Patient and disease characteristics associated with activation for self-management in patients with diabetes, chronic obstructive pulmonary disease, chronic heart failure and chronic renal disease: A cross-sectional survey study. PLoS One. 2015;10(5):e0126400.

44. Zwerink M, Brusse-Keizer M, van der Valk PD, et al. Self-management for patients with chronic obstructive pulmonary disease. Cochrane Database Syst Rev. 2014;(3):CD002990. 


\section{Appendix 1}

Table 1. Topic list

\begin{tabular}{|c|c|c|}
\hline Topics & Specifications & Questions (examples) \\
\hline \multirow{3}{*}{$\begin{array}{l}\text { Perceived } \\
\text { symptoms of } \\
\text { COPD }\end{array}$} & $\begin{array}{l}\text { Experience of COPD } \\
\text { in daily life }\end{array}$ & $\begin{array}{l}\text { Standard opening question: How do you experience } \\
\text { having a lung disease in your daily life? }\end{array}$ \\
\hline & $\begin{array}{l}\text { Course of the } \\
\text { condition }\end{array}$ & $\begin{array}{l}\text { Could you tell me about the course of your condition } \\
\text { so far? }\end{array}$ \\
\hline & $\begin{array}{l}\text { Day-to-day variations } \\
\text { in symptoms }\end{array}$ & $\begin{array}{l}\text { How do you experience day-to-day variations in } \\
\text { symptoms? }\end{array}$ \\
\hline \multirow[t]{6}{*}{$\begin{array}{l}\text { Perceptions } \\
\text { toward } \\
\text { exacerbations }\end{array}$} & $\begin{array}{l}\text { Recall of an } \\
\text { exacerbation }\end{array}$ & $\begin{array}{l}\text { Can you remember a period of increased symptoms } \\
\text { (for which prednisolone and/or antibiotics were } \\
\text { indicated) and can you describe your experience of } \\
\text { this period? }\end{array}$ \\
\hline & $\begin{array}{l}\text { Definition of an } \\
\text { exacerbation }\end{array}$ & $\begin{array}{l}\text { Which name does your health care professional give to } \\
\text { this period of increased symptoms? }\end{array}$ \\
\hline & $\begin{array}{l}\text { Experience of an } \\
\text { exacerbation }\end{array}$ & $\begin{array}{l}\text { How do you experience this period of increased } \\
\text { symptoms? }\end{array}$ \\
\hline & Recognition & $\begin{array}{l}\text { How do you recognize feeling worse than normal? } \\
\text { Which symptoms do you experience indicating the } \\
\text { start of an exacerbation? }\end{array}$ \\
\hline & Taking action & $\begin{array}{l}\text { What do you do when you experience an increase in } \\
\text { symptoms? Why? }\end{array}$ \\
\hline & \multicolumn{2}{|c|}{$\begin{array}{l}\text { I would like to talk with you about the specific period of increased symptoms. } \\
\text { Please remember a recent period of an exacerbation. }\end{array}$} \\
\hline \multirow{3}{*}{$\begin{array}{l}\text { During an } \\
\text { exacerbation }\end{array}$} & Performed actions & Which actions did you perform to feel better? Why? \\
\hline & Wish for change & $\begin{array}{l}\text { When you remember this period, are there any actions } \\
\text { that you would change in case of a future exacerbation? }\end{array}$ \\
\hline & Patients' needs & $\begin{array}{l}\text { Who, or what, could help you to perform certain actions } \\
\text { at a future exacerbation? }\end{array}$ \\
\hline \multirow[t]{3}{*}{$\begin{array}{l}\text { Perceptions } \\
\text { toward own role }\end{array}$} & $\begin{array}{l}\text { Cause of an } \\
\text { exacerbation }\end{array}$ & What do you think that causes an exacerbation? \\
\hline & $\begin{array}{l}\text { Own influence on } \\
\text { exacerbation course }\end{array}$ & $\begin{array}{l}\text { Do you think you can influence the course of an } \\
\text { exacerbation yourself? And how? }\end{array}$ \\
\hline & $\begin{array}{l}\text { Importance of own } \\
\text { actions }\end{array}$ & $\begin{array}{l}\text { What is in your opinion the importance of early } \\
\text { recognition of an exacerbation and taking actions } \\
\text { yourself? }\end{array}$ \\
\hline $\begin{array}{l}\text { After an } \\
\text { exacerbation }\end{array}$ & Performed actions & $\begin{array}{l}\text { Which actions did you perform after an exacerbation? } \\
\text { Why? What was important for you in this period? }\end{array}$ \\
\hline \multirow[t]{2}{*}{$\begin{array}{l}\text { Self-management } \\
\text { in stable phase }\end{array}$} & Performed actions & $\begin{array}{l}\text { When you feel relatively stable over a period, which } \\
\text { actions do you perform to manage your condition? } \\
\text { Why? }\end{array}$ \\
\hline & $\begin{array}{l}\text { Confidence in self- } \\
\text { management toward } \\
\text { future exacerbations }\end{array}$ & $\begin{array}{l}\text { Do you feel confident in managing a future } \\
\text { exacerbation? }\end{array}$ \\
\hline $\begin{array}{l}\text { Additional } \\
\text { questions } \\
\text { regarding } \\
\text { previous topics }\end{array}$ & $\begin{array}{l}\text { Advice from health } \\
\text { care professional }\end{array}$ & $\begin{array}{l}\text { Which advice did you receive from your health care } \\
\text { professional? } \\
\text { Do you have anything to add to the questions } \\
\text { I have asked? }\end{array}$ \\
\hline
\end{tabular}




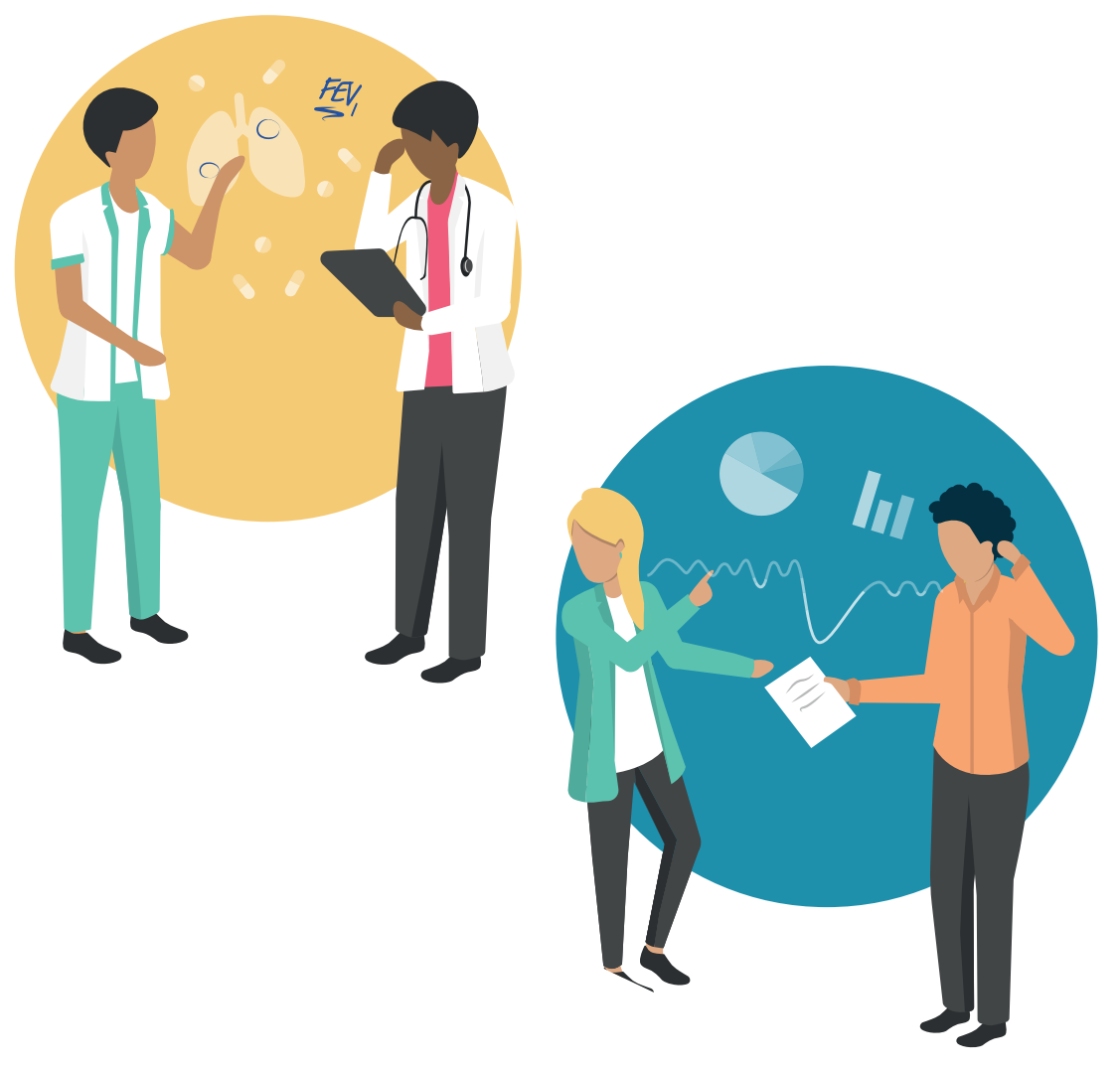




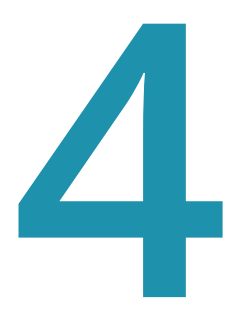

\section{Self-management behaviors to reduce exacerbation impact in COPD patients: a Delphi study}

Yvonne JG Korpershoek, Joyce C Bruins Slot, Tanja W Effing, Marieke J Schuurmans, Jaap CA Trappenburg 


\section{Abstract}

Background: Little is known about which self-management behaviors have the highest potential to influence exacerbation impact in COPD patients. We aimed to reach expert consensus on the most relevant set of self-management behaviors that can be targeted and influenced to maximize reduction of exacerbation impact.

Methods: A 2-round Delphi study was performed using online surveys to rate the relevance and feasibility of predetermined self-management behaviors identified by literature and expert opinion. Descriptive statistics and qualitative analyses were used.

Results: An international expert panel reached consensus on 17 self-management behaviors focusing on: stable phase $(n=5)$ : pharmacotherapy, vaccination, physical activity, avoiding stimuli and smoking cessation; periods of symptom deterioration $(n=1)$ : early detection; during an exacerbation $(n=5)$ : early detection, health care contact, self-treatment, managing stress/anxiety and physical activity; during recovery $(n=4)$ : completing treatment, managing stress/anxiety, physical activity and exercise training; and after recovery $(n=2)$ : awareness for recurrent exacerbations and restart of pulmonary rehabilitation.

Conclusion: This study has provided insight into expert opinion on the most relevant and feasible self-management behaviors that can be targeted and influenced before, during and after an exacerbation to exert the highest magnitude of influence on the impact of exacerbations. Future research should focus at developing more comprehensive patient-tailored interventions supporting patients in these exacerbation-related self-management behaviors. 


\section{Introduction}

Chronic obstructive pulmonary disease (COPD) is a major problem for health care worldwide and the fourth leading cause of mortality. ${ }^{1}$ A characteristic of COPD is that the natural course of symptoms and airflow limitation is slowly progressive. ${ }^{2}$ This natural course is interrupted by exacerbations characterized by a sustained worsening of patients' respiratory symptoms, which are beyond normal day-today variability, acute in onset and necessitates a change in regular medication. ${ }^{3}$ These exacerbations are associated with decline in lung function ${ }^{4}$ and quality of life $^{5,6}$ increased mortality, ${ }^{7}$ and increased health care utilization. ${ }^{8}$

To address the burden on both patients and society, self-management has become increasingly important in COPD care. ${ }^{9,10}$ Self-management is defined as 'an individual's ability to detect and manage symptoms, treatment, physical and psychosocial consequences, and lifestyle changes inherent in living with a chronic condition. ${ }^{11}$ COPD self-management interventions should be 'structured but personalized and often multi-component, with goals of motivating, engaging and supporting the patients to positively adapt their health behavior(s) and develop skills to better self-manage their disease. ${ }^{12}$ The pivotal objective is to change health behaviors and to equip patients with skills to actively participate in the management of their disease. ${ }^{13}$ In recent years, considerable research has shown that self-management interventions have positive effects on exacerbation recovery time, reduce hospital admissions and are associated with increased quality of life. ${ }^{9,14}$ However, it remains unclear which intervention components are most effective, and at which moment in time these should be applied to reduce exacerbation impact.

Although large heterogeneity in frequency, severity, symptoms and recovery time of exacerbations is observed both between and within COPD patients, ${ }^{15-18}$ recent evidence suggests that in general, each exacerbation follows a certain pattern of different phases: from the stable phase leading to an exacerbation, followed by a recovery phase and subsequently a high-risk period for recurrent exacerbations. ${ }^{15,17,19}$ To reduce exacerbation impact, previous self-management interventions focused mainly on self-management behaviors in a specific phase, solely aiming at early detection of exacerbations and taking prompt actions ${ }^{14,20}$ or at self-management after exacerbations..$^{21}$ However, patients could potentially exert more influence on the impact of exacerbations by aggregating selfmanagement behaviors prior to, during and after an exacerbation. 
To move toward more comprehensive and effective exacerbation-related selfmanagement interventions, it is essential to identify which self-management behaviors are most relevant to reduce exacerbation impact and in which phase these should be applied. Furthermore, it is important to determine which behaviors are feasible to influence. So far, evidence regarding the most relevant and feasible self-management behaviors to reduce exacerbation impact is inconclusive. By investigating expert opinion regarding self-management behaviors, including those for which limited evidence is available, a deeper understanding of self-management behaviors can be reached. ${ }^{22}$

The aim of this study was to reach consensus with experts on the most relevant set of self-management behaviors that has the potential to maximally reduce the impact of exacerbations and is feasible to target and influence, prior to, during and after an exacerbation. This knowledge is essential for the development of future targeted and tailored self-management interventions that can potentially further reduce exacerbation impact.

\section{Methods}

\section{Study design}

A Delphi study, based on components of the RAND/UCLA appropriateness method, ${ }^{23}$ was performed to reach consensus on the relevance and feasibility of self-management behaviors that maximize reduction of exacerbation impact. The RAND/UCLA appropriateness method aims to combine the best available scientific evidence with the collective judgement of experts to yield a statement regarding the appropriateness of performing a medical procedure when scientific evidence is lacking. ${ }^{23}$ This meets our objective to reach consensus on self-management behaviors by integrating both explicit and tacit unpublished knowledge and perspectives of experts in the absence of conclusive evidence. ${ }^{22,24}$ This Delphi study consists of different phases of data collection and data analysis following an iterative process. ${ }^{24}$

\section{Data collection}

The iterative phases of data collection and analysis of this Delphi study are presented in Figure 1. Methods were regularly discussed within the research team and subsequently adjusted in order to enhance validity. 


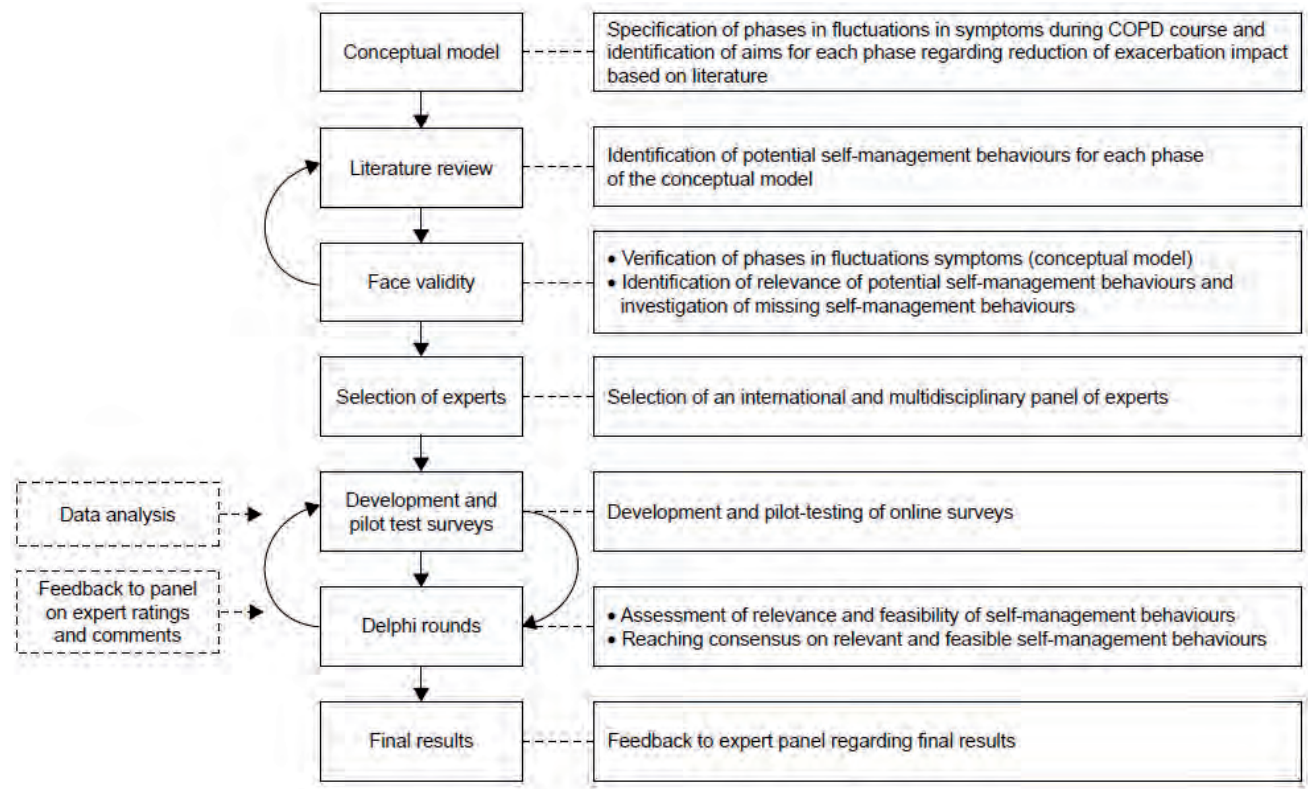

Figure 1. Study design of the Delphi study

\section{Development of a conceptual model}

At first, a scoping literature review was performed to specify different symptom fluctuation phases during the course of COPD and identify aims for each phase regarding reduction of exacerbation impact. First, articles suggested by COPD experts, and relevant studies from their reference lists, were reviewed. 3,15,17,19,25,26 Subsequently, a conceptual model of patients' fluctuations in symptoms during the course of COPD was developed by 2 researchers (YJGK and JCAT) (Figure 2). This model distinguishes 5 phases and is in line with previous studies presenting symptom fluctuations over time. ${ }^{3,26}$ Finally, overarching aims regarding reduction of exacerbation impact were formulated by our research team for each phase (Figure 2).

\section{Literature review}

Second, a scoping literature review was performed to identify potential selfmanagement behaviors aiming to reduce exacerbation impact in each phase of the conceptual model. Potential self-management behaviors were identified following a stepwise procedure. An initial set of self-management behaviors was generated by our research team. Relevant literature was searched to substantiate these behaviors and to identify additional behaviors. Literature was searched for strategies aiming to reduce exacerbation impact according to the following steps: 
1) relevant COPD guidelines; 2) (systematic) reviews and 3) longitudinal studies (randomized controlled trials [RCTs]/cohort studies). Database searches were performed in PubMed, ScienceDirect and Google Scholar using the following search terms and derivatives: COPD, exacerbation, self-management, prevention, treatment and recovery. Studies were selected when published between 2000 and 2016. Articles were first screened by title and abstract on relevance followed by reading the full text. An article was included only when it focused on strategies associated with reduction of exacerbation impact (based on the phases of the conceptual model) and requiring self-management behaviors. Strategies were extracted from literature and used as intermediate outcomes for self-management behaviors. Based on the strategies found, required self-management behaviors, as supported by previous self-management studies, were formulated by our research team for each phase of the conceptual model. ${ }^{9,13,20,21,25} \mathrm{An}$ overview of the selected literature can be found in Appendix 1.

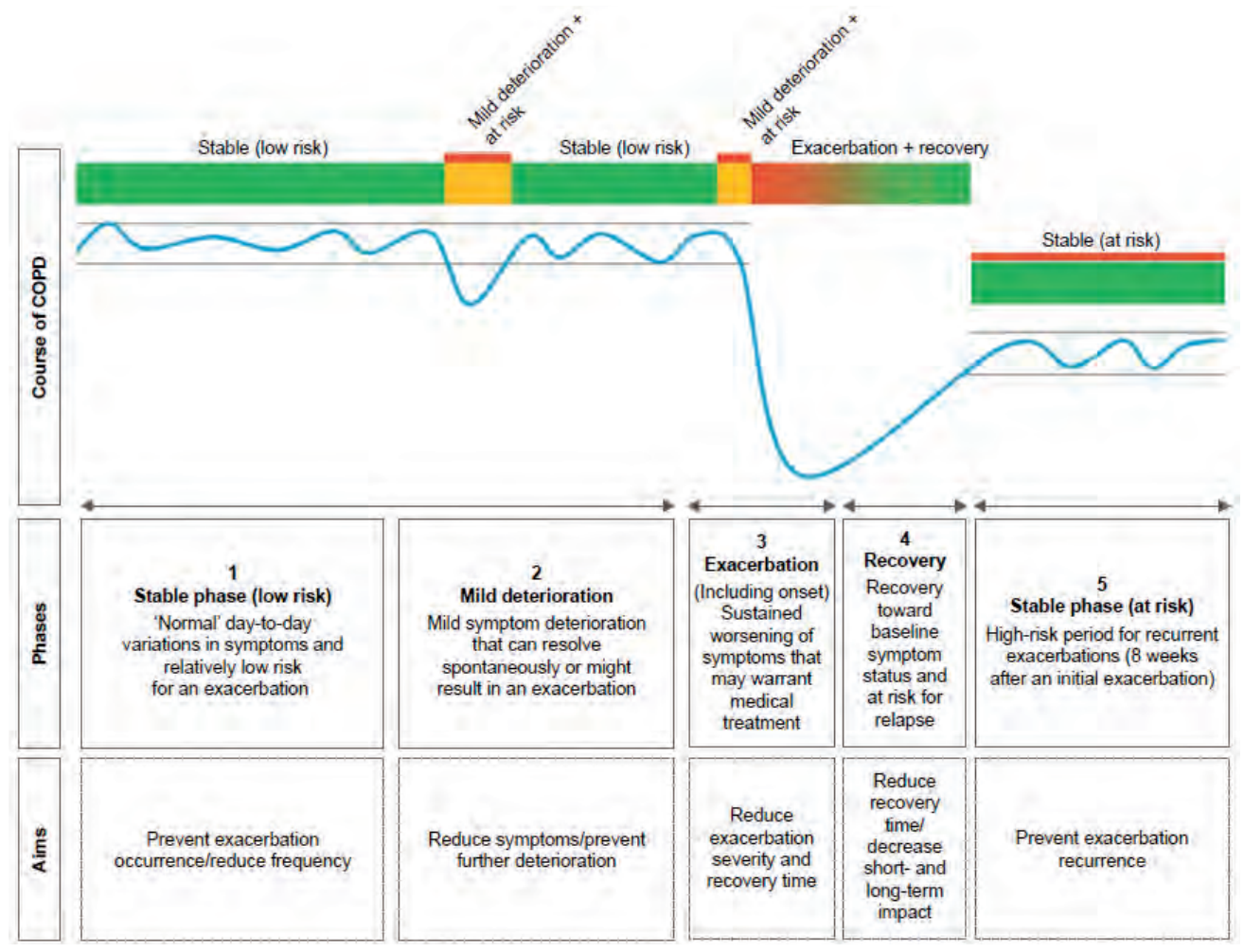

Figure 2. Conceptual model of patients' fluctuations in symptoms during the course of COPD 


\section{Selection of experts}

A purposive sample of international respiratory experts was selected for the face validity round and the Delphi study. The experts included in the face validity round were all invited to participate in the Delphi study. The aim was to include a panel of 15 experts for the Delphi study, since a panel of this size is considered sufficient to create diversity regarding representation, while being small enough to include solely key experts in this area. ${ }^{23,27}$ Based on an expected response rate of $60 \%,{ }^{28} 30$ experts were invited to participate.

Diversity of perspectives was pursued by selecting a heterogeneous and multidisciplinary panel of medical doctors (pulmonologists and general practitioners with specific interest in COPD) and key-researchers in the field of COPD. Inclusion criteria were: proven expertise on COPD exacerbations and/or COPD self-management and willingness to participate in the study. Two inclusion criteria were later added: at least 5 publications on the topic (researchers) and extensive COPD patient contact (medical doctors). Experts were selected based on their publications or connections with the research team. One expert of the panel was involved in this study by providing expert opinion on the process of the Delphi study (TWE).

Eligible experts were informed about the study and invited to participate by email. According to the Dutch law, a study with experts does not require any legal assessment by an Institutional Review Board. Experts were informed that the participation was voluntary and anonymous. Informed consent was obtained at each Delphi round.

\section{Face validity}

The conceptual model, including potential relevant self-management behaviors, was initially discussed in face-to-face meetings with international respiratory experts $(n=5)$ to determine face validity (YJGK and JCAT) to: 1 ) verify whether the conceptual model adequately reflected symptom fluctuation phases during the COPD course; 2 ) identify whether the selected behaviors were relevant; and 3) to investigate if relevant behaviors were missing. These expert meetings were structured by a topic list (Appendix 2). Based on this step, several behaviors were added to the conceptual model. No self-management behaviors were excluded. Additional literature was then consulted to substantiate the added self-management behaviors (YJGK and JCBS). The conceptual model was used to develop surveys for the Delphi rounds. 


\section{Delphi rounds}

In total, 2 Delphi surveys were developed in the online survey service SurveyMonkey (SurveyMonkey Inc., San Mateo, CA, USA); (YJGK and JCBS). Experts received an invitation to participate in the study by email, including the online survey for the first round. Background information on the study objectives, a survey instruction and questions about demographic characteristics were included in the survey. Experts were asked to complete the survey within 3 weeks. After round 1, experts received an overview of the results and were asked to complete the second online survey within 3 weeks. During both rounds, a reminder was sent 2 weeks after the initial mailing.

The aim of the first survey was to assess the relevance and feasibility of the predetermined self-management behaviors for each phase of the conceptual model and gain insight into the degree of consensus between experts. ${ }^{23,27,29}$ Each behavior was rated on 3 statements: 1) the association between a behavior and reduction of exacerbation impact in a specific phase (relevance), 2) the extent to whether there is room for improvement (relevance to intervene on a behavior) and 3) the feasibility to influence a behavior. The relevance of a behavior was determined by both statement 1 and 2 . Based on the RAND method, all statements were scored on a 9-point Likert scale ( $1=$ strongly disagree, $9=$ strongly agree). ${ }^{23}$ An example of a survey question is shown in Appendix 3. Behaviors that were considered to be relevant in more than one phase were assessed only once on all 3 statements. Only statement one, identifying the relevance of a behavior, was rated when a behavior returned in subsequent phases.

Open questions were asked at each phase to gain more in-depth understanding of the ratings, investigate whether relevant behaviors were missing, and check whether methodological inconsistencies were present. To anticipate missing data, participants were obliged to complete all ratings on a survey page before continuing to the next page. The survey was pilot-tested by 5 experts in the field. In addition, a linguist of English language verified the survey.

Based on the RAND-method, self-management behaviors were classified into 3 different categories based on median scores: not relevant/feasible (median 1-3), uncertain (median 4-6) and relevant/feasible (median 7-9). ${ }^{23}$ An interquartile range (IQR) was calculated to determine the level of consensus between experts, with smaller IQR values indicating higher degree of consensus. ${ }^{30,31}$ An IQR $\leq 2$ was considered as consensus among experts, ${ }^{27,32}$ meaning that at least $50 \%$ of all ratings are situated within 2 points around the median rating of the expert 
panel. ${ }^{33}$ The inclusion and exclusion criteria for the final behaviors are presented in Table 1. A behavior was considered to be relevant and feasible when at least 2 statements had a median score of 7-9 (including statement 1), no statement had a median score of $1-3$ and all 3 statements had an $I Q R \leq 2$. All statements without consensus (IQR >2) were presented again to the expert panel in Delphi round 2.

The aim of the second Delphi survey was to move toward consensus on selection of relevant and feasible self-management behaviors. Furthermore, the aim was to gain more understanding into the level of disagreement between experts. ${ }^{23}$ The survey consisted of behaviors without consensus based on Delphi round 1 and new behaviors that were suggested by experts in round 1. Experts were asked to re-rate the statements without consensus. For each statement, the median score, $\mathrm{IQR}$, and relevant remarks from round 1 were shown. Experts were asked to provide comments when their score deviated from the median from round 1 . This survey was again pilot-tested by 3 experts in the field. Same descriptive statistics and inclusion and exclusion criteria (Table 1) were used in this round. Ratings obtained from round 2 with consensus were used as final ratings. It was decided that if consensus could not be reached after 2 Delphi rounds, a third round would be initiated.

Table 1. Inclusion and exclusion criteria of self-management behaviors

\begin{tabular}{|c|c|}
\hline Inclusion or exclusion & Criteria \\
\hline Include in final list & $\begin{array}{l}\text { Median score of 7-9 for at least } 2 \text { statements, including statement } 1 \text { * } \\
\text { AND an IQR } \leq 2 \text { for all } 3 \text { statements AND no statement with a median } \\
\text { score of } 1-3 \text {. }\end{array}$ \\
\hline $\begin{array}{l}\text { Include in next Delphi } \\
\text { round }\end{array}$ & Each statement with an IQR>2. \\
\hline Exclude & $\begin{array}{l}\cdot 1 \text { (or more) statement(s) with a median of } 1-3 \text { AND an IQR } \leq 2 \text { for all } \\
3 \text { statements. } \\
\cdot 2 \text { (or more) statements with a median of } 4-6 \text { AND an IQR } \leq 2 \text { for all } \\
3 \text { statements. } \\
\text { - Statement } 1 \text { with a median of 4-6 AND an IQR } \leq 2 \text { for all } 3 \text { statements. }\end{array}$ \\
\hline
\end{tabular}

Notes: *A median of 7-9 on statement 1 was required in all cases since statement 1 investigated the association between a self-management behavior and reduction of exacerbation impact and was considered to be most important. Median 1-3= not relevant/feasible; median $4-6=$ uncertain; median 7-9= relevant/feasible.

Abbreviation: IQR, interquartile range.

\section{Data analysis}

Data analysis was supported by using SPSS version 22 (IBM Corporation, Armonk, NY, USA). ${ }^{34}$ Descriptive statistics were used to analyze and report all data. A qualitative analysis of comments provided by the expert panel in both online 
surveys was performed. First, all comments were read in full by 2 researchers (JCBS and YJGK). Second, one researcher summarized all comments from both rounds for each of the 5 phases (JCBS). This summary was subsequently reviewed to check accuracy (YJGK). Meaningful statements were verified based on consensus (JCBS and YJGK) and presented in the "Results" section.

\section{Results}

\section{Demographic characteristics}

Demographic characteristics of the Delphi panel are shown in Table 2. In total, 19 of the 30 (63\%) invited experts agreed to participate in this study. One expert completed the first survey after the round 1 deadline and was therefore excluded from round 1, but did participate in round 2. The second Delphi round was completed by 16 experts. Reasons for non-response were: retirement, limited time for participation and no longer working in this field.

\section{Delphi round 1}

The results of round 1 are show in Table 3. In total, 27 self-management behaviors, distributed among the 5 phases of the conceptual model, were rated in the first Delphi round.

Seven self-management behaviors were considered relevant and feasible with consensus (IQR $\leq 2)$ and were directly included in the final list. Highest ratings were observed regarding early detection of symptom deterioration/exacerbations and prompt treatment. Four behaviors were excluded after round 1. All statements without consensus (IQR $>2$ ) were included in round 2. Managing exposure to indoor air quality was added to the second round based on suggestions of 2 experts in round 1.

\section{Delphi round 2}

Table 3 shows the results of round 2 in which statements regarding 16 selfmanagement behaviors were re-rated and the added self-management behavior was rated for the first time. Based on round 2, 10 of the remaining behaviors were included in the final list. Seven behaviors were excluded after round 2.

\section{Final list of self-management behaviors}

Based on 2 Delphi rounds, the expert panel reached consensus on a set of 17 self-management behaviors that were both relevant and feasible to reduce 
exacerbation impact (Table 4). The expert panel agreed on 5 behaviors in the stable phase (low risk), 1 during mild deterioration of symptoms, 5 during an exacerbation, 4 during exacerbation recovery and 2 in the stable phase (at risk). Daily physical activity was considered to be relevant in 3 phases (1, 3 and 4$)$. Based on relations between behaviors, the final behaviors were subdivided into 9 categories (Table 4).

Table 2. Demographic characteristics of the Delphi panel $(n=19)^{*}$

\begin{tabular}{|c|c|}
\hline Characteristics & n (\%) \\
\hline \multicolumn{2}{|l|}{ Gender } \\
\hline Male & $15(79)$ \\
\hline \multicolumn{2}{|l|}{ Age (years) } \\
\hline $30-49$ & $9(47)$ \\
\hline $50-69$ & $9(47)$ \\
\hline$>70$ & $1(5)$ \\
\hline \multicolumn{2}{|c|}{ Experience in respiratory care focusing on COPD (years) } \\
\hline $0-5$ & $1(5)$ \\
\hline $6-15$ & $7(37)$ \\
\hline $16-25$ & $3(16)$ \\
\hline $26-35$ & $5(26)$ \\
\hline$>35$ & $3(16)$ \\
\hline \multicolumn{2}{|l|}{ Area of focus } \\
\hline Patient care & $1(5)$ \\
\hline Research & $5(26)$ \\
\hline Both patient care and research & $13(68)$ \\
\hline \multicolumn{2}{|l|}{ Country } \\
\hline the Netherlands & $8(42)$ \\
\hline UK & $2(11)$ \\
\hline Belgium & $1(5)$ \\
\hline Canada & $1(5)$ \\
\hline USA & $4(21)$ \\
\hline Australia & $3(16)$ \\
\hline \multicolumn{2}{|l|}{ Discipline } \\
\hline Pulmonology & $11(58)$ \\
\hline Primary care & $3(16)$ \\
\hline Nursing & $1(5)$ \\
\hline Physiotherapy & $1(5)$ \\
\hline Epidemiology & $3(16)$ \\
\hline
\end{tabular}

Note: *One expert of the panel was involved in this study by providing expert opinion on the process of the Delphi study. 
Table 3. Results of Delphi round 1 and 2

\begin{tabular}{lll}
\hline Phase & Self-management behaviors rated in Delphi rounds & $\begin{array}{l}\text { Behavior identified from } \\
\text { (source) }\end{array}$
\end{tabular}

\begin{tabular}{|c|c|c|}
\hline \multirow{7}{*}{ 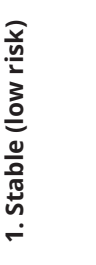 } & Adherence to pharmacotherapy (LABA/LAMA and/or ICS)* & Literature \\
\hline & Influenza vaccination uptake* & Literature \\
\hline & Daily physical activity* & Literature \\
\hline & Avoiding viral or bacterial stimuli* & Literature \\
\hline & Managing exposure to air quality** & Face validity \\
\hline & Smoking cessation* & Literature \\
\hline & Managing exposure to indoor air quality** & Delphi round 1 \\
\hline \multirow{4}{*}{ 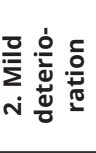 } & Early detection of symptom deterioration* & Face validity \\
\hline & Correct increase of SABA** & Literature \\
\hline & Performing breathing exercises** & Literature \\
\hline & Performing energy conservation techniques** & Literature \\
\hline \multirow{8}{*}{ 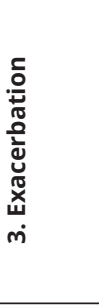 } & Early detection of an exacerbation* & Literature \\
\hline & Prompt treatment with corticosteroids and/or AB (self-treatment)* & Literature \\
\hline & Prompt treatment with corticosteroids and/or $\mathrm{AB}$ (contacting $\mathrm{HCP}$ )* & Literature \\
\hline & Manage stress and anxiety* & Literature \\
\hline & Correct increase of SABA** & Literature \\
\hline & Performing breathing exercises** & Literature \\
\hline & Daily physical activity* & Literature \\
\hline & Performing energy conservation techniques** & Literature \\
\hline \multirow{7}{*}{ 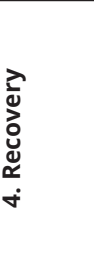 } & Completing treatment with corticosteroids and/or $\mathrm{AB}$ * & Face validity \\
\hline & Manage stress and anxiety (concerning current event)* & Literature \\
\hline & Adjusted exercise- and resistance training* & Literature \\
\hline & Daily physical activity* & Literature \\
\hline & Correct use of SABA** & Literature \\
\hline & Performing energy conservation techniques** & Literature \\
\hline & Performing breathing exercises** & Literature \\
\hline \multirow{2}{*}{ 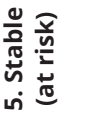 } & Increased awareness for recurring exacerbation* & Literature \\
\hline & Early (re)start of pulmonary rehabilitation* & Face validity \\
\hline
\end{tabular}

Notes: *Self-management behavior included in final list after round 1 or 2 based on median scores and consensus within the expert panel. **Self-management behavior excluded after round 1 or 2 based on median scores and consensus within the expert panel. aRelevance - The association of this behavior and reducing exacerbation impact (statement 1). ' Improvement - The extent to whether there is room for improvement in this behavior (statement 2). 'Feasibility - The feasibility to influence this behavior (statement 3). Scores are on a 9 point Likert scale $(1=$ strongly disagree, $9=$ strongly agree); bold type indicates the returning self-management behaviors in which only statement 1 was rated and therefore scores on statements 2 and 3 are not applicable. Abbreviations: NA, not applicable; $M$, median; IQR, interquartile range; $A B$, antibiotics; $H C P$, health care provider; $L A B A$, long-acting $\beta 2$-agonist; LAMA, long-acting muscarinic antagonist; ICS, inhaled corticosteroids; SABA, short-acting $\beta 2$-agonist. 


\begin{tabular}{|c|c|c|c|c|c|c|c|c|c|c|c|}
\hline \multicolumn{6}{|c|}{ Round 1} & \multicolumn{6}{|c|}{ Round 2} \\
\hline$M$ & IQR & $M$ & IQR & $M$ & IQR & $M$ & IQR & M & IQR & $M$ & IQR \\
\hline 8 & 3 & 8 & 1 & 7 & 2 & 8 & 0.75 & NA & NA & NA & NA \\
\hline 7 & 1.25 & 6 & 2.25 & 7 & 3 & NA & NA & 6 & 2 & 7 & 0.75 \\
\hline 7 & 2.25 & 9 & 1 & 7 & 1.25 & 7 & 1.5 & NA & NA & NA & NA \\
\hline 7 & 2 & 6 & 1.5 & 5 & 1.25 & NA & NA & NA & NA & NA & NA \\
\hline 8 & 2 & 8 & 2.25 & 7 & 3 & NA & NA & 8 & 0 & 7 & 1 \\
\hline NA & NA & NA & NA & NA & NA & 6 & 1.75 & 5 & 1.75 & 5.5 & 1 \\
\hline 8 & 1.25 & 8 & 0.5 & 7.5 & 1 & NA & NA & NA & NA & NA & $\mathrm{NA}$ \\
\hline 6 & 2 & 5.5 & 2.25 & 6 & 2.25 & NA & NA & 6 & 1 & 6 & 0.75 \\
\hline 8.5 & 1 & 8 & 1.25 & 7 & 1.25 & NA & NA & NA & NA & NA & NA \\
\hline 8.5 & 1 & 8 & 1.5 & 8 & 2.25 & NA & NA & NA & NA & 8 & 0 \\
\hline 7 & 1 & 7 & 0.5 & 6 & 2 & NA & NA & NA & NA & NA & NA \\
\hline 6 & 3.5 & NA & NA & NA & NA & 6 & 1 & NA & NA & NA & NA \\
\hline 6.5 & 2 & NA & NA & NA & NA & NA & NA & NA & NA & NA & NA \\
\hline 7 & 3 & NA & NA & NA & NA & 7 & 1.75 & NA & NA & NA & NA \\
\hline 6 & 2.25 & NA & NA & NA & NA & 6 & 1 & NA & NA & NA & NA \\
\hline 7 & 1.25 & 6.5 & 2.25 & 7 & 1.25 & NA & NA & 6.5 & 1 & NA & NA \\
\hline 7 & 1.5 & 7 & 1.25 & 7 & 2.25 & NA & NA & NA & NA & 7 & 0.75 \\
\hline 7 & 1.25 & 8 & 2 & 7 & 1.25 & NA & NA & NA & NA & NA & NA \\
\hline 8 & 2 & 8 & 2.25 & 7 & 2 & NA & NA & 8 & 0 & NA & NA \\
\hline
\end{tabular}


Table 4. Final self-management behaviors per phase of the conceptual model

\begin{tabular}{|c|c|c|c|c|c|}
\hline \multirow{2}{*}{$\begin{array}{l}\text { Phase } \\
\text { 1. Stable phase } \\
\text { (low risk) }\end{array}$} & \multicolumn{3}{|c|}{ Statement } & \multirow{2}{*}{$\begin{array}{l}\text { Relevant and feasible self- } \\
\text { management behaviors } \\
\text { Adherence to } \\
\text { pharmacotherapy (LABA/LAMA } \\
\text { and/or ICS) }\end{array}$} & \multirow{2}{*}{$\begin{array}{l}\text { Categories } \\
\text { Adherence to } \\
\text { pharmacotherapy }\end{array}$} \\
\hline & $\checkmark$ & $\checkmark$ & $\checkmark$ & & \\
\hline & $\checkmark$ & $\sim$ & $\checkmark$ & Influenza vaccination uptake & Influenza vaccination \\
\hline & $\checkmark$ & $\checkmark$ & $\checkmark$ & Daily physical activity & Physical activity/exercise \\
\hline & $\checkmark$ & $\checkmark$ & $\sim$ & $\begin{array}{l}\text { Avoiding viral or bacterial } \\
\text { stimuli }\end{array}$ & Avoiding stimuli \\
\hline & $\checkmark$ & $\checkmark$ & $\checkmark$ & Smoking cessation & Smoking cessation \\
\hline 2. Mild deterioration & $\checkmark$ & $\checkmark$ & $\checkmark$ & $\begin{array}{l}\text { Early detection of symptom } \\
\text { deterioration }\end{array}$ & $\begin{array}{l}\text { Early detection of symptom } \\
\text { deterioration }\end{array}$ \\
\hline \multirow[t]{5}{*}{$\begin{array}{l}\text { 3. Exacerbation } \\
\text { (including onset) }\end{array}$} & $\checkmark$ & $\checkmark$ & $\checkmark$ & $\begin{array}{l}\text { Early detection of an } \\
\text { exacerbation }\end{array}$ & $\begin{array}{l}\text { Early detection of symptom } \\
\text { deterioration }\end{array}$ \\
\hline & $\checkmark$ & $\checkmark$ & $\checkmark$ & $\begin{array}{l}\text { Prompt treatment } \\
\text { corticosteroids and/or AB (self- } \\
\text { treatment) }\end{array}$ & $\begin{array}{l}\text { Medical treatment of } \\
\text { exacerbations }\end{array}$ \\
\hline & $\checkmark$ & $\checkmark$ & $\checkmark$ & $\begin{array}{l}\text { Prompt treatment } \\
\text { corticosteroids and/or } A B \\
\text { (contact with } \mathrm{HCP} \text { ) }\end{array}$ & $\begin{array}{l}\text { Medical treatment of } \\
\text { exacerbations }\end{array}$ \\
\hline & $\checkmark$ & $\checkmark$ & $\sim$ & Manage stress and anxiety & Manage stress and anxiety \\
\hline & $\checkmark$ & NA & NA & Daily physical activity & Physical activity/exercise \\
\hline \multirow[t]{4}{*}{ 4. Recovery phase } & $\checkmark$ & $\sim$ & $\checkmark$ & $\begin{array}{l}\text { Completing treatment } \\
\text { of antibiotics and/or } \\
\text { corticosteroids }\end{array}$ & $\begin{array}{l}\text { Medical treatment of } \\
\text { exacerbations }\end{array}$ \\
\hline & $\checkmark$ & $\checkmark$ & $\checkmark$ & $\begin{array}{l}\text { Manage stress and anxiety } \\
\text { (concerning current event) }\end{array}$ & Manage stress and anxiety \\
\hline & $\checkmark$ & $\checkmark$ & $\checkmark$ & $\begin{array}{l}\text { Adjusted exercise- and } \\
\text { resistance training }\end{array}$ & Physical activity/exercise \\
\hline & $\checkmark$ & NA & NA & Daily physical activity & Physical activity/exercise \\
\hline \multirow[t]{2}{*}{$\begin{array}{l}\text { 5. Stable phase } \\
\text { (at risk) }\end{array}$} & $\checkmark$ & $\checkmark$ & $\checkmark$ & $\begin{array}{l}\text { Increased awareness for } \\
\text { recurring exacerbation }\end{array}$ & $\begin{array}{l}\text { Awareness for recurrent } \\
\text { exacerbations }\end{array}$ \\
\hline & $\checkmark$ & $\checkmark$ & $\checkmark$ & $\begin{array}{l}\text { Early (re)start of pulmonary } \\
\text { rehabilitation }\end{array}$ & Physical activity/exercise \\
\hline
\end{tabular}

Notes: Italic indicates the returning self-management behaviors in which only statement 1 was rated. $\checkmark=$ Median of 7-9 for statement. $\sim$ = Median of 4-6 for statement.

$1=$ Relevance - The association of this behavior and reducing exacerbation impact (statement 1 ). $2=$ Improvement - The extent to whether there is room for improvement in this behavior (statement 2). 3= Feasibility - The feasibility to influence this behavior (statement 3).

Abbreviations: $A B$, antibiotics; $H C P$, health care provider; LABA, long-acting $\beta 2$-agonist; LAMA, long-acting muscarinic antagonist; ICS, inhaled corticosteroids; NA, not applicable. 


\title{
Qualitative results
}

\author{
By asking open questions, experts commented on their ratings. No methodological \\ inconsistencies regarding the survey were identified based on experts' remarks. \\ Meaningful comments on self-management behaviors are described and further \\ explained by citations in Table 5 .
}

Table 5. Qualitative results of Delphi round 1 and 2

\begin{tabular}{|c|c|c|c|}
\hline Phase & Results & $\begin{array}{l}\text { Self-management } \\
\text { behavior }\end{array}$ & Citations \\
\hline \multirow{3}{*}{ 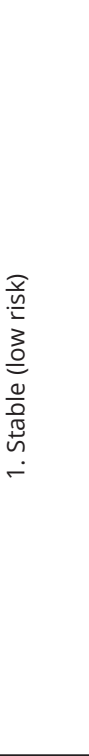 } & \multirow{3}{*}{$\begin{array}{l}\text { Experts initially disagreed on the relevance of } \\
\text { pharmacotherapy (LABA/LAMA and/or ICS). One expert } \\
\text { stated that high level evidence is available, whereas other } \\
\text { experts stated that ICS use is overrated in many COPD } \\
\text { patients and that the role of pharmacotherapy is small } \\
\text { and only relevant to a subgroup of patients. Furthermore, } \\
\text { experts initially disagreed on the room for improvement } \\
\text { regarding influenza vaccination uptake. Some experts } \\
\text { considered vaccination uptake to be high, whereas others } \\
\text { noted that room for improvement depends on region } \\
\text { and country. Disagreement on the feasibility to influence } \\
\text { vaccination uptake was observed since some experts } \\
\text { believed that influenza vaccination is already heavily } \\
\text { promoted and uptake is hard to influence [C1]. Regarding } \\
\text { managing exposure to air quality, experts agreed on the } \\
\text { relevance to reduce exacerbation impact, but explained } \\
\text { doubts regarding the feasibility to influence this behavior } \\
\text { that were related to patient activities [C2]. Finally, for } \\
\text { smoking cessation comments mainly focused on the } \\
\text { feasibility to influence this behavior. Experts believed } \\
\text { that this can be feasible and that we should keep trying, } \\
\text { however, they also stated that current smokers often } \\
\text { show resistance regarding quitting smoking and that it is } \\
\text { hard to influence this behavior [C3]. }\end{array}$} & Vaccination uptake & $\begin{array}{l}\text { I think that vaccination uptake } \\
\text { is harder to influence than other } \\
\text { pharmacotherapy. People may } \\
\text { have stronger opinions why to } \\
\text { do/not to do it. [C1] }\end{array}$ \\
\hline & & $\begin{array}{l}\text { Managing exposure to } \\
\text { air quality }\end{array}$ & $\begin{array}{l}\text { I have my doubts. Patients do } \\
\text { need to get out sometimes, and } \\
\text { if there are prolonged periods of } \\
\text { air pollution, I am not sure how } \\
\text { to solve this problem. [C2] }\end{array}$ \\
\hline & & $\begin{array}{l}\text { Quitting/cutting down } \\
\text { smoking }\end{array}$ & $\begin{array}{l}\text { Smokers with COPD are a } \\
\text { population that often have } \\
\text { difficulty quitting and therefore } \\
\text { will likely require more intensive } \\
\text { interventions to influence } \\
\text { smoking rates. [C3] }\end{array}$ \\
\hline \multirow{3}{*}{ 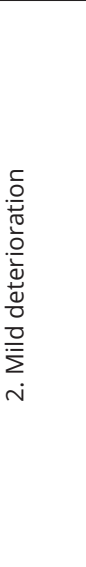 } & \multirow{3}{*}{$\begin{array}{l}\text { Several comments focused on the relevance of correctly } \\
\text { increasing SABA in several phases. Some experts } \\
\text { considered SABA as obsolete and one expert believed it } \\
\text { should not be stimulated at all. Moreover, the role of SABA } \\
\text { was questioned regarding further symptom deterioration } \\
\text { [C4]. Regarding breathing exercises, some experts } \\
\text { believed that these are only relevant for very few patients } \\
\text { and were not impressed by the strength of evidence [C5]. } \\
\text { As well as by SABA, experts believed that performing } \\
\text { breathing exercises will lead to symptom relieve, but does } \\
\text { not influence further symptom deterioration. Moreover, } \\
\text { experts questioned whether patients are aware of these } \\
\text { techniques. Finally, energy conservation techniques were } \\
\text { not considered to be relevant since experts believed that } \\
\text { this is a more general self-management strategy and not } \\
\text { specifically aimed at preventing exacerbations. In addition, } \\
\text { experts believed that most patients automatically perform } \\
\text { this behavior [C6]. }\end{array}$} & $\begin{array}{l}\text { Correct increase of } \\
\text { SABA }\end{array}$ & $\begin{array}{l}\text { [...] whereas the use of SABA } \\
\text { will lead to symptom relieve, } \\
\text { it will not (directly) influence } \\
\text { further deterioration of the } \\
\text { exacerbation. [C4] }\end{array}$ \\
\hline & & $\begin{array}{l}\text { Performing breathing } \\
\text { exercises }\end{array}$ & $\begin{array}{l}\text { Little is known about the } \\
\text { individual need for breathing } \\
\text { exercises. It is certainly not for all } \\
\text { patients. [C5] }\end{array}$ \\
\hline & & $\begin{array}{l}\text { Performing energy } \\
\text { conservation } \\
\text { techniques }\end{array}$ & $\begin{array}{l}\text { Most patients will conserve } \\
\text { energy to reduce their symptoms } \\
\text { during early exacerbations as a } \\
\text { natural behavior. [C6] }\end{array}$ \\
\hline
\end{tabular}


Table 5. (Continued)

Self-management Citations
behavior

\begin{tabular}{|c|c|}
\hline Phase & Results \\
\hline 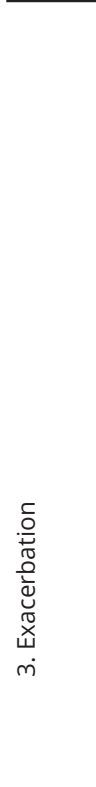 & $\begin{array}{l}\text { Experts directly agreed on the relevance of early } \\
\text { detection of symptom deterioration and exacerbations } \\
\text { in round 1. Experts believed that symptom diaries or } \\
\text { symptom scoring with action plans can be supportive. } \\
\text { Nevertheless, the complexity of this behavior was } \\
\text { emphasized as well as the importance of personalized } \\
\text { advice regarding this behavior by focusing on previous } \\
\text { experienced symptoms regarding exacerbations [C7\&8]. } \\
\text { Initially there was disagreement between experts on } \\
\text { the relevance of daily physical activity in both the stable } \\
\text { phase (low risk) and exacerbation phase. Some experts } \\
\text { stated that there is proven evidence for stimulating daily } \\
\text { physical activity and that this is important to reduce } \\
\text { exacerbation impact [C9]. Others were uncertain about } \\
\text { the evidence or even believed that daily physical activity } \\
\text { might worsen a patient's situation when experiencing } \\
\text { an exacerbation [C10]. Furthermore, one expert pointed } \\
\text { out that it is uncertain when physical activity should be } \\
\text { initiated [C11]. } \\
\text { Finally, although there was consensus on the feasibility } \\
\text { to influence self-treatment at exacerbation onset, some } \\
\text { experts have commented on this. Experts were confident } \\
\text { that self-treatment is feasible although not for all COPD } \\
\text { patients, considering health literacy, motivation, cognitive } \\
\text { levels and relatively high age in this population [C12]. }\end{array}$ \\
\hline
\end{tabular}

Early detection of an exacerbation

the exacerbation and prompt,
appropriate treatment of that
exacerbation is reasonable, but
this is not easily achieved. [C7]
I think generic non personalized
advice will fail. These are
recurrent exacerbations and
emphasis should be on: "When
you feel you are beginning to get
bad, like last time [...]." [C8]

Daily physical activity In my opinion, daily $P A$ is important to prevent the vicious circle of breathlessness and to increase fitness and health (and thereby preventing exacerbations). [C9] The exacerbation will cause reduced activity; and encouraging the patient who is so restricted to increase their activity might be counterproductive and perhaps even worsen the situation (especially given common comorbidities like cardiac disease). [C10] Although physical activity is likely important, there continues to be uncertainty of when to initiate physical activity and how intensive it should be. [C11]

Self-treatment with Ithink that self-treatment corticosteroids and/ is indicated for a select or $A B$ group of patients. Otherwise overtreatment is a potential risk. [C12]

Manage stress and anxiety With good quality interventions/ Relaxation techniques were considered to be important to manage stress and anxiety at exacerbation onset. However, initially disagreement was observed in the feasibility to change this behavior during exacerbation recovery. One expert thought that stress may be challenging to overcome, while another expert believed that well-designed interventions can influence stress and anxiety [C13].

Early (re)start of pulmonary rehabilitation was considered Early (re)start to be relevant and feasible, although initially consensus of pulmonary on room for improvement was lacking and challenges rehabilitation No this is health care providing politics. [C14] support stress and anxiety can be influenced; at least partly. [C13] towards feasibility to influence this behavior were reported. One expert specifically stated that there is substantial room for improvement in this behavior based on current patient performance, but this might be out of the scope of the patients own influence or health care providers influence [C14].

Abbreviations: LABA, long-acting $\beta 2$-agonist; LAMA, long-acting muscarinic antagonist; ICS, inhaled corticosteroids; SABA, short-acting $\beta 2$-agonist; $C$, citation from expert; PA, physical activity; $A B$ antibiotics. 


\section{Discussion}

To our knowledge, this is the first study providing insight into expert opinion on the most relevant and feasible self-management behaviors that can be targeted and influenced, prior to, during and after an exacerbation, to reduce the impact of COPD exacerbations. Based on 2 Delphi rounds, consensus within the expert panel was reached on a set of 17 self-management behaviors that were perceived both relevant and feasible to target and influence. According to our study results, self-management should focus on adherence to pharmacotherapy, influenza vaccination, physical activity/exercise, avoiding stimuli, smoking cessation, early detection of symptom deterioration, medical treatment of exacerbations, managing stress and anxiety, and awareness for recurrent exacerbations. This study shows that each symptom fluctuation phase requires aggregating specific self-management behaviors from COPD patients to maximally reduce the impact of exacerbations.

Self-management behaviors included in our final list were mostly in line with other studies. The importance of early detection of (recurrent) exacerbations and taking prompt actions was emphasized by the high ratings of our expert panel showing that there is still large room for improvement and that these behaviors are feasible to influence..$^{14,20,21}$ Furthermore, the importance of adherence to pharmacotherapy, influenza vaccination, smoking cessation, physical activity and exercise training is in line with recommendations in international guidelines. 2,35,36

In contrast, correct increase of short-acting $\beta 2$-agonist (SABA) use, performing breathing techniques and energy conservation techniques were expected to be relevant $t^{2,35,37,38}$ but were not included in our final list. This may be explained by our specific study focus on reducing exacerbation impact. Whereas, according to the experts, increasing SABA and performing breathing techniques were not expected to contribute to the reduction of exacerbation impact, experts considered this important for symptom relief. In addition, breathing exercises may not be relevant for all patients (as stated by one of our experts). Evidence regarding breathing techniques is also contradictory as one review showed that pursed lip breathing is effective to improve dyspnea, ${ }^{38}$ while 2 other reviews found no evidence that breathing exercises improve lung function or relieve symptoms. ${ }^{37,39}$

Furthermore, managing exposure to air quality was rated in our Delphi study since recent evidence shows that air pollution is related to an increased risk for exacerbations..$^{40}$ Additionally, managing exposure to "indoor" air quality was 
added based on expert suggestions. Although there was consensus between experts on the relevance of both behaviors, they were not included in the final list since room for improvement and feasibility to influence these behaviors were considered to be insufficient, which may be explained by the limited available evidence.

Surprisingly, avoiding viral or bacterial stimuli was considered to be important by our expert panel while convincing evidence is still lacking. The latter may be explained by the limited evidence regarding exacerbations cause, ${ }^{2}$ and the fact that this behavior is difficult to measure and challenging to influence. Furthermore, managing stress and anxiety was considered to be important during an exacerbation and recovery, while no convincing evidence was found regarding reduction of exacerbation impact. This might be explained by the fact that anxiety affects symptom perception and self-management ${ }^{13,41}$ and by the feasibility to influence this behavior. ${ }^{42}$ Finally, notable was that daily physical activity was considered to be both relevant and feasible to influence before, during and after an exacerbation. This is in line with evidence showing that maintaining daily activity prevents exacerbations and that lower physical activity levels are associated with an increased risk of exacerbation-related hospitalizations. 2,43,44 However, it is important to take into account that some experts in our panel believed that daily physical activity may worsen a patient's situation during an exacerbation and that it is uncertain when physical activity should be initiated.

\section{Strengths and limitations}

An important strength of this study was the tailored and iterative study design. Extensive literature review on self-management behaviors and a face validity check on the predetermined behaviors contributed to the validity of the study, as well as pilot-testing of the surveys. Furthermore, our specific focus on identifying the most promising self-management behaviors was strengthened by rating both relevance and feasibility of behaviors according to 3 statements. Moreover, validity was enhanced by including a small expert panel of key international experts in the field focusing on both research and patient care.

However, this study has also some limitations. Little foundation for our methodological decisions can be provided, given the great variation in the methodological designs of Delphi studies. In addition, our study did not include a face-to-face meeting with experts between the Delphi rounds to discuss ratings, investigate areas of disagreement, and gain more in-depth insights. We did, however, include open questions at each phase to gain more understanding into 
the ratings and to check whether methodological inconsistencies were present. Furthermore, our study focused on predetermined self-management behaviors derived from literature that might have caused experts to be less open-minded to introduce new behaviors themselves. To prevent missing additional input, a comment box was available to introduce new behaviors. Finally, it is important to note that experts' ratings on statement 2 and 3 of the Delphi survey may be influenced by local factors as, for example, the local health care context or policy in countries individual experts are living in. Therefore, supporting the identified self-management behaviors might require different strategies dependent on the local setting.

\section{Implications for practice and future research}

The findings of this study are important for both professionals providing selfmanagement support and researchers focusing on the development of selfmanagement interventions. This study highlights the importance of focusing on a tailored set of self-management behaviors in each phase of the course of COPD, so that patients can exert the highest magnitude of influence on the impact of exacerbations. This study therefore strengthens the need for multi-component interventions.

Future research should focus on the development of more comprehensive and tailored self-management interventions based on available evidence. As selfmanagement requires behavior change in COPD patients, it is important to identify effective intervention components aiming at behavior change. Recently, increased attention has been paid on determining intervention strategies that are effective in targeting the relevant mechanisms of change using behavior change techniques. Therefore, it is important to investigate patients' capabilities, opportunity and motivation to perform specific behaviors identified by this study. ${ }^{45}$ In future development of more comprehensive interventions eHealth or mHealth opportunities should be explored, since both provide possibilities to strongly individualize and tailor self-management interventions during the whole course of COPD. ${ }^{45}$

\section{Conclusion}

This study identified a set of 17 relevant and feasible self-management behaviors that can be targeted and influenced to maximize reduction of exacerbation impact based on consensus within an international expert panel. To exert the highest 
magnitude of influence on the impact of exacerbations, it is important that patients perform specific self-management behaviors before, during and after an exacerbation, that focus on adherence to pharmacotherapy, influenza vaccination, physical activity/exercise, avoiding stimuli, smoking cessation, early detection of symptom deterioration, medical treatment of exacerbations, managing stress and anxiety, and awareness for recurrent exacerbations. Future research should focus on developing and evaluating more comprehensive interventions supporting patients in these specific exacerbation-related self-management behaviors. Proven effective interventions addressing these behaviors should be considered in COPD care. 


\section{References}

1. Lopez AD, Shibuya K, Rao C, et al. Chronic obstructive pulmonary disease: current burden and future projections. Eur Respir J. 2006;27(2):397-412.

2. Global Initiative for Chronic Obstructive Lung Disease (GOLD). Global Strategy for the Diagnosis, Management, and Prevention of Chronic Obstructive Pulmonary Disease [updated 2016]. Available from: http://goldcopd.org/global-strategy-diagnosis-management-prevention-copd-2016/. Accessed February 2, 2016.

3. Rodriguez-Roisin R. Toward a consensus definition for COPD exacerbations. Chest. 2000;117(5 Suppl 2):398S-401S.

4. Donaldson GC, Seemungal TA, Bhowmik A, Wedzicha JA. Relationship between exacerbation frequency and lung function decline in chronic obstructive pulmonary disease. Thorax. 2002;57(10):847-852.

5. Llor C, Molina J, Naberan K, Cots JM, Ros F, Miravitlles M. Exacerbations worsen the quality of life of chronic obstructive pulmonary disease patients in primary healthcare. Int J Clin Pract. 2008;62(4):585-592.

6. Miravitlles M, Ferrer M, Pont A, et al; IMPAC Study Group. Effect of exacerbations on quality of life in patients with chronic obstructive pulmonary disease: a 2 year follow up study. Thorax. 2004;59(5):387-395.

7. Soler-Cataluña JJ, Martínez-García MÁ, Sánchez PR, Salcedo E, Navarro M, Ochando R. Severe acute exacerbations and mortality in patients with chronic obstructive pulmonary disease. Thorax. 2005;60(11):925-931.

8. Vestbo J, Hurd SS, Agustí AG, et al. Global strategy for the diagnosis, management, and prevention of chronic obstructive pulmonary disease GOLD executive summary. Am J Respir Crit Care Med. 2013;187(4):347-365.

9. Zwerink M, Brusse-Keizer M, van der Valk PDLPM, et al. Self-management for patients with chronic obstructive pulmonary disease. Cochrane Database Syst Rev. 2014;3(3):CD002990.

10. Bourbeau J, van der Palen J. Promoting effective self-management programmes to improve COPD. Eur Respir J. 2009;33(3):461-463.

11. Barlow J, Wright C, Sheasby J, Turner A, Hainsworth J. Self-management approaches for people with chronic conditions: a review. Patient Educ Couns. 2002;48(2):177-187.

12. Effing TW, Vercoulen JH, Bourbeau J, et al. Definition of a COPD self-management intervention: international Expert Group consensus. Eur Respir J. 2016;48(1):46-54.

13. Bourbeau J, Nault D. Self-management strategies in chronic obstructive pulmonary disease. Clin Chest Med. 2007;28(3):617-628.

14. TrappenburgJCA, Monninkhof EM, Bourbeau J, et al. Effect of an action plan with ongoing support by a case manager on exacerbation-related outcome in patients with COPD: a multicentre randomised controlled trial. Thorax. 2011;66(11):977-984.

15. Aaron SD, Donaldson GC, Whitmore GA, Hurst JR, Ramsay T, Wedzicha JA. Time course and pattern of COPD exacerbation onset. Thorax. 2012;67(3):238-243.

16. Donaldson GC, Seemungal TA, Patel IS, Lloyd-Owen SJ, Wilkinson TM, Wedzicha JA. Longitudinal changes in the nature, severity and frequency of COPD exacerbations. Eur RespirJ.2003;22(6):931936.

17. Hurst JR, Vestbo J, Anzueto A, et al; Evaluation of COPD Longitudinally to Identify Predictive Surrogate Endpoints (ECLIPSE) Investigators. Susceptibility to exacerbation in chronic obstructive pulmonary disease. N Eng/J Med. 2010;363(12):1128-1138.

18. Jenkins $C R$, Celli B, Anderson JA, et al. Seasonality and determinants of moderate and severe COPD exacerbations in the TORCH study. Eur Respir J. 2012;39(1):38-45. 
19. Hurst JR, Donaldson GC, Quint JK, Goldring JJP, Baghai-Ravary R, Wedzicha JA. Temporal clustering of exacerbations in chronic obstructive pulmonary disease. Am J Respir Crit Care Med. 2009;179(5):369-374.

20. Walters J, Turnock A, Walters E, Wood-Baker R. Action plans with limited patient education only for exacerbations of chronic obstructive pulmonary disease. Cochrane Database Syst Rev. 2010;(5):CD005074.

21. Harrison SL, Janaudis-Ferreira T, Brooks D, Desveaux L, Goldstein RS. Self-management following an acute exacerbation of COPD: a systematic review. Chest. 2015;147(3):646-661.

22. Hasson F, Keeney S, McKenna H. Research guidelines for the Delphi survey technique.J Adv Nurs. 2000;32(4):1008-1015.

23. Fitch K, Bernstein SJJ, Aguilar MDD, et al. The RAND/UCLA Appropriateness Method: User's Manual; 2001. Available from: https://www.rand.org/content/dam/rand/pubs/monograph_ reports/2011/MR1269.pdf. Accessed February 23, 2016.

24. McKenna HP. The Delphi technique: a worthwhile research approach for nursing? J Adv Nurs. 1994;19(6):1221-1225.

25. Wilkinson TM, Donaldson GC, Hurst JR, Seemungal TA, Wedzicha JA. Early therapy improves outcomes of exacerbations of chronic obstructive pulmonary disease. Am J Respir Crit Care Med. 2004;169(12):1298-1303.

26. Seemungal TAR, Donaldson GC, Bhowmik A, Jeffries DJ, Wedzicha JA. Time course and recovery of exacerbations in patients with chronic obstructive pulmonary disease. Am J Respir Crit care Med. 2000;161(5):1608-1613.

27. Birko S, Dove ES, Ozdemir V, Dalal K. Evaluation of nine consensus indices in delphi foresight research and their dependency on delphi survey characteristics: a simulation study and debate on delphi design and interpretation. PLoS One. 2015;10(8):1-14.

28. Asch DA, Jedrziewski MK, Christakis NA. Response rates to mail surveys published in medical journals. J Clin Epidemiol. 1997;50(10):1129-1136.

29. Rayens MK, Hahn EJ. Building consensus using the delphi policy. Policy Polit Nurs Pract. 2000;1(4):308-315.

30. University of Leicester. Measures of variability: the range, inter-quartile range and standard deviation; 2009:1-7. Available from: http://www2.le.ac.uk/offices/ld/resources/numerical-data/ variability. Accessed March 18, 2016.

31. Manikandan S. Measures of dispersion. J Pharmacol Pharmacother. 2011;2(4):315.

32. Linstone H, Turoff M. The Delphi Method: Technique and Applications. Reading MA: AddisonWesley; 1975.

33. Von der Gracht HA. Consensus measurement in Delphi studies. Review and implications for future quality assurance. Technol Forecast Soc Change. 2012;79(8):1525-1536.

34. IBM Corp. Released 2013. IBM SPSS Statistics for Windows, Version 22.0. Armonk, NY: IBM Corp.

35. Criner GJ, Bourbeau J, Diekemper RL, et al. Prevention of acute exacerbations of COPD. Chest. 2015;147(4):894-942.

36. Spruit MA, Singh SJ, Garvey C, et al; ATS/ERS Task Force on Pulmonary Rehabilitation. An official American thoracic society/European respiratory society statement: Key concepts and advances in pulmonary rehabilitation. Am J Respir Crit Care Med. 2013;188(8):e13-e64.

37. Hill K, Patman S, Brooks D. Effect of airway clearance techniques in patients experiencing an acute exacerbation of chronic obstructive pulmonary disease: a systematic review. Chron Respir Dis. 2010;7(1):9-17.

38. Facchiano L, Snyder $\mathrm{CH}$, Núñez DE. A literature review on breathing retraining as a selfmanagement strategy operationalized through Rosswurm and Larrabee's evidence-based practice model. J Am Acad Nurse Pract. 2011;23(8):421-426. 
39. Aaron SD. Management and prevention of exacerbations of COPD. BMJ. 2014;349(2):g5237.

40. Hansel NN, McCormack MC, Kim V. The effects of air pollution and temperature on COPD. COPD. 2016;13(3):372-379.

41. Disler RT, Gallagher RD, Davidson PM. Factors influencing self-management in chronic obstructive pulmonary disease: an integrative review. Int J Nurs Stud. 2012;49(2):230-242.

42. Tselebis A, Pachi A, Ilias I, et al. Strategies to improve anxiety and depression in patients with COPD: a mental health perspective. Neuropsychiatr Dis Treat. 2016;12:297-328.

43. Spruit MA, Pitta F, McAuley E, ZuWallack RL, Nici L. Pulmonary rehabilitation and physical activity in patients with chronic obstructive pulmonary disease. Am J Respir Crit Care Med. 2015;192(8):924-933.

44. Moy ML, Teylan M, Weston NA, Gagnon DR, Garshick E. Daily step count predicts acute exacerbations in a US cohort with COPD. PLoS One. 2013;8(4):19-23.

45. West R, Michie S. A Guide to Development and Evaluation of Digital Behaviour Change Interventions in Healthcare. London: Silverback Publishing; 2016. 


\section{Appendix 1}

\section{Results of literature review}

Potential relevant self-management behaviours identified from literature are presented in table 1-5 and substantiated by summaries of evidence. When evidence was available from COPD guidelines/statements, no additional (systematic) reviews or longitudinal studies are presented. By a lack of evidence from guidelines, available (systematic) reviews are presented. Longitudinal studies are presented when (systematic) reviews were lacking. Exceptions were made when relevant longitudinal studies were published after reviews or when relevant (systematic) reviews were not listed in guidelines. 
Table 1. Phase 1: Stable phase (low risk)

\begin{tabular}{|c|c|c|c|c|}
\hline $\begin{array}{l}\text { Self-management } \\
\text { behavior }\end{array}$ & $\begin{array}{l}\text { Guideline/ } \\
\text { statement }\end{array}$ & $\begin{array}{l}\text { (Systematic) } \\
\text { Review }\end{array}$ & $\begin{array}{l}\text { Longitudinal } \\
\text { study }\end{array}$ & $\begin{array}{l}\text { Summary of evidence regarding } \\
\text { behavior }\end{array}$ \\
\hline $\begin{array}{l}\text { Adherence to } \\
\text { pharmacotherapy } \\
\text { (LABA/LAMA and/or } \\
\text { ICS) }\end{array}$ & $\begin{array}{l}\text { - GOLD, } 2016^{1} \\
\text { - Criner, } 2015^{2}\end{array}$ & NA & NA & $\begin{array}{l}\text { Treatment with long-acting } \\
\text { inhaled bronchodilators (long- } \\
\text { acting } \beta 2 \text {-agonist } \angle A B A \text {, long-acting } \\
\text { muscarinic antagonist } \angle A M A \text {, or a } \\
\text { combination of), with or without } \\
\text { inhaled corticosteroids ICS, are } \\
\text { therapies that reduce the number of } \\
\text { exacerbations and hospitalizations., }\end{array}$ \\
\hline $\begin{array}{l}\text { Influenza vaccination } \\
\text { uptake }\end{array}$ & $\begin{array}{l}\text { - GOLD, } 2016^{1} \\
\text { - Criner, } 2015^{2}\end{array}$ & NA & NA & $\begin{array}{l}\text { Influenza vaccines is a therapy } \\
\text { that reduces the number of } \\
\text { exacerbations and hospitalizations } \\
\text { and is recommended to prevent } \\
\text { acute exacerbations. }{ }^{1,2}\end{array}$ \\
\hline Daily physical activity & $\begin{array}{l}\text { - GOLD, } 2016^{1} \\
\text { - Spruit, } 2013^{3}\end{array}$ & NA & NA & $\begin{array}{l}\text { Patients should be encouraged to } \\
\text { maintain physical activity to prevent } \\
\text { COPD exacerbations. }{ }^{1} \\
\text { Physical activity levels predict } \\
\text { important outcomes in COPD. } \\
\text { Lower physical activity levels are } \\
\text { associated with a higher risk of an } \\
\text { exacerbation-related hospitalization } \\
\text { and re-hospitalizations. }{ }^{3}\end{array}$ \\
\hline $\begin{array}{l}\text { Avoiding viral or } \\
\text { bacterial stimuli } \\
\text { (hand hygiene and/or } \\
\text { avoiding contact with } \\
\text { people with a cold) }\end{array}$ & NA & NA & $\begin{array}{l}\text { - Gandhi, } 2012^{4} \\
\text { - Donaldson, } 2012^{5} \\
\text { - Jenkins, } 2012^{6} \\
\text { - Rabe, } 2013^{7}\end{array}$ & $\begin{array}{l}\text { - The cohort study of Ghandi ( } 2012 \text { ) } \\
\text { shows that Human rhinoviruses } \\
\text { (HRV) can be detected in a large } \\
\text { proportion of acute exacerbations } \\
\text { of COPD. Contact with school } \\
\text { aged children is considered to } \\
\text { be a risk factor for both infection } \\
\text { and symptomatic HRV illness. } \\
\text { This study states that good hand } \\
\text { hygiene, and avoidance of direct } \\
\text { contact with ill children, may } \\
\text { avoid HRV related illness in COPD } \\
\text { patients. } \\
\text { - The cohort study of Donaldson } \\
\text { (2012) showed that patients } \\
\text { experienced } 1,052 \text { exacerbations in } \\
\text { the cold season compared to } 676 \\
\text { in the warm season: an excess of } \\
56.6 \% \text {. This study concludes that } \\
\text { exacerbation severity is worse in } \\
\text { the winter and recovery times are } \\
\text { longer, which may be influenced } \\
\text { by increased prevalence of viral } \\
\text { infections during winter.5little } \\
\text { is known about the impact of } \\
\text { the seasons on exacerbation } \\
\text { characteristics. IInIInMETHODS: } \\
\text { Between November } 1,1995, \text { and } \\
\text { November } 1,2009,307 \text { patients } \\
\text { in the London COPD cohort ( } 196 \\
\text { men; age, mean, } 68.1 \text { years [SD, } \\
8.4] \text {; FEV( } 1\end{array}$ \\
\hline
\end{tabular}


Table 1. (Continued)

\begin{tabular}{|c|c|c|c|}
\hline $\begin{array}{l}\text { Avoiding viral or } \\
\text { bacterial stimuli } \\
\text { (hand hygiene and/ } \\
\text { or avoiding contact } \\
\text { with people with a } \\
\text { cold) }\end{array}$ & NA & NA & $\begin{array}{l}\text { - Gandhi, } 2012^{4} \\
\text { - Donaldson, } \\
2012^{5} \\
\text { - Jenkins, } 2012^{6} \\
\text { - Rabe, } 2013^{7}\end{array}$ \\
\hline
\end{tabular}

- The RCT of Jenkins (2012)

showed that exacerbations in the northern and southern regions of the world almost had a two-fold increase in the winter months. This study states that factors potentially contributing to this include: increased exposure to viral infections, increased host susceptibility, greater time spent indoors, reduced physical activity and temperature-related reduction in lung function. These patterns also relate to lower weekly mean temperatures, influenza activity and personal cold exposure factors. ${ }^{6} 38 \%$ of exacerbations were treated with antibiotics only, $19 \%$ with systemic corticosteroids only and $43 \%$ with both, while $20 \%$ required hospital admission irrespective of the season. Exacerbation frequency was associated with older age, lower body mass index, lower FEV (1

- The study of Rabe (2013), based on POET-COPD trial, shows as well that mean monthly exacerbation rates during winter were higher than during summer. Exacerbationrelated hospitalizations remained constant throughout the year. This study highlights a marked impact of season on exacerbation outcomes, antibiotic treatment, timing of second exacerbations, and all-cause mortality. ${ }^{7}$ 
Table 1. (Continued)

Managing exposure NA
to air quality
(air pollution/
temperature/
humidity)*

- Song, NA
$2014^{8}$
- Hansel,
$2015^{9}$
- Ni, 2015 10

- The review of Hansel (2015) focused on both air pollution and temperature in COPD.

- Air pollution: Several studies relate outdoor air pollution to increased risk of COPD exacerbations. The APHEA project (data from 6 European cities) found increased risk of COPD hospital admissions with several air pollutants.

- Hot temperature: A study in New York City found an increased risk of $7,6 \%$ of COPD hospitalization for every $1^{\circ} \mathrm{C}$ increase above a threshold temperature of $29^{\circ} \mathrm{C}$.

- Humid air: Studies in asthma suggest that breathing hot humid air may result in bronchoconstriction that is mediated via cholinergic pathways.

- Cold temperature: Studies demonstrated an impact of cold temperatures on lung function and risk of exacerbations among COPD patients. A large study in Taiwan detected a $0.8 \%$ increase in COPD exacerbations for every $1^{\circ} \mathrm{C}$ decrease in mean daily temperature. ${ }^{9}$ 
Table 1. (Continued)

\begin{tabular}{lcc}
\hline Managing exposure & $\mathrm{NA}$ & $\cdot$ Song, \\
to air quality & $2014^{8}$ & $\mathrm{NA}$ \\
(air pollution/ & $\cdot$ Hansel, \\
temperature/ & $2015^{9}$ & \\
humidity)* & $\cdot \mathrm{Ni}, 2015^{10}$ &
\end{tabular}

- The review of $\mathrm{Ni}$ (2015)

focused on recent studies of the role of fine Particulate Matter (PM) in acute exacerbations of COPD (AECOPD). Fine PM leads to AECOPD via inflammation, oxidative stress, immune dysfunction, and altered airway epithelial structure and microbiome. This study shows that reducing fine PM levels is a suitable approach to lower $A E C O P D$ incidence and reduce COPD progression. ${ }^{10}$

\begin{tabular}{lccc}
\hline Quitting smoking or & $\cdot$ GOLD, & NA & NA \\
cutting down smoking & $2016^{1}$ & & \\
& $\begin{array}{lll}\text { Criner, } \\
2015^{2}\end{array}$ & & \\
& & &
\end{tabular}

Smoking cessation reduces the number of exacerbations and hospitalizations. ${ }^{1}$ Smoking cessation counselling and treatment using best practices is advised to prevent exacerbations. Although, the evidence for smoking cessation in the prevention of acute exacerbations of COPD is low, Criner et al (2015) state that evidence supports smoking cessation for many reasons. ${ }^{2}$

Notes: Italic indicates the self-management behaviours that are considered to be relevant in more than one phase and therefore return in several phases.

*Self-management behaviour added based on expert opinion in face validity round.

Abbreviations: LABA, longacting B2-agonist; LAMA, long-acting muscarinic antagonist; ICS, inhaled corticosteroids; NA, not applicable.

Table 2. Phase 2: Mild deterioration of symptoms phase

\begin{tabular}{|c|c|c|c|c|}
\hline $\begin{array}{l}\text { Self- } \\
\text { management } \\
\text { behavior }\end{array}$ & $\begin{array}{l}\text { Guideline } \\
\text { /statement }\end{array}$ & $\begin{array}{l}\text { (Systematic) } \\
\text { Review }\end{array}$ & $\begin{array}{l}\text { Longitudinal } \\
\text { study }\end{array}$ & $\begin{array}{l}\text { Summary of evidence regarding } \\
\text { behavior }\end{array}$ \\
\hline $\begin{array}{l}\text { Early detection } \\
\text { of symptom } \\
\text { deterioration* }\end{array}$ & NA & NA & $\begin{array}{l}\text { - Wilkinson, } \\
2004^{11}\end{array}$ & $\begin{array}{l}\text { - Recognition of exacerbation symptoms } \\
\text { and prompt treatment is a required } \\
\text { self-management skill to prevent } \\
\text { exacerbations as it is associated } \\
\text { with faster recovery, lower risk for } \\
\text { hospitalization and increased quality of } \\
\text { life.11 }\end{array}$ \\
\hline
\end{tabular}


Table 2. (Continued)

$\begin{array}{lccc}\begin{array}{l}\text { Correct increase } \\ \text { of short-acting }\end{array} & \begin{array}{c}\text { GOLD, } \\ 2016^{1}\end{array} & \text { NA } & \text { NA } \\ \text { bronchodilators } & \cdot \text { Criner, } & & \\ \text { (SABA) } & 2015^{2} & & \end{array}$

- SABA (with or without short-acting anticholinergics) are usually the preferred bronchodilators for treatment of exacerbations (although this is not based on RCT's). ${ }^{1}$

- In patients with moderate to severe COPD, the guideline of Criner et al (2015) suggests the use of shortacting bronchodilators (short-acting muscarinic antagonist plus short-acting b2 -agonist) to prevent acute moderate exacerbations of COPD. ${ }^{2}$

\begin{tabular}{lc}
\hline $\begin{array}{l}\text { Performing } \\
\text { breathing } \\
\text { exercises }\end{array}$ & - Facchiano, NA \\
$\begin{array}{l}\text { (i.e. dyspnea } \\
\text { regulation and/or }\end{array}$ & Hill, $2011^{12}$ \\
$\begin{array}{l}\text { mucus clearance } \\
\text { techniques) }\end{array}$ & - Aaron, \\
& $2014^{14}$ \\
&
\end{tabular}

- The literature review of Facchiano (2011) concluded that regularly practiced pursed lip breathing is an effective selfmanagement strategy for individuals with COPD to improve their dyspnea. ${ }^{12}$

- Both the systematic review of Hill (2010) and the review of Aaron (2014) provided no evidence that breathing exercises improves lung function or symptoms, or reduces admission to hospital, length of hospital stay or exacerbation rates..$^{13,14}$

\begin{tabular}{|c|c|}
\hline $\begin{array}{l}\text { Performing } \\
\text { energy } \\
\text { conservation } \\
\text { techniques } \\
\text { (prioritizing } \\
\text { activities / } \\
\text { managing energy } \\
\text { conservation for } \\
\text { physical activity) }\end{array}$ & $\begin{array}{l}\text { - Bourbeau, } \\
\text { 200715** } \\
\text { - Disler, } \\
2012^{16}\end{array}$ \\
\hline
\end{tabular}

- The article of Bourbeau (2007) concludes that energy conservation is important for COPD patients. The self-management skills needed from the patient is to prioritize activities, plan schedules and pace yourself. ${ }^{15}$

- According to Disler (2012) pacing physical activity has a positive impact on patients' ability to physically self-manage their COPD, as completing physical activity at one's own speed enables patients to conserve energy and achieve physical goals while avoiding exertional dyspnea and the emotional distress that comes with breathlessness. ${ }^{16}$ chronic and burdensome condition requiring the individual to engage in a range of self-management strategies. The capacity to engage in self-management is dependent on a range of internal (e.g. personal

Notes: Italic: indicates the self-management behaviours that are considered to be relevant in more than one phase and therefore return in several phases.

*Self-management behaviour added based on expert opinion in face validity round. ** Article included based on relevance, no (systematic) review.

Abbreviation: NA, not applicable. 
Table 3. Phase 3: Exacerbation (including onset)

\begin{tabular}{|c|c|c|c|c|}
\hline $\begin{array}{l}\text { Self-management } \\
\text { behavior }\end{array}$ & $\begin{array}{l}\text { Guideline } \\
\text { /statement }\end{array}$ & $\begin{array}{l}\text { (Systematic) } \\
\text { Review }\end{array}$ & $\begin{array}{l}\text { Longitudinal } \\
\text { study }\end{array}$ & $\begin{array}{l}\text { Summary of evidence } \\
\text { regarding behavior }\end{array}$ \\
\hline $\begin{array}{l}\text { Early detection of } \\
\text { an exacerbation }\end{array}$ & NA & NA & $\begin{array}{l}\text { - Trappenburg, } \\
2011^{17} \\
\text { - Wilkinson, } 2004^{11}\end{array}$ & $\begin{array}{l}\text { - The RCT of Trappenburg } \\
\text { (2011) and the cohort study of } \\
\text { Wilkinson (2004) underlined the } \\
\text { importance of improving self- } \\
\text { management skills to enhance } \\
\text { early detection and to take } \\
\text { early and appropriate actions } \\
\text { by patients in exacerbation } \\
\text { episodes. Recognition of } \\
\text { exacerbation symptoms } \\
\text { and prompt treatment was } \\
\text { associated with accelerated } \\
\text { recovery, lower risk for } \\
\text { hospitalization, increased } \\
\text { quality of life and lesser impact } \\
\text { on health status.111,17forced } \\
\text { expiratory volume in } 1 \mathrm{~s} 561 \\
\text { u00b121\% predicted }\end{array}$ \\
\hline $\begin{array}{l}\text { Prompt } \\
\text { treatment with } \\
\text { a course of } \\
\text { corticosteroids } \\
\text { and/or antibiotics } \\
\text { (Contacting } \\
\text { health care } \\
\text { provider) }\end{array}$ & GOLD, $2016^{1}$ & NA & NA & $\begin{array}{l}\text { - Systemic corticosteroids } \\
\text { shorten recovery times of } \\
\text { exacerbations, improve lung } \\
\text { function (FEV1) and arterial } \\
\text { hypoxemia. In addition, reduces } \\
\text { the risk of early relapse. Use of } \\
\text { antibiotics remain controversial. } \\
\text { There is evidence for antibiotic } \\
\text { use in case of clinical signs } \\
\text { of bacterial infection (e.g. } \\
\text { increased sputum purulence). } \\
\text { Advice of GOLD report is to } \\
\text { subscribe antibiotics based } \\
\text { on symptoms or if mechanic } \\
\text { ventilation is required. In } \\
\text { addition, prompt treatment is } \\
\text { vital to reduce the burden of } \\
\text { COPD. }\end{array}$ \\
\hline $\begin{array}{l}\text { Prompt } \\
\text { treatment with } \\
\text { a course of } \\
\text { corticosteroids } \\
\text { and/or antibiotics } \\
\text { (Self-treatment) }\end{array}$ & NA & NA & - Zwerink, $2016^{18}$ & $\begin{array}{l}\text { - The study of Zwerink (2016) } \\
\text { concludes that self-treatment } \\
\text { of exacerbations is beneficial } \\
\text { in COPD patients without } \\
\text { significant comorbidities } \\
\text { because it reduces exacerbation } \\
\text { duration, exacerbation severity } \\
\text { and health-care utilization } \\
\text { leading to considerable cost } \\
\text { savings. }{ }^{18} \text { the median number } \\
\text { of exacerbation days was } \\
\text { significantly lower in the STG } \\
\text { (50, IQR: } 32-115\end{array}$ \\
\hline
\end{tabular}


Table 3. (Continued)

\begin{tabular}{|c|c|c|c|c|}
\hline $\begin{array}{l}\text { Manage stress } \\
\text { and anxiety (by } \\
\text { using relaxation } \\
\text { techniques) }\end{array}$ & NA & $\begin{array}{l}\text { Hurst \& } \\
\text { Wedzicha, } \\
2009^{19}\end{array}$ & - Eisner, $2010^{20}$ & $\begin{array}{l}\text { - Depression and anxiety are } \\
\text { common in COPD, and likely } \\
\text { to affect symptom perception } \\
\text { and therefore exacerbation } \\
\text { presentation. It is important } \\
\text { to detect and treat comorbid } \\
\text { psychological conditions, } \\
\text { though a specific effect on } \\
\text { exacerbation reduction has not } \\
\text { been documented. }{ }^{19} \\
\text { - The cohort study of Eisner } \\
\text { (2010) showed that in patients } \\
\text { with COPD, anxiety was related } \\
\text { to poorer health outcomes } \\
\text { including worse submaximal } \\
\text { exercise performance and a } \\
\text { greater risk of self-reported } \\
\text { functional limitations. COPD } \\
\text { patients with anxiety had a } \\
\text { higher longitudinal risk of } \\
\text { COPD exacerbation. This study } \\
\text { states that further research is } \\
\text { needed to determine whether } \\
\text { systematic screening and } \\
\text { treatment of anxiety in COPD } \\
\text { will improve health outcomes } \\
\text { and prevent functional decline } \\
\text { and disability. }{ }^{20}\end{array}$ \\
\hline
\end{tabular}

Abbreviation: NA, not applicable. 
Table 4. Phase 4: Recovery

\begin{tabular}{|c|c|c|c|c|}
\hline $\begin{array}{l}\text { Self- } \\
\text { management } \\
\text { behavior }\end{array}$ & $\begin{array}{l}\text { Guideline/ } \\
\text { statement }\end{array}$ & $\begin{array}{l}\text { (Systematic) } \\
\text { Review }\end{array}$ & $\begin{array}{l}\text { Longitudinal } \\
\text { study }\end{array}$ & $\begin{array}{l}\text { Summary of evidence regarding } \\
\text { behavior }\end{array}$ \\
\hline $\begin{array}{l}\text { Completing } \\
\text { treatment of } \\
\text { antibiotics } \\
\text { and/or } \\
\text { corticosteroids* }\end{array}$ & GOLD, $2016^{1}$ & NA & NA & $\begin{array}{l}\text { The recommended length of } \\
\text { antibiotic therapy is usually 5-10 } \\
\text { days according to the GOLD } \\
\text { guideline. }\end{array}$ \\
\hline $\begin{array}{l}\text { Manage stress } \\
\text { and anxiety } \\
\text { (concerning } \\
\text { current event) }\end{array}$ & NA & $\begin{array}{l}\text { - Harrison, } 2014^{21} \\
\text { - Hurst \& } \\
\text { Wedzicha, } \\
2009^{19}\end{array}$ & NA & $\begin{array}{l}\text { - The review of Harrison (2014) } \\
\text { suggested that psychological } \\
\text { assessment should be routinely } \\
\text { conducted as part of patient } \\
\text { management, since exacerbations } \\
\text { have a profound emotional impact } \\
\text { on patients. Although symptoms } \\
\text { of anxiety and depression are } \\
\text { common in COPD patients, } \\
\text { patients rarely present with } \\
\text { psychological symptoms severe } \\
\text { enough to warrant a clinical } \\
\text { diagnosis. }{ }^{21} \\
\text { - Depression and anxiety are } \\
\text { common in COPD, and likely } \\
\text { to affect symptom perception } \\
\text { and therefore exacerbation } \\
\text { presentation. It is important } \\
\text { to detect and treat comorbid } \\
\text { psychological conditions, though } \\
\text { a specific effect on exacerbation } \\
\text { reduction has not been } \\
\text { documented. }{ }^{19}\end{array}$ \\
\hline $\begin{array}{l}\text { Adjusted } \\
\text { exercise- and } \\
\text { resistance } \\
\text { training }\end{array}$ & $\begin{array}{l}\text { - GOLD, } \\
2016^{1} \\
\cdot \text { - Spruit, } \\
2013^{3}\end{array}$ & NA & NA & $\begin{array}{l}\text { - Lack of routine physical activity } \\
\text { was found to be predictive of } \\
\text { readmission in a hospital. }{ }^{1} \\
\text { - } \text { Physical inactivity after AECOPD is } \\
\text { associated with readmission with } \\
\text { subsequent exacerbation. }{ }^{3}\end{array}$ \\
\hline
\end{tabular}

Notes: Italic: indicates the self-management behaviours that are considered to be relevant in more than one phase and therefore return in several phases. *Self-management behaviour added based on expert opinion in face validity round.

Abbreviation: NA, not applicable. 
Table 5. Phase 5: Stable phase (at risk)

\begin{tabular}{lllll}
\hline $\begin{array}{l}\text { Self- } \\
\text { management } \\
\text { behavior }\end{array}$ & $\begin{array}{l}\text { Guideline } \\
\text { /statement }\end{array}$ & $\begin{array}{l}\text { (Systematic) } \\
\text { Review }\end{array}$ & $\begin{array}{l}\text { Longitudinal } \\
\text { studie }\end{array}$ & $\begin{array}{l}\text { Summary of evidence regarding } \\
\text { behavior }\end{array}$ \\
\hline
\end{tabular}

\begin{tabular}{|c|c|c|}
\hline $\begin{array}{l}\text { Increased } \\
\text { awareness } \\
\text { for recurring } \\
\text { exacerbation }\end{array}$ & NA & $\begin{array}{l}\text { Hurst \& } \\
\text { Wedzicha, } \\
2009^{19}\end{array}$ \\
\hline
\end{tabular}

NA It is now recognized that

exacerbations are not random

exacerbation

together in time such that in the period immediately following a first exacerbation there is increased risk of a second. ${ }^{19}$ This review refers to a study of Hurst et al (2009) that shows that exacerbations cluster in time and that there is a high risk period

\begin{tabular}{lr}
\hline $\begin{array}{l}\text { Early (re)start } \\
\text { of pulmonary }\end{array}$ & Criner, $2015^{2} \cdot$ Spruit, \\
rehabilitation* & $2015^{23}$ \\
& Puhan, \\
& $2011^{24}$
\end{tabular}
for recurrent exacerbations in the 8-week period after an initial exacerbation. ${ }^{22}$

- In patients with moderate, severe, or very severe COPD who experienced a recent exacerbation (i.e., < 4 weeks) pulmonary rehabilitation is recommended to prevent acute exacerbations of COPD. ${ }^{2}$

- The review of Spruit (2015) found that although pulmonary rehabilitation has no direct effect on the physiologic derangements in lung function, it provides the greatest improvements in dyspnea, exercise tolerance, and healthrelated quality of life of any intervention available for patients with chronic respiratory disease. It also decreases subsequent healthcare use, especially when provided following an exacerbation of COPD. ${ }^{23}$

- A review of Puhan (2011) on the evidence from nine trials suggests that pulmonary rehabilitation is effective in COPD patients after acute exacerbations to reduce hospital admissions and mortality and improves quality of life..$^{24}$

Notes: *Self-management behaviour added based on expert opinion in face validity round. Abbreviation: NA, not applicable. 


\section{References}

1. Global Initiative for Chronic Obstructive Lung Disease (GOLD). Global Strategy for the Diagnosis, Management, and Prevention of Chronic Obstructive Pulmonary Disease [updated 2016]. Available from: http://goldcopd.org/global-strategy-diagnosis-management-prevention-copd-2016/. Accessed February 2, 2016.

2. Criner GJ, Bourbeau J, Diekemper RL, et al. Prevention of Acute Exacerbations of COPD. CHEST J. 2015;147(4):894.

3. Spruit MA, Singh SJ, Garvey C, et al. An official American thoracic society/European respiratory society statement: Key concepts and advances in pulmonary rehabilitation. Am J Respir Crit Care Med. 2013;188(8).

4. Gandhi A, Walsh EE, Formica MA, et al. Factors associated with symptomatic rhinovirus infection in patients with COPD. J Clin Virol. 2012;55(4):343-347.

5. Donaldson GC, Goldring JJ, Wedzicha JA. Influence of season on exacerbation characteristics in patients with COPD. Chest. 2012;141(1):94-100.

6. Jenkins $C R$, Celli B, Anderson JA, et al. Seasonality and determinants of moderate and severe COPD exacerbations in the TORCH study. Eur Respir J. 2012;39(1):38-45.

7. Rabe KF, Fabbri LM, Vogelmeier C, et al. Seasonal distribution of COPD exacerbations in the prevention of exacerbations with tiotropium in COPD trial. Chest. 2013;143(3):711-719.

8. Song Q, Christiani DC, XiaorongWang, Ren J. The global contribution of outdoor air pollution to the incidence, prevalence, mortality and hospital admission for chronic obstructive pulmonary disease: a systematic review and meta-analysis. Int J Environ Res Public Health. 2014;11(11):1182211832.

9. Hansel NN, McCormack MC, Kim V. The Effects of Air Pollution and Temperature on COPD. COPD J Chronic Obstr Pulm Dis. 2015;2555(January):1-8.

10. Ni L, Chuang C-C, Zuo L. Fine particulate matter in acute exacerbation of COPD. Front Physiol. 2015;6(October):1-10.

11. Wilkinson TM, Donaldson GC, Hurst JR, Seemungal TA, Wedzicha JA. Early therapy improves outcomes of exacerbations of chronic obstructive pulmonary disease. Am J Respir Crit Care Med. 2004;169(12):1298-1303.

12. Facchiano L, Snyder $\mathrm{CH}$, Núñez DE. A literature review on breathing retraining as a selfmanagement strategy operationalized through Rosswurm and Larrabee's evidence-based practice model. J Am Acad Nurse Pract. 2011;23(8):421-426.

13. Hill K, Patman S, Brooks D. Effect of airway clearance techniques in patients experiencing an acute exacerbation of chronic obstructive pulmonary disease: a systematic review. Chron Respir Dis. 2010;7:9-17.

14. Aaron SD. Management and prevention of exacerbations of COPD. BMJ. 2014;349(2):g5237. doi:10.1136/bmj.g5237.

15. Bourbeau J, Nault D. Self-Management Strategies in Chronic Obstructive Pulmonary Disease. Clin Chest Med. 2007;28(3):617-628.

16. Disler RT, Gallagher RD, Davidson PM. Factors influencing self-management in chronic obstructive pulmonary disease: An integrative review. Int J Nurs Stud. 2012;49(2):230-242.

17. TrappenburgJCA, Monninkhof EM, Bourbeau J, et al. Effect of an action plan with ongoing support by a case manager on exacerbation-related outcome in patients with COPD: a multicentre randomised controlled trial. Thorax. 2011;66(11):977-984.

18. Zwerink M, Kerstjens HAM, Van Der Palen J, et al. (Cost-)effectiveness of self-treatment of exacerbations in patients with COPD: 2 years follow-up of a RCT. Respirology. 2016;21(3):497503. 
19. Hurst JR, Wedzicha JA. Management and prevention of chronic obstructive pulmonary disease exacerbations: a state of the art review. BMC Med. 2009;7:40.

20. Eisner MD, Blanc PD, Yelin EH, et al. Influence of anxiety on health outcomes in COPD. Thorax. 2010;65(3):229-234.

21. Harrison SL, Goldstein R, Desveaux L, Tulloch V, Brooks D. Optimizing nonpharmacological management following an acute exacerbation of chronic obstructive pulmonary disease. Int J Chron Obstruct Pulmon Dis. 2014;9:1197-1205.

22. Hurst JR, Donaldson GC, Quint JK, Goldring JJP, Baghai-Ravary R, Wedzicha JA. Temporal clustering of exacerbations in chronic obstructive pulmonary disease. Am J Respir Crit Care Med. 2009;179(5):369-374.

23. Spruit MA, Pitta F, McAuley E, ZuWallack RL, Nici L. Pulmonary rehabilitation and physical activity in patients with chronic obstructive pulmonary disease. Am J Respir Crit Care Med. 2015;192(8):924-933.

24. Puhan MA, Gimeno-Santos E, Scharplatz M, Troosters T, Walters EH, Steurer J. Pulmonary rehabilitation following exacerbations of chronic obstructive pulmonary disease. Cochrane database Syst Rev. 2011;5(10). 


\section{Appendix 2}

\section{Topic list face validity round}

Reflection on conceptual model (without potential relevant self-management behaviors)

- Do you recognize this pattern in the COPD course and subdivision in phases?

- For each phase:

- What are relevant behaviors to reduce the impact of exacerbations in your opinion (for each phase of the conceptual model)?

-What is the association between these behaviors and reduction of impact of exacerbations?

- Which behaviors are most important to reduce the impact of exacerbations in your opinion?

Reflection on conceptual model with potential relevant self-management behaviors

- Do you recognize these self-management behaviors as being relevant to reduce the impact of exacerbations (for each phase of the conceptual model)?

- Which behaviors are most important in your opinion (to reduce the impact of exacerbations)?

- Are there any self-management behaviors missing in your opinion? 


\section{Appendix 3}

\section{Example question Delphi survey 1}

\section{Influenza vaccination uptake}

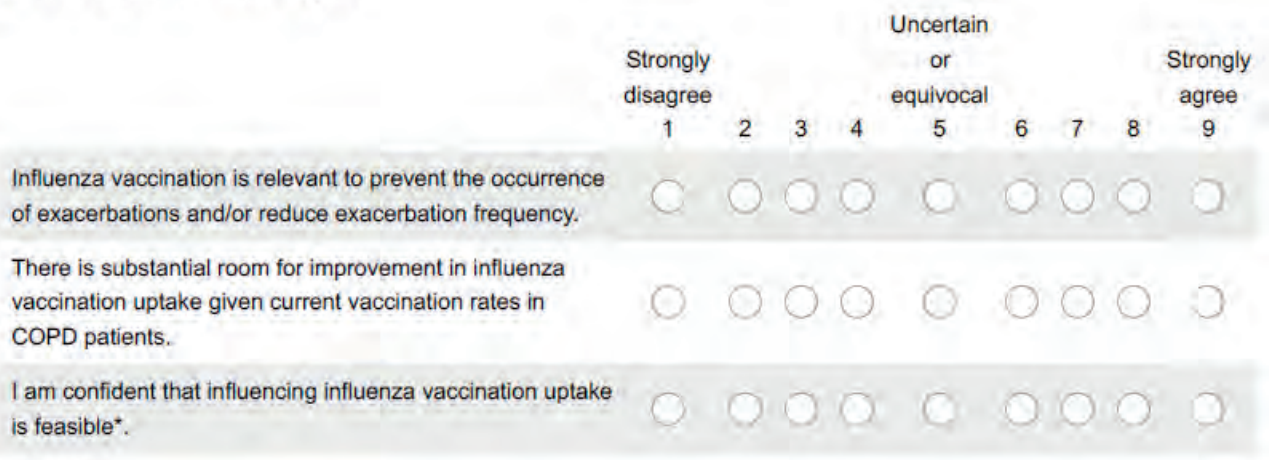

*Feasible: Potentially successful by balancing efforts/barriers versus benefits.

\section{Example question Delphi survey 2}

\section{2) Performing breathing exercises (i.e. dyspnea regulation and/or mucus clearance techniques)}

Statement 1: Breathing exercises are relevant to reduce symptoms and/or prevent further deterioration.

Panel feedback:

'I am unimpressed by strength of evidence'

'Little is known about the individual need for breathing exercises. It is certainly not for all patients'

'Whereas the use of breathing exercises will lead to symptom relieve, it will not (directly) influence further deterioration of the exacerbation:

Median $=5.5 /$ IQR $=2.25$
\begin{tabular}{|c|cc|c|c|c|c|}
\hline 1 & 2 & 3 & 4 & 5 & 6 & 7 \\
\hline
\end{tabular}

Please rate your level of agreement on the statement:

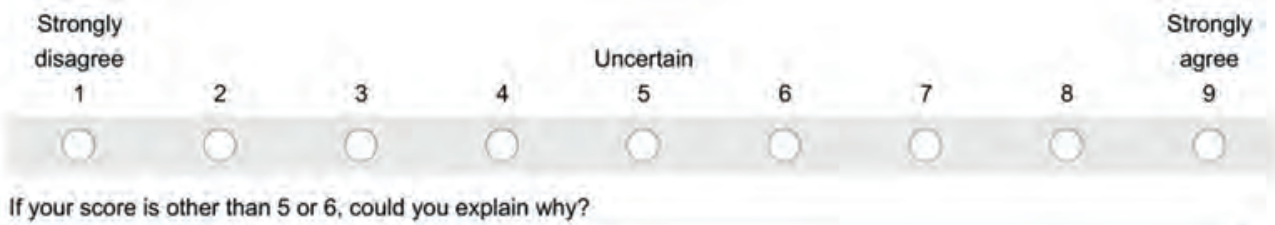




\section{Specification of self-management behaviors assessed in Delphi rounds}

- Adherence (fixed dose \& proper technique) to pharmacotherapy (Long-acting bronchodilators LABA/LAMA and/or inhaled corticosteroids ICS)

- Influenza vaccination uptake

- Daily physical activity

- Avoiding viral or bacterial stimuli (hand hygiene and/or avoiding contact with people with a cold)

- Managing exposure to air quality (air pollution/temperature/humidity)

- Quitting smoking or cutting down smoking

- Early detection of symptom deterioration

- Correct increase of short-acting bronchodilators (SABA)

- Performing breathing exercises (e.g. dyspnea regulation and/or mucus clearance techniques)

- Performing energy conservation techniques (e.g. prioritizing activities and managing energy conservation for physical activity)

- Early detection of an exacerbation

- Prompt treatment with a course of corticosteroids and/or antibiotics

- Self-treatment

- Contact with a healthcare provider for treatment

- Manage stress and anxiety (by using relaxation techniques)

- Completing treatment of antibiotics and/or corticosteroids

- Manage stress and anxiety (concerning current event)

- Adjusted exercise- and resistance training

- Increased awareness for a recurrent exacerbation

- Early (re)start of pulmonary rehabilitation

- New behavior that was added after round 1: Managing exposure to indoor air quality 
Self-management behaviors to reduce exacerbation impact 


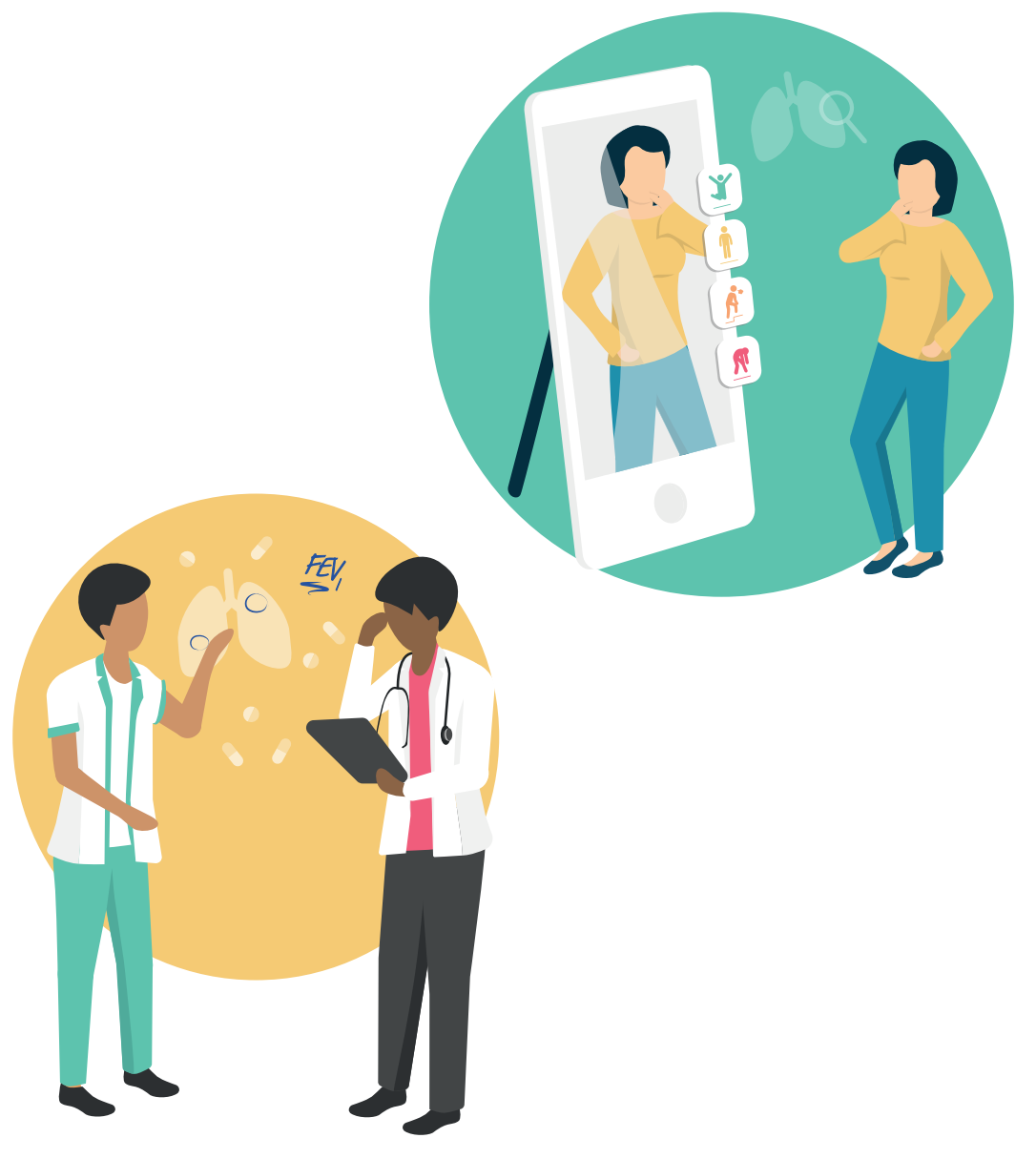




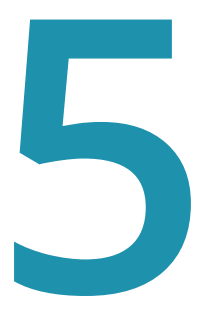

\section{Perceptions of patients with chronic obstructive pulmonary disease and their health care providers towards using mHealth for self-management of exacerbations: a qualitative study}

Yvonne JG Korpershoek, Sigrid CJM Vervoort, Jaap CA Trappenburg, Marieke J Schuurmans 


\section{Abstract}

Background: Self-management of exacerbations in COPD patients is important to reduce exacerbation impact. There is a need for more comprehensive and individualized interventions to improve exacerbation-related self-management behavior. The use of mobile health technology (mHealth) could help to achieve a wide variety of behavioral goals. Understanding of patients and health care providers perspectives towards using mHealth in promoting self-management will greatly enhance the development of solutions with optimal usability and feasibility. Therefore, the aim of this study was to explore perceptions of COPD patients and their health care providers towards using mHealth for self-management of exacerbations.

Methods: A qualitative study using focus group interviews with COPD patients $(n=13)$ and health care providers (HCPs) $(n=6)$ was performed to explore perceptions towards using mHealth to support exacerbation-related self-management. Data were analyzed by a thematic analysis.

Results: COPD patients and HCPs perceived mostly similar benefits and barriers of using mHealth for exacerbation-related self-management. These perceived benefits and barriers seem to be important drivers in the willingness to use mHealth. Both patients and HCPs strengthen the need for a multi-component and tailored mHealth intervention that improves patients' exacerbation-related self-management by determining their health status and providing adequate information, decision support and feedback on self-management behavior. Most importantly, patients and HCPs considered an mHealth intervention as support to improve self-management and emphasized that it should never replace patients' own feelings nor undermine their own decisions. In addition, the intervention should be complementary to regular contact with HCPs, as personal contact with a HCP was considered to be very important. To optimize engagement with mHealth, patients should have a positive attitude toward using mHealth and an mHealth intervention should be attractive, rewarding and safe.

Conclusion: This study provided insight into perceptions of COPD patients and their HCPs towards using mHealth for self-management of exacerbations. This study points out that future mHealth interventions should focus on developing selfmanagement skills over time by providing adequate information, decision support and feedback on self-management behavior and that mHealth should complement regular care. To optimize engagement, mHealth interventions should be attractive, rewarding, safe and tailored to the patient needs. 


\section{Introduction}

Chronic Obstructive Pulmonary Disease (COPD) is a highly prevalent chronic disease worldwide and is associated with a significant burden on both patients and society. ${ }^{1,2}$ The natural course of COPD is interrupted by exacerbations, defined as 'a sustained worsening of patients' respiratory symptoms, which are beyond normal day-to-day variability and may warrant medical treatment'. ${ }^{3}$ These exacerbations are associated with decline in lung function and quality of life, ${ }^{4-6}$ increased mortality, ${ }^{7}$ and increased healthcare use. ${ }^{8}$

The absence of an adequate imminent exacerbation marker requires to focus on supporting COPD patients in developing self-management skills to be able to adequately detect exacerbations and to take prompt actions and thereby reduce the impact of exacerbations. ${ }^{9,10} \mathrm{~A}$ recent Cochrane review shows that selfmanagement interventions including exacerbation action plans, are associated with improvements in quality of life and lower probability of hospital admissions. ${ }^{11}$ By focusing on exacerbations more specifically, another recent Cochrane review shows that solely exacerbation action plans also reduce in-hospital health care utilization and increase exacerbation treatment. ${ }^{12}$ However, a more detailed view on these aggregated results shows that still a substantial proportion of COPD patients barely benefits from these kind of interventions. This might be explained by the 'one size fits all' and static approach regarding design, intensity and mode of delivery, the sole focus on exacerbation detection and taking action and suboptimal use of interventions. ${ }^{12-14}$

To further reduce the impact of exacerbations, a more comprehensive, dynamic and individualized strategy is needed that improves the full spectrum of exacerbationrelated self-management behavior. ${ }^{11,14,15}$ Since previous studies have shown that self-management interventions only improve patient outcomes when changing self-management behavior of COPD patients, ${ }^{16,17}$ it is important that COPD selfmanagement interventions aim at motivating, engaging and supporting patients to positively adapt their behaviors. ${ }^{15}$ To address this complex challenge, the use of mobile health (mHealth) might be a solution..$^{18,19}$ In the past decade, research has increasingly focused on using mobile technology for self-management purposes in chronic lung diseases. ${ }^{20,21}$ Through mHealth, several accessible and essential real-time elements can be added to current static self-management support enlarging the intensity and set of options in communication, monitoring and delivery of therapeutic solutions and allowing delivery of self-management support when and where needed. Furthermore, mHealth creates opportunities 
to include effective behavior change techniques to enhance patient motivation for self-management, for example by monitoring the behavior and providing feedback and rewards. ${ }^{18}$ By using mHealth, self-management support could be more individualized and more dynamic and intensive therapeutic stimuli can be provided that fit current health status. To allow development of effective mHealth interventions and optimize engagement with these interventions, the patient's needs and current healthcare context should be thoroughly investigated during the intervention development stage. ${ }^{18,22,23}$ Furthermore, a deep understanding of both patients and health care providers perspectives towards using mHealth for exacerbation-related self-management will greatly enhance developing solutions with optimal usability and feasibility. ${ }^{24}$ Although mHealth technology is of growing interest in health care, patient and health care provider perspectives towards using mHealth for self-management are relatively unexplored. Little is known about COPD patients and health care providers willingness to use mHealth for self-management of exacerbations, their perceptions towards potential benefits and barriers of using mHealth and their preferences regarding potential content of mHealth interventions.

The main aim of the study was to explore perceptions of COPD patients and their health care providers towards using mHealth for self-management of exacerbations. More specific, the objectives were to:

- Explore both COPD patients and health care providers willingness to use mHealth for self- management of exacerbations.

- Identify potential benefits and barriers of using mHealth for self-management of exacerbations.

- Explore needs and preferences of both COPD patients and health care providers regarding content of an mHealth intervention for self-management of exacerbations.

\section{Methods}

\section{Study design}

A qualitative study using focus group interviews with COPD patients and health care providers was performed to elicit ideas, thoughts and perceptions towards using mHealth to support exacerbation-related self-management. ${ }^{25}$ Focus groups interviews were considered to be relevant since interaction between participants may lead to mutual understandings and ideas towards using mHealth. ${ }^{26}$ This 
study was approved by the Medical Ethics Research Committee of the University Medical Centre Utrecht (15-134/C).

\section{Study population}

A purposive sample of Dutch patients with a clinical diagnosis of COPD, who had experienced at least one exacerbation in the last twelve months, was selected from two general practices, two physiotherapy practices and one hospital in the region of Utrecht. Patients had to meet the inclusion- and exclusion criteria as described in Table 1. Maximum variation sampling was used to create a large diversity in patients' age, sex, COPD severity and mobile device skills, aiming to increase the likelihood of reflecting different perspectives in the findings. Furthermore, a purposive sample of health care providers (HCPs) was selected according to the inclusion- and exclusion criteria as described in Table 1. Diversity in professional disciplines, years of experience in COPD care and age was pursued using maximum variation sampling.

Table 1. Inclusion and exclusion criteria

\section{Participants}

Patients with a clinical diagnosis of COPD

\begin{tabular}{ll}
\hline Inclusion & Exclusion \\
\hline - Age $>40$ years & - Severe problems with vision or hearing \\
- FEV1/FVC ratio $<70 \%$ & - Diagnosed with cognitive impairments \\
- GOLD stage $\geq 2$, Spirometry FEV1<80\% & Primary diagnosis of asthma, cardiac disease \\
predicted & or other major functionally limiting diseases \\
- $\geq 1$ exacerbation in the last 12 months prior to & $\cdot$ Life expectancy $\leq$ three months \\
entering this study (to ensure adequate recall & \\
of their experience of an exacerbation). & \\
\hline
\end{tabular}

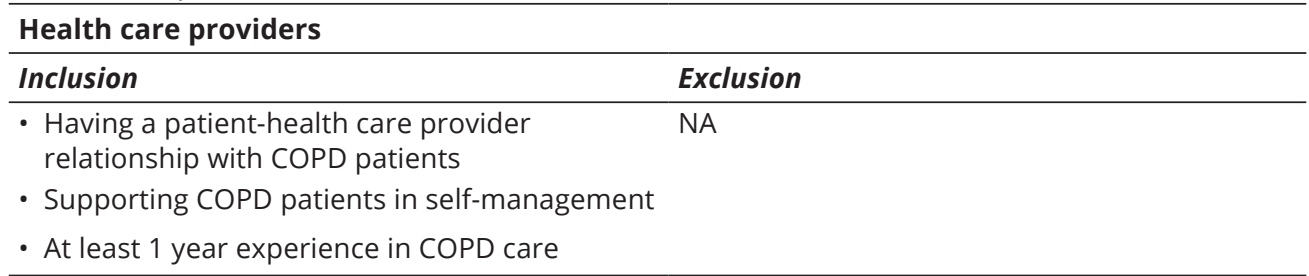

Notes: aAn exacerbation was defined as a period of symptom deterioration in which use of a course of corticosteroids and/or antibiotics was required or hospitalization was necessary; Clinical diagnosis was based on data from Global Initiative for Chronic Obstructive Pulmonary Disease. ${ }^{1}$

Abbreviations: NA = not applicable; GOLD, Global Initiative for Chronic Obstructive Lung Disease; $\mathrm{FEV}_{1}$, forced expiratory volume in $1 \mathrm{~s}$; FVC, forced vital capacity 


\section{Recruitment and informed consent}

Patients were informed about the study by their HCP and received written study information. A patient willing to participate, was contacted by the researcher to provide further information and to verify willingness to participate in the study. Two patients were approached for this study during their participation in a previous study focusing on perceptions towards exacerbation-related selfmanagement, ${ }^{27}$ and one patient was informed about the study by the Dutch patient society for lung disease. HCPs were informed about the study by the researcher (YK) by email and received written study information attached. Their willingness to participate in the study was coordinated by email. Written informed consent was obtained from all participants. Three focus groups were conducted between June 2015 and May 2016.

\section{Data collection}

Focus group interviews ( $n=6-8$ ) were performed using a topic list for formulating open questions. ${ }^{26}$ After a general introduction of the focus group aim, procedure and explanation of important terminology used in the focus group, the following broad topics were discussed in all focus groups investigating both patient and HCP perspectives: Experience with mobile devices (patients) or mHealth interventions (HCPs), patient needs towards exacerbation-related self-management support, perceptions towards use of mHealth for self-management of exacerbations (potential benefits and barriers), preferences regarding content of an mHealth intervention. After asking participants about their preferences regarding potential content in an open manner, the following predetermined topics were discussed: self-monitoring of symptoms, access to data by a HCP and contact with a HCP, feedback on behavior, education, decision making and reminders. In the focus group with patients specific emphasis was placed on their needs regarding self-management support. Contrastingly, the focus group with HCPs focused specifically on perspectives towards their own role in supporting patients' selfmanagement using mHealth. Both topic lists are detailed in Appendix 1.

All focus group interviews were conducted by an experienced moderator not part of our research team. In total, two independent moderators were involved in this study. Their role was to introduce the topics, encourage participants to share their thoughts, ask additional questions to clarify participants' expressions. Furthermore, assistant moderators were present at each focus group to coordinate practical issues and one of more secretaries were present to describe group interactions, reflect on methodological issues and capture initial ideas on themes in memos. 
The focus groups were held at the University Medical Center of Utrecht and each focus group lasted approximately two hours. All interviews were audiotaped. Baseline characteristics of participants were gathered after the focus group interview by a short questionnaire. All data were encoded to guarantee anonymity. To increase methodological quality of the study, an expert on qualitative research with a nursing background was involved in the process of data collection and data analysis (SV).

\section{Data analysis}

Data were analyzed according to a thematic analysis as described by Braun\&Clarke, to identify, analyse and report themes within the data. ${ }^{28}$ Data were analyzed by two independent researchers (YK\&SV). After the focus group interviews, initial ideas were captured in memos by the researcher (YK). All interviews were transcribed verbatim. Data analysis was supported by NVivo 10.0 software (QSR International Pty Ltd. Version 10, 2012).

Firstly, the two researchers read the transcripts in its entirety to get an overall picture and summarized information obtained with regard to the research objectives. Secondly, the interviews were reread in more detail, initial codes were connected to meaningful paragraphs by both researchers and discussed afterwards to reach consensus. Third, identified codes were brought under potential themes and, subsequently, reviewed for correspondence to the coded paragraphs. Finally, potential themes were further defined and clear definitions were generated. ${ }^{28}$ The process of analysis was supported by memo-writing.

Credibility of the study was enhanced by emphasizing the aim to learn from participants and an open, nonjudgmental attitude of the moderator during the focus group. Furthermore, discussions with two experts on the interpretation of data (JT\&MS) contributed to the study's credibility. ${ }^{29}$ Transcription of the focus group interviews and researcher triangulation in all phases of the study diminished chances to bias.

\section{Results}

A total of $n=13$ COPD patients ( 4 male and 9 female) and $n=6$ HCPs ( 4 male and 2 female) participated in the study. Baseline characteristics of the participants are presented in Tables 2 and 3. Maximum variation in COPD patients was reached in disease severity, age, sex and mobile technology use. Self-reported exacerbations 
ranged from less than one until 5 self-reported exacerbations per year (Table 2). The focus group with health care providers consisted of nurses, a general practitioner, a resident in pulmonology and a respiratory physiotherapist. Their age varied widely as well as their experience in COPD care (Table 3). The results of the focus group interviews are described in the following paragraphs and further illustrated by quotes of the participants in Tables 4 and 5 (Q references in the text refer to quotes of specific themes in Tables 4 and 5).

Table 2. Baseline characteristics of patients

\begin{tabular}{|c|c|c|c|c|c|c|c|}
\hline ID & $\begin{array}{l}\text { Age } \\
\text { range }\end{array}$ & Living situation & $\begin{array}{l}\text { Education } \\
\text { level }^{a}\end{array}$ & Smoking & $\begin{array}{l}\text { GOLD } \\
\text { stage }^{\text {b }}\end{array}$ & $\begin{array}{l}\text { Exacer- } \\
\text { bations } \\
\text { /yearc }\end{array}$ & $\begin{array}{l}\text { Mobile } \\
\text { technology use }\end{array}$ \\
\hline P01 & $50-59$ & With life partner & High & Former & $2 / 3^{d}$ & 3 & $\begin{array}{l}\text { Smartphone \& } \\
\text { tablet }\end{array}$ \\
\hline P02 & $50-59$ & With life partner & Low & Former & 2 & 5 & $\begin{array}{l}\text { Smartphone \& } \\
\text { tablet }\end{array}$ \\
\hline P03 & $50-59$ & - & - & - & $2 / 3$ & - & $\begin{array}{l}\text { Smartphone \& } \\
\text { tablet }\end{array}$ \\
\hline P04 & $60-69$ & With life partner & Low & Former & 4 & 3 & Tablet \\
\hline P05 & $60-69$ & Alone & High & Current & 4 & $<1$ & $\begin{array}{l}\text { Smartphone \& } \\
\text { tablet }\end{array}$ \\
\hline P06 & $60-69$ & With life partner & High & Former & 3 & $>3$ & None \\
\hline P07 & $70-79$ & Alone & High & Former & 2 & 2 & Tablet \\
\hline P08 & $80-89$ & With life partner & Medium & Former & 2 & 3 & None \\
\hline P09 & $50-59$ & With life partner & Medium & Former & 4 & 3 & $\begin{array}{l}\text { Smartphone \& } \\
\text { tablet }\end{array}$ \\
\hline P10 & $60-69$ & With children & High & Former & 3 & 1 & $\begin{array}{l}\text { Smartphone \& } \\
\text { tablet }\end{array}$ \\
\hline P11 & $60-69$ & With life partner & High & Former & 4 & $>3$ & Tablet \\
\hline P12 & $40-49$ & With life partner & Medium & Former & 3 & 3 & Tablet \\
\hline P13 & $70-79$ & With life partner & Low & Former & 2 & - & None \\
\hline
\end{tabular}

Notes: ${ }^{a}$ Low=primary school through vocational training, medium=secondary school or vocational training, high=college or university degree; baccording to GOLD classification in medical chart; camount of exacerbations determined by amount of prescriptions of corticosteriods and/or antibiotics for worsening of lung symptoms, estimated by patients themselves; ${ }^{d}$ patient self-reported GOLD stage; - = missing data.

Abbreviation: GOLD, Global Initiative for Chronic Obstructive Lung Disease. 
Table 3. Baseline characteristics of health care providers

\begin{tabular}{|c|c|c|c|c|c|c|}
\hline ID & $\begin{array}{l}\text { Age } \\
\text { range }\end{array}$ & Profession & Setting & $\begin{array}{l}\text { Work } \\
\text { experience } \\
\text { in years } \\
\text { ranges }\end{array}$ & $\begin{array}{l}\text { Patient GOLD } \\
\text { category most } \\
\text { frequently } \\
\text { cared for }^{\mathrm{a}}\end{array}$ & $\begin{array}{l}\text { mHealth } \\
\text { experience in } \\
\text { daily pratice }\end{array}$ \\
\hline H01 & $20-29$ & $\begin{array}{l}\text { Respiratory } \\
\text { nurse }\end{array}$ & Hospital & $0-5$ & $2-3 / 3-4$ & None \\
\hline H02 & $20-29$ & $\begin{array}{l}\text { Nurse at lung } \\
\text { department }\end{array}$ & Hospital & $0-5$ & $3-4$ & None \\
\hline H03 & $40-49$ & $\begin{array}{l}\text { Respiratory } \\
\text { nurse specialist }\end{array}$ & Hospital & $16-20$ & $3-4$ & Yes \\
\hline HO4 & $30-39$ & $\begin{array}{l}\text { Resident in } \\
\text { pulmonology }\end{array}$ & Hospital & $6-10$ & $3-4$ & None \\
\hline H05 & $30-39$ & $\begin{array}{l}\text { Respiratory } \\
\text { physiotherapist }\end{array}$ & $\begin{array}{l}\text { Physiotherapy } \\
\text { practice }\end{array}$ & $11-15$ & $2-3 / 3-4$ & None \\
\hline H06 & $50-59$ & $\begin{array}{l}\text { General } \\
\text { practitioner }\end{array}$ & $\begin{array}{l}\text { General } \\
\text { practice }\end{array}$ & $21-25$ & $1-2 / 2-3$ & None \\
\hline
\end{tabular}

Notes: ${ }^{a}$ classified by GOLD stage 1-2, 2-3 and/or 3-4.

Abbreviation: GOLD, Global Initiative for Chronic Obstructive Lung Disease.

\section{Experience with mobile technology}

Mobile technology use was introduced as either smartphone or tablet use. Some patients not using these mobile devices did use a computer or laptop and were encouraged to think about opportunities to support self-management through these devices. Most common purposes of mobile technology use by patients were: phoning, social media, seeking information on the internet, application use, messaging and gaming. Mobile technology was barely used for health purposes. Two patients had some experience with health applications by participating in previous eHealth research. According to patients, most common advantages of mobile technology use were the low threshold to use mobile technology and opportunities for social networking. Experienced disadvantages were: privacy sensitiveness and limited usability since mobile devices are too small to navigate properly. Although most patients were currently using mobile devices, some patients did not have a mobile device. Reasons not to use mobile devices were: no interest in mobile technology, poor digital skills and high costs. By asking HCP's about their experience with mobile technology in health care, only one HCP mentioned to have experience with health applications in daily practice.

\section{Patient needs toward exacerbation-related self-management support}

Before focusing on patient and HCP perspectives towards using mobile technology for exacerbation-related self-management, they were both asked about patient needs toward self-management support. Based on both patient 
and HCP responses, patient needs varied largely per individual. Although some patients mentioned that they had adequate skills for exacerbation-related selfmanagement, a substantial part mentioned having difficulties with exacerbation detection and taking prompt action. One of the most important needs, according to both patients and HCPs, was that patients are properly heard by their HCP and receive adequate support from their HCP (Q1\&2). Having a good relationship with HCPs was considered to be important for the decision process to perform selfmanagement actions. With regard to early exacerbation detection specifically, patients explained a need for tools to substantiate their current health status (Q3). Furthermore, adequate information regarding self-management actions and social support were considered to be important to reduce patients insecurity regarding self-management actions (Q4\&5). Finally, patients indicated a need for elimination of barriers in the health care system to reduce the threshold to contact a HCP since they are not always allowed to communicate with their HCP immediately (Q6).

\section{Potential benefits and barriers of using Mhealth for exacerbation- related self-management}

\section{Benefits}

By asking patients about their perspectives towards using mHealth for exacerbation related self-management, several potential benefits were mentioned. Most importantly, patients thought that mHealth could contribute to awareness of symptom deterioration and explaining possible causes (Q7). In their opinion, mHealth could contribute to demonstrating and underpinning of their current health status, which could increase patients' self-empowerment towards communication with HCPs and achieve that they feel to be heard (Q8). Furthermore, some patients felt that using mHealth could support them in taking adequate actions by reminding them of these actions and thereby eliminating feelings of insecurity and reducing the threshold to contact an HCP (Q9\&10). Some patients thought that recently diagnosed patients would benefit most from an mHealth intervention, since they had realized that they had a lack of information at the early stage of their disease. HCPs perspectives towards potential benefits are largely in line with the patients perspectives.

\section{Barriers}

Potential barriers to use mHealth, according to both patients and HCPs, were patients avoiding confrontation with the disease (Q11), preference for personal contact with an HCP (Q12), difficulties with displaying feelings in an application leading to invalid patient measures and lack of trust in advising characteristics of an mHealth intervention (Q13\&14). Additionally, already having adequate self- 
management skills and lack of enthusiasm for mHealth by HCPs, were mentioned as barriers according to patients (Q15\&16). Furthermore, an important potential barrier according to HCPs was a potential limited group of eligible patients (Q17). HCPs explained having doubts regarding eligibility based on disease severity, limited health skills and a lack of patient motivation and enthusiasm for selfmanagement as well as for using mHealth.

The HCPs had various perspectives regarding the influence of mHealth on health care contact. In line with the patients perspective, some HCPs were convinced that mHealth could stimulate prompt health care contact, whereas others thought that advising patients through mHealth could lead to postponing health care contact, as it could result in patients seeking information on self-management actions too long themselves (Q18).

Table 4. Illustrative quotes related to patient needs and benefits and barriers of using mHealth for self-management.

\begin{tabular}{|c|c|c|}
\hline Theme & Quote & \\
\hline \multicolumn{3}{|c|}{ Patient needs toward self-management support } \\
\hline $\begin{array}{l}\text { Being heard } \\
\text { by a HCP }\end{array}$ & Q1 & $\begin{array}{l}\text { P02: "The doctor said 'There's nothing I can do for you because you have } \\
\text { the flue' [...\} as result that I became really ill. [...] Yes, I always get really } \\
\text { emotional when I'm not being heard. It's really important that you are } \\
\text { being heard." } \\
\text { H06: "Because for the patient, I believe being heard is what's needed the } \\
\text { most." }\end{array}$ \\
\hline $\begin{array}{l}\text { Adequate } \\
\text { support from } \\
\text { a HCP }\end{array}$ & Q2 & $\begin{array}{l}\text { P04: "It was so bad that I called the pulmonary nurse at the hospital on } \\
\text { Friday. She said 'Yes, Madam, the flue is going around, so just take some } \\
\text { extra inhalations' and that's how I entered my weekend. I can't believe I } \\
\text { agreed with it. Then in the afternoon I called my own pulmonary nurse, } \\
\text { she's always really helpful. She immediately sent the prescription for } \\
\text { antibiotics to the pharmacy, but it was actually too late and I ended up in } \\
\text { hospital." } \\
\text { H05: "Patients really appreciate a little extra support. If you tell them that } \\
\text { it's all right to call and ask for help, they will do that much more easily." }\end{array}$ \\
\hline $\begin{array}{l}\text { Tools to } \\
\text { substantiate } \\
\text { health status }\end{array}$ & Q3 & $\begin{array}{l}\text { P11: "When it's really bad you can feel it. But most of the time it just grows } \\
\text { consistently. It would be really nice if earlier on I would feel it, so I can tell } \\
\text { myself to be careful. Then it would be possible to adjust my behavior, my } \\
\text { energy and based on those two, my medication." }\end{array}$ \\
\hline $\begin{array}{l}\text { Information } \\
\text { on actions }\end{array}$ & Q4 & $\begin{array}{l}\text { P01: "At the time, I thought it wasn't too bad. Well it actually is bad } \\
\text { nowadays. Back then I should have known what to do. [...] I wish I would } \\
\text { have had the information at that time about how I could recognize that I } \\
\text { am not doing well [...] how I can manage a threating attack." }\end{array}$ \\
\hline Social support & Q5 & $\begin{array}{l}\text { P12: "I am always late as I just explained. So it's usually my husband who } \\
\text { tells me 'If you don't go now, I will take care of it'. You know, like, then I } \\
\text { will make the call." }\end{array}$ \\
\hline
\end{tabular}


Table 4. (Continued)

\begin{tabular}{ll}
\hline $\begin{array}{l}\text { Elimination } \\
\text { of barriers in }\end{array}$ & Q6 \\
health care & $\begin{array}{l}\text { Pome in', and I tell them that I'm too short of breath and they tell me: 'We } \\
\text { system }\end{array}$ \\
$\begin{array}{l}\text { understand, but we can't just give you medication, so you have to come } \\
\text { in and see the doctor.' That's the point that I give up and tell them to } \\
\text { 'never mind' and I just hang up the phone. [...] Well it's just not possible to } \\
\text { directly see a pulmonologist, is it?" }\end{array}$ \\
\hline
\end{tabular}

\section{Benefits of using mHealth for self-management}

Contributes Q7 P07: "I would be willing to fill out a questionnaire but only so that I can get to awareness more insight into what it actually is that I have. [...] It would be a nice tool of symptom deterioration to help you point out what you feel. It would be like 'I feel like this' but also 'this could be the source of your problem' so what you should do is take some extra puffs, something like that."

H02: "Early detection of an exacerbation, that the app could help the patients find out if that is what is happing. That it would be possible for the patients to insert information on symptoms into the app every time they experience upcoming symptoms. So that the app can be supportive in detecting an exacerbation."

\begin{tabular}{|c|c|c|}
\hline $\begin{array}{l}\text { Demonstrate } \\
\text { and underpin } \\
\text { current health } \\
\text { status }\end{array}$ & Q8 & $\begin{array}{l}\text { P10: "It would help me in convincing the general practitioner, because } \\
\text { then I could support what I feel. Like, 'I feel this, and the app indicates this } \\
\text { as well"' } \\
\text { P01: "So that in that moment I can say, 'Listen, I've kept track of my } \\
\text { symptoms and I have COPD. Look, the app is giving me a warning'. Maybe } \\
\text { that would be supportive in being heard." }\end{array}$ \\
\hline $\begin{array}{l}\text { Supports } \\
\text { taking } \\
\text { adequate } \\
\text { actions }\end{array}$ & Q9 & $\begin{array}{l}\text { P08: "When I would be really short of breath and I would feel really bad, } \\
\text { what I would have to do." } \\
\text { H05: "Maybe it would help them in deciding that this is the moment to } \\
\text { take action and stimulate them to do so. The application could reduce the } \\
\text { threshold to take that step." }\end{array}$ \\
\hline $\begin{array}{l}\text { Supports } \\
\text { prompt health } \\
\text { care contact }\end{array}$ & Q10 & $\begin{array}{l}\text { H02: "An app could give an extra sign to patients when they've reached } \\
\text { a point that their symptoms are so bad, they have to call. That could } \\
\text { support patients at times when they feel guilty for calling or asking for } \\
\text { help, because the app said that it was all right to make a call." }\end{array}$ \\
\hline
\end{tabular}

Barriers of using mHealth for self-management

\begin{tabular}{|c|c|c|}
\hline $\begin{array}{l}\text { Avoiding } \\
\text { confrontation } \\
\text { with the } \\
\text { disease }\end{array}$ & Q11 & $\begin{array}{l}\text { P01: "I don't want to be too much confronted with being ill. I'm still } \\
\text { working and I don't know, I just want to be able to do that for as long as } \\
\text { possible. So I don't want to be thinking about being ill all the time." } \\
\text { P07: “On one hand you really want to know and on the other hand you } \\
\text { really don't!" } \\
\text { H01: "They don't want it to rule their day. If it's going well, it's going well." }\end{array}$ \\
\hline $\begin{array}{l}\text { Preference } \\
\text { for personal } \\
\text { contact }\end{array}$ & Q12 & $\begin{array}{l}\text { P12: "Yes, I'm leaning towards } 1 \text { on } 1 \text { contact, I mean personal contact. } \\
\text { That's the most important for me." } \\
\text { P05: “Being heard is necessary while being at the doctor, that's what I } \\
\text { think... An app doesn't support that." }\end{array}$ \\
\hline $\begin{array}{l}\text { Difficulties } \\
\text { with } \\
\text { displaying } \\
\text { feelings in } \\
\text { application }\end{array}$ & Q13 & $\begin{array}{l}\text { P09: "I would fill out a questionnaire but it's a bit black and white in my } \\
\text { opinion [...] How do I feel? Well, I feel 'so so'. How do you explain 'so so'?" } \\
\text { H06: "Yes, how sensitive is it when you ask 'How do you feel today?' H05 } \\
\text { responds: "Indeed, that's the question, how well able is a patient to give it } \\
\text { a rating?" H06: "Yes, in that case you need to have kind of a list, if it has to } \\
\text { be valid..." }\end{array}$ \\
\hline
\end{tabular}


Table 4. (Continued)

\begin{tabular}{|c|c|c|}
\hline $\begin{array}{l}\text { Lack of trust } \\
\text { in advice } \\
\text { through } \\
\text { mHealth }\end{array}$ & Q14 & $\begin{array}{l}\text { P10: "The dangerous thing is that the app can report something } \\
\text { differently than how I'm feeling. In that case, the app prevents me from } \\
\text { taking actions I would now do, that's the downside. I really have the idea } \\
\text { that you are the most capable yourself of feeling how you are doing at a } \\
\text { specific point." } \\
\text { P05: "Well...It would surprise me if an app is capable of advising me what } \\
\text { to do [...] How could an app think for me about what is the right thing to } \\
\text { do at a certain point in time? And whether or not I should take pills or get } \\
\text { a course of medicine...?" }\end{array}$ \\
\hline $\begin{array}{l}\text { Having } \\
\text { adequate self- } \\
\text { management } \\
\text { skills }\end{array}$ & Q15 & $\begin{array}{l}\text { P01: "Well to be honest, I have the feeling that with the knowledge } \\
\text { and support I have now, I'm capable to act in case of a upcoming } \\
\text { exacerbation...So I don't have the feeling that it would help me a lot." }\end{array}$ \\
\hline $\begin{array}{l}\text { Lack of } \\
\text { enthusiasm } \\
\text { for } m \text { Health } \\
\text { by HCPs }\end{array}$ & Q16 & $\begin{array}{l}\text { P02: "Because I have the idea that pulmonologists, and everybody, are } \\
\text { not waiting for it. Their enthusiasm for these things is a rare thing. Let me } \\
\text { put it this way, they're having their hands full already." }\end{array}$ \\
\hline $\begin{array}{l}\text { Not all } \\
\text { patients are } \\
\text { eligible }\end{array}$ & Q17 & $\begin{array}{l}\text { H06: "My great concern would be about who is going to use the app." } \\
\text { H03: "I think that patients with frequent exacerbations just won't use or } \\
\text { even install the app...[...] I had a patient who could not be motivated or be } \\
\text { stimulated at all. So no... that's really hard." }\end{array}$ \\
\hline $\begin{array}{l}\text { Could delay } \\
\text { health care } \\
\text { contact }\end{array}$ & Q18 & $\begin{array}{l}\text { H06: "A patient should not spent time on reading a forum to find out what } \\
\text { other patients with COPD would do." }\end{array}$ \\
\hline
\end{tabular}

Table 5. Illustrative quotes related to preferences regarding an mHealth intervention and facilitators for engagement with mHealth

\begin{tabular}{ll}
\hline Theme Quote & \\
\hline Preferences regarding content of an mHealth intervention \\
\hline $\begin{array}{l}\text { Providing } \\
\text { information }\end{array}$ & $\begin{array}{l}\text { P05: "Well to be specific, I think that the information on symptoms } \\
\text { would be a really good one...Whether your symptoms are severe or not, } \\
\text { or whether it's in an early stage or not. I really think that's what's really } \\
\text { important." }\end{array}$ \\
\hline $\begin{array}{l}\text { Action plan } \\
\text { for decision } \\
\text { support }\end{array}$ & $\begin{array}{l}\text { P11: "Sometimes when you are so short of breath, you forget things } \\
\text { because of that, or you skip a step...and eh...For me, it would be useful } \\
\text { to have the right steps clear for myself or to be able to adjust these } \\
\text { steps for myself, right? That you follow the right steps in case you are } \\
\text { short of breath...What is it? What to do? How to breath? Is there anyone } \\
\text { you should consult? Who to consult? And what kind of medicine?" } \\
\text { H02: "So when the app gives a certain score or something like that, or } \\
\text { you get a specific score over two days, that the app gives you a fitted } \\
\text { advice based on that, like: 'You need to contact your general practitioner } \\
\text { or pulmonary nurse'." }\end{array}$ \\
\hline $\begin{array}{l}\text { P03: "For people who are recently diagnosed with COPD, the reminders } \\
\text { could be useful. They won't have to re-invent things for themselves, like } \\
\text { I had to do." } \\
\text { H02: "Yes, for example, I think of reminders...Maybe for recently } \\
\text { diagnosed patients, for example to use their inhaler or medication." }\end{array}$ \\
\hline
\end{tabular}

(Continued) 
Table 5. (Continued)

\begin{tabular}{|c|c|c|}
\hline $\begin{array}{l}\text { Self-monitoring } \\
\text { of symptoms }\end{array}$ & Q22 & $\begin{array}{l}\text { P01: "To be honest, I don't know if I would use it...[...] With all the } \\
\text { respect, we are talking about some kind of app. I just have my doubts } \\
\text { because I actually want to be confronted with my illness as less as } \\
\text { possible..." } \\
\text { P05: "Well, it depends...on the length of the questionnaire you need to } \\
\text { fill out, that's what I think." } \\
\text { H06: "I think that after a while, a lot of patients just say 'it's going fine or } \\
\text { everything is okay'. And why would you fill out the questionnaire then?" }\end{array}$ \\
\hline $\begin{array}{l}\text { Information } \\
\text { exchange with } \\
\text { HCP }\end{array}$ & Q23 & $\begin{array}{l}\text { P10: "What I don't want is that the app communicates directly with my } \\
\text { caregiver. I want to be able to control that myself. That's a decision I } \\
\text { want to make. So when I think it's important, I believe I should be able } \\
\text { to communicate that. But I want to be the one that can make that } \\
\text { decision to do so." }\end{array}$ \\
\hline
\end{tabular}

Facilitators for engagement with mHealth

\begin{tabular}{|c|c|c|}
\hline $\begin{array}{l}\text { Targeting and } \\
\text { tailoring of } \\
\text { mHealth }\end{array}$ & Q24 & $\begin{array}{l}\text { P01: "I wonder if you shouldn't make a separation in the app for } \\
\text { patients with mild COPD and more severe COPD." } \\
\text { H01: "If so, it needs to be personalized." } \\
\text { H06: "On the other side, it needs to be manageable as well [...] For every } \\
\text { healthcare professional. Maybe I do know of my own patients how the } \\
\text { app has been tailored, but what if my patient comes to see you? You } \\
\text { should be able to directly see what it is about as well." }\end{array}$ \\
\hline Attractiveness & Q25 & $\begin{array}{l}\text { H05: "I think it's important to focus on the essence of the application. In } \\
\text { my opinion, it needs to be small and simple with a very specific goal." } \\
\text { H03: "It needs to be manageable for the patient category. When you } \\
\text { think about the elderly, it could already be difficult with mobile devices. } \\
\text { It shouldn't be too difficult with all kinds of dots and lines. Then I think } \\
\text { that they will stop using the app soon." }\end{array}$ \\
\hline $\begin{array}{l}\text { Positive } \\
\text { confirmation or } \\
\text { rewards }\end{array}$ & Q26 & $\begin{array}{l}\text { P01: "What might stimulate me to use the app, is to insert positive } \\
\text { things, like: 'I am seeing a physiotherapist twice a week, well done!"” } \\
\text { H04: "A reward is the best thing that works of course. [...] A reward } \\
\text { structure, so that when you have filled in things correctly, you will } \\
\text { receive a compliment. [...] People are simple, just something with } \\
\text { illustrations: positive confirmation." }\end{array}$ \\
\hline $\begin{array}{l}\text { Focus on } \\
\text { patients own } \\
\text { decisions }\end{array}$ & Q27 & $\begin{array}{l}\text { P09: "But it's possible to use the app for advice right? You always remain } \\
\text { in control right?" (Moderator asks: 'Would you like to receive an advice } \\
\text { based on the questions you answered?') P10: “Well maybe if it's really } \\
\text { an advice [...] I don't want to have to; I want to be able to make my own } \\
\text { decision to do it yes or no." }\end{array}$ \\
\hline
\end{tabular}

\begin{tabular}{|c|c|c|}
\hline $\begin{array}{l}\text { Having skills } \\
\text { and a positive } \\
\text { attitude }\end{array}$ & Q28 & $\begin{array}{l}\text { H06: "'You need to be open minded." } \\
\text { H03: "I noticed in my own practice (while testing another app) that } \\
\text { half, or maybe more than half, of the patients couldn't deal with it and } \\
\text { were also not willing to use it. The other patients, a smaller group, are } \\
\text { really enthusiastic about it and highly motivated. In that case, it doesn't } \\
\text { matter that much what kind of self-management intervention you offer } \\
\text { from a distance." (Moderator asks:" And what was the reason for that } \\
\text { difference?") "I think it depends on their cognitive skills, how they cope } \\
\text { with their disease." }\end{array}$ \\
\hline
\end{tabular}


Table 5. (Continued)

\begin{tabular}{|c|c|c|}
\hline \multicolumn{3}{|c|}{ HCP perspectives towards their role regarding mHealth use } \\
\hline $\begin{array}{l}\text { Adequate } \\
\text { positioning of } \\
\text { responsibilities }\end{array}$ & Q29 & $\begin{array}{l}\text { H03: "You try to leave it with the patient, but then you notice that it } \\
\text { just doesn't always work that way. And that you yourself need to take a } \\
\text { proactive role to reach out to the patient again" } \\
\text { H04: "It's preferable to give patients more responsibility in their self- } \\
\text { management and that you try to work towards that, so that should } \\
\text { be the aim.[...] That includes making proper arrangements about how } \\
\text { it's going to be when it works out, and of course emphasize that when } \\
\text { things don't work out, they can always count on help." }\end{array}$ \\
\hline $\begin{array}{l}\text { Perceived } \\
\text { control by } \\
\text { increasing } \\
\text { patient } \\
\text { responsibilities }\end{array}$ & Q30 & $\begin{array}{l}\text { H04: "That's rewarding for patients. When you report your symptoms } \\
\text { in the app and it leads to advice and you reach out for help. Then } \\
\text { something happens which makes that you can prevent things. As a } \\
\text { health care provider you can say at the beginning 'Well you're in control. } \\
\text { If you use the app, you can experience the benefits yourself.' And with } \\
\text { that the app becomes more important." }\end{array}$ \\
\hline $\begin{array}{l}\text { Monitoring by } \\
\text { an HCP can be } \\
\text { unsafe }\end{array}$ & Q31 & $\begin{array}{l}\text { H06: "I would think that would be dangerous too. Because, well...I } \\
\text { read my messages every fifteen minutes. If I don't do that for a couple } \\
\text { of hours then I could miss things, you don't want that to happen [...]. } \\
\text { For instance, you insert a really bad value, like you have a fever or } \\
\text { your saturation is low... when patients don't get a call from the nurse } \\
\text { or doctor at that time, they could think 'Well it's probably not that } \\
\text { important."' }\end{array}$ \\
\hline $\begin{array}{l}\text { Time investment } \\
\text { for } H C P\end{array}$ & Q32 & $\begin{array}{l}\text { H02: "I really wonder if as a nurse or primary care nurse you would } \\
\text { really have the time for that. Because when I think about self- } \\
\text { management, it's the patient's responsibility to do something with } \\
\text { the information he or she gets out of the app, instead of the nurse or } \\
\text { somebody else receiving notifications and having to call all the patients." }\end{array}$ \\
\hline $\begin{array}{l}\text { Goal of self- } \\
\text { management }\end{array}$ & Q33 & $\begin{array}{l}\text { H01:' "I really wonder if it's still self-management then..." } \\
\text { H05: "Especially the danger of patients thinking they can have a passive } \\
\text { role and don't have to do anything themselves anymore. That, of } \\
\text { course, does not correspond with the goal of self-management." }\end{array}$ \\
\hline
\end{tabular}

\section{Willingness to use mHealth for exacerbation-related self- management}

Based on the patient and HCP responses, the perceived benefits should outweigh the barriers of using mHealth to be willing to use an mHealth intervention. In general, patients who expressed the most needs towards self-management support and perceived mostly benefits of using mHealth, were most willing to use mHealth. In contrast, patients who expressed that they had enough skills to manage exacerbations themselves were less willing to use mHealth for selfmanagement support, as well as patients who perceive many barriers towards using mHealth or have no interest in using mobile technology at all. Some patients who were not using mobile devices stated that they might be willing to use mHealth when it is helpful in managing their disease and when they would be able to learn how to use mobile devices. 


\section{Preferences regarding content of an mHealth intervention}

Both patients and HCPs brought in a diversity in preferences regarding the content of an mHealth intervention to support self-management behavior and regarding intensity of mHealth use. All patients and HCPs perceived that an mHealth intervention should be a multi-component and tailored tool that improves selfmanagement of exacerbations by determining their health status to adequately detect exacerbations, provides decision support to overcome barriers to take prompt actions and stimulates prompt healthcare contact.

Both HCPs and patients were positive towards providing information regarding COPD and exacerbation-related self-management, an action plan for decision support and reminders for various activities (Q19-21). Both HCPs and patients perceived potential benefits regarding self-monitoring of symptoms over time, to create awareness on symptom deterioration and subsequently support exacerbation recognition. However, some patients and HCPs explained doubts about patient willingness to enter information in an application for selfmonitoring (Q22). Some patients explained that they tried to avoid confrontation with their disease and were therefore not willing to monitor symptoms over time, whereas others were convinced that they could feel best themselves how they are doing and therefore need no self-monitoring tool. Patients mentioned various preferences regarding potential frequency of entering information and corresponding duration.

Some HCPs and patients perceived potential benefits regarding information exchange between patients and HCPs through mobile devices. However, they explained doubts at the same time (Q23). Both patients and HCPs were positive towards a quick link to HCP contact details to support healthcare contact at the moment of symptom deterioration. Most patients expressed that they prefer to make the decision to communicate with their HCP themselves, instead of automatic communication through a mobile device. When talking about information exchange with HCPs, a more in-depth discussion focusing on positioning of the patients and HCPs role regarding mHealth use was elicited, which is described below.

Most importantly, patients and HCPs considered a mHealth intervention as support to improve self-management and emphasized that it should never replace patients' own feelings nor undermine their own decisions. An mHealth intervention should be complementary to regular contact with HCPs, as personal contact with a HCP was considered to be very important for patients, and 
for HCPs as well to be able to make adequate medical decisions. Some HCPs expressed that providing medical advice through mobile devices can be unsafe due to the large heterogeneity in patients and symptoms. These HCPS were convinced that a real life judgement on the patient's health status is necessary to provide adequate medical advice. Based on all focus groups, acceptance of the disease and engagement with mobile device use were considered to be important preconditions for successful outcomes.

\section{Facilitators for engagement with mHealth}

Both patients and HCPs agreed that targeting and tailoring an mHealth intervention is important to optimize engagement with mHealth, although HCPs had their doubts regarding the feasibility of targeting and tailoring (Q24). Some HCPs were equivocal towards the efforts of tailoring an intervention to the patient versus the potential benefits for the patient, as they explained doubts regarding their ability to manage tailored interventions. HCPs emphasized the importance of attractiveness of an mHealth intervention for engagement, meaning that an intervention should be straightforward, not too complex and should include mainly visual information (Q25). Furthermore, both HCPs and patients expressed that receiving positive confirmation or rewards from a mobile device is important. Patients emphasized that an intervention should evoke positive feelings and lead to positive patient outcomes (Q26). All patients emphasized the importance of making their own choices regarding the use of mHealth and that information or feedback should be presented in an advisory manner (Q27). Moreover, an essential precondition from their perspective is that all their HCPs should be familiar with the intervention. In addition, HCPs were convinced that patients should already have some self-management skills and a positive attitude towards using mHealth to optimize engagement with an mHealth intervention (Q28). Finally, safety of an application should be guaranteed at all times.

\section{HCPs perspectives towards their role regarding mHealth use}

HCPs were asked about their perspectives towards their role in supporting selfmanagement using mHealth. They emphasized the importance of adequate positioning of HCPs and patients responsibilities regarding mHealth use (Q29). Most HCPs were critical towards their own role and stated that a pro-active role is needed to achieve positive patient outcomes. Furthermore, most HCPs believe they have a role in estimating patient capabilities to use mHealth for self-management based on patient's motivation, technical- and self-management skills and cognitive level. 
HCPs were asked about potential benefits and barriers regarding patient responsibility toward symptom monitoring and taking action in comparison to monitoring and management by an HCP. One HCP mentioned that increasing patient responsibilities towards managing their disease is preferable and should be a starting point. An important benefit is that it may lead to perceived control on the disease (Q30). However, one HCP mentioned that HCPs have an essential role in judging which actions are appropriate at what time since patients have not enough skills to do that themselves. On the other side, most HCPs were predominantly reluctant regarding symptom monitoring by a HCP. HCPs expressed that monitoring by HCPs could provide a certain feeling of safety by patients which they cannot guarantee. HCPs explained that they will not be able to monitor their patients continuously and were therefore afraid to miss important signals, which might lead to patients who remain waiting until a HCP seeks contact (Q31). Furthermore, patient measures can be invalid, which might result in inadequate (medical) advice and negatively affect patient safety as well. Another barrier for HCPs to monitor patient symptoms through mHealth is the time investment for HCPs (Q32). Finally, HCPs discussed whether it remains self-management support when a HCP is monitoring a patient at home (Q33). Nevertheless, early detection of an exacerbation might be an important potential benefit of symptom monitoring by a HCP.

From the HCPs perspective, an mHealth intervention should be suitable for a wide range of patients and should support them in developing self-management skills over time. The HCPs role should then focus on monitoring how patient self-management skills are developing over time, by discussing patients self-management behavior during consults and providing feedback on self-management skills, leading to future goal setting.

\section{Discussion}

This study provided insight into perceptions of COPD patients and their HCPS towards using mHealth for self-management of exacerbations. This study shows that patients' needs regarding self-management of exacerbations vary widely and that patients and HCPs perceive mostly similar benefits and barriers regarding using mHealth for exacerbation-related self-management. Patient willingness to use mHealth seems to be driven by these perceived benefits and barriers. Both patients and HCPs are generally positive towards a multi-component and tailored mHealth intervention that aims at developing patients' self-management skills over time by providing adequate information, decision support regarding prompt 
actions and feedback on self-management behavior. Although mHealth could support patients in developing self-management skills at home, discussing selfmanagement skills with HCPs in person was considered to be essential for further improvement of these skills.

Several findings of this study were in line with other studies. The patient needs regarding exacerbation-related self-management found in this study correspond with barriers for exacerbation-related self-management that were identified in a previous qualitative study of our research group. ${ }^{27}$ Furthermore, we found in this study that using mHealth will remind patients of having COPD, which can be barrier to use mHealth for those patients who try to avoid confrontation with their disease. Huygens et al. described the disadvantage of being reminded of having a chronic condition as well in their study on patient perceptions regarding eHealth for self-management purposes. ${ }^{30}$ In line with that study, we found that mHealth should complement the care patients receive from their HCPs, that mHealth should not be too complex and that patients should be allowed to make their own choices regarding whether or not they would like to use mHealth. ${ }^{30}$ Moreover, our finding that expected benefits of using mHealth contributes to patient willingness to use mHealth is consistent with the study of Huygens et al. as well. ${ }^{30}$ The willingness to use mHealth has been described as an important determinant of actual system use according to the Technology Acceptance Model (TAM). ${ }^{31}$ Our finding that an mHealth intervention should be straightforward and not too complex, corresponds with the 'ease of use' determinant of the TAM. Finally, the attitude towards using technology is considered to be import for actual system use according to the TAM, which is in line with our finding that a positive attitude of patients was considered to be important for engagement with mHealth.

Recently, the Behavior Change Wheel has become increasingly important in the development of behavior change interventions. ${ }^{32}$ The BCW focuses on identifying relevant intervention functions based on what is understood about the behavior and uses the COM-B (capability, opportunity, motivation and behavior) model. ${ }^{32}$ Based on the COM-B model, patients should be capable and have the opportunity and motivation to perform a behavior to achieve behavior change. ${ }^{32}$ In line with this model, we found that a minimum level of self-management and technological skills and motivation for mHealth was considered to be important for mHealth use and subsequent behavior change. This supports our finding that not all COPD patients will be eligible for mHealth. 
Our findings expand upon prior work by identifying benefits and barriers of using mHealth for exacerbation-related self-management specifically. Our study shows that both patients and HCPs perceived that mHealth could contribute to awareness of symptom deterioration and could help patients in underpinning their current health status, which might increase their self-empowerment and subsequently stimulate prompt health care contact. These are important benefits since previous research has shown that many patients have difficulties with exacerbation detection and taking prompt actions. ${ }^{27,33,34}$ Although multiple benefits of mHealth were expressed by our participants, this study also shows that both patients and HCPs have doubts regarding the validity of patient measures and have limited trust in advising characteristics of an mHealth intervention. Furthermore, while previous research on action plans aiming at stimulating prompt health care contact, have shown positive outcomes, ${ }^{11,12}$ some participants in our study suggested that there might be a chance that an mHealth intervention results in the opposite. By using mHealth a patient might feel more responsible to find out themselves which actions would be adequate to undertake, could result in postponing health care contact as well. Nonetheless, most participants were convinced that an mHealth intervention can be an important stimulus for prompt health care contact.

Moreover, our study provided insight into patient and HCP preferences regarding content of an mHealth intervention. Based on a previous systematic review, a positive attitude regarding symptom monitoring by a HCP could be expected. ${ }^{35}$ However, our study found that both patients and their HCPs have doubts regarding information exchange between patients and HCPs through mobile devices, based on patient and HCP responsibilities towards mHealth use.

\section{Strengths and limitations}

An important strength of this study was our focus on both the patient and healthcare provider perspectives, since both are considered to be very important for intervention development and successful implementation. ${ }^{24}$ Furthermore, our study focused on future mHealth opportunities for self-management support which has stimulated participants to reflect on the opportunities of mHealth for self-management in an open manner and express their own ideas, needs and preferences, which provided important insights for future intervention development. Moreover, the trustworthiness of this study was enhanced by using different techniques. ${ }^{29}$ Independent moderators were involved in the focus group interviews to guarantee unbiased interviewing of participants and researcher triangulation during data analysis enhanced both the credibility and conformability of the interpretation of the data. 
A limitation of this study was the transferability of the results. The panel of HCPs consisted of $6 \mathrm{HCPs}$ with different professions yet lacking an experienced pulmonologist. Most HCP's had no experience with mHealth in daily practice. Including a larger sample of HCPs with more mHealth experience, could have resulted in a more diverse range of HCP perspectives. However, striving for maximum variation in both the HCP and patient panel contributed to the transferability of the results to other HCP's and COPD patients. Furthermore, it should be noted that the average age of the study population of COPD patients might be at the lower limit of the Dutch COPD population. ${ }^{36}$ Since mobile technology use was most common in the lowest age categories and technological skills were considered to be important for mHealth use, it might be argued whether perceptions regarding acceptability of technology could have been different when including more older patients. The results of this study are relevant for other countries, although the specific health care context and socio-economic level in other countries might influence perspectives regarding mHealth use.

\section{Implications for practice and future research}

The findings of this study are important for both health care providers supporting patients in exacerbation-related self-management as well as researchers focusing on the development of mHealth interventions. The knowledge on barriers towards using mHealth for exacerbation-related self-management might help health care providers to anticipate on potential barriers when using mHealth and to understand related patient behaviors.

This study strengthens the need for multi-component and tailored selfmanagement interventions in COPD care. Although evidence on effectiveness of current mHealth interventions is limited, recent studies suggest that mHealth interventions aimed at supporting self-management might improve patient

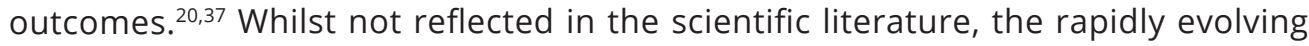
nature of mHealth technologies and their uptake is bound to influence the accessibility and the way we support self-management support in the future, also in patients with COPD. Our study shows that future mHealth interventions should specifically target at developing patients' self-management skills over time by providing adequate information, decision support regarding prompt actions and feedback on self-management behavior. Furthermore, we should ensure that interventions are attractive, rewarding, safe and tailored to the patients' needs and that these interventions are complementary to regular care. It needs to be emphasized that, at least for the coming years, not all COPD patients will be eligible for mHealth especially for those with a more negative attitude towards 
mHealth and with low digital literacy. ${ }^{20}$ Given the current trends in internet access and smartphone use, ${ }^{38}$ also in older populations, this will undoubtedly improve thereafter.

Since usability of mobile devices might depend on the size of devices, it is important that future mHealth interventions can be delivered on a tablet when experiencing problems with navigating on a smartphone. In general, for future development of mHealth interventions it is important to take into account the identified barriers in this study and to meet patient and HCP preferences regarding the content of an intervention. Therefore, both patients and HCPs should be actively involved during the intervention development stage. As self-management requires behavior change, it is important that an $\mathrm{mHealth}$ intervention focuses on effective behavior change techniques selected by a thorough analysis of patient capabilities, opportunities and motivation to use mHealth for self-management. Adequate positioning of HCP and patients responsibilities regarding the use of an mHealth intervention to support self-management is essential before implementing an mHealth intervention into COPD care.

\section{Conclusions}

This study provided insight into perceptions of COPD patients and their HCPS towards using mHealth for self-management of exacerbations. The patients willingness to use mHealth seems to be driven by the perceived benefits and barriers of using mHealth. This study points out that future mHealth interventions should focus on developing self-management skills over time by providing adequate information, decision support and feedback on self-management behavior. To optimize engagement with mHealth, it is important that patients have a positive attitude toward using mHealth and that mHealth interventions are attractive, rewarding, safe and tailored to the patient needs. Although mHealth could support patients in developing self-management skills at home, both patients and health care providers believe that the use of mHealth should be complementary to regular care. Future development of mHealth interventions should focus on selecting effective behavior change techniques and take into account the identified potential barriers toward mHealth use identified by this study. Adequate positioning of the HCP and patients role regarding mHealth use is essential before implementing mHealth interventions into COPD care. 


\section{References}

1. Global Initiative for Chronic Obstructive Lung Disease (GOLD). Global Strategy for the Diagnosis, Management, and Prevention of Chronic Obstructive Pulmonary Disease. [updated 2018]. Available from: https://goldcopd.org/gold-reports/. Accessed September 19, 2018.

2. Mathers CD, Loncar D. Projections of global mortality and burden of disease from 2002 to 2030 . PLoS Med. 2006;3:e442.

3. Rodriguez-Roisin R. Toward a consensus definition for COPD exacerbations. Chest. 2000;117(5 suppl2):398S-401S.

4. Donaldson GC, Seemungal TA, Bhowmik A, Wedzicha JA. Relationship between exacerbation frequency and lung function decline in chronic obstructive pulmonary disease. Thorax. 2002;57(10):847-52.

5. Seemungal TA, Donaldson GC, Paul EA, Bestall JC, Jeffries DJ, Wedzicha JA. Effect of exacerbation on quality of life in patients with chronic obstructive pulmonary disease. Am J Respir Crit Care Med. 1998;157(5 pt 1):1418-22.

6. Miravitlles M, Ferrer M, Pont A, Zalacain R, Alvarez-Sala JL, Masa F, Verea H, Murio C, Ros F, Vidal R, IMPAC Study Group. Effect of exacerbations on quality of life in patients with chronic obstructive pulmonary disease: a 2 year follow up study. Thorax. 2004;59(5):387-95.

7. Soler-Cataluna JJ, Martinez-Garcia MA, Roman Sanchez P, Salcedo E, Navarro M, Ochando R. Severe acute exacerbations and mortality in patients with chronic obstructive pulmonary disease. Thorax. 2005;60(11):925-931.

8. Toy EL, Gallagher KF, Stanley EL, Swensen AR, Duh MS. The economic impact of exacerbations of chronic obstructive pulmonary disease and exacerbation definition: a review. COPD. 2010;7(3):214-228.

9. Zwerink M, Brusse-Keizer M, van der Valk PD, Zielhuis GA, Monninkhof EM, van der Palen J, Frith PA, Effing T. Self management for patients with chronic obstructive pulmonary disease. Cochrane Database Syst Rev. 2014;19(3):CD002990

10. Bourbeau J, van der Palen J. Promoting effective self-management programmes to improve COPD. Eur Respir J. 2009;33(3):461-3.

11. Lenferink A, Brusse-Keizer M, van der Valk PD, Frith PA, Zwerink M, Monninkhof EM, van der Palen J, Effing TW. Self-management interventions including action plans for exacerbations versus usual care in patients with chronic obstructive pulmonary disease. Cochrane Database Syst Rev. 2017;4;8:CD011682

12. Howcroft M, Walters EH, Wood-Baker R, Walters JA. Action plans with brief patient education for exacerbations in chronic obstructive pulmonary disease. Cochrane Database Syst Rev. 2016;19;12:CD005074

13. Trappenburg J, Jonkman N, Jaarsma T, van Os-Medendorp H, Kort H, de Wit N, Hoes A, Schuurmans M. Self-management: one size does not fit all. Patient Educ Couns. 2013;92(1):134-137.

14. Korpershoek YJ, Bruins Slot JC, Effing TW, Schuurmans MJ, Trappenburg JC. Self-management behaviors to reduce exacerbation impact in COPD patients: a Delphi study. Int J Chron Obstruct Pulmon Dis. 2017;12:2735-2746.

15. Effing TW, Vercoulen JH, Bourbeau J, Trappenburg J, Lenferink A, Cafarella P, et al. Definition of a COPD self-management intervention: International Expert Group consensus. Eur Respir J. 2016. Eur Respir J. 2016; 48(1):46-54.

16. Bischoff EW, Hamd DH, Sedeno M, Benedetti A, Schermer TR, Bernard S, Maltais F, Bourbeau J. Effects of written action plan adherence on COPD exacerbation recovery. Thorax. 2011;66(1):26-31.

17. Bucknall CE, Miller G, Lloyd SM, Cleland J, McCluskey S, Cotton M, Stevenson RD, Cotton P, McConnachie A. Glasgow supported self-management trial (GSUST) for patients with moderate to severe COPD: randomised controlled trial. BMJ. 2012;6;344:e1060. 
18. West R, Michie S. A guide to development and evaluation of digital behavior change interventions in health care. London: Silverback Publishing; 2016.

19. Wang J, Wang Y, Wei C, Yao NA, Yuan A, Shan Y, Yuan C. Smartphone interventions for long-term health management of chronic diseases: an integrative review. Telemed J E Health. 2014;20(6):57083.

20. McCabe C, McCann M, Brady AM. Computer and mobile technology interventions for self-management in chronic obstructive pulmonary disease. Cochrane Database Syst Rev. 2017;5:CD011425

21. Marcano Belisario JS, Huckvale K, Greenfield G, Car J, Gunn LH. Smartphone and tablet selfmanagement apps for asthma. Cochrane Database Syst Rev. 2013 Nov 27;2013(11):CD010013.

22. van Meijel B, Gamel C, van Swieten-Duijfjes B, Grypdonck MH. The development of evidencebased nursing interventions: methodological considerations. J Adv Nurs. 2004;48(1):84-92.

23. Perski $\mathrm{O}$, Blandford $\mathrm{A}$, West $\mathrm{R}$, Michie $\mathrm{S}$. Conceptualising engagement with digital behaviour change interventions: a systematic review using principles from critical interpretive synthesis. Transl Behav Med. 2017;7(2):254-267.

24. Shah SG, Robinson I, AIShawi S. Developing medical device technologies from users' perspectives: a theoretical framework for involving users in the development process. Int J Technol Assess Health Care. 2009 Oct;25(4):514-21.

25. Holloway I, Wheeler S. Qualitative research in nursing and healthcare: 3rd ed: Wiley-Blackwell; 2010.

26. Krueger RA, Casey MA. Focus groups: a practical guide for applied research: 4th ed: SAGE Publications, Inc; 2008.

27. Korpershoek Y, Vervoort S, Nijssen L, Trappenburg J, Schuurmans MJ. Factors influencing exacerbation-related self-management in patients with COPD: a qualitative study. Int J Chron Obstruct Pulmon Dis. 2016;11:2977-2990

28. Braun V, Clark V. Using thematic analysis in psychology. Qual Res Psychol. 2006;3(2):77-101.

29. Lincoln YS, Guba EG. Naturalistic inquiry. Newbury Park CA: Sage publications; 1985.

30. Huygens MW, Vermeulen J, Swinkels IC, Friele RD, van Schayck OC, de Witte LP. Expectations and needs of patients with a chronic disease toward selfmanagement and eHealth for selfmanagement purposes. BMC Health Serv Res. 2016;8;16:232.

31. Davis FD. Perceived usefulness, perceived ease of use, and user acceptance of information technology. MIS Quartely. 1989;13(3):319-40.

32. Michie $S$, Atkins L, West R. The behaviour change wheel. A guide to designing interventions. Great Britain: Silverback Publishing; 2014.

33. Trappenburg JC, Schaap D, Monninkhof EM, Bourbeau J, de Weert-van Oene GH, Verheij TJ, Lammers JW, Schrijvers AJ. How do COPD patients respond to exacerbations? BMC Pulm Med. 2011; 19;11:43.

34. Kessler R, Stahl E, Vogelmeier C, Haughney J, Trudeau E, Lofdahl CG, Partridge MR. Patient understanding, detection, and experience of COPD exacerbations: an observational, interviewbased study. Chest. 2006;130(1): 133-42.

35. McLean S, Nurmatov U, Liu JL, Pagliari C, Car J, Sheikh A. Telehealthcare for chronic obstructive pulmonary disease: Cochrane Review and meta-analysis. Br J Gen Pract. 2012;62(604):e739-e749.

36. Ursum J, Hek K, Spronk I, Nielen MMJ, Davids R, Verheij RA. Hoe vaak komt COPD voor en bij wie? 2016. Available from: www.nivel.nl/node/4402. Accessed August 17, 2018.

37. Alwashmi M, Hawboldt J, Davis E, Marra C, Gamble JM, Abu AW. The Effect of Smartphone Interventions on Patients With Chronic Obstructive Pulmonary Disease Exacerbations: A Systematic Review and Meta-Analysis. JMIR Mhealth Uhealth. 2016;4(3):e105.

38. World Health Organisation. Mhealth. New horizons for health through mobile technologies. Second global survey on eHealth. Available from: http://www.who.int/goe/publications/goe_mhealth_web. pdf. Updated 2011. Accessed August 17, 2018. 


\section{Appendix 1}

Topic list focus group interview with patients

\begin{tabular}{|c|c|}
\hline Topic & Specification \\
\hline \multirow[t]{2}{*}{ Introduction } & Aim of the study \\
\hline & Introduction of important terminology (exacerbation/mHealth) \\
\hline \multirow[t]{2}{*}{ Use of mobile devices } & Current use of mobile devices \\
\hline & Perceived advantages \& disadvantages \\
\hline Patient needs & $\begin{array}{l}\text { Patient needs towards self-management (support) of } \\
\text { exacerbations }\end{array}$ \\
\hline \multirow[t]{2}{*}{ Perceptions towards mHealth } & $\begin{array}{l}\text { Perceptions towards use of mHealth for self-management of } \\
\text { exacerbations }\end{array}$ \\
\hline & Potential benefits and barriers of mHealth \\
\hline \multirow{3}{*}{$\begin{array}{l}\text { Content of an mHealth } \\
\text { intervention }\end{array}$} & Initial ideas on content of mHealth intervention \\
\hline & Initial ideas on design and functions \\
\hline & $\begin{array}{l}\text { Reflection on specific topics: } \\
\text { - Self-monitoring/entering data by patients } \\
\text { - Access to data by health care provider } \\
\text { - Feedback on behavior } \\
\text { - Contact with health care provider } \\
\text { - Education } \\
\text { - Decision making } \\
\text { - Reminders }\end{array}$ \\
\hline \multirow[t]{2}{*}{ Intensity of mHealth use } & Perceptions towards intensity of using mHealth technology \\
\hline & Perceptions towards daily symptoms monitoring \\
\hline
\end{tabular}


Topic list focus group interview with health care providers

\begin{tabular}{|c|c|}
\hline Topic & Specification \\
\hline \multirow[t]{2}{*}{ Introduction } & Aim of the study \\
\hline & Introduction of important terminolgy (mHealth) \\
\hline \multirow{2}{*}{$\begin{array}{l}\text { Experience with mHealth in } \\
\text { health care }\end{array}$} & Current use of mobile technology in health care \\
\hline & Perceived advantages \& disadvantages \\
\hline Patient needs & $\begin{array}{l}\text { Patient needs toward self-management (support) of } \\
\text { exacerbations }\end{array}$ \\
\hline \multirow[t]{2}{*}{ Perceptions towards mHealth } & $\begin{array}{l}\text { Perceptions towards use of mHealth for self-management of } \\
\text { exacerbations }\end{array}$ \\
\hline & Potential benefits and barriers of mHealth \\
\hline \multirow{3}{*}{$\begin{array}{l}\text { Content of an mHealth } \\
\text { intervention }\end{array}$} & Initial ideas on content of mHealth intervention \\
\hline & Initial ideas on design and functions \\
\hline & $\begin{array}{l}\text { Reflection on specific topics: } \\
\text { - Self-monitoring/entering data by patients } \\
\text { - Access to data by health care provider } \\
\text { - Feedback on behavior } \\
\text { - Contact with health care provider } \\
\text { - Education } \\
\text { - Decision making } \\
\text { - Reminders }\end{array}$ \\
\hline \multirow[t]{3}{*}{ Role of health care provider } & $\begin{array}{l}\text { Perceptions towards HCP role regarding self-management } \\
\text { support with mHealth }\end{array}$ \\
\hline & $\begin{array}{l}\text { Perceptions towards time investment regarding self- } \\
\text { management support with mHealth }\end{array}$ \\
\hline & $\begin{array}{l}\text { Perceptions towards communication between patients and } \\
\text { HCPs through mHealth }\end{array}$ \\
\hline
\end{tabular}


Perceptions towards using mHealth for self-management 


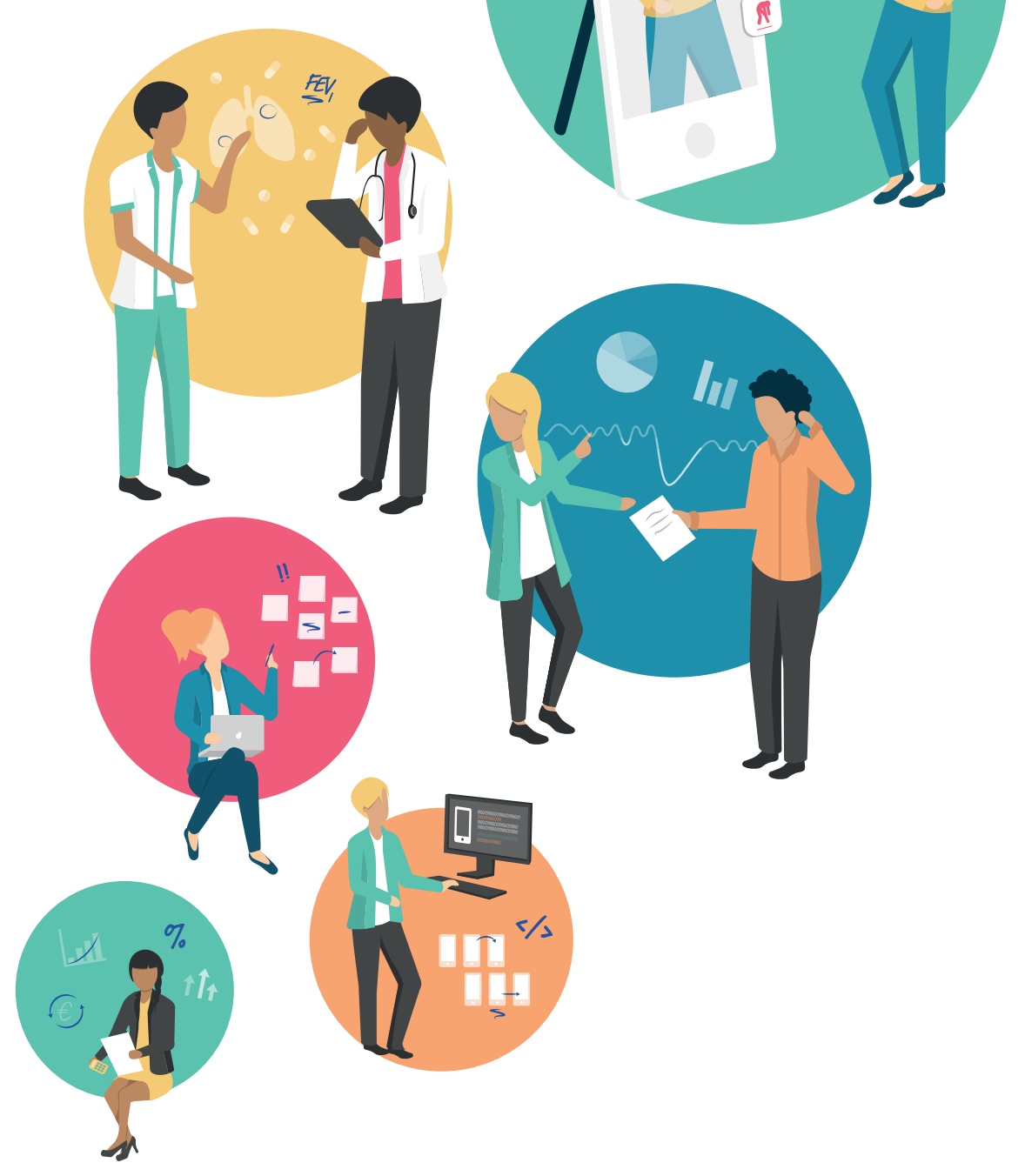




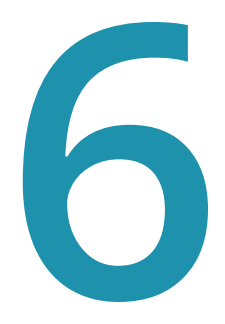

\section{User-centered design of a mobile health intervention to enhance exacerbation- related self-management in patients with chronic obstructive pulmonary disease (Copilot): mixed methods study}

Yvonne JG Korpershoek, Sander Hermsen, Lisette Schoonhoven, Marieke J Schuurmans, Jaap CA Trappenburg Journal of Medical Internet Research. 2020; 22(6):e15449 


\section{Abstract}

Background: Adequate self-management skills are of great importance for patients with chronic obstructive pulmonary disease (COPD) to reduce the impact of COPD exacerbations. Using mobile health (mHealth) to support exacerbation-related self-management could be promising in engaging patients in their own health and changing health behaviors. However, there is limited knowledge on how to design mHealth interventions that are effective, meet the needs of end users, and are perceived as useful. By following an iterative user-centered design (UCD) process, an evidence-driven and usable mHealth intervention was developed to enhance exacerbation-related self-management in patients with COPD. This study aimed to describe in detail the full UCD and development process of an evidence-driven and usable mHealth intervention to enhance exacerbation-related self-management in patients with COPD.

Methods: The UCD process consisted of four iterative phases: (1) background analysis and design conceptualization, (2) alpha usability testing, (3) iterative software development, and (4) field usability testing. Patients with COPD, health care providers, COPD experts, designers, software developers, and a behavioral scientist were involved throughout the design and development process. The intervention was developed using the behavior change wheel (BCW), a theoretically based approach for designing behavior change interventions, and logic modeling was used to map out the potential working mechanism of the intervention. Furthermore, the principles of design thinking were used for the creative design of the intervention. Qualitative and quantitative research methods were used throughout the design and development process.

Results: The background analysis and design conceptualization phase resulted in final guiding principles for the intervention, a logic model to underpin the working mechanism of the intervention, and design requirements. Usability requirements were obtained from the usability testing phases. The iterative software development resulted in an evidencedriven and usable mHealth intervention - Copilot, a mobile app consisting of a symptommonitoring module, and a personalized COPD action plan.

Conclusion: By following a UCD process, an mHealth intervention was developed that meets the needs and preferences of patients with COPD, is likely to be used by patients with COPD, and has a high potential to be effective in reducing exacerbation impact. This extensive report of the intervention development process contributes to more transparency in the development of complex interventions in health care and can be used by researchers and designers as guidance for the development of future mHealth interventions. 


\section{Introduction}

\section{Background}

Chronic obstructive pulmonary disease (COPD) is a highly prevalent chronic disease and is predicted to be the third leading cause of mortality worldwide in 2030., Exacerbations are important events in the course of COPD, as they accelerate the decline in lung function, ${ }^{3}$ negatively affect the quality of life,, 45 and lead to increased mortality and high socioeconomic costs. ${ }^{6,7}$ An exacerbation is defined as a sustained worsening of patients'respiratory symptoms, which are beyond normal day-to-day variability and may warrant medical treatment. ${ }^{8}$ The absence of an adequate imminent exacerbation marker requires a focus on supporting patients with COPD in developing self-management skills to reduce the impact of exacerbations. ${ }^{9}$ Self-management is defined as an individual's ability to detect and manage symptoms, treatment, physical and psychosocial consequences, and lifestyle changes inherent in living with a chronic condition. ${ }^{10}$

Recent interventions focusing on exacerbation-related self-management (including the use of action plans) have shown positive outcomes on quality of life and hospital admissions. ${ }^{11,12}$ However, there is still a substantial proportion of patients with COPD who barely benefit from these kinds of interventions. ${ }^{11-13}$ This might be explained by the one-size-fits-all and static approach regarding design, intensity, and mode of delivery without a focus on individual exacerbation patterns and actions. Moreover, recent interventions have a strict focus on exacerbation detection and taking action and the use is suboptimal.11,14,15 To further reduce the impact of exacerbations, more comprehensive, dynamic, and individualized strategies are needed to improve the full spectrum of exacerbationrelated self-management behavior that meet patients' needs, perceptions, and capabilities. ${ }^{12,16}$

Mobile health (mHealth) is considered promising in engaging patients in their own health and changing health behaviors. ${ }^{17,18}$ The rapidly evolving nature and increased uptake of mHealth are bound to influence the accessibility and the way self-management support will be provided in the future, also in patients with COPD. ${ }^{19-21}$ Recent studies suggest that mHealth interventions focusing on COPD self-management lead to positive outcomes, although no firm conclusions could be drawn because of poor quality and heterogeneity among the studies. ${ }^{19,20}$ Nonetheless, the use of mHealth creates opportunities to strongly individualize interventions and to provide more dynamic and intensive therapeutic stimuli that fit with real-time health status and individual exacerbation patterns. As a result, 
mHealth can reach patients at the right moment and can provide tailored support anytime and anywhere, which could stimulate the development of effective selfmanagement skills and change health behaviors.

To date, there is limited knowledge on how to design mHealth interventions that are effective, meet the needs of intended end users, and are perceived as useful. ${ }^{17,22}$ Designing mHealth interventions to change health behaviors is complex and needs theoretical grounding to increase the design's efficacy. In current thinking about the development of behavior change interventions, the importance of theory is clear, ${ }^{23-26}$ but the way in which theory should be incorporated in the design process is not. ${ }^{24,27,28}$ Furthermore, specific steps in the development of evidence- and theory-driven interventions that involve the end users are rarely described transparently in literature. ${ }^{22,29}$

\section{Objectives}

During a 4-year period, our research team has developed an evidence-driven and usable mHealth intervention to enhance exacerbation-related self-management in patients with COPD. By following an iterative user-centered design (UCD) process, several studies were performed to increase the likelihood of developing an mHealth intervention that is effective, fits with patients' needs and preferences, and can be successfully implemented in routine COPD care. Some of these studies have recently been published. . $5,30,31$ This paper underpins the design and working mechanism of this COPD-specific mHealth intervention and offers a novel and potentially effective method to use evidence and theory to inform the design of mHealth interventions in general.

The aim of this paper was to describe in detail the full UCD and development process of an evidence-driven and usable mHealth intervention to enhance exacerbation-related self-management in patients with COPD, including the design, iterative software development, and usability testing.

\section{Methods}

\section{User-centered design process}

Guiding principles for the mHealth intervention were formulated by the research team at an early stage to provide a framework for making decisions during intervention development (Textbox 1). ${ }^{32}$ The guiding principles were based on recent evidence regarding COPD self-management and were progressively refined as the 
intervention development proceeded based on outcomes of specific development steps that we described in this paper. The mHealth intervention was developed by following a UCD process involving patients with COPD, health care providers (HCPs), COPD experts, designers, software developers, and a behavioral scientist. The UCD was based on the methodology as described by Johnston et al ${ }^{33}$ consisting of four iterative phases: (1) background analysis and design conceptualization, (2) alpha usability testing, (3) iterative software development, and (4) field usability testing (Figure 1)..$^{33}$ Johnston et $\mathrm{a}^{33}$ provide limited guidance on the specific steps needed to develop an effective mHealth intervention that meets patients' needs and preferences and fits with current COPD care. Therefore, we extended the first phase of the UCD with subphases based on a comprehensive approach that combines elements of the Medical Research Council (MRC) framework development phase with elements of existing development models (Figure 1). ${ }^{34}$ The MRC framework is a well-known and often used framework for the development and evaluation of complex interventions in health care with a specific focus on developing theoryand evidence-driven interventions. The whole design and development process was carried out between 2015 and 2019. The methods of each phase are chronologically described in the following paragraphs. The results of each phase are detailed in the Results section.

Textbox 1. Guiding principles for a mobile health intervention to enhance exacerbation-related self-management in patients with chronic obstructive pulmonary disease.

The mobile health intervention should:

- meet individual patient needs, perceptions, and preferences regarding exacerbationrelated self-management;

- synchronize with current health status and anticipate on the heterogeneity of exacerbations in and between patients;

- focus on target behaviors in the full spectrum of exacerbation-related selfmanagement;

- include a chronic obstructive pulmonary disease (COPD) action plan along with ongoing self-management support;

- focus on the continuous development of self-management skills and behavior change;

- stimulate proactive self-monitoring;

- be safe, literacy-sensitive, and patient-friendly;

- be feasible in current Dutch COPD care; and

- meet the conceptual definition of a COPD self-management intervention: $A$ COPD self-management intervention should be structured but personalized and often multicomponent, with goals of motivating, engaging and supporting the patients to positively adapt their health behavior(s) and develop skills to better manage their disease. ${ }^{16}$ 


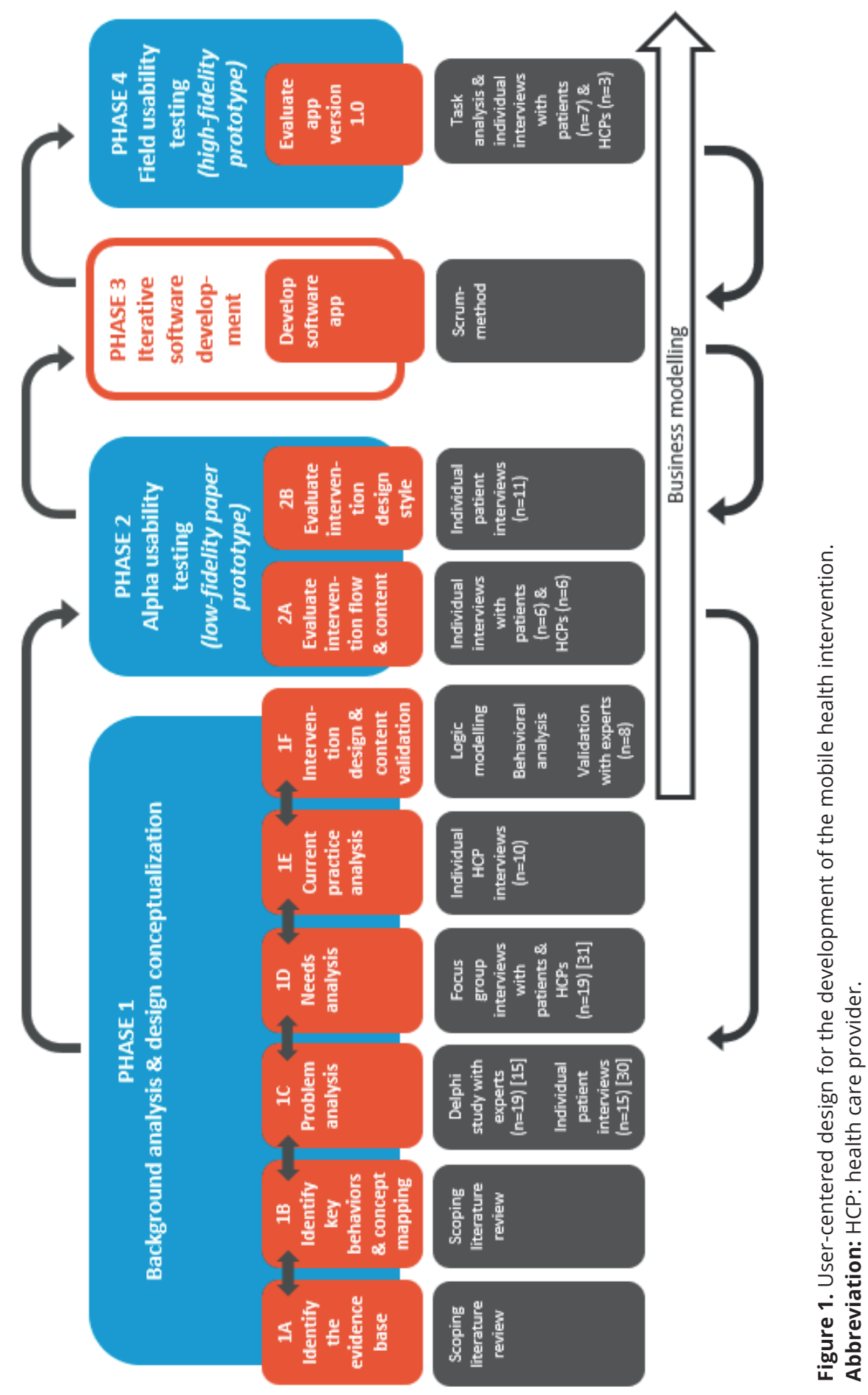




\section{Phase 1: Background analysis and design conceptualization}

The aim of the first phase was to identify the evidence base and to achieve a theoretical understanding of the underlying process of change for the intervention. ${ }^{35}$

\section{A: Identify the evidence base}

In phase 1A, a scoping literature review was performed in Medical Literature Analysis and Retrieval System Online (MEDLINE) to explore current systematic reviews on interventions that focus on enhancing exacerbation-related selfmanagement in patients with COPD, including mHealth interventions, and to identify potential effective intervention components (Figure 1; phase 1A). Literature review on interventions was an ongoing process during the whole intervention development process, to stay up to date on developments about (mHealth) interventions focusing on exacerbation-related self-management.

\section{B: Identify key behaviors and concept mapping}

In phase 1B, a scoping literature review was performed in MEDLINE to specify symptom fluctuation phases during the course of COPD and to identify relevant self-management behaviors that can reduce exacerbation impact (Figure 1; phase 1B). Two researchers (YK and JT) developed a conceptual model of patients' fluctuations in symptoms during the course of COPD. Then, an initial set of relevant self-management behaviors was generated and added to the conceptual model. The methods of the scoping review and stepwise development of the conceptual model are published elsewhere. ${ }^{15}$

\section{C: Problem analysis}

A problem analysis was included to provide insight into the problems experienced by patients and identified by experts to determine the intervention targets and to set boundaries of the intervention (Figure 1; phase 1C). A tworound Delphi study with 19 international respiratory experts (medical doctors and key researchers in the field of COPD) was performed. In this study, insight into expert opinion was provided on the most relevant set of selfmanagement behaviors that have the potential to maximally reduce the impact of exacerbations and is feasible to target and influence before, during, and after an exacerbation. The methodology is described in depth in the publication of this study. ${ }^{15}$ Furthermore, a grounded theory study using individual in-depth interviews with patients with COPD $(n=15)$ was performed. ${ }^{36}$ In this study, patient perceptions, capabilities, and needs with regard to exacerbation-related self-management were explored to identify and explain the underlying process 
of exacerbation-related self-management behavior in patients with COPD. The methodology is described in depth elsewhere. ${ }^{30}$

\section{D: Needs analysis}

Patients' needs regarding exacerbation-related self-management were partially identified in phase $1 \mathrm{C}$ because these needs flowed naturally from the problems perceived by patients. ${ }^{37}$ An additional needs analysis was performed to further investigate specific needs and explicit requests for care with regard to using mHealth for self-management (Figure 1; phase 1D). ${ }^{37}$ To develop an mHealth intervention with optimal usability and feasibility, a deep and early understanding of both patients' and HCPs' perspectives was considered to be important. ${ }^{38}$ Therefore, a qualitative study using focus group interviews with both patients with COPD ( $n=13)$ and HCPs ( $n=6)$ was performed to (1) explore their willingness to use mHealth for self-management of exacerbations, (2) identify potential benefits and barriers of using mHealth, and (3) explore needs and preferences regarding the content of an mHealth intervention. ${ }^{39}$ The methods of this step are further described in the paper of this study. ${ }^{31}$

\section{E: Current practice analysis}

An analysis of COPD guidelines and current practice was performed to gain insight into current exacerbation-related self-management support and to explore the added value of the intended intervention compared with regular care (Figure 1; phase 1E). Individual semi-structured interviews with HCPs $(n=10)$ were performed to identify HCPs' perspectives with regard to care provided and their role in providing self-management support. Purposive sampling was performed in primary and secondary care settings. The following topics were discussed: current interventions to support exacerbation-related self-management, HCP experiences with providing self-management support, perceptions toward HCPs' roles and responsibilities, barriers in providing self-management support, and the potential to use mHealth for self-management support. All interviews were audiotaped, transcribed verbatim, and analyzed by open, axial, and selective coding. ${ }^{40}$

\section{F: Intervention design}

The aim of the intervention design phase (Figure 1; phase 1F) was twofold: (1) to map out the potential working mechanisms triggered by the intervention and (2) to develop the flow and content of the intervention. During this phase, a decision was made on the target behaviors of the intervention. The behavior change wheel (BCW) method was used to analyze the target behaviors and to 
design intervention components. ${ }^{41}$ First, based on the literature, behavioral analysis was performed by two researchers ( $\mathrm{YK}$ and $\mathrm{SH}$ ) to identify what needs to change in patients' capability, opportunity, and motivation to improve each target behavior (capability, opportunity, and motivation model of behavior [COM-B] analysis). ${ }^{41}$ Second, the theoretical domains framework (TDF) was used to elaborate on the behavioral analysis by mapping the 14 domains of the framework onto the capability, opportunity, and motivation components of COM-B. ${ }^{41}$ Third, potentially relevant intervention functions and behavior change techniques (BCTs), matching users and context, were selected using criteria provided by the $\mathrm{BCW}^{41}$ (see Appendix 1). Logic modeling was used to map out the potential working mechanism of the intervention by detailing all evidence and assumptions underpinning the pathway from the intervention to the long-term impact on outcomes. ${ }^{42,43}$ The logic model starts with the target behaviors and details what needs to change in behavior (TDF), by which intervention functions and BCTs, and through which specific intervention components, including factors that could influence the working mechanism, and results in short and long-term outcomes. The logic model components were based on the evidence gained from all previous phases, and consensus on the components was reached during research group meetings. On the basis of this model, design requirements were formulated.

Furthermore, creative ideas with regard to the intervention design were explored using methods derived from design thinking. ${ }^{44}$ In a pressure cooker session with three independent creative designers, initial ideas on the design were presented by focusing on potential techniques to change health behaviors and to enhance engagement with mHealth. After this session, collaboration with a creative design agency (Panton BV, Deventer, the Netherlands) specifically focusing on health care solutions was initiated. By following an iterative design process, the flow and content of the intervention were designed, and various design styles were developed using low-fidelity prototypes-paper prototypes that visualize design solutions. In the early stages of digital user interface design, such low-fidelity paper prototypes are often used to determine requirements for the architecture and functionalities of the specific intervention to be designed. ${ }^{45}$ The paper prototypes were tested in phase 2 of the UCD.

Moreover, the content of a symptom-monitoring module was developed during this stage. The module aimed to determine the individual COPD patient's normal day-to-day variability in symptoms to be able to set the patient's normal symptom pattern. The content validity of the module was evaluated by experts in the field of 
COPD $(n=8)$ according to the Lynn method. ${ }^{46}$ Each symptom was rated on relevance and linguistics by answering four questions. All questions about relevance were rated on a 4-point Likert scale (1=not relevant, 4=relevant). Linguistics was determined by if the interpretation was clear (yes or no). The item-content validity index (I-CVI) was calculated for each relevance question to determine the number of experts judging the content as valid (I-CVI>0.78=relevant). Subsequently, the scale-content validity index (S-CVI) was calculated to determine the relevance of the whole symptommonitoring module ( $\mathrm{S}-\mathrm{CVI}>0.90=$ excellent). ${ }^{46}$ Linguistics was considered to be clear when at least $75 \%$ of the expert panel rated clearness of interpretation as a yes. A more in-depth description of the development and content validity assessment of the symptom-monitoring module is given in Appendix 2.

\section{Phase 2: Alpha usability testing}

In the second phase, alpha usability tests were performed by investigating patient and HCP responses to low-fidelity paper prototypes of the intervention in two steps: (1) evaluating the intervention flow and content and (2) evaluating intervention design styles..$^{33}$ At each phase of usability testing, we only included patients who had not evaluated an earlier prototype.

\section{A: Evaluate intervention flow and content}

Perceptions, needs, and preferences regarding the intervention flow and structure were evaluated with both patients with COPD $(n=6)$ and HCPS $(n=6)$ to identify usability requirements (Figure 1; phase $2 \mathrm{~A}$ ). Individual semi-structured interviews were held using low-fidelity paper prototypes. The following topics were discussed: experience with mHealth and written action plans, the overall flow of the intervention, symptom-monitoring/action plan scenarios, and the added value of the intervention. Purposive sampling of participants was performed in primary, secondary, and tertiary care settings. In total, 6 patients and 6 HCPs were included based on the general rule of thumb that approximately $80 \%$ of all potential usability problems could be identified by including 5 to 10 end users. ${ }^{47}$ The inclusion and exclusion criteria of the participants during usability testing are detailed in Textboxes 2 and 3, respectively. Data were thematically analyzed by two researchers independently. ${ }^{48}$ Data analysis was supported by NVivo 10.0 software (2012; QSR International Pty Ltd.).

\section{B: Evaluate intervention design style}

Next, the preferences of patients with COPD regarding intervention design style were explored by individual semi-structured interviews ( $n=11$; Figure 1; phase 2B). ${ }^{33}$ Low-fidelity paper prototypes were used to present variations in design 
style and tone of voice. Purposive sampling of participants was performed in a physiotherapy practice and a rehabilitation center according to the inclusion and exclusion criteria for patients in Textboxes 2 and 3. Data were analyzed by 2 researchers independently through summarizing the advantages and disadvantages of each design style and the overall preferences regarding design style. On the basis of the results of both alpha usability steps, the intervention design was finalized for further software development.

Textbox 2. Inclusion criteria of participants during usability testing.

\section{Inclusion criteria for patients with a clinical diagnosis ${ }^{2}$ of chronic obstructive pulmonary disease (COPD)}

- Age $>40$ years

- Spirometry forced expiratory volume in 1 second/forced vital capacity ratio $<70 \%$

- $\geq 1$ exacerbation in the last 12 months before entering the study (defined as a period of symptom deterioration in which the use of a course of corticosteroids and/or antibiotics was required, or hospitalization was necessary)

- Adequate communication skills

- Willing and able to comply with study procedures and give written informed consent

- Patients who are judged by their health care provider to have suitable hearing and vision

\section{Inclusion criteria for health care providers}

- Having a patient-health care provider relationship with patients with COPD

- Supporting patients with COPD in self-management

- At least one year of experience with COPD care

Textbox 3. Exclusion criteria of participants during usability testing.

Exclusion criteria for patients with a clinical diagnosis of chronic obstructive pulmonary disease

- Diagnosed with cognitive impairments

- Life expectancy $\leq 3$ months

- Primary diagnosis of asthma, cardiac disease, or other major functionally limiting diseases

\section{Exclusion criteria for health care providers}

- Not applicable 


\section{Phase 3: Iterative software development}

The software of the mHealth intervention was developed during a 12-week period according to a scrum-based design method consisting of five development sprints (Figure 1; phase 3)..$^{49}$ During biweekly stakeholder meetings, the research team, designers, and software developers met in person to evaluate the current stage of development and to make decisions on the further development of the first version of the mHealth intervention (minimum viable product; MVP). The mHealth intervention was built in React Native (Massachusetts Institute of Technology licenses), a software structure that is easy to adapt and suitable for both iOS and Android. This saves time and money during the initial and future development of the intervention and fits within the agile development process of the intervention.

\section{Phase 4: Field usability testing}

In the fourth phase, field usability tests of the MVP (ie, tests with a high-fidelity prototype within the context in which the intervention will actually be used) were performed with patients with COPD $(n=7)$ and HCPs $(n=3)$ using cognitive task analysis. ${ }^{47,50}$ This mixed methods study focused on three quality components: task success, user errors/problems, and satisfaction, based on Nielsen's heuristics and the International Organization for Standardization's usability standard 9241-11. ${ }^{51}$ Purposive sampling of participants was performed in primary, secondary, and tertiary care settings until data saturation was reached. In line with the procedure of phase 2, a minimum of 5 patients were included according to the inclusion and exclusion criteria of Textboxes 2 and 3. Participants were observed while performing tasks with the MVP and asked to think aloud to clarify their decisionmaking process and express experienced user problems and errors. ${ }^{51}$ After the task analysis, the validated 10-item system usability scale (SUS) was filled out by patients to get a global view of usability. ${ }^{52}$ Each item was scored on a 5-point Likert scale, and all items were converted to a total score (range $0-100$, a score $>70$ is considered to be acceptable).52,53 Furthermore, semi-structured interviews were conducted. On the basis of previous research and the technology acceptance model, ${ }^{54,55}$ the following topics were formulated: the first impression of the app, ease of use, satisfaction, perceived usefulness, applicability, attitude toward using the app, and the content of the app. The whole procedure with patients was video recorded without the faces of participants being visible. The procedure with HCPs was more pragmatic in nature because the MVP did not include a specific HCP interface. However, the relevant functions for HCPs could be tested within the MVP. Therefore, only 3 HCPs were included, and the procedure was only observed by 1 researcher who simultaneously made notes. 
The performance of tasks by patients was observed by two researchers independently. An observation list was used to note task success, users' errors/ problems, and participants' expressions for each task. The performance of tasks was scored as successful (1 point), partially successful (0.5 points), or unsuccessful ( 0 points). ${ }^{56}$ The observation lists were discussed by the researchers to reach a consensus on the performance of tasks and the identified problems and errors. The data from the think-aloud method were used to derive a better understanding of task performance. A severity score ranging from 0 (no usability problem) to 4 (usability catastrophe) was given to each problem based on the impact and frequency of the problem..$^{57}$ Data from the semi-structured interviews were analyzed by 2 researchers independently using thematic analysis. ${ }^{48}$ The data analysis of HCPs observations was performed by only 1 researcher, and the semistructured interviews were only summarized.

The usability studies were approved by the Medical Ethics Research Committee of the University Medical Center Utrecht (17-887), and all participants gave written informed consent.

\section{Business modeling}

Business modeling, based on the principles of the lean startup methodology, ${ }^{58}$ was performed parallel to phase $1 \mathrm{~F}$ until phase 4 to ensure valorization and sustainable implementation of the mHealth intervention in its intended care practice (Figure 1). ${ }^{59}$ Business modeling included contextual inquiry and continuous investigation of relevant stakeholder needs (patients with COPD, HCPs, policy makers, and health care insurers) to better understand what should be accomplished with our mHealth intervention and to obtain value drivers to underpin choices in what to design. ${ }^{59}$ The needs of patients with COPD and HCPs were investigated in phases $1 \mathrm{C}, 1 \mathrm{D}$, and $1 \mathrm{E}$, and individual conversations with policy makers and health care insurers were held to identify their perspectives toward the mHealth intervention. Furthermore, the best innovation and distribution routes and market opportunities were explored in conversations with stakeholders to investigate their interests and financial incentives to support self-management with mHealth. Competition analysis was performed to explore the value of our intervention with respect to existing mHealth technologies. Finally, conversations with vendors in the field were held to explore business opportunities. 


\section{Results}

\section{Phase 1: Background analysis and design conceptualization 1A: Identify the evidence base}

A total of four relevant systematic reviews on exacerbation-related selfmanagement interventions and two systematic reviews specifically focusing on mHealth interventions to improve exacerbation-related outcomes were identified. Self-management interventions, including exacerbation action plans along with ongoing self-management support, were associated with positive outcomes on quality of life, hospital admissions, and health care use. ${ }^{11,12,60} \mathrm{~A}$ review of self-management interventions delivered immediately following an acute exacerbation showed no significant effect on quality of life nor hospital admissions. ${ }^{61}$ All reviews showed large heterogeneity in interventions making it hard to draw conclusions on effective components of these interventions. Furthermore, mHealth interventions facilitating, supporting, and sustaining selfmanagement among people with COPD significantly improved quality of life, and levels of activity. ${ }^{19}$ Smartphone interventions in patients with COPD with exacerbations, without a specific focus on self-management, were found to be useful in reducing the number of patients having a COPD exacerbation. ${ }^{20}$ These results should also be interpreted with caution because of the heterogeneity among studies.

On the basis of these findings, it seemed promising to use mHealth strategies that specifically aim at enhancing self-management behavior. It was considered important that the mHealth intervention includes a COPD action plan along with ongoing self-management support, which confirmed our guiding principle to include an action plan. Furthermore, a conceptual definition of a COPD selfmanagement intervention was published in 2016. ${ }^{16}$ Given the need for consensus on what defines a COPD self-management intervention, this definition was added to the guiding principles (Textbox 1).

\section{B: Identify key behaviors and concept mapping}

A conceptual model picturing the event of an exacerbation was developed by distinguishing five phases before, during, and after an index event. Specific aims regarding the reduction of exacerbation impact were formulated for each phase of the conceptual model. The conceptual model is published elsewhere. ${ }^{15}$ On the basis of the knowledge generated from the literature, an initial set of 27 relevant self-management behaviors aiming to reduce exacerbation impact was identified and assigned to the relevant phases of the conceptual model. This initial set of self- 
management behaviors was introduced to experts in the first round of the Delphi study (Figure 1; phase $1 \mathrm{C}$ ) to reach a consensus on the most relevant behaviors. ${ }^{15}$

\section{C: Problem analysis}

A Delphi panel of 19 international experts reached a consensus on 17 selfmanagement behaviors that can be targeted and influenced before, during, and after an exacerbation (Figure 1; phase 1C). This set of behaviors has the potential to maximally reduce the impact of exacerbations. The self-management behaviors were related to the following broader categories: adherence to pharmacotherapy, influenza vaccination, physical activity/exercise, avoiding stimuli, smoking cessation, early detection of symptom deterioration, medical treatment of exacerbations, managing stress and anxiety, and awareness of recurrent exacerbations. ${ }^{15}$ The 17 self-management behaviors were considered as potential target behaviors for the mHealth intervention. Our grounded theory study (Figure 1; phase 1C) has resulted in a conceptual model explaining factors that influence exacerbationrelated self-management from the patients' perspective. The conceptual model is published elsewhere. ${ }^{30}$ The conceptual model shows that exacerbation-related self-management is influenced by five generic factors: acceptance of COPD, perceived severity of symptoms, knowledge of exacerbations, former experiences with exacerbations, and social support. Furthermore, heterogeneity of exacerbations and habituation to symptoms were identified as specific factors influencing the capability to recognize an exacerbation. Performance of self-management actions was specifically influenced by perceived influence on exacerbation course, feelings of fear, self-empowerment, trust in health care provider, patient beliefs, and ambivalence toward treatment. ${ }^{30}$ These factors were included as moderating and mediating factors in the working mechanism of the intervention (see also 1F: Intervention Design section).

\section{D: Needs analysis}

Our needs analysis (Figure 1; phase 1D) resulted in an overview of potential benefits and barriers regarding the use of mHealth to support self-management and early ideas on the content of the intervention. ${ }^{31}$ Both patients and HCPs emphasized the need for a multicomponent and tailored mHealth intervention that focuses on improving patient self-management skills by determining health status and providing adequate information, decision support, and feedback on self-management behavior in an advisory manner. Important findings were that patients and HCPs emphasized that an mHealth intervention should never replace patients' own feelings nor undermine their own decisions. The intervention should be complementary to regular (personal) contact with HCPs and should facilitate 
adequate self-management support by HCPs. Discussing self-management skills with HCPs in personal consultations was believed to be essential to improve these skills. Both patients and HCPs expressed doubts regarding (real-time) the monitoring of symptoms by HCPs because of safety reasons and time constraints, although early detection of exacerbations was considered to be an important benefit. Moreover, the intervention should be attractive, straightforward, rewarding, and safe. Finally, patients emphasized that using mHealth should be their own choice and should never be enforced. On the basis of these findings, the design requirements for the intervention were formulated. Further results of the focus group interviews are published elsewhere. ${ }^{31}$

\section{E: Current Practice Analysis}

On the basis of three Dutch health care standards focusing on COPD ${ }^{62-64}$ and 10 interviews with HCPs, insight into current exacerbation-related selfmanagement support was provided. Two pulmonologists, 2 nurse specialists, 2 pulmonary nurses, 2 general practitioners, and 1 primary care nurse (4 males/6 females, work experience range 3-20 years) were interviewed. An important finding was the lack of standardized self-management support and limited use of evidence-based interventions by HCPs. There was a large variation in providing information about exacerbation-related self-management with regard to timing, topics discussed, and mode of delivery. Only a few HCPS used a COPD action plan and prescribed self-treatment with prednisolone and/ or antibiotics to stimulate self-management. More than half of the HCPs $(n=6)$ expressed that patients had no specific case manager. Providing self-management support was mostly perceived as a shared responsibility between HCPs, although individual responsibilities of the HCPs involved were unclear. Most HCPs felt that there is large room for improvement in self-management support by HCPs. Barriers in providing self-management support were the lack of standardized self-management support and clarity in responsibilities between HCPs, limited availability of HCPs, limited case management, limited time during consultations, limited financial resources, and suboptimal interdisciplinary communication in COPD care. The findings from the current practice analysis were included as moderating and mediating factors in the working mechanism of the intervention (see also 1F: Intervention Design section).

\section{F: Intervention design}

During the intervention design phase, the research team decided to initially focus on the three target behaviors: (1) self-monitoring of symptoms and early detection of an exacerbation, (2) taking prompt individualized self-management actions, and (3) 
prompt contact with an HCP. On the basis of insights from phase 1C, these behaviors were expected to contribute most to the reduction of exacerbation impact, had the potential for large improvement, and were considered most feasible to influence. The choice for these three behaviors was made, given the importance of aggregating the target behaviors that fit together and are considered to have the largest impact on exacerbations..$^{65}$ On the basis of behavioral analysis of these behaviors, potential intervention functions and BCTs were selected for the intervention. ${ }^{41}$. The behavioral analysis of the target behaviors, including the final intervention functions and BCTs is described in detail in Appendix 1. Figure 2 shows the logic model of the intervention that synthesizes all the evidence gained in the previous phases (phase $1 \mathrm{~A}$ until $1 \mathrm{E}$ ), including the selection of final intervention functions and BCTs.

On the basis of the results of all previous phases, design requirements for the mHealth intervention were formulated (see Textbox 4). At this stage, the research team and design agency decided to develop a mobile app to enhance exacerbation-related selfmanagement in patients with COPD. On the basis of design requirements, a concept of the flow and content of the app and various design styles were developed using low-fidelity paper prototypes.

Textbox 4. Design requirements for the mobile health intervention.

The mobile health (mHealth) intervention should:

- at least focus on self-monitoring of symptoms and early detection of exacerbations and taking prompt self-management actions including prompt contact with a health care provider (HCP);

- support patients in developing self-management skills over time (learning by doing) and changing behaviors;

- focus on (aggregated) self-management behaviors before, during, and after an exacerbation;

- include a chronic obstructive pulmonary disease (COPD) action plan with an educational component along with ongoing support;

- be comprehensive/multicomponent and tailored to individual patients;

- provide adequate information, decision support, and feedback on self-management behavior (in an advisory manner);

- take into account the factors influencing exacerbation-related self-management;

- fit with current COPD care and be accessible for HCPs;

- facilitate adequate self-management support by HCPs;

- be complementary to regular (personal) contact with HCPs;

- be attractive, straightforward, rewarding, and safe;

- never replace patients' own feelings nor undermine their own decisions; and

- not be enforced to patients. Using mHealth should be the patient's own choice. 


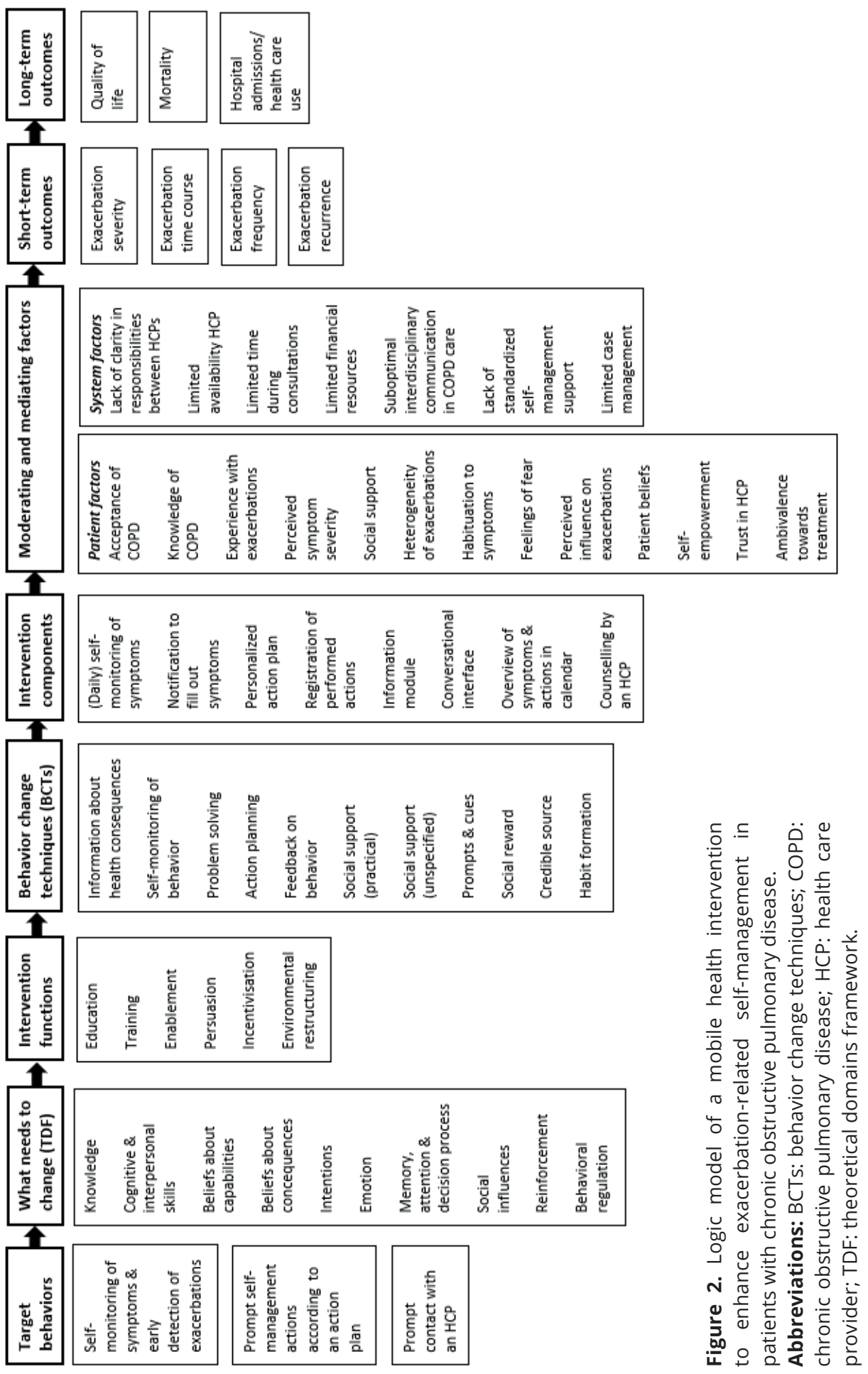


Furthermore, the symptom-monitoring module was developed during this stage. Content validity of the symptom-monitoring module was determined after two expert rounds. In total, these eight symptoms were rated as relevant (I-CVI>0.78) and clear ( $\geq 75 \%$ of the expert panel): Dyspnea, wheezing, nighttime symptoms, coughing, sputum volume, sputum purulence, sputum color, and fatigue. The relevance of the final symptom-monitoring module, determined by three questions, was considered to be high with S-CVIs of 0.93 or greater. More detailed results and the final symptom-monitoring module are shown in Appendix 2.

\section{Phase 2: Alpha usability testing \\ 2A: Evaluate intervention flow and content}

Evaluation of the flow and content of the intervention with both patients with COPD and HCPs resulted in overarching themes related to the intervention flow and an overview of usability requirements. The baseline characteristics of the participants are shown in Appendix 3. The patients recruited from tertiary care all had a written action plan, whereas the other patients only had verbal agreements with their HCPs.

\section{The intervention flow and content}

Overall, all patients and HCPs were positive about the intervention flow that consisted of four steps: (1) personalization of an action plan, (2) intensive monitoring of symptoms, (3) adjusting initial action plan based on monitoring period, and (4) regular use (filling out symptoms on a regular basis and receiving support on individualized actions). However, the patients who believed that they were well aware of their symptoms did not directly perceive that they could benefit from the intensive monitoring period. Overall, patients preferred personalization of the duration of intensive monitoring and the timing of notifications. HCPs felt that they should have autonomy in determining how, and at which moment, the action plan should be reviewed and adjusted. On the basis of specific mockups used to explore preferences regarding symptom registration and determining symptoms status, the most intuitive and straightforward scenarios were identified. For example, mockup 1 was considered to be the best solution to determine symptom status by all patients (Figure 3).

\section{The added value of the intervention}

Patients expressed that the app could create awareness into their own situation and could support early detection of symptom deterioration and taking prompt actions. The adjustability and accessibility of the app were perceived as benefits compared with using a written action plan. Furthermore, both patients and HCPs 
were positive about the overview of registered symptoms and undertaken actions as a tool to start the dialog about patients' self-management behavior. Moreover, personalization and tailoring of the app were considered to be an important benefit: 'Finally an app that is not for COPD but for me personally.' [Patient 2]

\section{Needs with regard to the intervention}

Patients expressed a clear need for an accessible and reliable app that provides insight into their own situation and eliminates their doubts by including reflective questions. Patients stressed the importance of an app that is straightforward, for example, by providing simple and effortless instructions in case of serious dyspnea that causes panic, such as: 'breathe slowly or call the doctor: It has to be simple, because energy is air.' [Patient 3] They would like to use the app to inform relatives about their situation. Both patients and HCPs emphasized that the app should stimulate prompt contact with an HCP: 'Patients experience feelings of fear you know, like: when I am raising an alarm, I might have to take prednisolone or I might be admitted to the hospital, so therefore I won't make the call... Will that be included in the app as well?' [HCP 1] Furthermore, HCPs explained that the app should provide insight into patient symptoms over time and realize more proactive care instead of reactive care. Most HCPs felt that a separate HCP interface to personalize the app would increase the usability of the app in daily practice.

\section{Usability Requirements}

On the basis of the results of phase $2 \mathrm{~A}$, usability requirements were formulated for the software development phase (see Table 1).

Table 1. Usability requirements for the mHealth intervention

\begin{tabular}{ll}
\hline Topics of importance & COPD patients $(\mathbf{n}=\mathbf{6})$ and HCPs $(\mathbf{n}=6)$ \\
to users & - App should be reliable and accessible \\
\hline Content & Information should be straightforward and individualized \\
& - App should provide insight into symptoms over time \\
& - App should support prompt contact with a HCP \\
& - App should be a tool that can be used to get into dialogue with HCPs \\
& about self-management behavior \\
\hline Tailoring of the app & - Intensive monitoring period and timing of notifications should be \\
& - HCPs should have autonomy in determining how, and at which moment in \\
& the care process, the action plan should be reviewed and adjusted \\
\hline Interface & interface \\
\hline Design style & The design style should be restrained and clear without too much text \\
\hline
\end{tabular}

Abbreviation: HCP: health care provider 

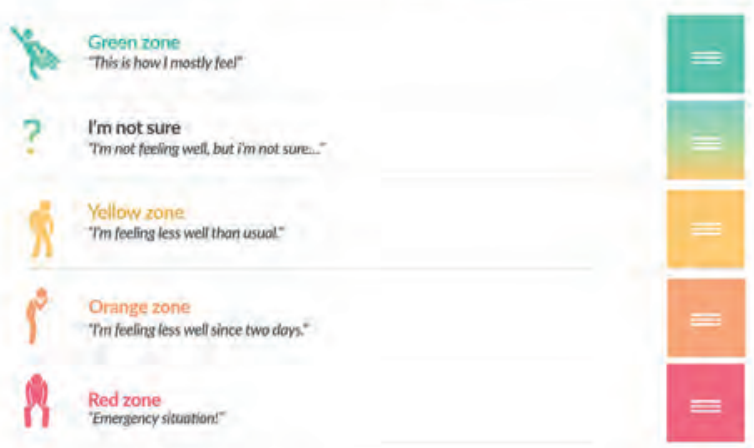

Mockup 1

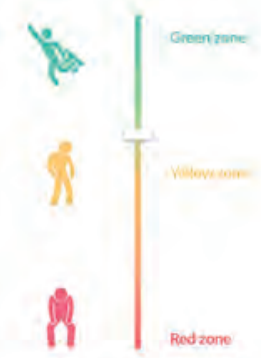

Mockup 2

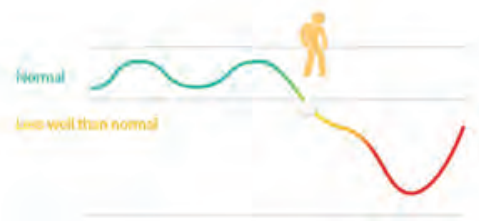

Mockup 3

Figure 3. Low-fidelity paper prototypes of 3 scenarios to determine symptoms status. 


\section{B: Evaluate intervention design style}

In total, three potential design styles of the intervention were explored with patients with COPD (see Baseline characteristics in Appendix 3. Mockups of the action plan, symptom registration, action registration, and the overview of symptoms and actions over time were used (see example in Figure 4). There was no consensus on a preferred design style. In general, patients preferred a restrained and clear design style without too much text. A few patients were positive about a more numerical design, whereas other patients found it hard to express their symptoms in numbers. There was a wide variety in preference regarding the tone of voice (distant vs personal tone of voice). Overall, patients were positive about using symbols. Most patients were negative about using an avatar in the app as it has no added value, and some patients considered an avatar to be childish. On the basis of these results, a restrained and clear design style without too much text was included as a usability requirement (see Table 1).

\section{Phase 3: Iterative software development}

Iterative software development resulted in a functional mobile app for patients (Copilot app) that can be used to (1) compose an action plan together with an HCP (based on a COPD action plan using color zones that is included in Dutch care standards), ${ }^{66}(2)$ monitor symptoms and undertaken actions, (3) review symptoms and undertaken actions, and (4) read information about COPD and exacerbations. At this stage, the final integrated list of BCTs needed to ensure this MVP adhered to both the guiding principles (Textbox 1) and the design requirements (Textbox 4) was constructed by two researchers ( $\mathrm{YK}$ and $\mathrm{SH}$ ) using the BCW framework. In total, 6 intervention functions and 11 BCTs were selected for the MVP (see Figure 2 and Appendix 1). During the iterative software development process, the research team made decisions to add steps to the flow of the app that were not thought of beforehand, such as including an onboarding program to register and personalize the patient's action plan. At the same time, owing to time and financial constraints, some steps were disregarded and moved to later versions of the intervention, such as including assistance in cases where patients are in doubt about contacting their HCP.

\section{Phase 4: Field usability testing}

All functionalities of the MVP were tested by patients with COPD, and all functionalities that belong to the HCP role were evaluated with HCPs (see baseline characteristics in Appendix 3). Examples of the MVP are shown in Figure 5. 

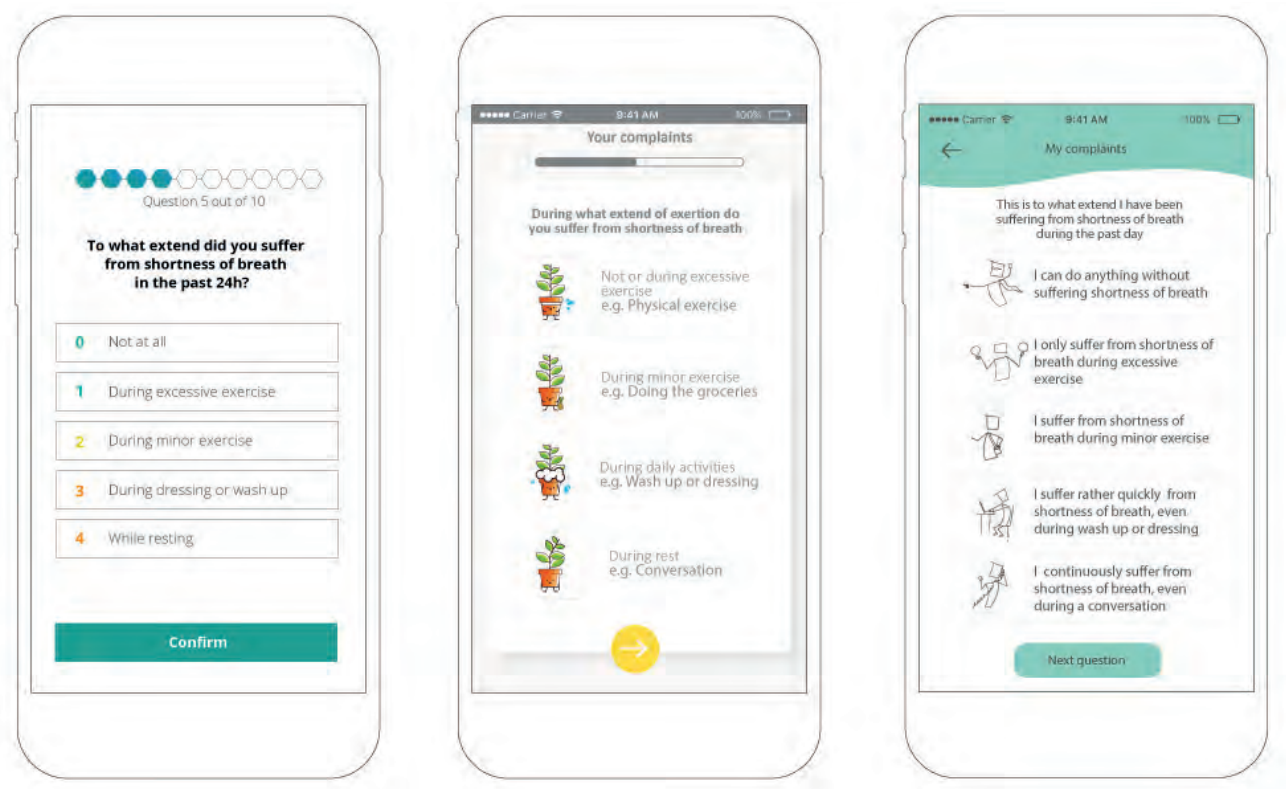

Figure 4. Low-fidelity paper prototypes of three symptom monitoring design styles
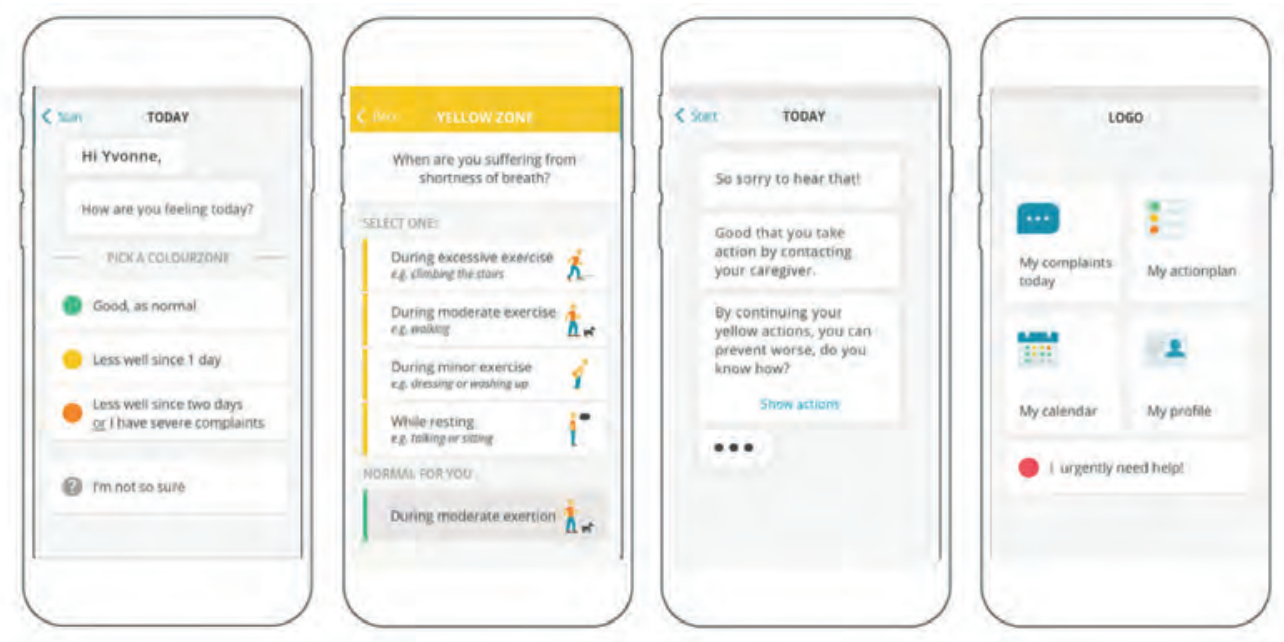

Figure 5. High-fidelity prototype of the Copilot app (minimum viable product) 


\section{Usability assessment}

According to patients with COPD, the general usability of the MVP was considered to be good based on the average rating of 90.7 (SD 6.7) on the SUS.

\section{Task success}

Key tasks within the app were performed by all patients, and some tasks were performed only by a few patients because of time constraints (see Appendix 4). Almost all patients were successful in consulting the app for HCP contact details and immediate help as well as to check self-management actions in the specific color zones. Furthermore, reviewing symptoms and undertaken actions was performed successfully overall, except for 2 participants who did not know where to find this overview. The information module was easily found by most of the patients. Most difficulties in the performance of tasks were observed during the symptom and action registration. Most patients were able to fill out their symptoms, but some patients overlooked the save button. One patient experienced difficulty with selecting the right color zone because of difficulty with scenario thinking. The support option for selecting a color zone (gray zone) appeared not to be intuitive, and navigation problems in the gray zone were observed. Overall, the HCPs were able to personalize the action plan and to evaluate the symptom-monitoring period. The performance of tasks by both patients and HCPs is further specified in Appendix 4.

\section{User errors and problems}

On the basis of task analysis and observations during random navigation in the app, 23 user errors and problems were identified by patients with COPD. In total, seven problems were rated with the highest severity score of 4 . These problems were related to saving registered symptoms, accidentally deleting symptoms and navigation in the gray zone. Moreover, five problems had a severity score of 3 and were related to the action plan overview, understanding of buttons on the home screen, and changing HCP contact details. The lowest severity scores ( 1 and 2 ) were assigned to 11 problems. Furthermore, 11 user errors and problems were observed during the use of the app by HCPs. The HCPs experienced problems with saving registered symptoms as well. Another severe problem was related to changing contact details (severity score 4). Two less severe problems were related to personalizing and changing the yellow zone of the action plan (severity score 3). The lowest severity scores (0-2) were assigned to seven problems. A more detailed overview of all user problems and errors is provided in Appendix 4. 


\section{Patients' and health care providers' perceptions toward using the app}

Overall, patients were positive about the app, as they found the app supportive with regard to monitoring and evaluating symptoms and taking prompt actions. On a scale from 1 to 10, patients' satisfaction rates ranged from 8 to 10 because of the ease of use and the interface being intuitive. The patients who frequently experienced exacerbations expressed an important need for the app. Two patients who rarely experienced exacerbations explained that the app will only have an added value if additional support would be provided during the stable phase (green zone). The interviews resulted in 13 themes that were categorized into feelings about the app, the added value of the app, the content of the app, and facilitators and barriers to use the app. A description of these themes and illustrative quotes is provided in Appendix 4.

Field usability testing showed that a usable mHealth intervention has been developed. On the basis of these results, improvements for future versions of the app were revealed. The improvements were determined in collaboration with the designers and focus on the user errors and problems that were rated as most severe (severity ratings 3 and 4), problems that were observed in both patients and HCPs, or additional problems that were mentioned in the interviews. An overview of these improvements is shown in Appendix 4.

\section{Business modeling}

Business modeling resulted in a preliminary business plan that provided important design input during the development steps and will direct future development and implementation steps. The business plan guided the direction to actively involve HCPs in providing the intervention to patients and the specific focus on developing self-management skills over time (learning by doing) to be distinctive from other Dutch mHealth solutions. These outcomes were added to the design requirements (Textbox 4). During business modeling, market volume, and segmentation, different innovation and distribution routes and revenue models were systematically evaluated. Given current positive developments with regard to funding of apps in the Netherlands, especially those that are evidencedriven, a distribution strategy will be chosen that includes health care insurers to ensure implementation and continued use in Dutch COPD care. 


\section{Discussion}

\section{Principal findings}

This paper provides insight into a systematic and thorough way of developing an evidence-driven and usable mHealth intervention (Copilot) for patients with COPD to enhance exacerbation-related self-management. Following an iterative UCD process, a mobile app consisting of a personalized action plan and symptommonitoring module has been developed. The intervention was developed by following a thorough and well-underpinned process consisting of a background analysis and design conceptualization phase leading to final guiding principles, a logic model and design requirements, usability testing phases leading to usability requirements, and iterative software development of an MVP that adheres to these guiding principles and design and usability requirements. This unique approach of scientific engineering has resulted in an mHealth intervention that meets the needs and preferences of patients with COPD, is likely to be used by patients with COPD, and has a high potential to be effective in reducing exacerbation impact. Involving patients with COPD, HCPs, COPD experts, and experts from design and behavioral science throughout the development process increased the likelihood that the mHealth intervention can be successfully implemented into Dutch COPD care.

Copilot requires an active case manager role, as previous studies have shown the need for ongoing case manager support alongside the use of an action plan to achieve effective and safe self-management. ${ }^{11,67}$ The mHealth intervention was developed as a tool to enhance patient self-management skills that is complementary to personal interaction with an HCP. This is in line with recent research underlining that a good patient-HCP relationship is important for patients to engage and take responsibility for their own health care. ${ }^{68,69}$ The specific focus on developing self-management skills over time is distinctive from other mHealth initiatives, as research in the past decade has focused increasingly on telemonitoring strategies to decrease the impact of exacerbations. ${ }^{21,70,71}$ The impact of telemonitoring in the COPD population is, however, still equivocal because of trial designs, unstandardized interventions, and limited follow-up. ${ }^{21,70}$ With telemonitoring, the decision-making process is profession based. The working mechanism of Copilot focuses on enhancing patients' self-management skills over time. Therefore, no telemonitoring strategies were included in our mHealth intervention. 
Although our Delphi study has shown the need for a comprehensive strategy to improve the full spectrum of exacerbation-related self-management behavior, ${ }^{15}$ the first version of our mHealth intervention focuses specifically on selfmonitoring of symptoms and taking prompt individualized self-management actions. A less is more approach consisting of only a few strong target behaviors that fit together was considered to be imperative in creating impact. ${ }^{41,65}$ When changing these target behaviors is proven effective, we could build upon these behaviors incrementally. ${ }^{41}$ It is important to note that not all relevant selfmanagement behaviors have to be addressed through mHealth, as HCPs should continue to have an essential role in providing self-management support as well. ${ }^{31}$

\section{Strengths and limitations}

A major strength was the systematic and thorough way of developing Copilot according to a UCD that was based on existing development models and diminished the chance of missing important steps. ${ }^{33,34}$ We have systematically investigated and incorporated the views of end users, continuously evaluated prototypes, and involved persuasive design techniques to match user profiles and motivate patients to engage in self-management, which is in line with the personbased approach and the holistic framework for the development of electronic health (eHealth) technologies.32,72 Furthermore, we used guiding principles to easily recall the principal and distinctive features of the intervention during the extensive, iterative intervention development process. ${ }^{32}$ Another important strength was the detailed analysis of behaviors of patients with COPD using the BCW method and selection of BCTs to underpin the pathway toward behavior change. ${ }^{41}$ Using the BCW method along with a UCD is comparable with the methodology used by Curtis et $\mathrm{a}^{22}$ to develop a theory-driven and user-centered healthy eating app. Their work also focused on a thorough analysis of target behaviors, selection of BCTs, and exploration of user preferences to underpin the design of the app with relevant theory and evidence and ensure engagement among the target population. However, Curtis et $a^{22}$ performed no specific activities with regard to valorization and implementation of their app during their development process. ${ }^{22}$ To make both the design and the implementation of our app value driven, we performed valorization activities throughout the development process of our app..$^{59,72}$ Business modeling helped us to identify critical success factors that will influence the sustainability and effectiveness of the app, which is often overlooked during the development process of eHealth and mHealth technologies. ${ }^{59}$ 
From a health care and behavior change perspective, we chose to use the MRC framework for the development of complex interventions as a basis for our UCD, instead of a more general software development approach. The four iterative phases were inspired by the user-centered methodology used by Johnston et al ${ }^{33}$ for the development of a Web-based interface for patients with COPD. The use of a more general software development approach as a basis for the development process might have provided more specific guidance to the software development and usability phases beforehand. However, such approaches pay less attention to the activities needed to design a theory-and evidence-driven intervention, which was an important focus in our design process.

Furthermore, it should be noted that the extensive and thorough development process increased the likelihood of developing an effective intervention, although it is questionable if this process is feasible in daily practice. The whole intervention development process took place over a 4-year period, which is quite time consuming and could increase the risk of a misfit with current market developments or that technology has moved on by the time of implementation. 22,73,74 The time-consuming development was partly because of the inclusion of all the development phases but was also related to developing an mHealth intervention from a scientific environment. Developing an intervention from science involves completing an empirical cycle at each development phase and often includes an extensive review of a study protocol by a medical ethics research committee. Pursuing the rules of science during the development process of an mHealth intervention has slowed down the process at certain points in time. Furthermore, development from a scientific environment generally means less focus on business modeling and entrepreneurship, which could delay the process of bringing the app to the market. Finally, a limitation in this study was the restricted budget available for the creative design and development of the mHealth intervention, which required us to make a selection in the development of intervention components.

\section{Implications for practice and future research}

The findings of this study are important for both patients with COPD and HCPS supporting patients with COPD in self-management as well as for researchers and designers focusing on the development of mHealth interventions. For patients with COPD, an evidence-driven and usable mobile app has been developed to assist them in developing exacerbation-related self-management skills. It needs to be emphasized that, at least for the coming years, not all patients with COPD will be eligible for the mHealth intervention, especially for those with a more 
negative attitude toward mHealth and low digital literacy. ${ }^{19,31}$ However, a positive change in attitudes toward mHealth and digital skills can be expected in the future, given the current trends in internet access and smartphone use. ${ }^{18}$ For HCPs, the mHealth intervention can be used to provide more evidence-based, structured, and tailored self-management support. The mHealth intervention can be embedded in primary, secondary, and tertiary care settings, which could contribute to improving integrated care. To increase the likelihood of successful implementation in Dutch COPD care, the intervention can easily be adapted to a specific setting and context. Hereby, the intervention would be available for a wide range of health care settings in which patients with COPD are currently treated. For future practice, it is important that more intervention components will be added to the mHealth intervention to optimally address the selected target behaviors, such as adding self-treatment with prednisolone and/or antibiotics and providing assistance in case patients are in doubt about if they should contact their HCP. Furthermore, a separate dashboard for HCPs should be developed to be able to individualize the mHealth intervention and to review registered symptoms and actions during consultations without having to use the patient's own device. An essential step would then be to establish cooperation with external vendors in the field and health care insurers to ensure implementation in COPD care. In the next phase, it is important that the mHealth intervention takes into account patient comorbidities to make the intervention available for a wider population and to ensure patient safety. ${ }^{12}$ Future steps should focus on adding target behaviors that are relevant before, during, and after an exacerbation to maximize the reduction of exacerbation impact.

For researchers and designers, the UCD in this study can be used as guidance for the development of mHealth interventions that meet end user needs and preferences, have high potential to be effective, and are likely to be used by the target population. Essential in the development is that interventions are grounded in theory and evidence and that user needs and preferences are thoroughly investigated. Moreover, valorization and implementation activities should be regarded as continuous activities throughout the development process to ensure sustainable use in its intended practice. This extensive reporting of the intervention development process enhances the reproducibility of the intervention and contributes to more transparency in the development of complex interventions in health care, which is needed to strengthen the internal and external validity of interventions and to add value to health care research. ${ }^{34}$ All in all, it is helpful to have multiple examples and variants on how to develop evidence- and theory-driven mHealth interventions. It should be considered if 
the thoroughness of this UCD is needed for all mHealth interventions that will be developed in the future. Depending on the topic, decisions should be made about which phases and steps are relevant to the topic and should be included in the development process. In addition, taking time aspects into consideration, it should be questioned how thoroughly an individual step should be executed. The need for efficiency in the development of mHealth interventions is currently a highly discussed topic. ${ }^{75}$ Our work contributes to this discussion by mapping out a state-of-the-art design and development process and showing how time consuming this is.

Future research should focus on evaluating the feasibility of the mHealth intervention in the daily practice of HCPs, as they have a key role in personalizing the mHealth intervention before patient use. In a second phase, the feasibility of the mHealth intervention should be evaluated with patients with COPD to investigate the delivery and acceptability of the intervention, compliance with the intervention, and recruitment and retention of patients. In the next phase, the effect of the mHealth intervention on the relevant patient outcomes and health care use should be evaluated. Recent studies on mHealth interventions in patients with COPD suggest the use of randomized controlled trials (RCTs) with adequately powered sample sizes and a 1-year follow-up period to be sufficient to comment on behavioral change and impact of treatment. ${ }^{19,20}$ However, this time-consuming design may not be ideal for rapidly evolving mHealth technologies. ${ }^{73,76}$ Using an RCT implies two or more years of research in which this mHealth intervention with high potential for effectiveness, and no expected harm will not be available for patients with COPD. Furthermore, an RCT only enables identifying if this complex mHealth intervention as a whole work and the cost-effectiveness of it, without identifying which intervention components work in whom. Alternatively, more rapid study designs such as n-of-1 trials or observational designs could be used to understand the working mechanism of the intervention and simultaneously focus on bringing the mHealth intervention to the market as soon as possible. . $33,75-77^{-1}$ Within these designs, it is important to evaluate self-management skills and behavior change as outcomes, and the way this is assessed should be clearly reported. ${ }^{19,77,78}$ 


\section{Conclusion}

This paper described in detail the full UCD and development process of an evidence-driven and usable mHealth intervention to enhance exacerbationrelated self-management in patients with COPD. By following a UCD process, an mHealth intervention was developed that meets the needs and preferences of patients with COPD, is likely to be used by patients with COPD, and has a high potential to be effective in reducing exacerbation impact. This extensive reporting of the intervention development process contributes to more transparency in the development of complex interventions in health care. The UCD process in this study can be used by researchers and designers as guidance for the development of mHealth interventions. However, taking time aspects into consideration, decisions have to be made about the thoroughness of executing individual phases. 


\section{References}

1. World Health Organization. The Global Burden of Disease: Update 2004. Available from: http:// www.who.int/healthinfo/global_burden_disease/GBD_report_2004update_full.pdf?ua=1. Updated 2008. Accessed June 12, 2018.

2. Global Initiative for Chronic Obstructive Lung Disease (GOLD). Global Strategy for the Diagnosis, Management, and Prevention of Chronic Obstructive Pulmonary Disease. [updated 2018]. Available from: https://goldcopd.org/wp-content/uploads/2017/11/GOLD-2018-v6.0-FINAL-revised-20Nov_WMS.pdf. Accessed June 12, 2018.

3. Donaldson GC, Seemungal TA, Bhowmik A, Wedzicha JA. Relationship between exacerbation frequency and lung function decline in chronic obstructive pulmonary disease. Thorax. 2002;57(10):847-852.

4. Seemungal TA, Donaldson GC, Paul EA, Bestall JC, Jeffries DJ, Wedzicha JA. Effect of exacerbation on quality of life in patients with chronic obstructive pulmonary disease. Am J Respir Crit Care Med. 1998;157(5 Pt 1):1418-1422.

5. Miravitlles M, Ferrer M, Pont A, et al. Effect of exacerbations on quality of life in patients with chronic obstructive pulmonary disease: a 2 year follow up study. Thorax. 2004;59(5):387-395.

6. Toy EL, Gallagher KF, Stanley EL, Swensen AR, Duh MS. The economic impact of exacerbations of chronic obstructive pulmonary disease and exacerbation definition: a review. COPD. 2010;7(3):214-228.

7. Soler-Cataluña JJ, Martínez-García MA, Sánchez PR, Salcedo E, Navarro M, Ochando R. Severe acute exacerbations and mortality in patients with chronic obstructive pulmonary disease. Thorax. 2005;60(11):925-931.

8. Rodriguez-Roisin R. Toward a consensus definition for COPD exacerbations. Chest. 2000;117(5 Suppl 2):398S-401S.

9. Bourbeau J, van der Palen J. Promoting effective self-management programmes to improve COPD. Eur Respir J. 2009;33(3):461-463.

10. Barlow J, Wright C, Sheasby J, Turner A, Hainsworth J. Self-management approaches for people with chronic conditions: a review. Patient Educ Couns. 2002;48(2):177-187.

11. Howcroft M, Walters EH, Wood-Baker R, Walters JA. Action plans with brief patient education for exacerbations in chronic obstructive pulmonary disease. Cochrane Database Syst Rev. 2016;19;12:CD005074.

12. Lenferink A, Brusse-Keizer M, van der Valk PD, Frith PA, Zwerink M, Monninkhof EM, et al. Selfmanagement interventions including action plans for exacerbations versus usual care in patients with chronic obstructive pulmonary disease. Cochrane Database Syst Rev. 2017;4;8:CD011682.

13. Jonkman NH, Westland H, Trappenburg JC, Groenwold RH, Bischoff EW, Bourbeau J, et al. Characteristics of effective self-management interventions in patients with COPD: individual patient data meta-analysis. Eur Respir J. 2016; 48(1):55-68.

14. Trappenburg J, Jonkman $N$, Jaarsma $T$, van Os-Medendorp $H$, Kort $H$, de Wit $N$, et al. Selfmanagement: one size does not fit all. Patient Educ Couns. 2013;92(1):134-137.

15. Korpershoek YJ, Slot JC, Effing TW, Schuurmans MJ, Trappenburg JC. Self-management behaviors to reduce exacerbation impact in COPD patients: a Delphi study. Int J Chron Obstruct Pulmon Dis. 2017; 12:2735-2746.

16. Effing TW, Vercoulen JH, Bourbeau J, Trappenburg J, Lenferink A, Cafarella P, et al. Definition of a COPD self-management intervention: International Expert Group consensus. Eur Respir J. 2016; 48(1):46-54.

17. Schnall R, Rojas M, Bakken S, Brown W, Carballo-Dieguez A, Carry M, et al. A user-centered model for designing consumer mobile health (mHealth) applications (apps). J Biomed Inform. 2016;60:243-251. 
18. World Health Organisation. mHealth. new horizons for health through mobile technologies. Available from: http://www.who.int/goe/publications/goe_mhealth_web.pdf. Updated 2011. Accessed August 3, 2018

19. McCabe C, McCann M, Brady AM. Computer and mobile technology interventions for self-management in chronic obstructive pulmonary disease. Cochrane Database Syst Rev. 2017;23;5:CD011425.

20. Alwashmi M, Hawboldt J, Davis E, Marra C, Gamble J, Ashour WA. The effect of smartphone interventions on patients with chronic obstructive pulmonary disease exacerbations: a systematic review and meta-analysis. JMIR Mhealth Uhealth. 2016;1;4(3):e105.

21. McLean S, Nurmatov U, Liu JL, Pagliari C, Car J, Sheikh A. Telehealthcare for chronic obstructive pulmonary disease: Cochrane Review and meta-analysis. BrJ Gen Pract. 2012;62(604):e739-e749.

22. Curtis KE, Lahiri S, Brown KE. Targeting parents for childhood weight management: development of a theory-driven and user-centered healthy eating app. JMIR Mhealth Uhealth. 2015;3(2):e69.

23. Glanz K, Bishop DB. The role of behavioral science theory in development and implementation of public health interventions. Annu Rev Public Health. 2010;31:399-418.

24. Hagger MS, Weed M. DEBATE: Do interventions based on behavioral theory work in the real world? Int J Behav Nutr Phys Act. 2019;16(1):36.

25. Michie S, Carey RN, Johnston M, Rothman AJ, de Bruin M, Kelly MP, et al. From theory-inspired to theory-based interventions: a protocol for developing and testing a methodology for linking behaviour change techniques to theoretical mechanisms of action. Ann Behav Med. 2018;18;52(6):501-512.

26. Sheeran $\mathrm{P}, \mathrm{Klein} \mathrm{WM}$, Rothman AJ. Health behavior change: moving from observation to intervention. Annu Rev Psychol. 2017; 3;68:573-600.

27. Prestwich A, Sniehotta FF, Whittington C, Dombrowski SU, Rogers L, Michie S. Does theory influence the effectiveness of health behavior interventions? Meta-analysis. Health Psychol. 2014;;33(5):465-474.

28. Conn VS, Hafdahl AR, Cooper PS, Brown LM, Lusk SL. Meta-analysis of workplace physical activity interventions. Am J Prev Med. 2009;37(4):330-339.

29. Michie S, Brown J, Geraghty AW, Miller S, Yardley L, Gardner B, et al. Development of StopAdvisor: A theory-based interactive internet-based smoking cessation intervention. Trans/ Behav Med. 2012; Sep;2(3):263-275.

30. Korpershoek Y, Vervoort S, Nijssen L, Trappenburg J, Schuurmans MJ. Factors influencing exacerbation-related self-management in patients with COPD: a qualitative study. Int J Chron Obstruct Pulmon Dis. 2016;11:2977-2990.

31. Korpershoek YJ, Vervoort SC, Trappenburg JC, Schuurmans MJ. Perceptions of patients with chronic obstructive pulmonary disease and their health care providers towards using mHealth for self-management of exacerbations: a qualitative study. BMC Health Serv Res. 2018;4;18(1):757.

32. Yardley L, Ainsworth B, Arden-Close E, Muller I. The person-based approach to enhancing the acceptability and feasibility of interventions. Pilot Feasibility Stud. 2015;1:37.

33. Johnston SK, Nguyen HQ, Wolpin S. Designing and testing a web-based interface for selfmonitoring of exercise and symptoms for older adults with chronic obstructive pulmonary disease. Comput Inform Nurs. 2009;27(3):166-174.

34. Bleijenberg N, Ginkel JM, Trappenburg JC, Ettema RG, Sino CG, Heim N, et al. Increasing value and reducing waste by optimizing the development of complex interventions: Enriching the development phase of the Medical Research Council (MRC) Framework. Int J Nurs Stud. 2018;79:86-93.

35. Craig P, Dieppe P, Macintyre S, Michie S, Nazareth I, Petticrew M, Medical Research Council Guidance. Developing and evaluating complex interventions: the new Medical Research Council guidance. Br Med J. 2008;29;337:a1655. 
36. Strauss AL, Corbin J. Basics of Qualitative Research: Techniques and Procedures for Developing Grounded Theory. Third Edition. Thousand Oaks, CA: Sage Publications; 2007.

37. van Meijel B, Gamel C, van Swieten-Duijfjes B, Grypdonck MH. The development of evidencebased nursing interventions: methodological considerations. J Adv Nurs. 2004;48(1):84-92.

38. Shah SG, Robinson I, AIShawi S. Developing medical device technologies from users' perspectives: a theoretical framework for involving users in the development process. Int J Technol Assess Health Care. 2009;25(4):514-521.

39. Krueger RA, Casey MA. Focus Groups: A Practical Guide for Applied Research. Fourth Edition. Los Angeles: Sage; 2008.

40. Boeije H. Analysis in Qualitative Research. London: Sage Publications; 2009.

41. Michie S, Atkins L, West R. The Behaviour Change Wheel: A Guide to Designing Interventions. Great Britain: Silverback; 2014.

42. Baxter SK, Blank L, Woods HB, Payne N, Rimmer M, Goyder E. Using logic model methods in systematic review synthesis: describing complex pathways in referral management interventions. BMC Med Res Methodol. 2014;10;14:62.

43. West R, Michie S. A Guide to Development and Evaluation of Digital Behavior Change Interventions in Health Care. London: Silverback Publishing; 2016.

44. Scholten $\mathrm{H}$, Granic I. Use of the principles of design thinking to address limitations of digital mental health interventions for youth: viewpoint. J Med Internet Res. 2019;14;21(1):e11528.

45. Wiklund M, Kendler JA, Strochlic A. Usability Testing of Medical Devices. Second Edition. Boca Raton, FL: CRC press; 2011.

46. Lynn MR. Determination and quantification of content validity. Nurs Res. 1986;35(6):382-385.

47. Kushniruk AW, Patel VL. Cognitive and usability engineering methods for the evaluation of clinical information systems.J Biomed Inform. 2004;37(1):56-76.

48. Braun V, Clarke V. Using thematic analysis in psychology. Qual Res Psychol. 2006;3(2):77-101.

49. van Amstel DP, Heemskerk M, Renes RJ, Hermsen S. The value of agile methods in designing for behavioural change: a case study. Des J. 2017;20(sup1):S681-S690.

50. Kushniruk AW, Patel VL, Cimino Jj. Usability testing in medical informatics: cognitive approaches to evaluation of information systems and user interfaces. Proc AMIA Annu Fall Symp. 1997:218222.

51. Nielsen J. Usability Engineering. Boston, MA: Academic Press; 1993.

52. Brooke J. System Usability Scale (SUS). Available from: https://www.usability.gov/how-to-andtools/methods/system-usability-scale.html. Updated 1986. Accessed September 2, 2018.

53. Science Direct. System Usability Scale. Available from: https://www.sciencedirect.com/topics/ computer-science/system-usability-scale. Updated 2019. Accessed May 23, 2019.

54. Crane D, Garnett C, Brown J, West R, Michie S. Factors influencing usability of a smartphone app to reduce excessive alcohol consumption: think aloud and interview studies. Front Public Health;2017;5:39. doi:10.3389/fpubh.2017.00039.

55. Davis FD, Bagozzi RP, Warshaw PR. User acceptance of computer technology: a comparison of two theoretical models. Manag Sci. 1989;5(8):982-1003.

56. Nielsen J. Nielsen Norman Group. Success Rate: The Simplest Usability Metric 2001. Available from: https://www.nngroup.com/articles/success-rate-the-simplest-usability-metric/. Accessed November 28, 2017.

57. Nielsen J. Nielsen Norman Group. 1994. Severity Ratings for Usability Problems. Available from: https://www.nngroup.com/articles/how-to-rate-the-severity-of-usability-problems/. Accessed November 21, 2017.

58. Ries E. The Lean Startup: How Today's Entrepreneurs Use Continuous Innovation To Create Radically Successful Businesses. USA: Crown Publishing Group; 2011. 
59. van Limburg M, van Gemert-Pijnen JE, Nijland N, Ossebaard HC, Hendrix RM, Seydel ER. Why business modeling is crucial in the development of eHealth technologies. J Med Internet Res. 2011;28;13(4):e124.

60. Zwerink M, Brusse-Keizer M, van der Valk PD, Zielhuis GA, Monninkhof EM, van der Palen J, et al. Self-management for patients with chronic obstructive pulmonary disease. Cochrane Database Syst Rev. 2014;19(3):CD002990.

61. Harrison SL, Janaudis-Ferreira T, Brooks D, Desveaux L, Goldstein RS. Self-management following an acute exacerbation of COPD: a systematic review. Chest. 2015;147(3):646-661.

62. Long Alliantie Nederland (LAN). [National Care Path COPD Lung Attack with Hospitalization]. Netherlands: Long Alliantie Nederland; 2019.

63. Nederlands Huisartsen Genootschap. NHG standaard COPD. Available from: https://www.nhg. org/standaarden/volledig/nhg-standaard-copd. Updated 2015. Accessed June 1, 2017.

64. Long Alliantie Nederland (LAN). [COPD Care Standard]. Netherlands: Long Alliantie Nederland; 2016.

65. Richards DA. Complex interventions and the amalgamation of marginal gains: A way forward for understanding and researching essential nursing care? Int J Nurs Stud. 2015;52(7):1143-1145.

66. Trappenburg JC, Monninkhof EM, Bourbeau J, Troosters T, Schrijvers AJ, Verheij TJ, et al. Effect of an action plan with ongoing support by a case manager on exacerbation-related outcome in patients with COPD: a multicentre randomized controlled trial. Thorax. 2011;66(11):977-984.

67. Effing T. Action plans and case manager support may hasten recovery of symptoms following an acute exacerbation in patients with chronic obstructive pulmonary disease (COPD). J Physiother; 2012;58(1):60.

68. Luhr K, Holmefur M, Theander K, Eldh AC. Patient participation during and after a selfmanagement programme in primary healthcare - The experience of patients with chronic obstructive pulmonary disease or chronic heart failure. Patient Educ Couns. 2018;101(6):11371142.

69. Andersen IC, Thomsen TG, Bruun P, Bødtger U, Hounsgaard L. Between hope and hopelessness: COPD patients' and their family members' experiences of interacting with healthcare providers a qualitative longitudinal study. Scand J Caring Sci. 2018;32(3):1197-1206.

70. Goldstein RS, O'Hoski S. Telemedicine in COPD: time to pause. Chest. 2014;145(5):945-949. doi:10.1378/chest.13-1656.

71. McKinstry B. The use of remote monitoring technologies in managing chronic obstructive pulmonary disease. QJ Med. 2013;106(10):883-885.

72. van Gemert-Pijnen JE, Nijland N, van Limburg M, Ossebaard HC, Kelders SM, Eysenbach G, et al. A holistic framework to improve the uptake and impact of eHealth technologies. J Med Internet Res. 2011;5;13(4):e111.

73. Riley WT, Glasgow RE, Etheredge L, Abernethy AP. Rapid, responsive, relevant (R3) research: a call for a rapid learning health research enterprise. Clin Trans/ Med. 2013;10;2(1):10.

74. Ben-Zeev D, Schueller SM, Begale M, Duffecy J, Kane JM, Mohr DC. Strategies for mHealth research: lessons from 3 mobile intervention studies. Adm Policy Ment Health. 2015;42(2):157-167.

75. McCallum C, Rooksby J, Gray CM. Evaluating the impact of physical activity apps and wearables: interdisciplinary review. JMIR Mhealth Uhealth. 2018;23;6(3):e58.

76. Kumar S, Nilsen WJ, Abernethy A, Atienza A, Patrick K, Pavel M, et al. Mobile health technology evaluation: the mHealth evidence workshop. Am J Prev Med. 2013;45(2):228-236.

77. Michie S, Yardley L, West R, Patrick K, Greaves F. Developing and evaluating digital interventions to promote behavior change in health and health care: recommendations resulting from an international workshop. J Med Internet Res. 2017;19(6):e232.

78. Effing TW, Bourbeau J, Vercoulen J, Apter AJ, Coultas D, Meek P, et al. Self-management programmes for COPD: moving forward. Chron Respir Dis. 2012;9(1):27-35. 


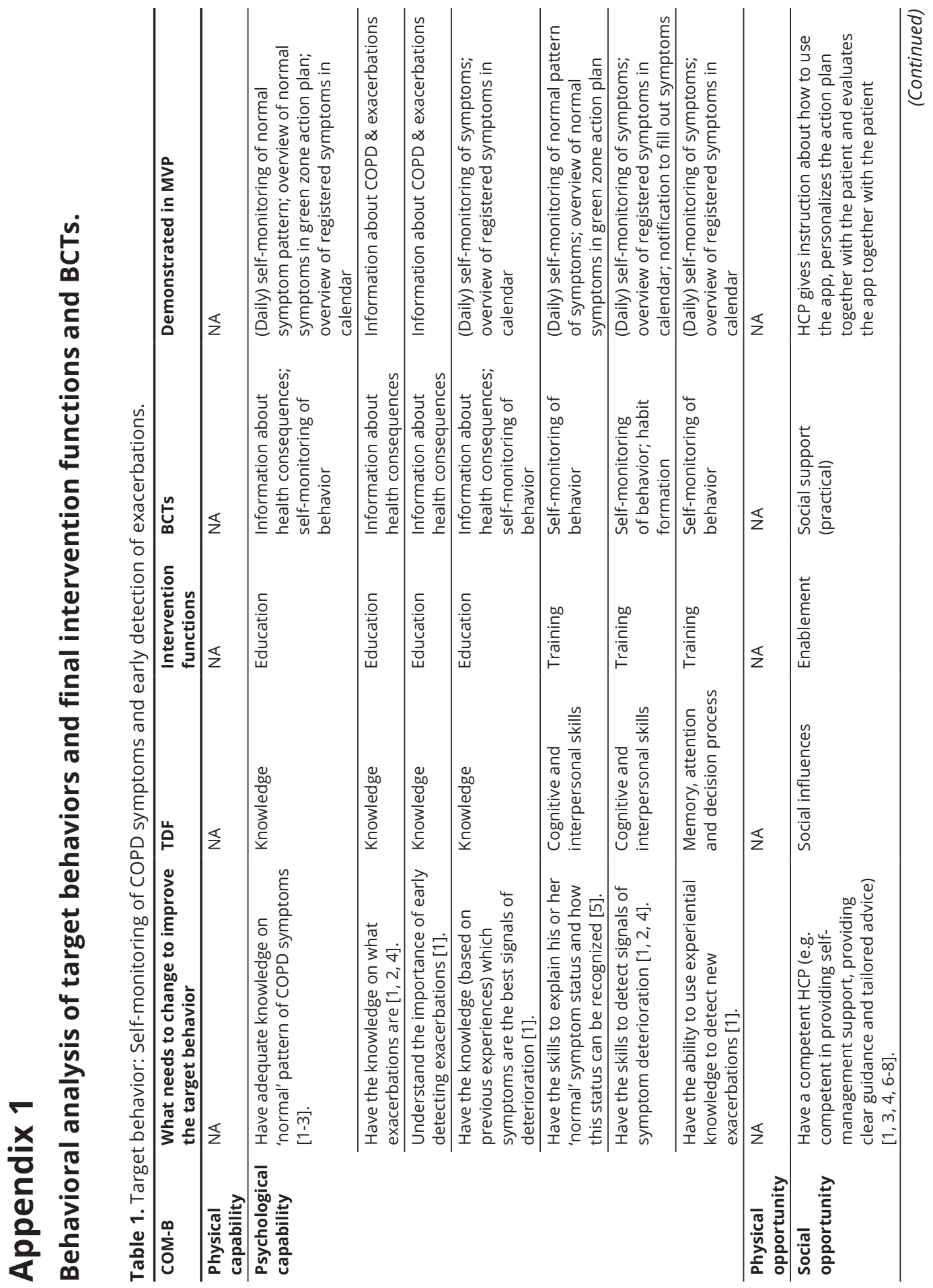




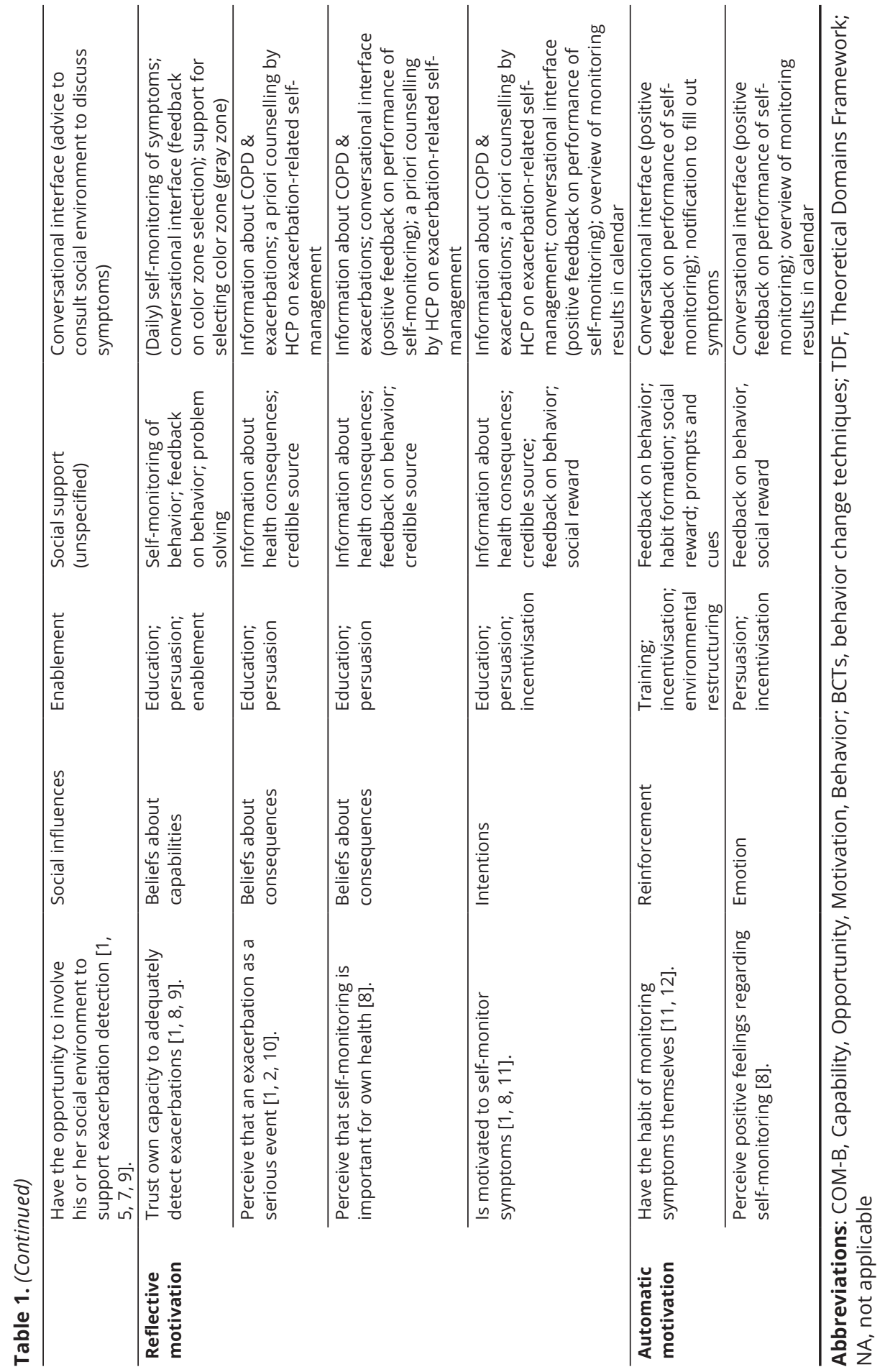




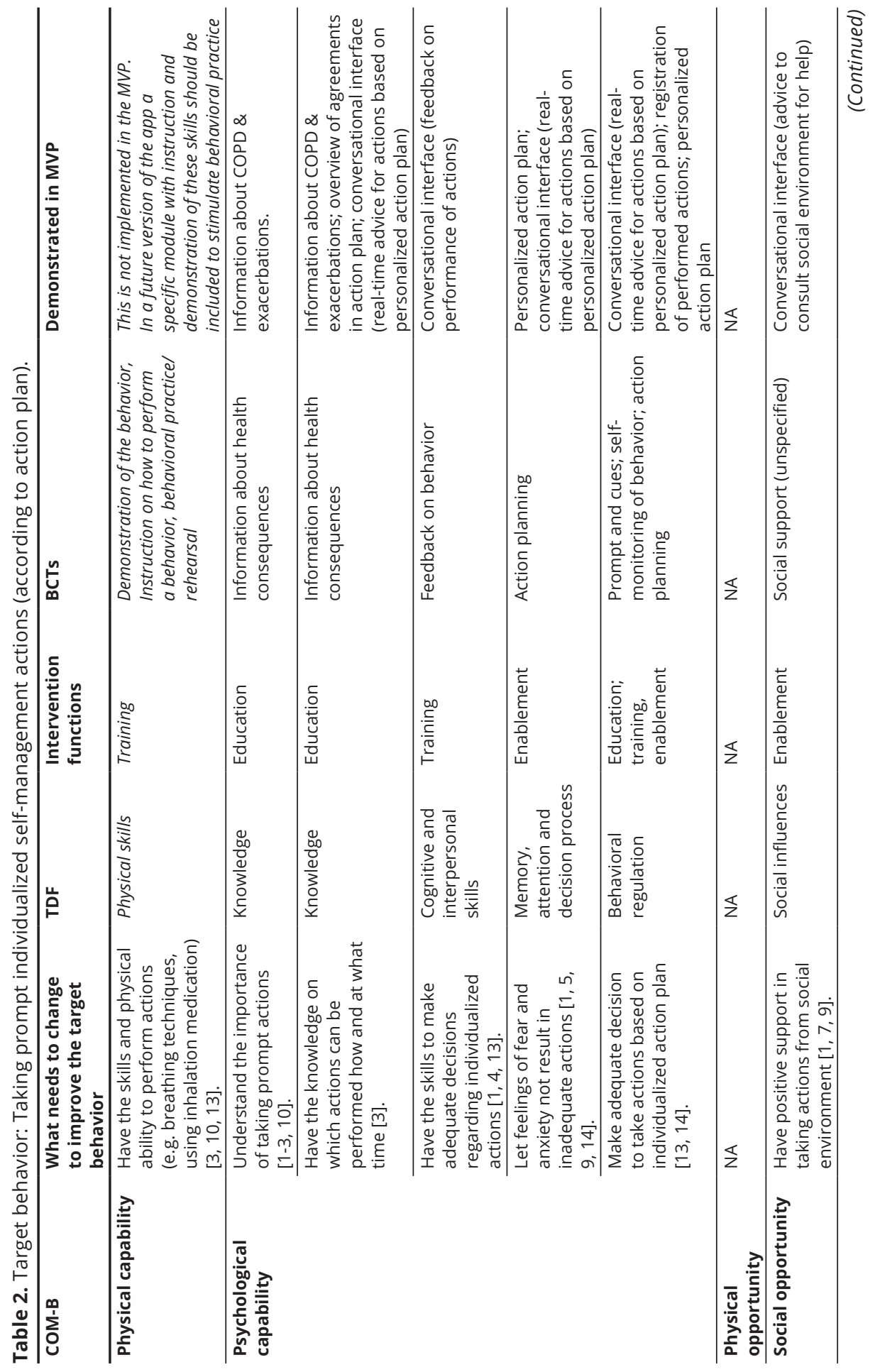




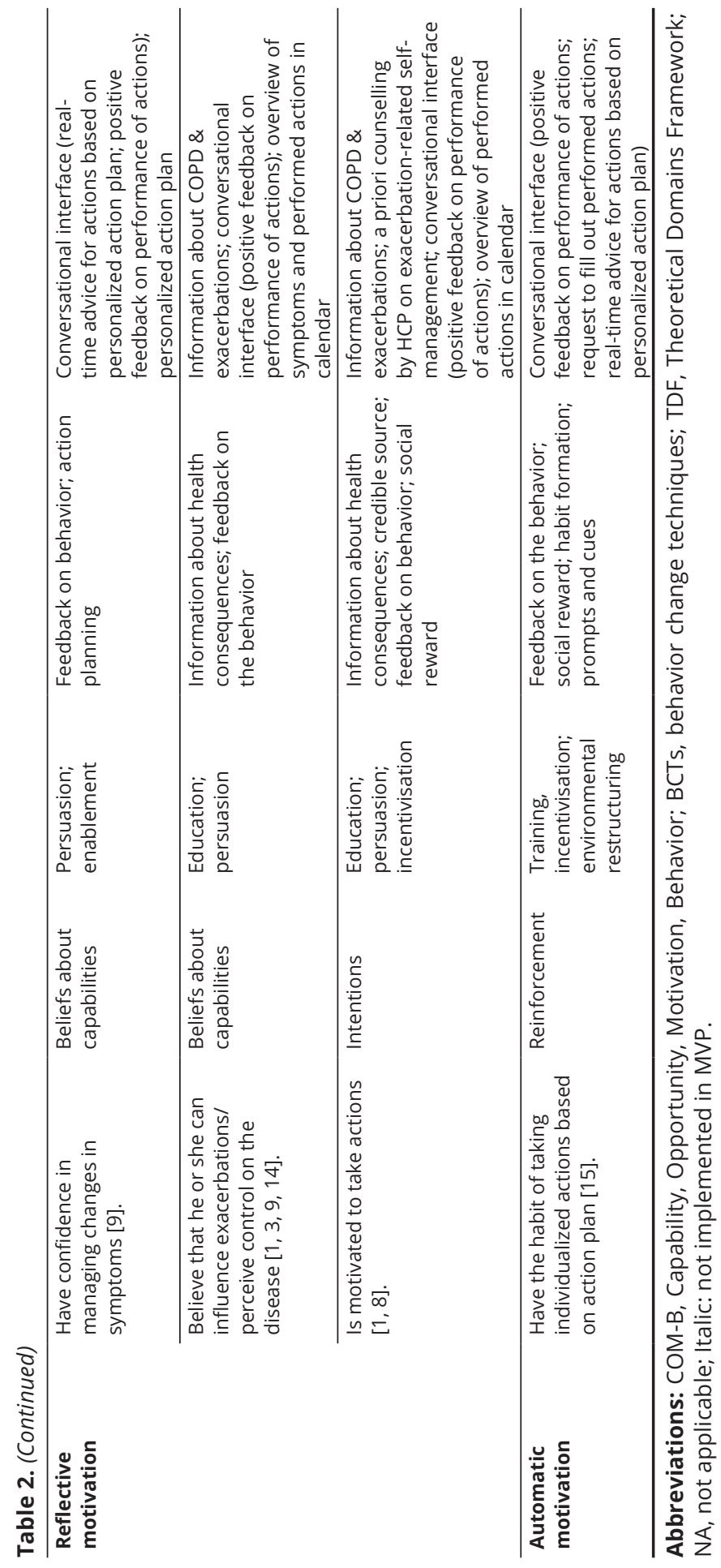




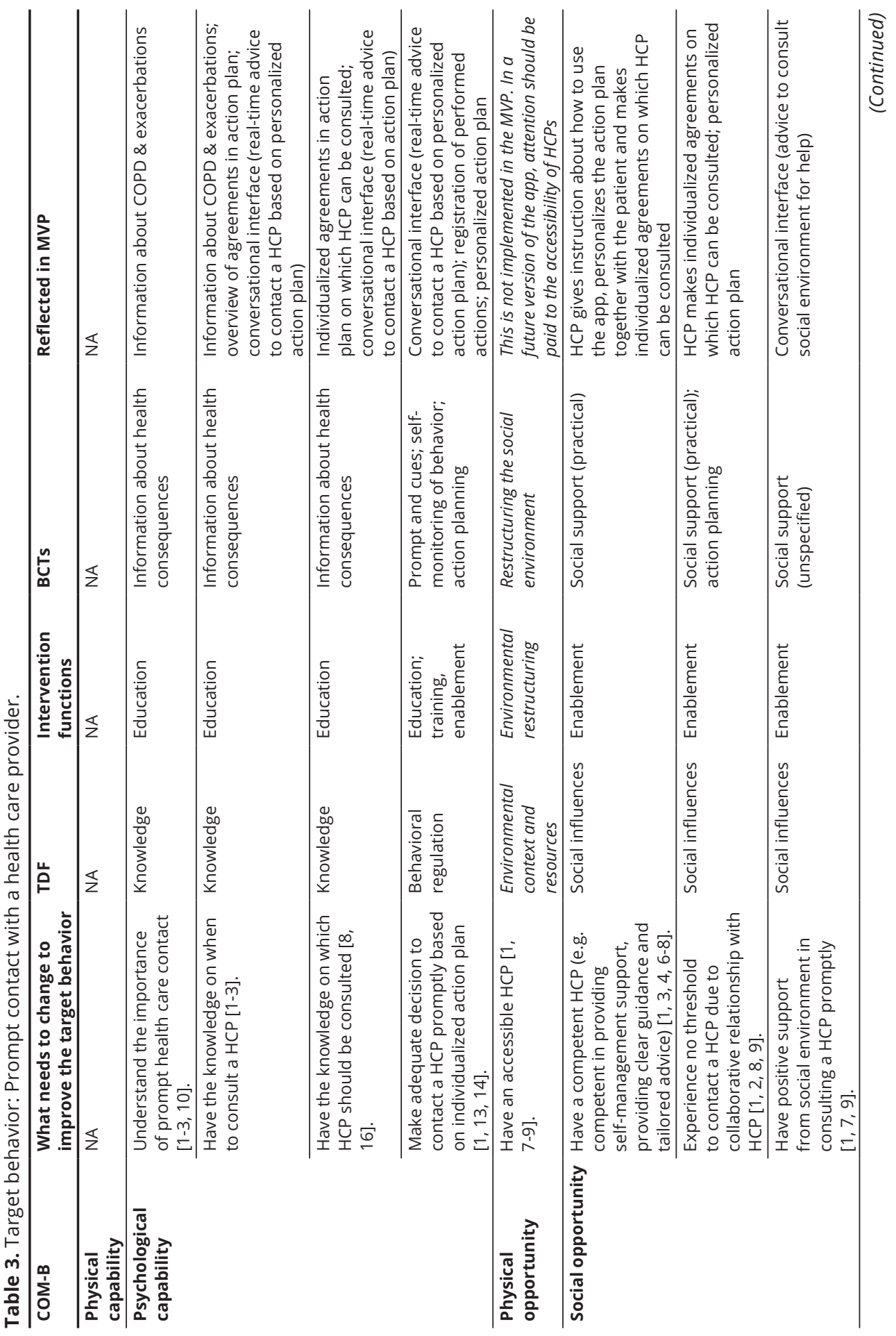




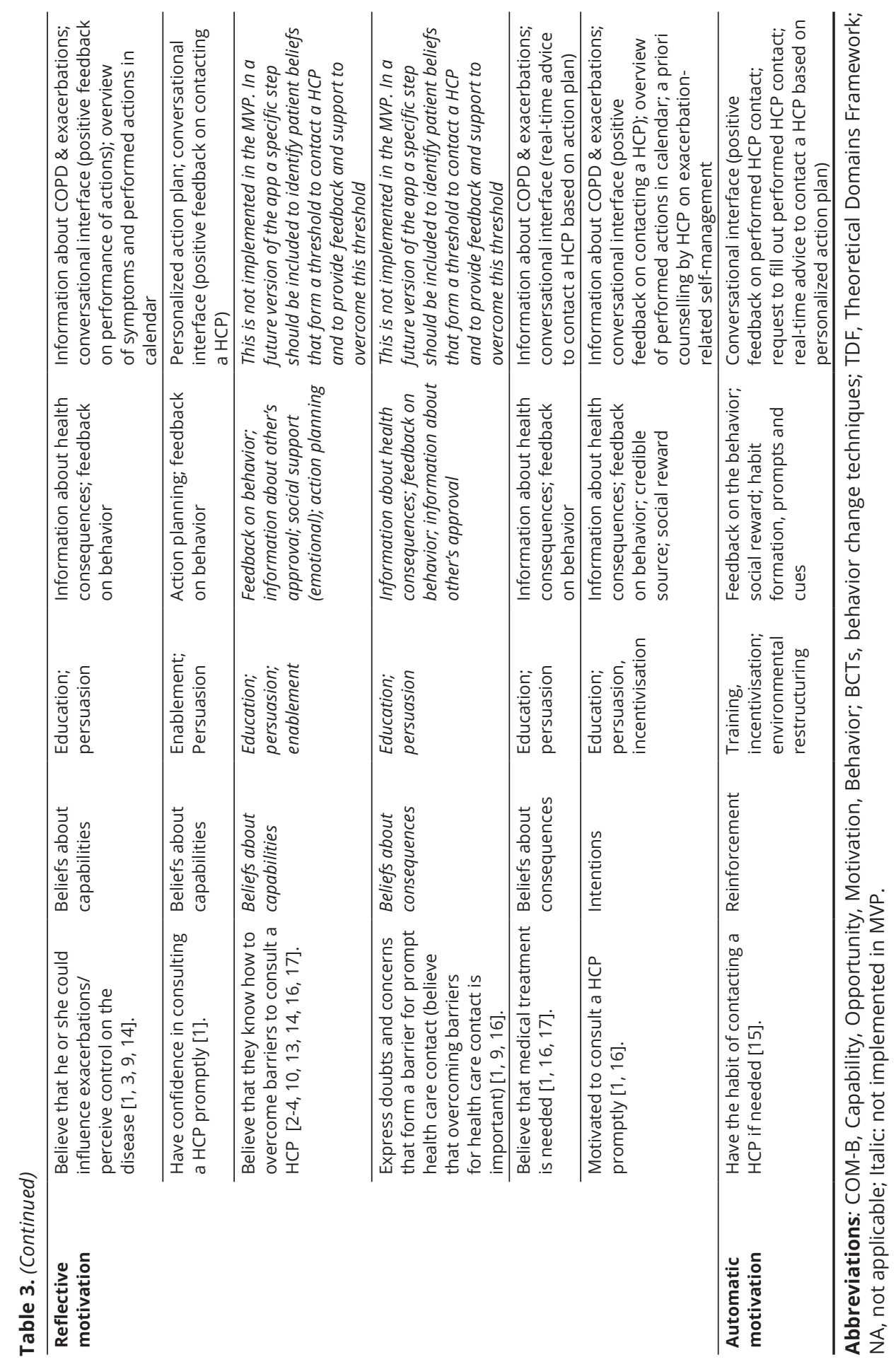




\section{References}

1. Korpershoek $Y$, Vervoort $S$, Nijssen $L$, et al. Factors influencing exacerbation-related selfmanagement in patients with COPD: a qualitative study. Int J Chron Obstruct Pulmon Dis. 2016;28; 11:2977-2990. PMID: 27932877.

2. Adams R, Chavannes N, Jones K, et al. Exacerbations of chronic obstructive pulmonary disease-a patients' perspective. Prim Care Respir J. 2006;15(2):102-109.

3. Hernandez P, Balter M, Bourbeau J, et al. Living with chronic obstructive pulmonary disease: a survey of patients' knowledge and attitudes. Respir Med. 2009;103(7):1004-1012.

4. Kessler R, Stahl E, Vogelmeier C, et al. Patient understanding, detection, and experience of COPD exacerbations: an observational, interview-based study. Chest; 2006 Jul; 130(1):133-142.

5. Harrison SL, Apps L, Singh SJ, et al. 'Consumed by breathing' - a critical interpretive metasynthesis of the qualitative literature. Chronic IIIn. 2014; 10(1):31-49.

6. Wortz K, Cade A, Menard JR, et al. A qualitative study of patients' goals and expectations for selfmanagement of COPD. Prim Care Respir J .2012; 21(4):384-391.

7. Cicutto L, Brooks D, Henderson K. Self-care issues from the perspective of individuals with chronic obstructive pulmonary disease. Patient Educ Couns. 2004;55(2):168-176.

8. Korpershoek YJG, Vervoort SCJM, Trappenburg JCA, et al. Perceptions of patients with chronic obstructive pulmonary disease and their health care providers towards using mHealth for selfmanagement of exacerbations: a qualitative study. BMC Health Serv Res. 2018; 4; 18(1):757-0183545-4.

9. Disler RT, Gallagher RD, Davidson PM. Factors influencing self-management in chronic obstructive pulmonary disease: an integrative review. Int J Nurs Stud. 2012;49(2):230-242.

10. Barnes N, Calverley PM, Kaplan A, et al. Chronic obstructive pulmonary disease and exacerbations: patient insights from the global Hidden Depths of COPD survey. BMC Pulm Med. 2013; 13:54-2466-13-54.

11. Huniche L, Dinesen B, Nielsen C, et al. Patients' use of self-monitored readings for managing everyday life with COPD: a qualitative study. Telemed J E Health. 2013; 19(5):396-402.

12. Perski $\mathrm{O}$, Blandford $\mathrm{A}$, West $\mathrm{R}$, et al. Conceptualising engagement with digital behaviour change interventions: a systematic review using principles from critical interpretive synthesis. Trans/ Behav Med. 2017; 7(2):254-267.

13. Trappenburg JC, Schaap D, Monninkhof EM, et al. How do COPD patients respond to exacerbations?. BMC Pulm Med. 2011; 11:43-2466-11-43.

14. Dowson CA, Town GI, Frampton C, et al. Psychopathology and illness beliefs influence COPD self-management. J Psychosom Res. 2004;56(3):333-340.

15. Bischoff EW, Hamd DH, Sedeno M, et al. Effects of written action plan adherence on COPD exacerbation recovery. Thorax. 2011; 66(1):26-31.

16. Gruffydd-Jones K, Langley-Johnson C, Dyer C, et al. What are the needs of patients following discharge from hospital after an acute exacerbation of chronic obstructive pulmonary disease (COPD)?. Prim Care Respir J. 2007; 16(6):363-368.

17. Williams V, Hardinge $M$, Ryan $S$, et al. Patients' experience of identifying and managing exacerbations in COPD: a qualitative study. NPJ Prim Care Respir Med. 2014; 24:14062. 


\section{Appendix 2}

\section{Content validity of the symptom monitoring module}

The aim of the symptom monitoring module was 'to determine the individual COPD patients' normal day-to-day variability in symptoms to be able to set the patients normal symptom pattern.' An initial module was developed by two researchers (YK \& JT) based on studies focusing on the incidence and course of exacerbations at a symptom level, ${ }^{1-3}$ studies evaluating COPD action plans ${ }^{4-6}$ and the Global Initiative for Chronic Obstructive Lung Disease (GOLD) report. ${ }^{7}$ The symptom monitoring module was developed and assessed on content validity by following a stepwise procedure (see Figure 1). The content validity of the module was evaluated by experts in the field of COPD $(n=8)$ according to the Lynn method. ${ }^{8}$ To assess the content validity, a survey was developed in the online survey service SurveyMonkey (SurveyMonkey Inc., San Mateo, CA, USA).

\section{Content validity rating}

The aim of the symptom monitoring module was to determine the normal symptom pattern of a patient with COPD'. Each symptom was rated on relevance and linguistics by answering 4 questions:

1) Is the symptom relevant for measuring the construct?

2) Is the question relevant to measure the specific symptom?

3) Are the answering options relevant?

4) Is the interpretation of both the question and answering options clear?

All questions on relevance (question 1-3) were rated on a 4-point Likert-scale ( $1=$ not relevant, $4=$ =relevant). Linguistics was determined by whether interpretation was clear ('yes' or 'no'). Feedback was asked in case of rating 1 or 2 or in case of unclear interpretation. Furthermore, participants were asked whether important symptoms were missing to measure the construct.

\section{Data analysis}

All ratings on relevance (questions 1-3) were dichotomized into not relevant $(0=$ rating 1 and 2$)$ and relevant ( $1=$ rating 3 and 4$)$. Then, the Item-Content Validity Index (I-CVI) for each question was calculated by summing all scores of one question and dividing this by the number of experts. A score above 0.78 was considered to be relevant. Second, the Scale-Content Validity Index (S-CVI) was calculated by summing all I-CVIs for each question and dividing this by the number of items. A score above 0.90 was considered to be excellent. To analyze 
linguistics, the frequency of 'yes' and 'no' ratings was determined. Linguistics was considered to be clear when at least $75 \%$ of the expert panel rated clearness of interpretation as a 'yes'.

\section{Decision rules}

Symptoms that were rated as both relevant and clear (all I-CVIs $>0.78$ and clear interpretation $\geq 75 \%$ yes), without suggestions for adjustments, were included in the final module. When suggestions for adjustments were given, the symptom was included in the next round. Furthermore, symptoms with one or more questions rated as not relevant or unclear (I-CVI $\leq 0.78$ or $<75 \%$ yes) were included in the next round. A symptom was excluded when the first question was considered as not relevant $(\mathrm{I}-\mathrm{CVI} \leq 0.78)$, unless there were serious reasons within the research team to ask feedback on that symptom again in the next round.

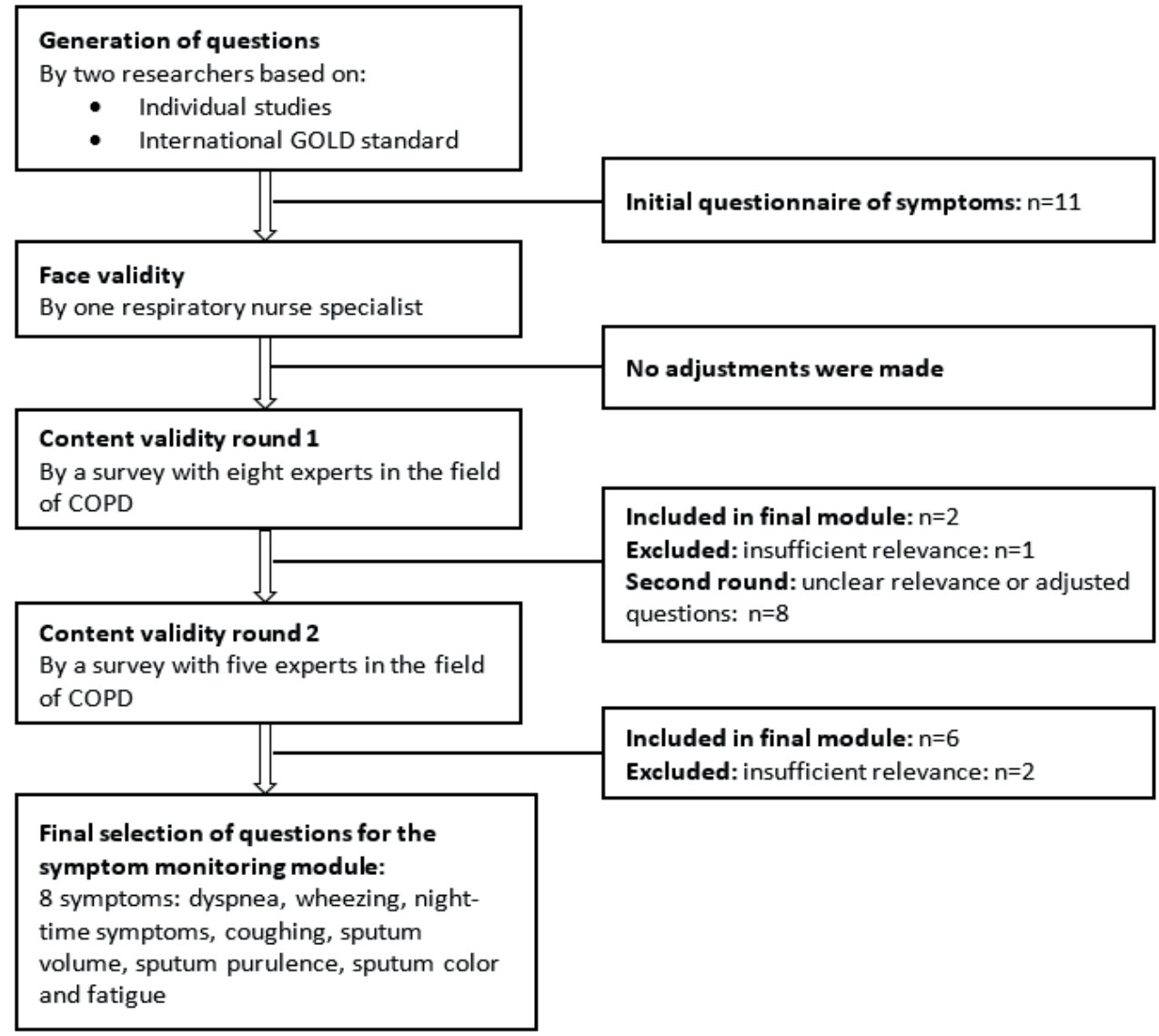

Figure 1. Development and content validity assessment of the symptom monitoring module 


\section{Results}

The final module was completed after 2 experts rounds (see Figure 1). The expert panel consisted of four researchers in the field of COPD $(n=4)$, respiratory nurse specialists $(n=2)$ a pulmonologist $(n=1)$ and a respiratory nurse $(n=1)$. The initial questionnaire of 11 symptoms was reduced to 10 symptoms after round 1. In total, eight items were included in round 2. Six of these items were adjusted based on feedback. The other two items were rated as not relevant, but the research team had doubts about this outcome. After the second round, eight symptoms were rated as relevant and clear (all I-CVIs $>0.78$ and clear interpretation $\geq 75 \%$ yes) (see Figure 1). The relevance of the final symptom monitoring module consisting of eight symptoms, determined by question 1-3, was considered to be high with $\mathrm{S}-\mathrm{CVIS} \geq 0.93$ (S-SCVI question 1= 0.93; S-CVI question $2=0.98$ and $\mathrm{S}-\mathrm{CVI}$ question $3=0.94$ ). The final selection of questions for the symptom monitoring module is shown in table 1.

Table 1. Final selection of questions for the symptom monitoring module

\begin{tabular}{ll}
\hline Symptoms & Questions \\
\hline 1. Dyspnea & When did you experience shortness of breath in the past 24 hours? \\
& Choose the answer that suits you best: \\
& No shortness of breath \\
& Shortness of breath during strenuous activity (like walking the stairs or rushing) \\
& Shortness of breath during moderate activity (like walking or domestic work) \\
& Shortness of breath during light activity (like washing or dressing) \\
& Shortness of breath when resting (like talking or sitting still) \\
& How often did you experience wheezing in the past 24 hours? \\
& Never / Occasionally / Often / All the time \\
\hline 2. Wheezing & Last night, how often did you wake up due to shortness of breath? \\
& Never / Occasionally / Often / All the time \\
\hline 3. Night-time & How often did you cough in the past 24 hours? \\
symptoms & Never / Occasionally / Often / All the time \\
\hline 4. Coughing & How much mucus did you bring up when coughing in the past 24 hours? \\
& None / A Little / A lot / Very much \\
\hline 5. Sputum volume & Did you experience thick or tough mucus in the past 24 hours? \\
\hline 6. Sputum purulence & No / Yes \\
\hline 7. Sputum color & Which color did your mucus have in the past 24 hours? \\
& Transparant / Gray / Yellow / Green / Brown \\
\hline 8. Fatigue & How tired were you in the past 24 hours? \\
& Not at all tired / A bit tired / Very tired / Exhausted
\end{tabular}

${ }^{a}$ Questions are translated from Dutch to English for this publication. Content validity was assessed for the Dutch questionnaire. 


\section{References}

1. Aaron SD, Donaldson GC, Whitmore GA, et al. Time course and pattern of COPD exacerbation onset. Thorax. 2012; 67(3):238-243.

2. Wilkinson TM, Donaldson GC, Hurst JR, et al. Early therapy improves outcomes of exacerbations of chronic obstructive pulmonary disease. Am J Respir Crit Care Med. 2004 Jun 15; 169(12):12981303.

3. Seemungal TA, Donaldson GC, Bhowmik A, et al. Time course and recovery of exacerbations in patients with chronic obstructive pulmonary disease. Am J Respir Crit Care Med. 2000; 161(5):1608-1613. PMID: 10806163.

4. Trappenburg JC, Monninkhof EM, Bourbeau J, et al. Effect of an action plan with ongoing support by a case manager on exacerbation-related outcome in patients with COPD: a multicentre randomised controlled trial. Thorax. 2011; 66(11):977-984.

5. Bourbeau J, Julien M, Maltais F, et al. Reduction of hospital utilization in patients with chronic obstructive pulmonary disease: a disease-specific self-management intervention. Arch Intern Med. 2003; 163(5):585-591.

6. Lenferink $A$, Frith $P$, van der Valk $P$, et al. A self-management approach using self-initiated action plans for symptoms with ongoing nurse support in patients with Chronic Obstructive Pulmonary Disease (COPD) and comorbidities: the COPE-III study protocol. Contemp Clin Trials. 2013; 36(1):81-89.

7. Global Initiative for Chronic Obstructive Lung Disease (GOLD). Global Strategy for Prevention, Diagnosis and Management of COPD. [updated 2018]. Available from: https://goldcopd.org/wpcontent/uploads/2017/11/GOLD-2018-v6.0-FINAL-revised-20-Nov_WMS.pdf. Accessed June 12, 2018.

8. Lynn MR. Determination and quantification of content validity. Nurs Res. 1986; 35(6):382-385. 


\section{Appendix 3}

\section{Demographic characteristics of participants during usability testing phases}

\begin{tabular}{|c|c|c|c|}
\hline Demographic characteristics & Phase 2A & Phase 2B & Phase 4 \\
\hline \multicolumn{4}{|c|}{ Characteristics of COPD ${ }^{\text {a }}$ patients } \\
\hline$n=24$ & 6 & 11 & 7 \\
\hline \multicolumn{4}{|l|}{ Sex, $n=24(100)$} \\
\hline Female & $3(50)$ & $5(45)$ & $5(71)$ \\
\hline Age (years), mean (SD) & $62(4.3)$ & $66(7.8)$ & $58(10.6)$ \\
\hline \multicolumn{4}{|l|}{ Ethnicity, $n=13$ (54) } \\
\hline Dutch & $6(100)$ & $N / A^{b}$ & $7(100)$ \\
\hline \multicolumn{4}{|l|}{ Living situation, $n=13$ (54) } \\
\hline Alone & $2(33)$ & N/A & $1(14)$ \\
\hline \multicolumn{4}{|l|}{ Education level, n=13 (54) } \\
\hline Low & 0 & N/A & $2(29)$ \\
\hline Medium & $4(67)$ & N/A & $4(57)$ \\
\hline High & $2(33)$ & N/A & $1(14)$ \\
\hline \multicolumn{4}{|c|}{ Self-reported GOLD` stage, $n=24(100)$} \\
\hline $1-2$ & 0 & $4(36)$ & 0 \\
\hline $3-4$ & $5(83)$ & $7(64)$ & $5(71)$ \\
\hline Unknown & $1(17)$ & 0 & $2(29)$ \\
\hline \multicolumn{4}{|c|}{ Average number of exacerbations per year, $n=13$ (54) } \\
\hline$\leq 3$ & $3(50)$ & N/A & $4(57)$ \\
\hline$>3$ & $2(33)$ & N/A & 0 \\
\hline Unknown & $1(17)$ & N/A & $3(43)$ \\
\hline \multicolumn{4}{|c|}{ Mobile technology use, $n=13$ (54) } \\
\hline Smartphone & $3(50)$ & N/A & $4(57)$ \\
\hline Smartphone and tablet & $3(50)$ & N/A & $3(43)$ \\
\hline \multicolumn{4}{|c|}{ Mobile technology use for health purposes, $n=13$ (54) } \\
\hline Yes & $3(50)$ & N/A & $2(29)$ \\
\hline
\end{tabular}


Table. (Continued)

\section{Characteristics of health care providers, $n=9$ (100)}

$n=9$

6

N/A

3

Sex, $n=9(100)$

Female

Age (years), mean (SD)

$5(83) \quad$ N/A $2(67)$

Profession, $n=9(100)$

Primary care nurse

$43(12.3) \quad N / A \quad N / A$

General practitioner

$1(17) \quad N / A \quad N / A$

Respiratory nurse specialist (secondary care)

N/A N/A $1(33)$

Respiratory nurse (secondary/tertiary care)

$1(17) \quad N / A \quad 1(33)$

Clinical nurse (secondary care)

2 (33) N/A 1 (33)

Physician assistant (tertiary care)

1 (17) N/A N/A

1 (17) N/A N/A

Work experience (years), mean (SD)

$14(9.4) \quad N / A \quad N / A$

Patient GOLD category most frequently cared for, $n=6$ (67)

\section{$1-2$ \\ 2-3 \\ 3-4}

Use of mobile health in COPD care, $n=6$ (67)

Yes

Use of written action plan in daily care, $n=6$ (67)
1 (17) N/A N/A

2 (33) N/A N/A

$3(50) \quad N / A \quad N / A$

$2(33) \quad$ N/A N/A

$5(83) \quad$ N/A $\quad 1(33)$

${ }^{a}$ COPD: chronic obstructive pulmonary disease, ${ }^{b} N / A$ : not applicable, ${ }^{c} G O L D$ : Global Initiative for Chronic Obstructive Lung Disease. 


\section{Appendix 4}

Table 1. Task success of COPD patients

\begin{tabular}{|c|c|c|c|}
\hline $\begin{array}{l}\text { Task } \\
\text { category }\end{array}$ & Task & $\begin{array}{l}\text { Task } \\
\text { succes }^{\mathrm{a}}\end{array}$ & $\mathbf{n}$ \\
\hline \multirow{18}{*}{$\begin{array}{l}\text { Monitor } \\
\text { symptoms } \\
\text { and } \\
\text { undertaken } \\
\text { actions }\end{array}$} & \multirow[t]{2}{*}{ Fill out in the app that you feel well today, like you normally feel. } & 1 & 4 \\
\hline & & 0,5 & 1 \\
\hline & \multirow{2}{*}{$\begin{array}{l}\text { Imagine: You are feeling worse than the day before. Fill out how you } \\
\text { feel in the app and check which actions you should undertake. }\end{array}$} & 1 & 3 \\
\hline & & 0,5 & 1 \\
\hline & \multirow{3}{*}{$\begin{array}{l}\text { Imagine: You feel worse since two days, you experience more } \\
\text { symptoms than you normally do ( increased dyspnea and more } \\
\text { coughing). Fill this out in the app and view the actions you should } \\
\text { undertake. }\end{array}$} & 1 & 1 \\
\hline & & 0,5 & 1 \\
\hline & & 0 & 1 \\
\hline & \multirow{3}{*}{$\begin{array}{l}\text { Imagine that you still feel less well and you would like to fill out } \\
\text { which actions you have undertaken. Fill out the actions in the app } \\
\text { and save these actions. }\end{array}$} & 1 & 5 \\
\hline & & 0,5 & 1 \\
\hline & & 0 & 1 \\
\hline & \multirow{3}{*}{$\begin{array}{l}\text { Turn of the daily notifications to fill out your symptoms by turning } \\
\text { of the symptom diary. }\end{array}$} & 1 & 5 \\
\hline & & 0,5 & 1 \\
\hline & & 0 & 1 \\
\hline & \multirow{3}{*}{$\begin{array}{l}\text { Imagine: You have doubts about how you are feeling on a new day. } \\
\text { Fill this out in the app and register your symptoms. }\end{array}$} & 1 & 1 \\
\hline & & 0,5 & 1 \\
\hline & & 0 & 2 \\
\hline & \multirow{2}{*}{$\begin{array}{l}\text { After completing registration in the gray zone, choose a color zone } \\
\text { that corresponds with how you are feeling. }\end{array}$} & 1 & 2 \\
\hline & & 0 & 1 \\
\hline \multirow{9}{*}{$\begin{array}{l}\text { View and } \\
\text { adjust action } \\
\text { plan }\end{array}$} & \multirow{2}{*}{$\begin{array}{l}\text { Imagine that you need medical help immediately. Use the app as } \\
\text { you would do in this case. }\end{array}$} & 1 & 6 \\
\hline & & 0 & 1 \\
\hline & $\begin{array}{l}\text { View the agreements you made with your HCP about the actions } \\
\text { you should undertake when you feel well, like you normally do. }\end{array}$ & 1 & 5 \\
\hline & \multirow{2}{*}{$\begin{array}{l}\text { You would like to check the agreements you made with your HCP } \\
\text { about the actions in the yellow zone. Look up these actions in the } \\
\text { app. }\end{array}$} & 1 & 3 \\
\hline & & 0,5 & 1 \\
\hline & \multirow{2}{*}{$\begin{array}{l}\text { Look up the agreements you made with your HCP about the actions } \\
\text { you should undertake in the orange zone. }\end{array}$} & 1 & 2 \\
\hline & & 0 & 1 \\
\hline & Look up the HCP you should contact if needed. & 1 & 7 \\
\hline & $\begin{array}{l}\text { Imagine: You would like to adjust the symptoms in the green zone. } \\
\text { Adjust these symptoms in the action plan. }\end{array}$ & 1 & 2 \\
\hline \multirow{4}{*}{$\begin{array}{l}\text { Review } \\
\text { symptoms } \\
\text { and actions } \\
\text { (calendar) }\end{array}$} & \multirow[t]{2}{*}{ Look up in the app how you felt last week. } & 1 & 5 \\
\hline & & 0,5 & 2 \\
\hline & \multirow{2}{*}{$\begin{array}{l}\text { Imagine: You would like to show your physician how you felt } \\
\text { yesterday and which actions you have undertaken at that time. } \\
\text { Show this in the app. }\end{array}$} & 1 & 4 \\
\hline & & 0,5 & 2 \\
\hline \multirow{5}{*}{$\begin{array}{l}\text { Read } \\
\text { information } \\
\text { (information } \\
\text { module) }\end{array}$} & \multirow{2}{*}{$\begin{array}{l}\text { You would like to know more about this app. Look up the } \\
\text { information 'about the app'. }\end{array}$} & 1 & 6 \\
\hline & & 0,5 & 1 \\
\hline & \multirow{3}{*}{$\begin{array}{l}\text { You would like to know more about COPD and exacerbations. Look } \\
\text { up this information in the app. }\end{array}$} & 1 & 4 \\
\hline & & 0,5 & 1 \\
\hline & & 0 & 2 \\
\hline
\end{tabular}

${ }^{a}$ performance of tasks: 1 point $=$ successful; 0,5 point $=$ partially successful; 0 points $=$ unsuccessful. 
Table 2. Task success of HCPs

\begin{tabular}{|c|c|c|c|}
\hline Task category & Task & $\begin{array}{l}\text { Task } \\
\text { succes }\end{array}$ & $\mathbf{n}$ \\
\hline \multirow{6}{*}{$\begin{array}{l}\text { Personalize action } \\
\text { plan }\end{array}$} & \multirow{2}{*}{ Set up and personalize action plan. } & 1 & 2 \\
\hline & & 0,5 & 1 \\
\hline & \multirow[t]{2}{*}{ Adjust action plan (green zone). } & 1 & 2 \\
\hline & & 0,5 & 1 \\
\hline & Adjust medication in action plan (yellow zone). & 1 & 2 \\
\hline & Add contact person to action plan. & 0 & 3 \\
\hline Review calendar & Evaluate symptom monitoring period. & 1 & 2 \\
\hline $\begin{array}{l}\text { Look up } \\
\text { information }\end{array}$ & Look up the information in the app. & 1 & 2 \\
\hline
\end{tabular}


Table 3. Observed user errors and problems in COPD patients

\begin{tabular}{|c|c|c|c|}
\hline User errors and problems & App location & $\begin{array}{l}\text { Severity } \\
(0-4)^{a}\end{array}$ & $\begin{array}{l}\text { Freq } \\
\text { (n) }\end{array}$ \\
\hline $\begin{array}{l}\text { 1. The saving button after symptom registration is overlooked/ } \\
\text { unclear. }\end{array}$ & $\begin{array}{l}\text { Symptom } \\
\text { monitoring }\end{array}$ & 4 & 5 \\
\hline 2. Symptoms were unchecked without noticing. & $\begin{array}{l}\text { Symptom } \\
\text { monitoring }\end{array}$ & 4 & 1 \\
\hline 3. Choosing the gray zone is not intuitive. & $\begin{array}{l}\text { Choice for color } \\
\text { zone }\end{array}$ & 4 & 3 \\
\hline 4. The questions following in the gray zone appear too fast. & $\begin{array}{l}\text { Conversation } \\
\text { gray zone }\end{array}$ & 4 & 2 \\
\hline $\begin{array}{l}\text { 5. There are too many questions asked/unclear what users } \\
\text { have to do. }\end{array}$ & $\begin{array}{l}\text { Conversation } \\
\text { gray zone }\end{array}$ & 4 & 2 \\
\hline $\begin{array}{l}\text { 6. The questions in the gray zone could not be read due to } \\
\text { pop-up screen. }\end{array}$ & $\begin{array}{l}\text { Conversation } \\
\text { gray zone }\end{array}$ & 4 & 1 \\
\hline 7. Symptoms in green zone could not be unchecked. & Action plan & 4 & 1 \\
\hline $\begin{array}{l}\text { 8. It is unclear that the action plan is an overview of symptoms } \\
\text { due to similarities in lay-out with symptom registration. }\end{array}$ & $\begin{array}{l}\text { Action plan - } \\
\text { overview }\end{array}$ & 3 & 4 \\
\hline $\begin{array}{l}\text { 9. It is unclear that the 'today' button can be used to fill out } \\
\text { symptoms. }\end{array}$ & Home screen & 3 & 1 \\
\hline $\begin{array}{l}\text { 10. It is unclear that the 'today' button can be used to register } \\
\text { actions. }\end{array}$ & Home screen & 3 & 2 \\
\hline 11. Changing contact details is not intuitive. ${ }^{b}$ & Contact details & 3 & 1 \\
\hline $\begin{array}{l}\text { 12. It is unclear that patients are in the yellow zone when } \\
\text { experiencing one or more symptoms. }\end{array}$ & $\begin{array}{l}\text { Action plan - } \\
\text { color zone }\end{array}$ & 3 & 1 \\
\hline $\begin{array}{l}\text { 13. Actions cannot be found easily as users have to scroll down } \\
\text { in the screen. }\end{array}$ & Action plan & 2 & 2 \\
\hline $\begin{array}{l}\text { 14. The color denotation of yellow and orange is not } \\
\text { sufficiently distinctive. }\end{array}$ & $\begin{array}{l}\text { Choice for color } \\
\text { zone }\end{array}$ & 2 & 1 \\
\hline $\begin{array}{l}\text { 15. Symptom diary could not be found as scrolling down the } \\
\text { screen is needed. }\end{array}$ & $\begin{array}{l}\text { Symptom diary } \\
\text { module }\end{array}$ & 2 & 3 \\
\hline $\begin{array}{l}\text { 16. In case of multiple symptom registration on one day, only } \\
\text { the last registration can be found in the calendar. }\end{array}$ & Calendar & 2 & 1 \\
\hline $\begin{array}{l}\text { 17.Appointments for each color zone could not be found } \\
\text { immediately. }\end{array}$ & Action plan & 2 & 1 \\
\hline $\begin{array}{l}\text { 18. It is unclear how medication in the action plan can be } \\
\text { changed as users first have to go through the symptom list. }\end{array}$ & $\begin{array}{l}\text { Change action } \\
\text { plan }\end{array}$ & 2 & 1 \\
\hline 19. Registered actions could not be found immediately. & Start screen & 2 & 2 \\
\hline $\begin{array}{l}\text { 20. It is unclear that symptom registration in the green zone } \\
\text { means filling out 'normal' symptoms. }\end{array}$ & $\begin{array}{l}\text { Symptom } \\
\text { monitoring }\end{array}$ & 1 & 1 \\
\hline 21. Information 'about the app' cannot be found immediately. & Start screen & 1 & 2 \\
\hline 22. Expectations regarding the calendar function are unclear. ${ }^{b}$ & Calendar & 1 & 1 \\
\hline $\begin{array}{l}\text { 23. Information module 'about the app' does not include } \\
\text { information about turning of the symptom diary. }\end{array}$ & $\begin{array}{l}\text { Information } \\
\text { 'about the app' }\end{array}$ & 1 & 1 \\
\hline
\end{tabular}

${ }^{a} 0$ = no problem; 1 = cosmetic problem only; 2 = minor usability problem, 3 = major usability problem;

4 = usability catastrophe; ${ }^{\text {b }}$ problems observed during free navigation in the app 
Table 4. Observed user errors and problems in HCPs

\begin{tabular}{|c|c|c|c|}
\hline User errors and problems & App location & $\begin{array}{l}\text { Severity } \\
(0-4)^{\mathrm{a}}\end{array}$ & $\begin{array}{l}\text { Freq } \\
\text { (n) }\end{array}$ \\
\hline $\begin{array}{l}\text { 1. Green zone: The saving button after registration of } \\
\text { symptoms is overlooked. }\end{array}$ & $\begin{array}{l}\text { Personalize action } \\
\text { plan }\end{array}$ & 4 & 2 \\
\hline 2. Changing contact details is not intuitive. ${ }^{b}$ & Contact details & 4 & 3 \\
\hline $\begin{array}{l}\text { 3. Yellow zone: User clicks on symptoms. It is unclear that } \\
\text { the yellow zone is an overview of symptoms that cannot } \\
\text { be personalized. }\end{array}$ & $\begin{array}{l}\text { Personalize action } \\
\text { plan }\end{array}$ & 3 & 2 \\
\hline $\begin{array}{l}\text { 4. Change medication: When user forgets to save adjusted } \\
\text { symptoms, the screen to change medication does not } \\
\text { appear. }\end{array}$ & Change action plan & 3 & 1 \\
\hline $\begin{array}{l}\text { 5. User would like to distinguish short- and long-acting } \\
\text { bronchodilators. }\end{array}$ & Fill out medication & 2 & 2 \\
\hline 6. User fills out only a number to define medication dose. & Fill out medication & 2 & 2 \\
\hline $\begin{array}{l}\text { 7. Red button does not meet with current practice in } \\
\text { primary care. }\end{array}$ & $\begin{array}{l}\text { Action plan - red } \\
\text { zone }\end{array}$ & 2 & 1 \\
\hline $\begin{array}{l}\text { 8. User would like to add a course of antibiotics and/or } \\
\text { prednisolone to the orange zone. }\end{array}$ & $\begin{array}{l}\text { Personalize action } \\
\text { plan }\end{array}$ & 2 & 1 \\
\hline $\begin{array}{l}\text { 9. Onboarding text is not easy to read, user has to scroll } \\
\text { down on the screen. }\end{array}$ & Onboarding app & 1 & 1 \\
\hline 10. Onboarding text appears too fast. & Onboarding app & 1 & 1 \\
\hline $\begin{array}{l}\text { 11. Yellow zone: Unclear which medication should be } \\
\text { added to the yellow zone as green zone includes also } \\
\text { medication 'if needed'. }\end{array}$ & $\begin{array}{l}\text { Personalize action } \\
\text { plan }\end{array}$ & 0 & 1 \\
\hline
\end{tabular}


Table 5. Patient and HCP perceptions towards using the app

\begin{tabular}{|c|c|c|}
\hline Themes & Description & Quotes of COPD patients \\
\hline \multicolumn{3}{|c|}{ Feelings about the app } \\
\hline $\begin{array}{l}\text { Feeling safe and } \\
\text { confident }\end{array}$ & $\begin{array}{l}\text { A few patients mentioned that } \\
\text { the app provided a certain } \\
\text { feeling of safety and could } \\
\text { increase their self-confidence. }\end{array}$ & $\begin{array}{l}\text { "I would start using the app immediately. It's } \\
\text { the safety... and exactly knowing how you } \\
\text { should act. A confident feeling that I can } \\
\text { promptly take actions.'(P05) } \\
\text { 'I believe I would calmer...It gives me a more } \\
\text { pleasant feeling, already. I would feel calmer } \\
\text { when I would get the advice to raise the alarm. } \\
\text { That increases my self-confidence.'(P3) }\end{array}$ \\
\hline $\begin{array}{l}\text { Being taken } \\
\text { seriously }\end{array}$ & $\begin{array}{l}\text { Patients felt being taken } \\
\text { seriously due to the } \\
\text { conversation in the app that } \\
\text { provides adequate feedback on } \\
\text { registrations. }\end{array}$ & $\begin{array}{l}\text { 'I really like that! It feels like I am being taken } \\
\text { seriously in a way. (P5) } \\
\text { 'I like it. It's very personal. I have the idea that } \\
\text { I am having a conversation with someone, that } \\
\text { is more open and makes you feel better.' (P7) }\end{array}$ \\
\hline $\begin{array}{l}\text { Feeling confident } \\
\text { about using the } \\
\text { app at home }\end{array}$ & $\begin{array}{l}\text { Most patients felt confident } \\
\text { about using the app at home. } \\
\text { One patient explained a need } \\
\text { for assistance from relatives. }\end{array}$ & $\begin{array}{l}\text { 'I am 100\% confident. If the app is installed on } \\
\text { my phone, I can easily use it. No problem.'(P6) } \\
\text { 'I think I would have to learn how to use the } \\
\text { app, but I could call my daughter, my wife or } \\
\text { granddaughter for that.' (P2) }\end{array}$ \\
\hline
\end{tabular}

Added value of the app

\begin{tabular}{ll}
\hline Increases & Most patients were convinced \\
awareness on & that the app would be \\
wellbeing and & helpful in detecting symptom \\
taking adequate & deterioration and taking \\
actions & adequate actions.
\end{tabular}

'It is a useful tool to examine how you are really doing, you are not always aware of that.' (P6)

"I think it is an educational tool for myself. That I could learn to recognize when I need help and when I should take extra medication.' (P1)

'It would help me to go to the general practitioner on time. By filling out how I feel daily, I would realize early when it's getting worse.'(P4)

Calendar provides All patients felt the calendar insight into patient's own situation would provide insight into help them in conversations their own situation and would with HCPs. HCPs expressed that insights from the calendar could support making personalized agreements on self-management.
'I could use the calendar to show my doctor how I have been doing and how I have acted, because you won't remember that. If I could use the app for that, that would be quit motivating (...) It is a reminder for myself as well, that I can check 'How is my disease progressing?'. (P1)

I am positive about the colors that pop up in the calendar, so you can show the general practitioner 'This is how it was doing.' (P4) 
Table 5. (Continued)

\section{Content of the app}

\begin{tabular}{|c|c|c|}
\hline $\begin{array}{l}\text { Recognizable } \\
\text { symptoms and } \\
\text { advice }\end{array}$ & $\begin{array}{l}\text { Overall, patients were positive } \\
\text { about the content of the app. } \\
\text { Some patients trusted the app } \\
\text { as they recognized the symptom } \\
\text { color zones and the advices } \\
\text { provided. }\end{array}$ & $\begin{array}{l}\text { 'The app seems reliable because you know } \\
\text { what kind of answer you could expect yourself. } \\
\text { And if it is right what you are thinking, and } \\
\text { you are afraid to take actions, you could think } \\
\text { 'the app says it as well'. So it is actually more a } \\
\text { confirmation you would ask...to feel sure.'(P3) }\end{array}$ \\
\hline $\begin{array}{l}\text { Additional } \\
\text { measures and } \\
\text { actions }\end{array}$ & $\begin{array}{l}\text { One patient expressed that } \\
\text { registration of weight and } \\
\text { physical activity would be nice. } \\
\text { HCPs expressed a need for } \\
\text { including self-treatment with } \\
\text { prednisolone/AB. }\end{array}$ & $\begin{array}{l}\text { 'It would be nice if I could register my weight } \\
\text { and if my sports program could be included in } \\
\text { the app.'(P3) }\end{array}$ \\
\hline
\end{tabular}

\section{Facilitators to use the app}

\begin{tabular}{ll}
\hline Easy to use & Most patients found the app \\
& easy the use and learned quickly \\
& how to work with the app. HCPs \\
& found the app easy to use as \\
& well, although it was somewhat \\
& unclear which parts of the action \\
& plan had to be personalized.
\end{tabular}

'It is all quite new, so you have to think about

it...but it is quite compact and that makes it easy to use. I can't say it is difficult, you are at the right place in only a few steps.' (P1)

'You would learn by using the app in daily practice.'(P3)

'The first time you have to seek where everything is located. But, if you would use the app for a week, then it would be automatic. And using apps is not that easy for me in general.'(P4)

\begin{tabular}{ll}
\hline $\begin{array}{l}\text { Personalized to } \\
\text { own situation }\end{array}$ & $\begin{array}{l}\text { Patients were positive about the } \\
\text { app being personalized to their } \\
\text { situation. }\end{array}$
\end{tabular}

'The app being personal, that is very positive. Like, it is 'my green zone', and not of someone else.' (P06)

\begin{tabular}{lll}
\hline $\begin{array}{l}\text { Agreement with } \\
\text { HCP }\end{array}$ & $\begin{array}{l}\text { One patient expressed that } \\
\text { agreement with a HCP to use } \\
\text { the app would stimulate actual } \\
\text { use. }\end{array}$ & $\begin{array}{l}\text { 'I would definitely use the app if I would agree } \\
\text { with my health care provider on that.'(PO6) }\end{array}$ \\
\hline
\end{tabular}

\section{Barriers to use the app}

\begin{tabular}{lll}
\hline $\begin{array}{l}\text { Limited support } \\
\text { during stable } \\
\text { phase }\end{array}$ & $\begin{array}{l}\text { Two patients who rarely } \\
\text { experienced exacerbations } \\
\text { explained that the app would } \\
\text { only have an added value if } \\
\text { additional support is provided } \\
\text { during the stable phase (green } \\
\text { zone). }\end{array}$ & $\begin{array}{l}\text { 'I don't experience that many symptoms at the } \\
\text { moment. If I would suffer a lot, then I would } \\
\text { use the app quite often. Now I would fill out }\end{array}$ \\
& $\begin{array}{l}\text { nice to use the app. So, therefore I would } \\
\text { prefer to have more preventive components } \\
\text { in the app. On the other hand, maybe I would } \\
\text { use the app, because then I could examine } \\
\text { how I am really feeling. I would like to try } \\
\text { that.'(PO6) }\end{array}$
\end{tabular}


Table 5. (Continued)

\begin{tabular}{lll}
\hline $\begin{array}{l}\text { Lack of separate } \\
\text { interface for HCPS }\end{array}$ & $\begin{array}{l}\text { One HCP expressed that a } \\
\text { separate HCP interface to } \\
\text { personalize and review the } \\
\text { app would be helpful in daily } \\
\text { practice. Another HCP however } \\
\text { felt that using the app on the } \\
\text { patients device would help to } \\
\text { estimate if patients are able to } \\
\text { use the app at home. }\end{array}$ & \\
\hline $\begin{array}{l}\text { Further } \\
\text { personalization of } \\
\text { the app is needed }\end{array}$ & $\begin{array}{l}\text { Some patients mentioned } \\
\text { that further personalization of } \\
\text { the app by including personal } \\
\text { comments would facilitate the } \\
\text { use of the app. }\end{array}$ & $\begin{array}{l}\text { 'The app could be improved by making it even } \\
\text { learn to know you better. (P01) }\end{array}$ \\
& & $\begin{array}{l}\text { 'Maybe a diary could be included, so that you } \\
\text { have free space to write down 'I specifically } \\
\text { experience this today.' (P03) }\end{array}$ \\
\hline
\end{tabular}

Textbox 1. Improvements for second version of the app

\section{Problems that have to be solved for second version of the app}

- Saving symptoms in the app

- Lay-out of action plan view (overview of symptoms and self-management actions)

- Naming and explanation of buttons on home screen

- Clarifying distinction between color zones

- Clarifying which parts of the action plan should be individualized

- Appearance of onboarding text in app

- Selection of the gray zone and navigation in the gray zone

- Changing contact details

- Changing medication in action plan

\section{Functionalities that should be added to second version of the app}

- Further personalization of the content in the app and including free spaces for personal comments

- Self-treatment (antibiotics and/or prednisolone) as self-management action in orange color zone

- Differentiating short- and long acting bronchodilators

- Assistance in case when patients are doubting about whether they should contact their $\mathrm{HCP}$ in case of symptom deterioration

- Detailed feedback on importance of self-management actions in case of symptom deterioration

- Including more preventive self-management actions in stable phase (green zone)

- Including additional information on self-management actions in information module 


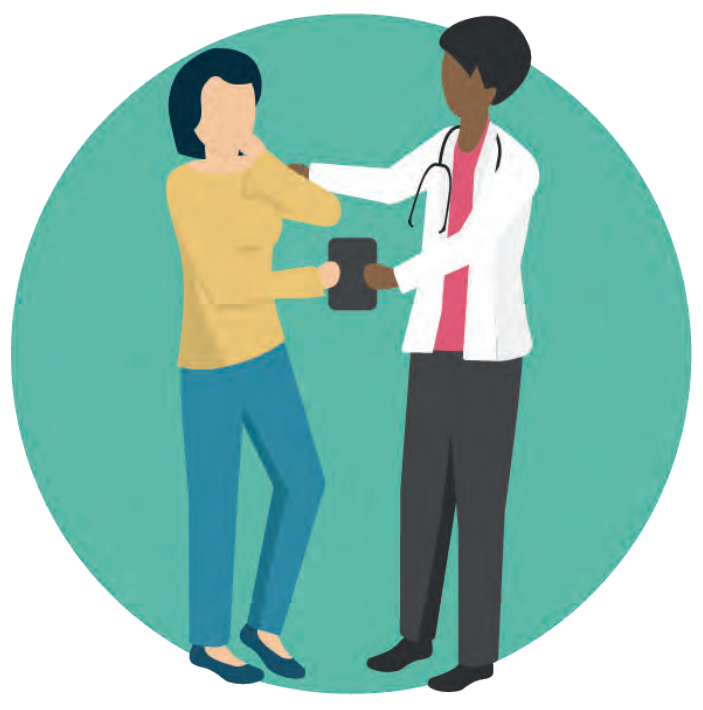




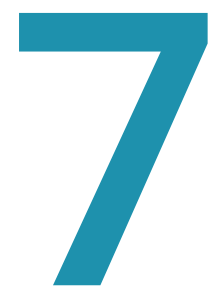

\section{Early-stage feasibility of a mobile health intervention (Copilot) to enhance exacerbation-related self- management in patients with chronic obstructive pulmonary disease: multimethods approach}

Yvonne JG Korpershoek, Tjitske Holtrop, Sigrid CJM Vervoort, Lisette Schoonhoven, Marieke J Schuurmans, Jaap CA Trappenburg 


\section{Abstract}

Background: There is an emergence of mobile health (mHealth) interventions to support self-management in patients with chronic obstructive pulmonary disease (COPD). Recently, an evidence-driven mHealth intervention has been developed to support patients with COPD in exacerbation-related self-management: the Copilot app. Health care providers (HCPs) are important stakeholders as they are the ones who have to provide the app to patients, personalize the app, and review the app. It is, therefore, important to investigate at an early stage whether the app is feasible in the daily practice of the HCPs. The aim of this study is to evaluate the perceived feasibility of the Copilot app in the daily practice of HCPs.

Methods: A multimethods design was used to investigate how HCPs experience working with the app and how they perceive the feasibility of the app in their daily practice. The feasibility areas described by Bowen et al were used for guidance. HCPs were observed while performing tasks in the app and asked to think aloud. The System Usability Scale was used to investigate the usability of the app, and semistructured interviews were conducted to explore the feasibility of the app. The study was conducted in primary, secondary, and tertiary care settings in the Netherlands from February 2019 to September 2019.

Results: In total, 14 HCPs participated in this study- 8 nurses, 5 physicians, and 1 physician assistant. The HCPs found the acceptable to use. The expected key benefits of the app were an increased insight into patient symptoms, more structured patient conversations, and more tailored self-management support. The app especially fits within the available time and workflow of nurses. The use of the app will be influenced by the autonomy of the professional, the focus of the organization on eHealth, costs associated with the app, and compatibility with the current systems used. Most HCPs expressed that there are conditions that must be met to be able to use the app. The app can be integrated into the existing care paths of primary, secondary, and tertiary health care settings. Individual organizational factors must be taken into account when integrating the app into daily practice.

Conclusion: This early-stage feasibility study shows that the Copilot app is feasible to use in the daily practice of HCPs and can be integrated into primary, secondary, and tertiary health care settings in the Netherlands. The app was considered to best fit the role of the nurses. The app will be less feasible for those organizations in which many conditions need to be met to use the app. This study provides a new approach to evaluate the perceived feasibility of mHealth interventions at an early stage and provides valuable insights for further feasibility testing. 


\section{Introduction}

Chronic obstructive pulmonary disease (COPD) is a highly prevalent disease and a major cause of mortality worldwide. ${ }^{1,2}$ Exacerbations are important events during the course of COPD because they accelerate the decline in lung function, ${ }^{3}$ negatively affect quality of life, ${ }^{4,5}$ and lead to increased mortality and high socioeconomic costs. ${ }^{6,7}$ Self-management is important to reduce the impact of COPD exacerbations on both patients and society. Self-management is defined as "an individual's ability to detect and manage symptoms, treatment, physical and psychosocial consequences, and lifestyle changes inherent in living with a chronic condition". ${ }^{8}$ Over the past years, research has increasingly focused on exacerbation-related self-management interventions, as they have shown to have positive effects on quality of life and hospital admissions. ${ }^{9,10}$ In this context, the use of mobile health (mHealth) is considered to be promising to engage patients in their own health and to change health behaviors. ${ }^{11-13}$

Current eHealth and mHealth interventions often focus on telemonitoring strategies to reduce the impact of exacerbations. ${ }^{14-19}$ Although positive outcomes were found for telemonitoring, the results are thus far inconclusive because of the poor quality of the studies and the heterogeneity among the studies. ${ }^{15,18,19}$ The inconclusive results might also be explained by the lack of focus on enhancing self-management skills, as the decision-making process is mostly professional based. mHealth interventions aimed at facilitating, supporting, and sustaining self-management in patients with COPD have shown to improve quality of life and levels of activity; however, no firm conclusions could be drawn from them. ${ }^{13}$ Recently developed mHealth interventions focusing on self-management have shown variable results. Farias et $\mathrm{al}^{20}$ showed that using telehealth technologies to enhance adherence to a COPD action plan resulted in faster exacerbation recovery and decreased number of COPD-related emergency department visits and hospitalizations. Another mHealth tool that supports self-management of exacerbations showed no positive effects on exacerbation-free time, health status, and health care utilization. ${ }^{21}$ However, given the proven effectiveness of self-management interventions in patients with COPD, it could be expected that mHealth interventions supporting patients in self-management can be effective in reducing exacerbation impact.

Recently, an evidence-driven mHealth intervention has been developed in the Netherlands to support patients with COPD (the end users) in exacerbation-related self-management-the Copilot app. The Copilot app is a mobile app that targets the 
early detection of exacerbations through self-monitoring and performing prompt actions by using individualized action planning. The Copilot app consists of 4 components: (1) a personalized COPD action plan, (2) symptom monitoring, (3) an overview of registered symptoms and undertaken self-management actions, and (4) an information module about COPD and self-management. The Copilot app focuses specifically on developing patient self-management skills over time (learning by doing) without real-time monitoring by health care providers (HCPs). Nevertheless, the HCPs are important stakeholders as the Copilot app requires a case manager role from HCPs. The role of the HCPs is to provide the app to patients, instruct patients on how to use the app, set up a personalized action plan together with a patient, and evaluate the patient's condition based on registrations in the app during consultations. The app can be provided by HCPs across health care settings. The Copilot app was developed by following a usercentered design that included several phases of usability testing. ${ }^{22}$ The usability of the Copilot app for patients was considered to be good. ${ }^{22}$ More information about the Copilot app is provided in Figure 1.

An important next step is to investigate whether the Copilot app can work within the daily practice of HCPs by evaluating how HCPs perceive the feasibility of the Copilot app. ${ }^{23}$ Evaluating feasibility within the daily practice of HCPs at an early stage helps to determine whether the Copilot app is appropriate for further testing and to identify what changes are needed and how they might occur. ${ }^{23}$ Although patients with COPD and HCPs are both crucial stakeholders in feasibility evaluation, adequate personalization of the app and evaluation of the patient's condition by HCPs is essential for safe and effective self-management by patients using the Copilot app. ${ }^{24,25}$ Therefore, early feasibility evaluation in the daily practice of the HCPs should precede further longitudinal feasibility testing among patients. On the basis of this step, essential design input for optimization of the Copilot app can be generated and a substantial part of the feasibility problems in the daily care by HCPs can be eliminated before further testing.

\section{Objectives}

The aim of this study is to evaluate the perceived feasibility of the Copilot app in the daily practice of HCPs. 


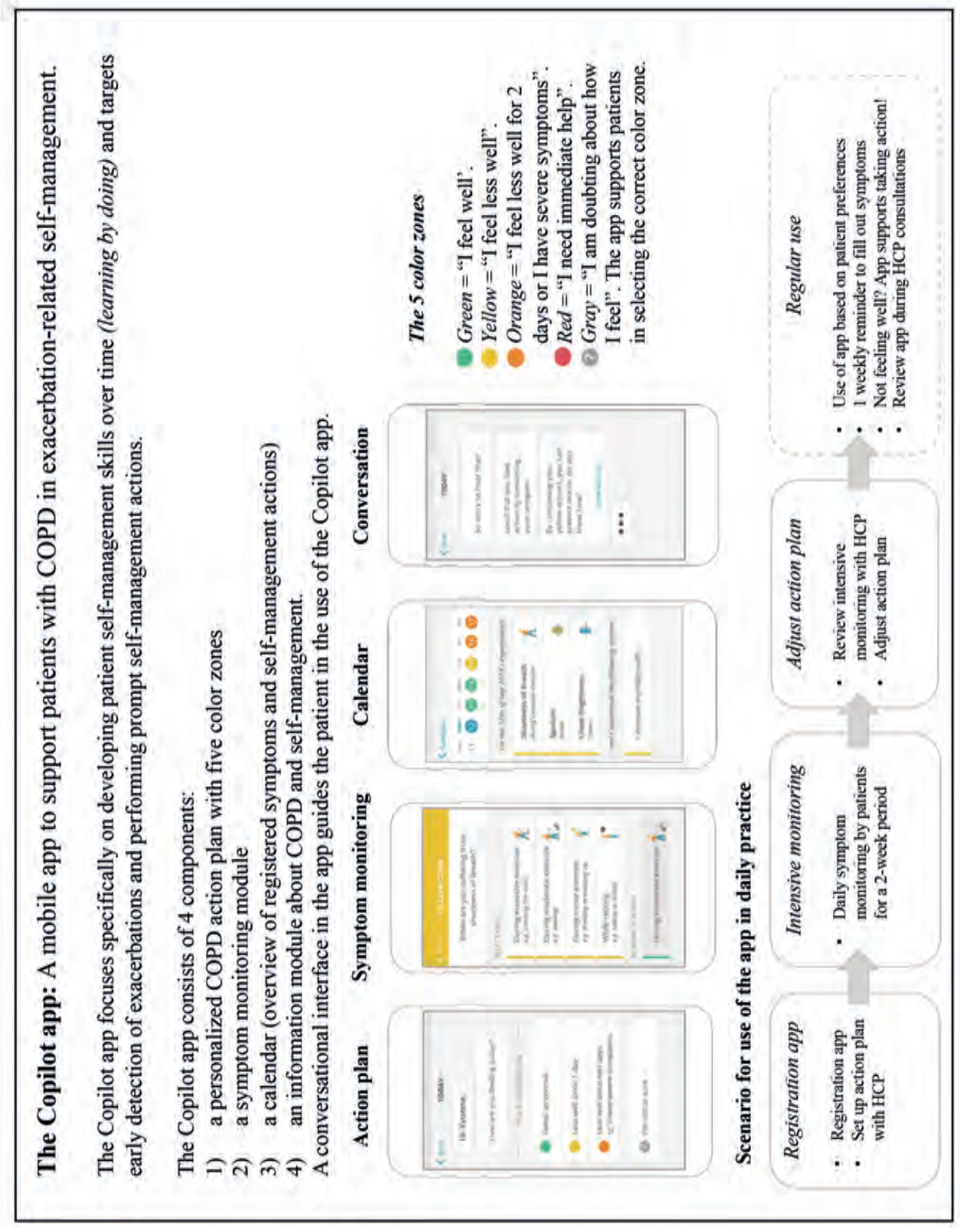

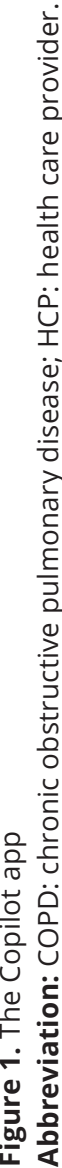




\section{Methods}

\section{Study design}

A feasibility study with a multimethods design was used to investigate how HCPs experience working with the first version of the Copilot app and how they perceive the feasibility of the app in their daily practice. On the basis of the work by Bowen et al, ${ }^{23}$ feasibility areas relevant for this early-stage feasibility evaluation were used for guidance. This study evaluates how HCPs react to the Copilot app (acceptability); the extent to which the Copilot app is likely to be used by HCPs (demand); the extent, likelihood, and manner in which the Copilot app can be used by HCPs as planned and proposed (implementation); the extent to which the app can be used by HCPs in their routine daily practice considering the available resources (practicality); and the extent to which the Copilot app can be integrated within the context of Dutch health care settings (integration). ${ }^{23} \mathrm{~A}$ onetime interactive session was conducted to observe how HCPs interacted with the app. HCPs were observed while performing tasks with the app and asked to think aloud to verbalize initial perceptions and feelings toward the app, clarify their process of decision making, and express experienced problems. ${ }^{26,27}$ Afterward, a standardized usability questionnaire was used to investigate how HCPs perceived the usability of the app, and semistructured interviews were conducted with HCPs to further explore how they perceive the feasibility of the app. The study was conducted in primary, secondary, and tertiary care settings in the Netherlands from February 2019 to September 2019. The study was approved by the Medical Ethics Research Committee of the University Medical Centre Utrecht (18/831).

\section{Study population}

A purposive sample of HCPs who have a case manager role in COPD care was selected from primary, secondary, and tertiary care settings in the Netherlands. Case management was defined as physicians or nurses who provide ongoing and/ or follow-up self-management support during patient consultations. ${ }^{28}$ Eligible HCPs were pulmonologists, general practitioners, respiratory nurses, respiratory nurse specialists, physician assistants, and primary care nurses, with a minimum work experience of 1 year and employment at their present organization for at least one year. The 1-year cutoff point was considered relevant in providing meaningful insights into the feasibility areas. The maximum variation in profession and work setting was pursued to select a sample that adequately represents the HCPs providing self-management support in Dutch COPD care and to increase the likelihood of capturing different perspectives in the findings. On the basis of the guidance for evaluating the use of apps in general, a minimum of 10 HCPs were 
approached. ${ }^{27}$ HCPs were included until saturation was reached for acceptability, demand, and implementation. Practicality and integration vary greatly across various health care organizations; therefore, it was not considered feasible to achieve saturation in these areas of focus using this study design. Therefore, data collected on practicality and integration are only described in this study.

\section{Recruitment and informed consent}

HCPs were approached by email or telephone to participate in this study by 2 researchers (YK and TH). Four HCPs were approached based on their expressed interest during participation in previous studies related to the development of the app, whereas others were recruited through local COPD networks. The HCPs received an invitation to participate in the study by email. A reminder was sent after 1 week in case of nonresponse. In case of continued absence of a response, the HCPs were contacted within a week by phone to determine their interest to participate in the study. The HCPs willing to participate received further study information and an informed consent form. An appointment was scheduled at the place of employment of the HCPs, and the informed consent form was signed during the appointment. Recruitment started initially with 5 HCPs to initiate data analysis. Further recruitment was determined based on ongoing data analysis and data saturation for acceptability, demand, and implementation.

\section{Data collection}

Data were collected during a single, 1-hour session following a stepwise procedure. The stepwise procedure is described in the following sections.

\section{Step 1: Interactive session (observations and the Think Aloud method)}

Before starting the interactive session, participants were informed about the study procedure and received further information about the Copilot app, the scenario for use of the app in daily practice, the intended role of both HCPs and patients, and the developmental stage of the app (Appendix 1). Furthermore, the researcher walked through the 4 components of the app together with the participants. The participants were then asked to read a fictional patient case together with a set of tasks developed by the research team (Appendix 2). These tasks focused on personalizing the action plan, adjusting the action plan, and evaluating the overview of registered symptoms and actions in the app. The participants were asked to perform these tasks in the app and were instructed and stimulated to think aloud while performing these tasks. ${ }^{26,27}$ Almost all HCPs used the first version of the Copilot app. In the final interview, an updated version of the Copilot app was used, in which minor changes were made to improve 
usability. No major changes were made to the content and functions of the app; therefore, the influence of these changes on study outcomes was considered to be minor.

\section{Step 2: The System Usability Scale}

After working with the app, participants were asked to fill in the validated 10item System Usability Scale (SUS) to obtain an overall view of the usability of the app for HCPs. ${ }^{29}$ Each item was scored on a 5-point Likert scale, and all items were converted to a total score (range $0-100$; a score $>70$ is considered to be acceptable).29,30 Although investigating usability was not the objective of this study, usability problems could have been experienced by participants who worked with the first version of the Copilot app. The perceived usability by HCPs was considered to be an important factor that could influence the adoption of the app by HCPs in daily practice and was therefore evaluated roughly in this study as well. ${ }^{31}$

\section{Step 3: Semistructured interview}

A semistructured interview was conducted to investigate perceptions toward the feasibility of the Copilot app in daily practice. A topic list was developed based on the 5 areas of focus and their related outcomes of interest. ${ }^{23}$ Questions that were formulated by Bowen et $\mathrm{al}^{23}$ to illustrate the areas of focus and the outcomes of interest were used as a basis for formulating interview questions. The topic list is further detailed in Appendix 3. During and directly after the interviews, memos were created to describe observations, reflect on methodological issues, and capture initial thoughts related to theoretical concepts. Insights gained during the interviews were introduced in subsequent interviews, leading to data saturation.

\section{Step 4: Baseline questionnaire}

After finishing the interview, participants were asked to fill in a questionnaire to collect baseline characteristics. The stepwise procedure of data collection is further detailed in Table 1 and Appendix 1.

All sessions were conducted by 1 researcher ( $\mathrm{YK}$ or $\mathrm{TH}$ ) who guided the interactive sessions and conducted the interview. The whole procedure was video recorded to observe the hand interaction of participants with the app and to audio record verbalizations during the interactive session and the interview. In addition, the researcher made notes on observed user problems and relevant verbalizations of the participants while they were working with the app. Before starting the data collection, 2 pilot sessions with professionals in COPD care were conducted to 
investigate whether participants understood the procedure and questions, to determine whether the questions resulted in relevant answers, and to determine whether the stepwise data collection procedure fitted in a 1-hour session. Findings of the pilot sessions were used to modify data collection procedures by reducing the set of tasks that HCPs had to perform, by adjusting the information about the app and study procedure, and by merging interview questions that resulted in similar answers. The results of the pilot sessions were not included in this study. Practical issues that arose during the study resulted in iterations in the data collection guideline (Appendix 1).

Table 1. Stepwise data collection procedure related to the areas of focus and outcomes of interest

\begin{tabular}{|c|c|}
\hline $\begin{array}{l}\text { Method and area of } \\
\text { focus }\end{array}$ & Outcome of interest \\
\hline \multicolumn{2}{|l|}{$\begin{array}{l}\text { Step 1: Interactive } \\
\text { session }\end{array}$} \\
\hline Implementation ${ }^{a}$ & $\begin{array}{l}\text { Degree of execution of tasks and success or failure of execution of } \\
\text { tasks }\end{array}$ \\
\hline \multicolumn{2}{|l|}{ Step 2: SUS } \\
\hline Acceptabilityc & Satisfaction with the app \\
\hline Demand $^{d}$ & Intention to use the app \\
\hline Implementation & Degree of execution of tasks \\
\hline \multicolumn{2}{|l|}{ Step 3: Interview } \\
\hline Acceptability & $\begin{array}{l}\text { Satisfaction with the app, perceived appropriateness, and fit within the } \\
\text { organizational culture }\end{array}$ \\
\hline Demand $^{c}$ & Perceived demand and intention to use the app \\
\hline Implementation & $\begin{array}{l}\text { Degree of execution of tasks, success or failure of execution of tasks, } \\
\text { and factors affecting implementation ease or difficulty }\end{array}$ \\
\hline Practicality e & $\begin{array}{l}\text { Expected benefits and burden for end-users and ability of HCPs to } \\
\text { carry out tasks in their routine daily practice }\end{array}$ \\
\hline Integrationg & $\begin{array}{l}\text { Perceived fit with local care infrastructure at the patient and } \\
\text { organizational level and perceived sustainability at the patient and } \\
\text { organizational level }\end{array}$ \\
\hline $\begin{array}{l}\text { Step 4: baseline } \\
\text { questionnaire }\end{array}$ & $\begin{array}{l}\text { Profession, age, work experience, size of organization, amount of } \\
\text { patient consultations for COPD in a week, average time available for } \\
\text { patient consultations, disease severity of patients with COPD in daily } \\
\text { care, current use of written action plan, current use of mobile health. }\end{array}$ \\
\hline
\end{tabular}

a Implementation: the extent, likelihood, and manner in which the Copilot app can be used by health care providers as planned and proposed; ${ }^{b}$ SUS: System Usability Scale; ${ }^{\mathrm{c}}$ Acceptability: how the health care provider reacts to the Copilot app; ${ }^{d}$ Demand: to what extent is the Copilot app likely to be

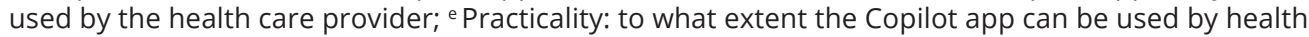
care providers in their routine daily practice considering the available resources; ${ }^{f} \mathrm{HCP}$ : health care provider; ${ }^{g}$ Integration: to what extent can the Copilot app be integrated in Dutch primary, secondary, and tertiary care settings; ${ }^{\mathrm{h}}$ COPD: chronic obstructive pulmonary disease. 


\section{Data analysis}

Data from the interactive sessions and semistructured interviews were analyzed according to a thematic analysis as described by Braun and Clarke. ${ }^{32}$ Video recordings were reviewed for usability issues and categorized according to the type of problem. All video recordings, including both the think aloud comments of the interactive sessions and the interviews, were transcribed verbatim. In total, 13 hours of video recordings were transcribed verbatim, resulting in 230 pages of transcription. Data analysis was supported by NVivo 11.0 software (QSR International Pty Ltd Version 11). The analysis took place in a cyclic process, alternating data analysis with data collection. Data were analyzed by 2 researchers (YK and TH) and were discussed with a third researcher (SV).

First, the 2 researchers independently read the transcripts to obtain an overall picture and noted initial ideas on relevant themes. Second, the transcripts were reread in more detail, and initial codes were linked to meaningful paragraphs by both researchers and discussed afterward to reach consensus. Next, identified codes were brought under potential themes and were reviewed for correspondence to the coded paragraphs, generating a thematic map of the analysis. Finally, potential themes were further refined, and clear definitions were generated for each theme. The third researcher was involved from the stage at which potential themes were reviewed, by coding a selection of data and participating in discussions on the final definition of themes. Interpretation of the data was discussed with experts in the fields of nursing science, self-management, and mHealth UT, MS, and LS), which contributed to the credibility of the study. ${ }^{33}$ Memo writing supported the data analysis process. The confirmability of the study was enhanced by peer review of the methodological quality by an external expert on qualitative research (SV). ${ }^{33}$

Data from the SUS and the baseline questionnaire were analyzed with SPSS 25.0 (IBM Corporation) using descriptive statistics.

\section{Results}

\section{Baseline characteristics of the participants}

A total of $14 \mathrm{HCPs}$ (9 females and 5 males) participated in this study, including 8 nurses, 5 physicians and 1 physician assistant recruited from 5 primary, 7 secondary, and 2 tertiary care settings. The baseline characteristics of the participants are presented in Table 2. A total of 11 HCPs currently used written COPD action plans in their daily care to some extent, varying from barely using 


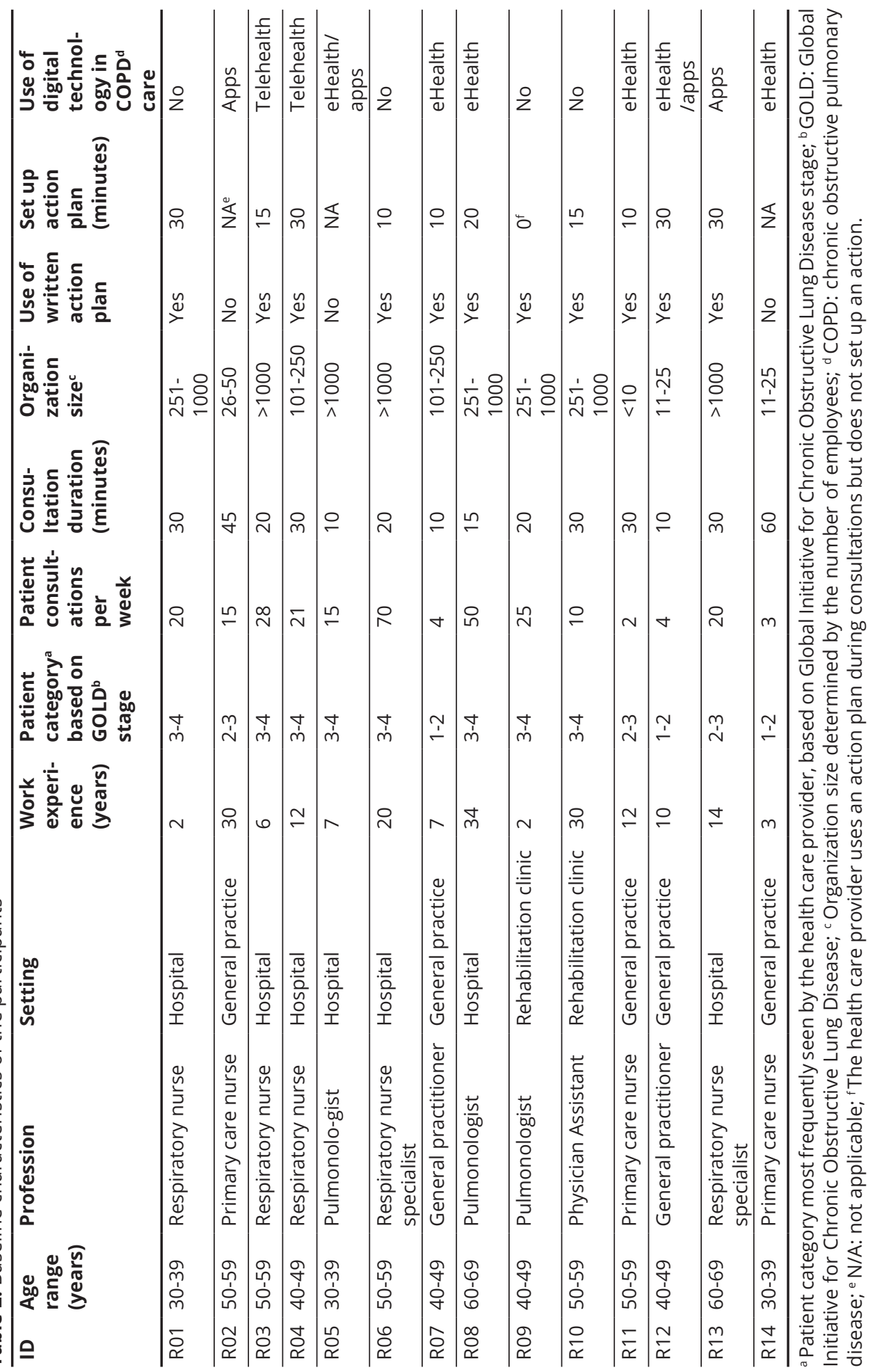


action plans to integrating action plans in regular care. A total of $10 \mathrm{HCPs}$ had experience with the use of digital technology in COPD care; however, in most cases, technology was only used occasionally or within a study context. Maximum variation was achieved for profession, work setting, age, work experience, patient category most frequently seen by the HCP based on disease severity, number of patient consultations for COPD during a week, and organization size.

The themes that emerged from this study are described in the following paragraphs and illustrated by quotes of the HCPs. Q references in the text refer to quotes of specific themes that are provided in the textboxes at the end of each paragraph. An overview of the themes is provided in Table 3. The themes are categorized based on the areas of focus, and the perceived benefits and risks of using the app in daily practice are described separately.

Table 3. Overview of the themes

\begin{tabular}{|c|c|}
\hline Area of focus & Themes \\
\hline $\begin{array}{l}\text { Acceptability of the app and } \\
\text { perceived demand }\end{array}$ & $\begin{array}{l}\text { - High satisfaction } \\
\text { - User friendly } \\
\text { - Relevant for daily practice } \\
\text { - App fits well within the organizational culture } \\
\text { - High level of interest }\end{array}$ \\
\hline $\begin{array}{l}\text { Perceived benefits and risks of } \\
\text { using the app in daily practice }\end{array}$ & $\begin{array}{l}\text { - A useful tool for patients to support self-management } \\
\text { behavior } \\
\text { - Patients being the owner of the app could enhance patient } \\
\text { control } \\
\text { - Improvement for patients compared with the use of written } \\
\text { action plans } \\
\text { - More in-depth and structured patient conversations } \\
\text { - More insight into actual experienced symptoms } \\
\text { - More tailored treatment and self-management support } \\
\text { - Increase uniformity in self-management support by HCPs } \\
\text { - Enhance collaboration between HCPs within and across } \\
\text { settings } \\
\text { - Concerns about the safety of the app } \\
\text { - Patients substituting HCP contact with the app } \\
\text { - The app could be distracting from interacting with patients } \\
\text { - Contribute to an increase in treatment burden }\end{array}$ \\
\hline $\begin{array}{l}\text { Factors that could influence the } \\
\text { use of the app in daily practice }\end{array}$ & $\begin{array}{l}\text { - Patient skills, opportunity, and motivation } \\
\text { - The fit with the available time and workflow of HCPs } \\
\text { - The autonomy of the professional } \\
\text { - The focus of the organization on eHealth and self- } \\
\text { management } \\
\text { - Costs associated with the use of the app } \\
\text { - Compatibility of the app with the current systems and } \\
\text { eHealth initiatives }\end{array}$ \\
\hline
\end{tabular}


Table 3. (Continued)

\begin{tabular}{|c|c|}
\hline $\begin{array}{l}\text { The extent to which the app can } \\
\text { be used in current daily practice }\end{array}$ & $\begin{array}{l}\text { - The app being in line with the GDPR }{ }^{\mathrm{b}} \text { rules } \\
\text { - Clear instruction about the app for both patients and HCPs } \\
\text { - Sufficient time during consultations } \\
\text { - Approval of using the app within the organization } \\
\text { - Having a plan for implementation of the app } \\
\text { - Access to a fast Wi-Fi connection } \\
\text { - Good coordination between HCPs in collaborating } \\
\text { organizations with regard to their roles and responsibilities } \\
\text { - A separate HCP portal would have added value } \\
\text { - Concerns about the privacy sensitivity of an HCP portal } \\
\text { - HCPs having access to the app could undermine or diminish } \\
\text { self-management behavior of the patient }\end{array}$ \\
\hline $\begin{array}{l}\text { Integration of the app across } \\
\text { Dutch health care settings }\end{array}$ & \\
\hline $\begin{array}{l}\text { How to integrate the app into } \\
\text { daily practice }\end{array}$ & $\begin{array}{l}\text { - The app is feasible to integrate into their daily practice and } \\
\text { in already existing paths of care } \\
\text { - Flexibility in the moment of introducing the app to patients } \\
\text { and evaluating of the app } \\
\text { - Could be used as guidance during patient consultations } \\
\text { - Replace the use of written actions plans for the app } \\
\text { - Sustainable in Dutch COPDc care }\end{array}$ \\
\hline $\begin{array}{l}\text { The role of health care } \\
\text { professionals }\end{array}$ & $\begin{array}{l}\text { - A shared responsibility between nurses and physicians } \\
\text { - The selection of eligible patients for the app should be the } \\
\text { responsibility of HCPS } \\
\text { - Role in installing and personalizing the app } \\
\text { - Evaluate patient skills and use of the app }\end{array}$ \\
\hline
\end{tabular}

${ }^{\mathrm{a}} \mathrm{HCP}$ : health care provider; ${ }^{\mathrm{b}}$ GDPR: General Data Protection Regulation; ${ }^{\mathrm{c} C O P D}$ : chronic obstructive pulmonary disease.

\section{Acceptability of the app and perceived demand}

When the HCPs were asked about their first impressions of the app, the HCPs spoke about the usability aspects of the app and the relevance of the app for daily practice. Overall, high satisfaction about working with the app was expressed by ratings of 7 or higher on a 10-point numeric scale. These high ratings were attributed to finding the app user friendly because of its ease of use, intuitive navigation, design simplicity, attractive layout, and receiving positive feedback when using the app (Q1). Although HCPs needed time to familiarize themselves with the app, working with the app was perceived to be easy to learn. The high level of satisfaction and the app being perceived as user friendly was also supported by an average score of 83.8 (SD 15.1) on the SUS, indicating good usability of the app. 
Furthermore, almost all HCPs believed that the app would be relevant for daily practice (Q2). HCPs recognized the content of the app, and particularly nurses found the app in line with the current self-management support. The calendar function in the app was considered to be most relevant for HCPs as it provided a compact, rapid, and clear overview of registered symptoms and actions. The action plan was largely in line with the current written action plans used by HCPs. The gray zone for decision support in determining the correct color zone (Figure 1) and the focus on personalizing the green zone based on registered symptoms were considered to have added value compared with written action plans. However, 8 HCPs preferred further tailoring of the yellow and orange zones (Figure 1) by adding more personalized signals for symptom deterioration. The information module was considered to be clear and relevant, although information could be presented more attractively and could be extended with more detailed information about self-management actions. Most HCPs were positive about the symptom monitoring module, as indicating symptoms fits well with how patients would describe their symptoms. A total of 3 HCPs found the symptom monitoring module to be more convenient than the currently used questionnaires in COPD care, such as the Medical Research Council dyspnea scale and the Clinical COPD Questionnaire, ${ }^{34,35}$ whereas 6 HCPs expressed a wish to add those questionnaires to the app.

A total of $11 \mathrm{HCPs}$ expressed that the app fits well within the organizational culture as their organizations are open to digital innovations in health care because of the fit with the current environment in which health care digitalization is rapidly evolving. However, some organizations neither prioritize nor facilitate digital innovations yet. Almost all HCPs had a positive attitude toward using the app in daily practice because of opportunities to improve the quality of self-management support (Q3). When discussing colleagues' attitudes toward using mHealth, 3 HCPs believed that physicians would be hesitant and resistant toward these innovations on account of time constraints in their profession.

The majority of HCPs expressed a high level of interest in using the app, scoring an 8 or higher on a 10-point numeric scale. HCPs explained these ratings by their personal interest and enthusiasm for innovations and the fit with their needs and demands for health care improvement, such as more structured self-management support for patients with COPD (Q4). All HCPs expressed having the intention to use the app in their own practice, except for 1 general practitioner who believed the app will not fit with the current workflow and related time constraints. 
Quotes of HCPs (Q references in the text) related to acceptability of the app and perceived demand are provided in Textbox 1.

Textbox 1. Quotes related to acceptability of the app and perceived demand.

Quotes of health care providers related to acceptability of the app and perceived demand:

- Q1: "I find it very useful, it is accurate and well-arranged and I find the lay-out very pleasant, actually. You're not distracted by small letters or something on the side edge of the screen. I think it's very clear." (R10)

- Q2: "I believe the app is clinically relevant, yes. It is very much based on the questions we are asking nowadays, based on the Medical Research Council dyspnea scale and the Clinical COPD Questionnaire. I recognize those questions in the app, but it is more logically translated to the daily practice of the patients themselves in my opinion" (R14)

- Q3: "I think these sort of initiatives for a large part have the future and...and that it can make it easier for people, and that it will help. So I am very, very enthusiastic." (R05)

- Q4: Interviewer: "How interested are you in using the app and why?" R11: "I think an 8 or 9 , because self-management is returned to the person who has the disease. Also because currently, there is nothing. The culture is finally shifting as we discover, oh yes...the patient has to do it. What we have been doing with patients with diabetes for years already." (R11)

\section{Perceived benefits and risks of using the app in daily practice}

The HCPs believed that there would mainly be benefits of using the app in daily practice at the patient, HCP, and organizational levels and only a few potential risks. Almost all HCPs found the app a useful tool for patients to support selfmanagement behavior as it can help patients to create awareness of their stable symptoms and signals of symptom deterioration and could then support taking prompt and adequate actions. More than half of the HCPs believed that patients being the owner of the app could enhance patient control of the disease by becoming less dependent on their HCP and being in control when receiving support from HCPs across health care settings (Q5). The 4 HCPs explicitly mentioned that the app would be an improvement for patients compared with the use of written action plans as patients carry the app with them all the time and an app stays clean and readable.

The HCPs perceived many benefits of using the app for their own practice. Most importantly, 11 HCPs believed the app could lead to more in-depth and structured patient conversations, as the conversations would be more initiated by patients and, therefore, be more tailored to the specific needs and preferences of the patients (Q6). HCPs experience that patients often have difficulties with recalling 
experienced symptoms and performed actions and tend to underestimate or exaggerate their symptoms. The calendar in the app would provide more insight into actual experienced symptoms when patients are at home and prevents that HCPs have to dig for information. This could save valuable time and lead to more meaningful contact between HCPs and patients. The calendar could contribute more tailored treatment and self-management support by HCPs as the output could be used by physicians to evaluate medication treatment and by nurses to match patient needs with relevant self-management support (Q7-8). In addition, 5 HCPs believed that the app could increase uniformity in self-management support by HCPS. Nowadays, self-management support by HCPs is often inconsistent between HCPs within and across health care organizations. Some HCPs mentioned that the app could provide more guidance in providing self-management support and could also facilitate making clear agreements on which HCPs are assigned as contact persons for a patient (Q9). Moreover, most HCPs agreed that the app could be used by various HCPs throughout and across health care settings, including those without a case manager role, and could enhance collaboration between HCPs within and across health care settings. Although some HCPs expressed having good contact with HCPs in other health care organizations and clear agreements about their roles and responsibilities, others expressed experiencing limited collaboration between HCPs in primary, secondary, and tertiary care. Some HCPs expressed that the patient being the owner of the app would facilitate the patients themselves being able to show the agreements made about their treatment with an HCP in one setting to HCPs in other settings. This could result in more continuity of care (Q10). Most HCPs found it difficult to reflect on the potential benefits of the app on an organizational level. A few HCPs mentioned that the app could potentially reduce health care costs by preventing hospital admissions or reducing the duration of hospital admissions.

Most HCPs perceived limited risks associated with the use of the app in daily practice. However, some HCPs expressed concerns about the safety of the app as there is potential for making mistakes during manual registration of medication into the app. In addition, 1 nurse specialist was concerned about the misinterpretation of the color zones by patients. Furthermore, 1 general practitioner expressed that patients substituting HCP contact with the app could be a risk, as patients might be less likely to involve their HCP when they have the app to guide them. Especially during a stable phase, a patient might think that the HCP contact is redundant because their app indicates that all is well. Moreover, 1 pulmonologist felt that using the app could be distracting from interacting with patients, which could form an obstacle for the HCPs role (Q11). Finally, 1 HCP from 
tertiary care expressed that the app could contribute to an increase in treatment burden for patients as they are already treated in multidisciplinary teams with a variety of (digital) interventions (Q12).

Quotes of HCPs (Q references in the text) related to the benefits and risks of using the app in daily practice are provided in Textbox 2.

Textbox 2. Quotes related to the benefits and risks of using the app in daily practice.

Quotes of health care providers related to the benefits and risks of using the app in daily practice:

- Q5: "I think patients will be more equipped to say: 'These are my symptoms, and when if I have this then something really needs to be done'. And I think that especially in a situation when the orange zone is going towards red, that patients will be heard by HCPs, especially by the ones they don't know well. A substitute general practitioner or emergency doctor or so...It gives them confidence that they know." (R10)

- Q6: "Now you have a specific topic to discuss. Usually it's small talk, but now patients will know in advance, 'okay, we will discuss this.' So also they will prepare in advance. So yes, I think it could be positive." (R01)

- Q7: "I think, in the end, it could also save time because patients could clearly express their questions and problems. Based on that overview you could better target your consults and adequately meet patient needs." (R03)

- Q8: “Look, if someone's calendar is continuously 'green', you can say, 'well, that looks really good!, maybe we should cut back or adjust some medication. Let's see if that is possible'. So that is all profit." (R08)

- Q9: "Maybe more uniformity in how HCPs work, since the app would require a specific method of working. Currently, we all work in our own individual way (...) When you look at colleagues' notes, you notice variation in reporting due to differences in focus. There is no consistency. So the app could stimulate that as well." (R06)

- Q10: "By having the action plan on the phone the responsibility is given to the patient. When he comes into contact with other HCPs (...) you can say: 'Look, the patient has it on his phone!' And not only for us outpatient clinic but also for the nursing ward they can say: 'Hey, what has the patient done? What happened?"' (R04)

- Q11: "You don't have the time to fill out the app during a consult. In those 10 minutes you already have to type in a lot in the electronic patient file, and you have to talk to your patient and examine your patient as well. That doesn't work. Looking patients in the eyes and listening to their lungs is most important for patients." (R05)

- Q12: "If I put myself into the patients position, I think, 'Now I have an app for exacerbations, and the food intake app and move monitor app. That is quite a lot.' That's the only thing that makes me hesitant, the treatment burden." (R10) 


\section{Use of the app by HCPs and factors that could influence the use of the app in daily practice \\ Observed use of the app by HCPs}

During the interactive session, all HCPs clearly understood the tasks they had to perform in the app and they were able to perform those tasks well. HCPs who had experience with written action plans expressed that setting up the action plan in the app corresponds with the current workflow of setting up a written action plan and could even improve this workflow. All HCPs were able to set up and adjust the action plan and review registered symptoms and actions in the calendar function of the app. Support from the researcher was needed when usability issues were observed. These issues were mostly related to the registration of medication, setting up the yellow zone of the action plan, and saving registrations.

\section{Factors that could influence the use of the app in daily practice}

By asking HCPs about their perceptions toward using the app in their daily practice, HCPs reflected on factors that could facilitate or hinder using the app as intended at the level of patients, HCPs, and the organization. All HCPs believed patient skills, opportunity, and motivation influence the use of the app (Q13-14). The proliferation of mobile device use and improvement in the digital skills of patients were believed to facilitate the use of the app in a large patient population. However, low health literacy, avoiding confrontation with illness, limited digital skills, lack of access to the internet, and loss of interest in the app on the long term were considered to be threats for continued use.

The fit with the available time and workflow of HCPs was perceived to be an important factor that would influence the use of the app in daily practice. HCPs' perceptions toward this fit were influenced by the traditional division between the roles of nurses and physicians. Most HCPs mentioned that the app fits within the available time and workflow of nurses as they already have an important role in providing self-management support (Q15). A total of 6 HCPs believed that the app does not fit within the available time and workflow of physicians as they have a main focus on medical treatment in the limited time they have available for patients (Q16). Two physicians even felt that using the app could result in more work as they would be obligated to focus on issues that normally would not come to light. For physicians, it was important to determine whether the app would improve their work efficiency (Q17). Furthermore, the autonomy of the professional in implementing innovations and scheduling extra time for consultations, if needed, was perceived to facilitate use of the app in daily practice (Q18). Moreover, 2 HCPs in primary care mentioned that primary care nurses might not feel comfortable 
with adding medication prescriptions to the app, which could hinder the use of the app as intended.

The focus of the organization on eHealth and self-management was considered to be an important facilitator for implementation of the app, as this would also facilitate the existence of innovation teams within organizations that could support HCPs in the use of digital innovations (Q19). Furthermore, some HCPs mentioned that costs associated with the use of the app would influence the use of the app in an organization, as innovations should not be too expensive and should ideally lead to a reduction in health care costs. Finally, some HCPs expressed that the compatibility of the app with current systems and eHealth initiatives in their organization is important, as a mismatch with current systems could hinder the use of the app in an organization (Q20).

Quotes of HCPs (Q references in the text) related to performance of tasks in the app and factors that could influence the use of the app in daily practice are provided in Textbox 3 .

Textbox 3. Quotes related to performance of tasks in the app and factors that could influence the use of the app in daily practice.

Quotes of health care providers related to performance of tasks in the app and factors that could influence the use of the app in daily practice:

- Q13: "We have a lot of older generations here. That could be complicated for them. But sometimes it takes me by surprise when someone of 90 has a tablet and iPhone. I am often surprised because you think, 'Oh no, they will not do that', and then all of the sudden, there is their phone!" (R04)

- Q14: "I do wonder if someone will actually work with it. Because there are also people who do not constantly want to be reminded about their illness and prefer to hide it." (R01)

- Q15: "The content, we also work with that when we make plans. So it is in agreement with the work procedure we do without the app, what we do on paper now." (R03)

- Q16: "Right now I am already thinking, for a doctor, for the consultation time available, this is too complicated, it takes too long. I am already thinking: 'I have to continue. I don't have that much time.' Look, now I am not even talking with the patient." (R05)

- Q17: "For patients, it would be an obvious improvement, but it will not directly be an improvement in efficiency for us." (R05)

- Q18: "To an extent, I am free to provide that kind of care of which I believe is necessary or has added value." (R14)

- Q19: "Yes, we are actually ready for implementation at this time since we are currently working on all kinds of innovations, also innovations that support patients to be in control over their disease." (R03)

- Q20: “I am not sure whether the app matches with the integrated care system we are currently using, since you have to focus a part of your consultation on the app where we normally follow our integrated care system that provides a certain structure for a consult." (R14) 


\section{The extent to which the app can be used in current daily practice}

By asking HCPs how the app would fit within the current daily practice, 3 HCPs explained that the app could already be used in daily practice considering the available conditions, time, and resources. However, the majority of HCPs mentioned conditions that should be met before being able to use the app in daily practice. An important condition that should be met is the app being in line with the General Data Protection Regulation (GDPR) rules, as HCPs asked questions about privacy issues (Q21). In addition, some HCPs explained that the app should function technically well on various devices so that patients can use the device they prefer.

On patient and HCP levels, most HCPs expressed a need for clear instruction about the app for both patients and HCPs, such as written information or a demo about the app, to have sufficient knowledge about how the app should be used and to show patients how the app works (Q22). Especially for HCPs without the experience of working with written action plans, instruction on how to set up an action plan that includes medication prescription is important. Furthermore, for HCPs specifically, there should be sufficient time during consultations to be able to work with the app. On the basis of this study, HCPs expected to need approximately $30 \mathrm{~min}$ to install the app and to personalize the action plan for the patient. They believed this would probably take longer in daily practice as they would have to communicate with patients at the same time. Therefore, some HCPs explained that their consultation time should be extended. Most of these HCPs expressed that they would have the opportunity to schedule some extra time for consultations. Two HCPs emphasized the importance of embedding the app into current workflows to realize sustained use over time.

Many HCPs insisted that approval of using the app within the organization was considered to be an important condition that must be met before being able to use the app in daily practice (Q23). Having an organizational mandate to implement the app was considered to contribute to the allocation of time and resources. Overall, HCPs working in larger organizations believed acquiring management support to be more difficult and time consuming than HCPs working in smaller organizations. Moreover, 2 HCPs working in larger organizations expressed that having a plan for implementation of the app would be important to mobilize people in an organization to start working with the app. Furthermore, a practical issue mentioned was that organizations need to have access to a fast Wi-Fi connection to be able to quickly download and use the app in daily practice. Finally, HCPs emphasized the importance of good coordination between HCPs in collaborating organizations with regard to their 
roles and responsibilities in the use of the app. A total of 7 HCPs indicated that training and instructional material for HCPs across health care settings would help to create awareness about the app among HCPs and about their role in using the app (Q24).

On the basis of the question whether HCPs would prefer to have access to a separate HCP portal to set up an action plan and review patients' registrations on their own computer, $8 \mathrm{HCPs}$ expressed that a separate HCP portal would have added value for their daily practice. These HCPs, mostly physicians, believed that a separate portal would be more user friendly and efficient, would be helpful in preparing patient consultations, and would enable HCPs to review the app during consultations by telephone. Furthermore, it could reduce the administrative burden and could support collaboration between HCPs in an organization when the HCP portal is integrated into local information technology systems. Concerns about the privacy sensitivity of an HCP portal influenced the perceptions of the HCPs on having a separate portal. On one hand, 2 HCPs expressed that they would not feel comfortable if they had to work on the patient's device itself, as this is a private device. On the other hand, some HCPs expressed that a connection with a separate portal or patient system could entail privacy risks as well. A separate HCP portal was less important for nurses. Three nurses argued that HCPs having access to the app could undermine or diminish self-management behavior of the patient. It could give patients the feeling of being monitored by their HCP, which emphasizes an external locus of control (Q25). Nonetheless, most HCPs perceived a separate HCP portal as an important condition that must be met to stimulate use of the app in daily practice.

Quotes of HCPs (Q references in the text) related to the extent to which the app can be used in current daily practice are provided in Textbox 4.

\section{Integration of the app across Dutch health care settings How to integrate the app into daily practice}

Overall, the HCPs from primary, secondary, and tertiary care settings felt that the app is feasible to integrate into their daily practice and in already existing paths of care as the app could be easily adapted to the specific context of health care organizations. The HCPs believed that the app could be introduced in annual COPD checkups in primary care; clinical care paths, outpatient follow-up care, and pulmonary rehabilitation programs in secondary care; and pulmonary rehabilitation programs in tertiary care (Q26). Most HCPs emphasized the importance of flexibility in the moment of introducing the app to patients and evaluating the app to be able to integrate the app into their workflow. Individual 
organizational factors, such as a specific path of care or division between HCP roles, would determine the specifics of how the app is to be integrated. The HCPs explained that the app could be used as guidance during patient consultations. HCPs currently using written action plans intended to replace the use of written action plans for the app. Nonetheless, for them, patient preferences and skills would determine whether a written action plan could be replaced by the app. Most HCPs felt that the use of the app would be sustainable in Dutch COPD care because of the fit within national COPD guidelines and current paths of care and their wish for more structured self-management support (Q27). However, 3 HCPs mentioned that the need for the app could decrease over time when the self-management skills of patients have been improved.

Textbox 4. Quotes related to the extent to which the app can be used in current daily practice.

Quotes of health care providers related to the extent to which the app can be used in current daily practice:

- Q21: "It is important to know what will happen with the data. Will data be used for further research? What will happen with it? Will data be stored somewhere? Or will it only be available for patients themselves?" (R04)

- Q22: "Of course training for HCPs is necessary, but also to show patients the app. That you have an app with a an example of a patients and that you can show what you can do with it. Then the patient can decide to use the app or not. And yes.. an instructional flyer, with preferably a demo as well. Preferably on a desktop or on mobile device, that would work most handy because that is what they will work with." (R02)

- Q23: "We have an agreement that new studies or implementations must be approved of by the management team. On the one hand, it always costs a little bit of time. On the other hand, you know when its approved then everybody has to abide by it. Then it will be supported by all location managers." (R07)

- Q24: “We do collaborate with primary care, although this is not really translated into detailed care. If we were to implement the app, we also should inform primary care organizations about the app and that patients may come to their consults with the app instead of a written action plan." (R06)

- Q25: “No, no...then you actually affirm or emphasize the external locus of control. The patient becomes passive, 'I am being taken care of.' And that is what we don't want anymore!" (R06) 


\section{The role of health care professionals toward using the app}

Although all HCPs indicated that working with the app best fits the role of the nurses because of their current role in providing self-management support, most HCPs considered the use of the app to be a shared responsibility between nurses and physicians (Q28). As nurses and physicians have a shared responsibility in the care for patients with COPD, this also applies to the use of the app in daily practice. Overall, introducing the app to patients and initiating and evaluating the action plan was considered to best fit the role of the nurses. However, some HCPs explained that physicians could have a role in prescribing and evaluating medication treatment in the action plan, which depends on the autonomy of the nurses with regard to medication prescription. HCPs expressed that reviewing the calendar of the app could be integrated in the consultations of both the nurses and physicians.

Most HCPs felt that the selection of eligible patients for the app should be the responsibility of HCPs. Although $4 \mathrm{HCPs}$ expressed the intention to provide the app to all of their patients, most HCPs believed that not all patients will be eligible for the app. Therefore, they would select patients based on their assumptions about patient skills and motivation to use the app. A few HCPs explained that the motivation to use the app could be related to the severity of the disease. HCPs expected that patients with severe COPD and frequent exacerbations would be more motivated for exacerbation-related self-management compared with patients with an early stage of COPD who prefer to avoid confrontation with the disease. Therefore, most HCPs mentioned that they would provide the app to patients who frequently have exacerbations (Q29). Furthermore, most HCPs believed they would have an important role in installing and personalizing the app together with a patient, although 2 HCPs believed patients could do this initially by themselves. Finally, 6 HCPs mentioned that they would evaluate patient skills and use of the app so that they could provide support in using the app when needed, thereby guaranteeing safe and effective use by patients over time (Q30).

Quotes of HCPs (Q references in the text) related to integration of the app across Dutch health care settings are provided in Textbox 5. 
Textbox 5. Quotes related to integration of the app across Dutch health care settings.

Quotes of health care providers related to integration of the app across Dutch health care settings:

- Q26: 'The app could actually fit in the current path of care we have in in this hospital, in which we also discuss self-management. It would fit with that. (...) It would be a new element to integrate, but it could be used as a supportive tool." (R13)

- Q27: "The action plan can always be improved. And I think this app is an improvement. So in my opinion, it is future proof." (R09)

- Q28: "The primary care nurses could start with filling out the patients name and symptoms. And if they do not feel comfortable with filling out medication, they can instruct the patient to bring the app with them to the yearly consult with the general practitioner who can fill out that part." (R07)

- Q29: "The app can be useful for everyone, but I think it would be very useful for those patients that have clear symptoms and feel disabled, especially for those who frequently experience exacerbations. So if patients have frequent exacerbations I would be more inclined to offer the app to patients. However, I think I would have assumptions, unconsciously, about patients digital skills as well that could influence this decision." (R07)

- Q30: “During the consult in which the symptom monitoring is evaluated you could as well evaluate how patients have used the app so far. You could let patients practice for example with how they could adjust the app. They have to learn how to use a new instrument." (R6)

\section{Discussion}

\section{Principal findings}

This early-stage feasibility study provides insight into the perceptions of Dutch HCPs with a case manager role in COPD care regarding the use of the Copilot app in daily practice. Overall, the HCPs were able to work with the app and found the app acceptable to use in daily practice. The app could be used as guidance during patient consultations and could replace the use of written action plans in COPD care. Many benefits and only a few risks were expected regarding the use of the app in daily practice at the patient, HCP, and organizational levels. The app was considered to best fit the role of the nurses. Physicians were expected to have a marginal role in working with the app because of time constraints and misfit with their workflow. Other key factors that could influence the use of the app were the autonomy of the professional, the focus of the organization on eHealth, costs associated with the app, and compatibility with the current systems used. There are various conditions that must be met to be able to use the app in daily practice. The level of importance of these conditions varied between professions and contexts and may be attributed to organizational factors or fundamental 
differences in needs between physicians and nurses. The app was considered to be feasible to integrate into existing care paths of primary, secondary, and tertiary health care settings. Individual organizational factors must be taken into account when integrating the app in daily practice.

Some of the findings of this study are in line with those of other studies. Two recent studies focusing on the adoption of mHealth by HCPs also identified usefulness, ease of use, perceived benefits, autonomy of the professional, and integration with other systems as facilitators for the adoption of mHealth by HCPs. ${ }^{31,36}$ Similar to our results, these studies considered disruption to workflow, lack of time, increased workload, cost issues, and privacy and security issues as key adoption barriers. ${ }^{31,36}$ Gagnon et $a^{31}$ pointed out that the use of mHealth could be disruptive during visits as it could influence the interaction between patients and health care professionals; this was identified in our study as well and was perceived as a risk for the use of the app in daily practice. Furthermore, a study focusing on the adoption of new technology by physicians found that high initial physician time costs, uncertain financial benefits, and lack of electronic exchange between systems were key physician-related barriers. ${ }^{37}$ These studies indicate that nurses may hold the key to successful implementation of the Copilot app because of their role, the fit with their workflow and available time, and numerous advantages for their daily practice. Moreover, these studies strengthen our findings on the importance of meeting specific conditions to use the app in daily practice. According to our results, a separate portal for HCPs and integration with current systems could potentially facilitate the use of the app, especially for physicians. However, HCPs' perspectives toward system integration differ, which was also observed in conversations with HCPs during the development of the Copilot app.22 On the basis of the literature, it could be expected that interoperability is important for integration of the app across health care settings. ${ }^{31}$

The findings of this study show that factors influencing future implementation and integration of the app into health care organizations are context dependent. Recently, much emphasis has been placed on the importance of taking into account the context in intervention research aiming at changing behaviors, to increase the likelihood of developing appropriate, implementable, effective, and sustainable interventions. ${ }^{38}$ On the basis of HCPs' perceptions that the app is feasible to implement and integrate into Dutch health care organizations, taking context into account in the development of the app seemed to have resulted in sufficient flexibility in the design of the app to work across a range of contexts. ${ }^{22,38}$ 


\section{Strengths and limitations}

A strength of this study was the maximum variation in settings and HCPs resulting in a broad range of perspectives, thereby increasing the transferability of our findings to similar settings in the Netherlands. ${ }^{33}$ Furthermore, the credibility and confirmability of this study were enhanced by using data and researcher triangulation. ${ }^{33}$ The feasibility framework described by Bowen et $\mathrm{al}^{23}$ ensured that feasibility was evaluated by considering several important areas of focus to determine if the app can work within the constraints of daily practice. Although not the focus of data saturation, data collected on integration and practicality gave a general impression of contextual differences on how to integrate the app and which HCP role is perceived to be most suited.

A limitation of this study was the variation in the course of the interactive sessions and interviews because of time constraints and unforeseen circumstances within the HCPs' workflow. In some cases, this resulted in limited in-depth interviews and underexposure of some topics. However, systematic reflection on these methodological issues and subsequently adapting the guideline of the session resulted in more in-depth data collection as the study proceeded. Furthermore, a relatively large part of the study population had experience with digital technology to some extent. This may have resulted in a more positive perception toward the use of technology as familiarity with mHealth and technologies in general is considered to facilitate the adoption of mHealth. ${ }^{31}$ Finally, this early-stage feasibility study evaluated the Copilot app within an artificial context, consisting of 1 interactive session with a fictional patients' case. It could be discussed whether perceptions of feasibility would be different in the case of actual implementation of the app in the daily practice of the HCPs. Nonetheless, HCPs have experienced working with the app by simulating the use of the app in daily practice.

\section{Implications for practice and future research}

The findings of this study are important for HCPs in COPD care and for researchers focusing on the development and evaluation of mHealth interventions. The study shows that the Copilot app is considered to be relevant and acceptable to use in the daily practice of the HCPs. The app could result in various benefits for patients, HCPs, and health care organizations and has high potential for successful implementation and integration across Dutch health care settings. Important lessons can be learned from this study with regard to practicality, which we described in this study as conditions that have to be met to use the app in daily practice. To use the app in daily practice, it is important that clear instruction about the use of the app is provided to both patients and HCPs, that there is 
sufficient time during consultations, and that approval to use the app within organizations is realized. In addition, good coordination about the use of the app between HCPs in collaborating organizations is needed. Adequate training and support for HCPs regarding the use of the app is important for implementation and integration of the app in daily practice, as using the app requires behavior change from HCPs. Essential in changing HCPs' behaviors is that they have the capability, motivation, and opportunity to use the app in daily practice. ${ }^{39}$ Training and support should therefore focus on motivating HCPs to use the app and enhancing HCPs' knowledge and skills needed to use the app, with a specific focus on the use of action plans. ${ }^{40}$ Finally, a separate portal for HCPs is an important condition that must be met in some organizations to stimulate the use of the app in daily practice. Contextual factors across health care settings will determine the specific conditions that should be met to be able to use the app in daily practice.

For researchers and developers focusing on the development and evaluation of mHealth interventions, this study provides insight into a new approach to evaluate the feasibility of mHealth interventions at an early stage. This approach has been shown to be a thorough and relatively quick way to investigate perceptions toward feasibility. The methods used in this study provided rapid insight into influencing factors and conditions regarding feasibility, thereby allowing researchers and developers to adapt mHealth interventions by moving backward or forward quickly. Evaluating feasibility at an early stage helps to determine whether mHealth interventions are appropriate for further feasibility testing with end users over a longer time period.

Further research on the Copilot app should focus on longitudinal feasibility testing of the Copilot app with both patients and HCPs to investigate the delivery and acceptability of the intervention, compliance with the intervention, and recruitment of patients and to investigate limited efficacy. In a next phase, the effect of the Copilot app on relevant patient outcomes and health care use should be evaluated. This evaluation should include an assessment of how context influences the effectiveness of the app. ${ }^{38}$ Understanding how the app relates to context is critical to understand how the app works and for whom, what influences implementation success and failure, whether the app can be successfully adapted or scaled-up from one context to another, and to what extent effects could be generalized to other contexts. ${ }^{38}$ To achieve this, a thorough process evaluation using qualitative and quantitative methods from a system lens is recommended. ${ }^{38,41,42}$ 


\section{Conclusions}

This early-stage feasibility study shows that the Copilot app is feasible to use in the daily practice of Dutch HCPs and is considered to best fit the role of the nurses. The app is perceived to be acceptable to use and relevant for the daily practice of HCPs. The app can be used as guidance during patient consultations and could replace the use of written action plans in COPD care. Many benefits and only a few risks were expected regarding the use of the app in daily practice at the patient, HCP, and organizational levels. The app will be less feasible in organizations where relatively many conditions need to be met. The app is considered to be feasible to be integrated into primary, secondary, and tertiary health care settings in the Netherlands. Individual organizational factors must be taken into account when integrating the app in daily practice. This study provides a new approach to evaluate the perceived feasibility of mHealth interventions at an early stage and provides valuable insights for further feasibility testing. Future research should focus on longitudinal feasibility testing of the Copilot app by both patients and HCPs. 


\section{References}

1. World Health Organization. The global burden of disease. Update 2004. Available from: http:// www.who.int/healthinfo/global_burden_disease/GBD_report_2004update_full.pdf?ua=1. Updated 2008. Accessed October 28, 2018.

2. Global Initiative for Chronic Obstructive Lung Disease (GOLD). Global strategy for prevention, diagnosis and management of COPD. Available from: https://goldcopd.org/wp-content/ uploads/2017/11/GOLD-2018-v6.0-FINAL-revised-20-Nov_WMS.pdf. Updated 2018. Accessed November 12, 2019.

3. Donaldson GC, Seemungal TA, Bhowmik A, Wedzicha JA. Relationship between exacerbation frequency and lung function decline in chronic obstructive pulmonary disease. Thorax. 2002;57(10):847-852.

4. Seemungal TA, Donaldson GC, Paul EA, Bestall JC, Jeffries DJ, Wedzicha JA. Effect of exacerbation on quality of life in patients with chronic obstructive pulmonary disease. Am J Respir Crit Care Med. 1998;157(5 Pt 1):1418-1422.

5. Miravitlles M, Ferrer M, Pont A, et al. Effect of exacerbations on quality of life in patients with chronic obstructive pulmonary disease: A 2 year follow up study. Thorax. 2004;59(5):387-395.

6. Soler-Cataluna JJ, Martinez-Garcia MA, Roman Sanchez P, Salcedo E, Navarro M, Ochando R. Severe acute exacerbations and mortality in patients with chronic obstructive pulmonary disease. Thorax. 2005;60(11):925-931.

7. Toy EL, Gallagher KF, Stanley EL, Swensen AR, Duh MS. The economic impact of exacerbations of chronic obstructive pulmonary disease and exacerbation definition: A review. COPD. 2010;7(3):214-228.

8. Barlow J, Wright C, Sheasby J, Turner A, Hainsworth J. Self-management approaches for people with chronic conditions: A review. Patient Educ Couns. 2002;48(2):177-187.

9. Howcroft M, Walters EH, Wood-Baker R, Walters JA. Action plans with brief patient education for exacerbations in chronic obstructive pulmonary disease. Cochrane Database Syst Rev. 2016;12:CD005074.

10. Lenferink A, Brusse-Keizer M, van der Valk, P D, et al. Self-management interventions including action plans for exacerbations versus usual care in patients with chronic obstructive pulmonary disease. Cochrane Database Syst Rev. 2017;8:CD011682.

11. Schnall R, Rojas M, Bakken S, et al. A user-centered model for designing consumer mobile health (mHealth) applications (apps). J Biomed Inform. 2016;60:243-251.

12. World Health Organization. Mhealth. New horizons for health through mobile technologies. Second global survey on eHealth. Available at: http://www.who.int/goe/publications/goe_mhealth_web. pdf. Updated 2011. Accessed August 17, 2018.

13. McCabe C, McCann M, Brady AM. Computer and mobile technology interventions for self-management in chronic obstructive pulmonary disease. Cochrane Database Syst Rev. 2017;5:CD011425.

14. Sul AR, Lyu DH, Park DA. Effectiveness of telemonitoring versus usual care for chronic obstructive pulmonary disease: A systematic review and meta-analysis. J Telemed Telecare. 2020;26(4): 189-199.

15. Goldstein RS, O'Hoski S. Telemedicine in COPD: Time to pause. Chest. 2014;145(5):945-949.

16. McKinstry B. The use of remote monitoring technologies in managing chronic obstructive pulmonary disease. QJM. 2013;106(10):883-885.

17. Alwashmi M, Hawboldt J, Davis E, Marra C, Gamble JM, Abu Ashour W. The effect of smartphone interventions on patients with chronic obstructive pulmonary disease exacerbations: A systematic review and meta-analysis. JMIR Mhealth Uhealth. 2016;4(3):e105. 
18. Bolton CE, Waters CS, Peirce S, Elwyn G, EPSRC and MRC Grand Challenge Team. Insufficient evidence of benefit: A systematic review of home telemonitoring for COPD. J Eval Clin Pract. 2011;17(6):1216-1222.

19. McLean S, Nurmatov U, Liu JL, Pagliari C, Car J, Sheikh A. Telehealthcare for chronic obstructive pulmonary disease: Cochrane review and meta-analysis. Br J Gen Pract. 2012;62(604):e739-49.

20. Farias R, Sedeno M, Beaucage $D$, et al. Innovating the treatment of COPD exacerbations: A phone interactive telesystem to increase COPD action plan adherence. BMJ Open Respir Res. 2019;6(1):e000379-2018

21. Boer L, Bischoff E, van der Heijden M, et al. A smart mobile health tool versus a paper action plan to support self-management of chronic obstructive pulmonary disease exacerbations: Randomized controlled trial. JMIR Mhealth Uhealth. 2019;7(10):e14408.

22. Korpershoek YJG, Hermsen S, Schoonhoven L, Schuurmans MJ, Trappenburg JCA. User-centered design of a mobile health intervention to enhance exacerbation-related self-management in patients with chronic obstructive pulmonary disease (copilot): Mixed methods study. J Med Internet Res. 2020;22(6):e15449.

23. Bowen DJ, Kreuter $M$, Spring $B$, et al. How we design feasibility studies. Am J Prev Med. 2009;36(5):452-457.

24. Walters JA, Turnock AC, Walters EH, Wood-Baker R. Action plans with limited patient education only for exacerbations of chronic obstructive pulmonary disease. Cochrane Database Syst Rev. 2010;(5):CD005074. doi(5):CD005074.

25. Effing T. Action plans and case manager support may hasten recovery of symptoms following an acute exacerbation in patients with chronic obstructive pulmonary disease (COPD). J Physiother. 2012;58(1):60-9553(12)70076.

26. Kushniruk AW, Patel VL. Cognitive and usability engineering methods for the evaluation of clinical information systems. J Biomed Inform. 2004;37(1):56-76.

27. Nielsen J. Usability engineering. Boston: MA: Academic Press, Inc.; 1993.

28. Long Alliantie Nederland (LAN). Zorgstandaard COPD [COPD Care Standard]. Available from: http:// www.longalliantie.nl/files/9014/5578/9160/LAN_Zorgstandaard_COPD-2016-2.pdf. Updated 2016. Accessed October 2, 2019.

29. Brooke J. System Usability Scale (SUS). Available from: https://www.usability.gov/how-to-andtools/methods/system-usability-scale.html. Updated 1986. Accessed September 02, 2018.

30. Sciencedirect. System Usability Scale. Available from: https://www.sciencedirect.com/topics/ computer-science/system-usability-scale. Updated 2019. Accessed May 23, 2019.

31. Gagnon MP, Ngangue P, Payne-Gagnon J, Desmartis M. M-health adoption by healthcare professionals: A systematic review. J Am Med Inform Assoc. 2016;23(1):212-220.

32. Braun V, Clark V. Using thematic analysis in psychology. Qualitative Research in Psychology. 2006;3(2):77-101.

33. Lincoln YS, Guba EG. Naturalistic inquiry. Newbury Park CA: Sage Publications; 1985.

34. Bestall JC, Paul EA, Garrod R, Garnham R, Jones PW, Wedzicha JA. Usefulness of the medical research council (MRC) dyspnoea scale as a measure of disability in patients with chronic obstructive pulmonary disease. Thorax. 1999;54(7):581-586.

35. van der Molen T, Willemse BW, Schokker S, ten Hacken NH, Postma DS, Juniper EF. Development, validity and responsiveness of the clinical COPD questionnaire. Health Qual Life Outcomes. 2003;1:13-7525.

36. Alwashmi MF, Fitzpatrick B, Davis E, Gamble JM, Farrell J, Hawboldt J. Perceptions of health care providers regarding a mobile health intervention to manage chronic obstructive pulmonary disease: Qualitative study. JMIR Mhealth Uhealth. 2019;7(6):e13950.

37. Miller RH, Sim I. Physicians' use of electronic medical records: Barriers and solutions. Health Aff (Millwood). 2004;23(2):116-126. 
38. Craig P, Di Ruggiero E. Taking account of context in population health intervention research: Guidance for producers, users and funders of research. 2018.

39. Michie S, Atkins L, West R. The behaviour change wheel. A guide to designing interventions. Great Britain: Silverback Publishing; 2014.

40. Feiring E, Friis T. Facilitators and barriers to clinicians' use of COPD action plans in selfmanagement support: A qualitative study. Patient Educ Couns. 2020;103(4):693-701

41. Moore GF, Evans RE, Hawkins J, et al. From complex social interventions to interventions in complex social systems: Future directions and unresolved questions for intervention development and evaluation. Evaluation (Lond). 2019;25(1):23-45.

42. Craig P, Dieppe P, Macintyre $S$, et al. Developing and evaluating complex interventions: The new medical research council guidance. BMJ. 2008;337:a1655. 


\section{Appendix 1}

\section{Stepwise procedure of data collection Guideline for stepwise procedure of data collection}

\begin{tabular}{|c|c|}
\hline \multicolumn{2}{|l|}{ Introduction } \\
\hline Introduce study aim & $\begin{array}{l}\text { - Evaluation of perceived feasibility of the Copilot app in the HCPs daily } \\
\text { practice. } \\
\text { - This is an early feasibility study meaning that the perceived fit of the } \\
\text { app in daily practice will be evaluated. } \\
\text { - The session consists of three parts: } \\
\text { - An interactive session } \rightarrow \text { HCP works with the app using a patient } \\
\text { case; } \\
\text { - Filling out System Usability Scale (SUS) } \\
\text { - An interview } \rightarrow \text { HCP reflects on the interactive session and on } \\
\text { perceptions towards feasibility of the app in daily practice; } \\
\text { - Filling out questionnaire on participant characteristics. } \\
\text { - Estimated duration: interactive session \& SUS ( } 20 \text { minutes); interview } \\
\text { (20 minutes), questionnaire (5 minutes) and rounding off session (5 } \\
\text { minutes). }\end{array}$ \\
\hline $\begin{array}{l}\text { Describe aim of video } \\
\text { recording }\end{array}$ & $\begin{array}{l}\text { To observe the hand interaction of HCPs while working with the app } \\
\text { and to audio record verbalizations during the interactive session and } \\
\text { the interview. }\end{array}$ \\
\hline $\begin{array}{l}\text { Collect informed } \\
\text { consent \& questions }\end{array}$ & $\begin{array}{l}\text { - HCPs are asked to sign the informed consent form in duplicate. } \\
\text { - Potential questions are answered. }\end{array}$ \\
\hline $\begin{array}{l}\text { Questions to ask before } \\
\text { starting session }\end{array}$ & $\begin{array}{l}\text { - HCPs are asked about their current experiences with COPD action } \\
\text { plans. } \\
\text { HCPs are asked about their experiences with using technology in } \\
\text { COPD care. }\end{array}$ \\
\hline
\end{tabular}

Introduction of the Copilot app [by showing the app to HCPs]

Explain the intended use The Copilot app:

of the app

- Is developed for patients with COPD;

- Helps patients to recognize fluctuations in symptoms and to take prompt self-management actions;

- Contains a symptom diary, a personalized action plan, an overview of registered symptoms and actions (calendar) and information about COPD and self-management [show components in app];

- Is specifically intended to be used for self-monitoring of symptoms by patients. It is explicitly not a monitoring system for professionals (this is a difference compared to systems that focus on monitoring by HCPs).

Explain color zones of the action plan
- Green = “I feel well'. Current symptoms are 'normal'. The app supports patients in creating awareness on their 'normal' symptoms, their maintenance therapy and how they can stay in the green zone.

- Yellow = "I feel less well". There is an increase in one or more symptoms. The app supports patients to take action according to the mutual agreed actions between patient and HCP included in the action plan. 
(Continued)

Explain color zones of the action plan

- Orange $=$ "I feel less well for 2 days or I have severe symptoms". The app supports patients to take action according to the mutual agreed actions between patient and HCP included in the action plan.

- $\mathbf{R e d}=$ "I need immediate help". Symptoms are life threatening. The app supports calling for immediate help.

- Gray = "I am doubting about how I feel". The app supports patients in selecting the correct color zone.

\section{Explain the scenario 'how to use the app'}

1. Registration of app and During a patient consultation, the HCP and/or patient downloads personalization of action the app onto the mobile device of the patient and together they plan personalize the action plan.

2. Intensive symptom monitoring

To determine what are the patients 'normal' symptoms, the patient intensively monitors his/her symptoms for two weeks by turning on the 'symptom diary'.

3. Reviewing and adjusting the action plan

After two weeks of daily symptom monitoring, the action plan can be adjusted. How and when adjustment of the action plan takes place is flexible, meaning this could be decided by individual health care organizations.

4. Regular use (self- One a week, the patient is actively asked how he/she feels by receiving monitoring) a notification on the mobile device. Besides this request, the patient can register symptoms any time they want based on individual preferences.

5. Regular use (actions) Dependent on the color zone, the patient receives tailored support regarding self-management actions.

6. Evaluating app Using the calendar, the registered symptoms and actions are evaluated during patient consultations. If necessary, a new period of intensive monitoring can be deployed.

\section{Explain the role of patients and HCPs}

The patient role - Is the owner of the app, shows the app to all relevant HCPs involved;

- Makes a personalized action plan together with an HCP;

- Registers symptoms and undertaken actions;

- Uses the information module to search for information about COPD, exacerbations and self-management.

The HCP role - Personalizes the action plan together with the patient;

- Specifically focusses on filling out the green zone: what symptoms are 'normal' for the patient;

- Evaluates the calendar with the patient during consultations $\rightarrow$ evaluation of registered symptoms and actions; if necessary, adjustment of action plan.

\section{Explain current developmental stage of app}

- The app HCPs work with is the first prototype of the app;

- Researchers are currently exploring potential ways to develop a portal for HCPs to be able to personalize and review the app;

- Usability testing with patients and HCPs has been completed. Some usability issues are not yet resolved in this current prototype. The researcher emphasizes the primary focus on evaluating perceptions towards feasibility of the app instead of focusing on usability issues.

(Continued) 


\section{Explain expectations during interactive session}

- HCPs are asked to read the fictional patient case (see Multimedia Appendix 2) which focuses on an initial consultation in which the app will be personalized and a follow-up consultation;

- HCPs are asked to conduct several tasks within the app using the patient case, tasks are in line with how the HCP would work with the app in daily practice;

- HCPs are asked to 'think aloud' during the interactive session $\rightarrow$ explain feelings, thoughts, etc.

\begin{tabular}{ll}
\hline Part 1: & Show patient case and explain: \\
Initial consultation & Pretend that Mr. Janssen* is sitting ahead of you for his first \\
& consultation; \\
& Set up an initial action plan based on the information provided in the \\
& patient case about symptoms and actions.
\end{tabular}

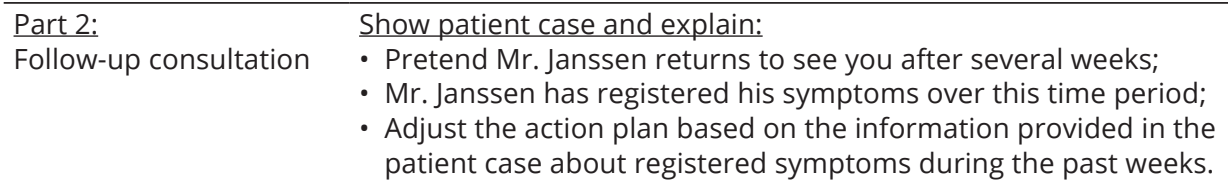

Hand out System Usability Scale (SUS)

Conduct semi-structured interview (see topic list in Appendix 3)

Collect participant's baseline characteristics by handing out the questionnaire

Abbreviation: HCP: health care provider. *Mr. Janssen is a fictional patient. 


\section{Appendix 2}

\section{Fictional patient case and assignment for health care providers}

Textbox 1. Patient case: Initial consultation with 'Mr. Janssen'*

\section{Aim: Installing and personalizing the action plan with Mr. Janssen.}

Patient information for initial consultation:

- Mr. Janssen, 63 years of age, COPD GOLD II/D, knows you as HCP.

- Mr. Janssen has experienced frequent exacerbations during the past year, including being hospitalized four months ago.

- 'Normal' COPD symptoms include:

- Shortness of breath (during light activity)

- Coughing (occasionally)

- Sputum (a little)

- Fatigue (a bit tired)

- Normal treatment (green zone):

- Long-acting bronchodilator: Spiriva Respimat 1x 2 doses per day

- Inhaled corticosteroids: Foster doses aerosol $2 \times 1$ doses per day

- Actions to be taken in case of symptom deterioration (yellow zone):

- Extra medication:

- Atrovent doses aerosol 3-4 doses per day

- "I divide my energy/activities throughout the day"

- "I conduct by breathing exercises"

- "In case of questions, I contact my HCP"

- Mutual agreements in orange zone:

- Call your contact person (contact person(s) can be filled out by the HCP)

${ }^{*}$ Mr. Janssen is a fictional patient. 
Textbox 2. Patient case: Follow-up consultation with 'Mr. Janssen'* after several weeks

\begin{abstract}
Aim: Evaluate registered symptoms/actions and adjust action plan
Patient information for follow-up consultation:

Mr. Janssen has registered his symptoms every day for the past two weeks. He also registered the actions he undertook when feeling less well. Mr. Janssen is visiting you and shows which symptoms he had experienced. After evaluating this overview, you can tell the symptoms he indicated 'normal' do not correspond to symptoms of the green zone that were initially filled out in the action plan. At that time, Mr. Janssen did not exactly know which symptoms are normal for him. The registered symptoms indicate that Mr. Janssen coughs often (instead of coughing occasionally) and is very tired (instead of a bit tired). Furthermore, Mr. Janssen has experienced that he wheezes occasionally. Based on this information, you agree with Mr. Janssen that he can increase the dosage Foster from $2 \times 1$ to $2 \times 2$ per day during the green zone.
\end{abstract}

*Mr. Janssen is a fictional patient.

Textbox 3. Assignment for HCPs

\title{
Tasks to conduct within the app using the patient case of 'Mr. Janssen'*
}

\section{Initial consultation:}

1) Read the information in the patient case related to the initial consultation.

2) Register the Copilot app according to the onboarding conversation of the app.

3) Individualize all color zones of the action plan according to the provided patient information.

\section{Follow-up consultation:}

1) Read the information in the patient case related to the follow-up consultation.

2) Adjust Mr. Janssen's normal symptoms (green zone) [based on the provided patient information]

3) Adjust the medication in the green zone.

4) Using the calendar, evaluate the registered symptoms and actions with Mr. Janssen.

5) Take a look at the information module in the app. You can use the module to educate patients about COPD and the importance of self-management.

*Mr. Janssen is a fictional patient. 


\section{Appendix 3}

\section{Topic list semi-structured interview}

\begin{tabular}{|c|c|c|}
\hline Parameter & $\begin{array}{l}\text { Outcome of } \\
\text { interest }\end{array}$ & Questions for HCP \\
\hline \multirow[t]{3}{*}{ Acceptability } & $\begin{array}{l}\text { Satisfaction with } \\
\text { the app }\end{array}$ & $\begin{array}{l}\text { - What is your first impression of the app? } \\
\text { - How did you experience working with the app? (What did } \\
\text { you find easy to use? What did you find difficult to use?) } \\
\text { - On a ten-point numeric scale, how satisfied were you about } \\
\text { working with the app? (why this rating? To increase this } \\
\text { rating, what should be changed?) } \\
\text { - What is your opinion about the content of the app? Please } \\
\text { explain } \\
\text { - Would you advice the app to your colleagues? Please explain } \\
\text { why. }\end{array}$ \\
\hline & $\begin{array}{l}\text { Perceived } \\
\text { appropriateness }\end{array}$ & $\begin{array}{l}\text { How usable is the app in your daily practice? } \\
\text { - How usable is the app for your patients? }\end{array}$ \\
\hline & $\begin{array}{l}\text { Fit within the } \\
\text { organizational } \\
\text { culture }\end{array}$ & $\begin{array}{l}\text { - To what extent does the app fit within the culture of your } \\
\text { organization? } \\
\text { - To what extent is your organization willing to use an app to } \\
\text { support self-management in patients with COPD? }\end{array}$ \\
\hline \multirow[t]{2}{*}{ Demand } & $\begin{array}{l}\text { Perceived } \\
\text { demand of the } \\
\text { app }\end{array}$ & $\begin{array}{l}\text { - On a ten-point numeric scale, to what extent are you } \\
\text { interested in using the app in your daily practice? (why this } \\
\text { rating? To increase this rating, what should be changed?) } \\
\text { - To what extent does the app fulfill your needs/wishes } \\
\text { regarding improvement of COPD care? } \\
\text { - What would it mean for your daily practice when you start } \\
\text { using the app? }\end{array}$ \\
\hline & $\begin{array}{l}\text { Intention to use } \\
\text { the app }\end{array}$ & $\begin{array}{l}\text { - On a ten-point numeric scale, how motivated are you to use } \\
\text { the app in daily practice? (why this rating? To increase this } \\
\text { rating, what should be changed?) } \\
\text { - How would you most likely use the app in your daily } \\
\text { practice? } \\
\text { - How do you think the app would be used in your } \\
\text { organization? } \\
\text { - Are there elements of the app that would be used more } \\
\text { likely than other elements? }\end{array}$ \\
\hline \multirow[t]{3}{*}{ Implementation } & $\begin{array}{l}\text { Degree of } \\
\text { execution of } \\
\text { tasks }\end{array}$ & $\begin{array}{l}\text { - To what extent did you succeed in working with the app } \\
\text { based on the tasks? Please explain. } \\
\text { - Were you able to individualize the action plan in the app like } \\
\text { you would normally do using a written COPD action plan? }\end{array}$ \\
\hline & $\begin{array}{l}\text { Success/failure } \\
\text { of execution of } \\
\text { tasks }\end{array}$ & $\begin{array}{l}\text {-What went well during performance of tasks? }{ }^{\mathrm{b}} \\
\text { - What was hard to handle during performance of tasks? }{ }^{\mathrm{b}}\end{array}$ \\
\hline & $\begin{array}{l}\text { Factors affecting } \\
\text { implementation } \\
\text { ease or difficulty }\end{array}$ & $\begin{array}{l}\text { - Which factors in your daily practice might hinder the app } \\
\text { being used as intended? (HCP level/organizational level) } \\
\text { - Which factors in your daily practice could facilitate the app } \\
\text { being used as intended? (HCP level/organizational level) }\end{array}$ \\
\hline
\end{tabular}


(Continued)

\begin{tabular}{|c|c|c|}
\hline \multirow[t]{2}{*}{ Practicality } & $\begin{array}{l}\text { Expected benefits } \\
\text { and burden for HCPs }\end{array}$ & $\begin{array}{l}\text { - To what extent can the app be used in your daily } \\
\text { practice considering the available resources, time } \\
\text { and commitment? } \\
\text { - In your opinion, what are expected benefits of using } \\
\text { the app? } \\
\text { - For your workflow } \\
\text { - For your interaction with patients } \\
\text { - For your organization } \\
\text { - In your opinion, what are expected disadvantages or } \\
\text { potential risks of using the app? } \\
\text { - For your workflow } \\
\text { - For your interaction with patients } \\
\text { - For your organization }\end{array}$ \\
\hline & $\begin{array}{l}\text { Ability of HCPs to } \\
\text { carry out tasks in } \\
\text { their routine daily } \\
\text { practice }\end{array}$ & $\begin{array}{l}\text { - To what extent do you feel able to use the app } \\
\text { in your daily practice, considering the available } \\
\text { resources, if the app was currently available? } \\
\text { - To what extent are the right conditions present to be } \\
\text { able use the app? } \\
\text { - Which resources/conditions need to be met in order } \\
\text { to use the app within your organization? } \\
\text { - What are your expectations regarding the time } \\
\text { it takes to: 1) individualize the app? 2) adjust and } \\
\text { evaluate the app in a follow-up consultation? }\end{array}$ \\
\hline \multirow[t]{2}{*}{ Integration } & $\begin{array}{l}\text { Perceived fit } \\
\text { with local care } \\
\text { infrastructure } \\
\text { at patient and } \\
\text { organizational level }\end{array}$ & $\begin{array}{l}\text { - To what extent does working with the app fit within } \\
\text { your routine daily practice? } \\
\text { - How do you think the app can be integrated into } \\
\text { your daily practice? } \\
\text { - How do you think the app can be integrated into the } \\
\text { daily practice of your colleagues? Which HCPs should } \\
\text { be involved in working with the app? In which patient } \\
\text { consultations could the app be integrated? } \\
\text { - How do you think the app can be integrated into } \\
\text { your organization? } \\
\text { - To what extent does the app fit within the current } \\
\text { collaboration between primary, secondary and } \\
\text { tertiary care? }\end{array}$ \\
\hline & $\begin{array}{l}\text { Perceived } \\
\text { sustainability } \\
\text { at patient and } \\
\text { organizational level }\end{array}$ & $\begin{array}{l}\text { - In your opinion, which changes need to occur in } \\
\text { order to integrate the app into your daily practice? } \\
\text { And into your organization? And within current } \\
\text { collaboration with other health care organizations? } \\
\text { - To what extent will the app be sustainable to use } \\
\text { within your organization? }\end{array}$ \\
\hline
\end{tabular}

a HCPs were asked in the baseline questionnaire to fill out their intention to use the app in daily practice. Therefore, this question was often omitted during the interview; ${ }^{b}$ Performance of tasks was also observed by the researcher during the interactive session. If needed, this was further evaluated during the interview. Abbreviation: HCP: health care provider. 
Early-stage feasibility of the Copilot app 


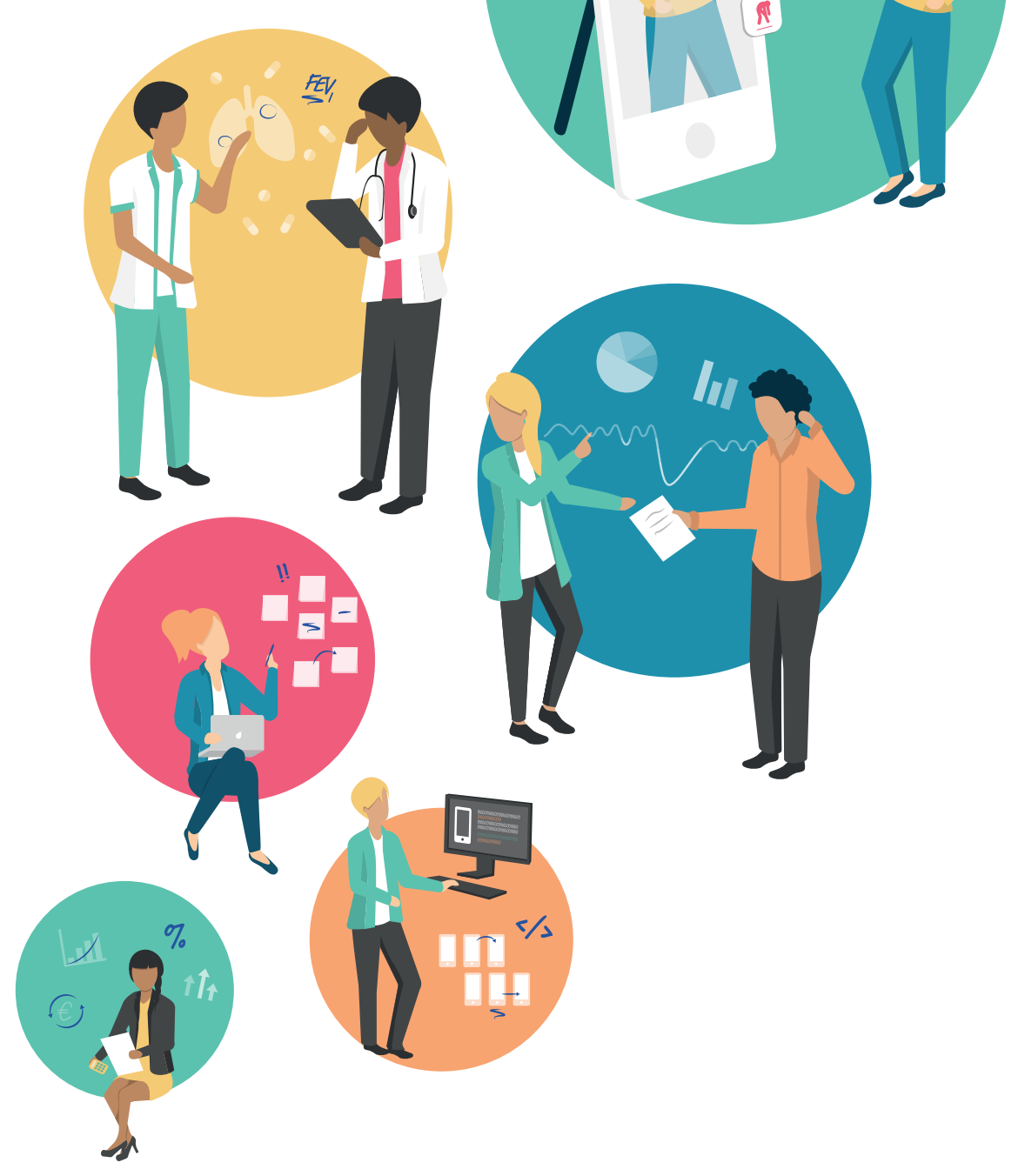




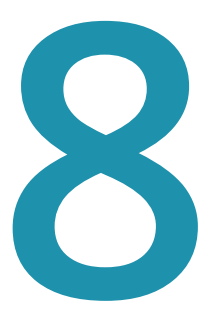

General Discussion 
COPD is a chronic inflammatory lung disease associated with episodes of symptom deterioration called exacerbations. ${ }^{1}$ Exacerbations are serious events during the course of COPD as they accelerate the decline in lung function, ${ }^{2}$ negatively affect quality of life ${ }^{3,4}$ and lead to increased mortality and high socio-economic costs. ${ }^{5,6}$ Self-management is widely recognized to be important to reduce the impact of COPD exacerbations on both patients and society. ${ }^{1}$ Patients can influence the frequency, severity and recovery of exacerbations themselves by performing adequate self-management behavior before, during and after exacerbations. 1,7-9 However, self-management can be challenging for patients and therefore requires adequate self-management support. Thus far, supporting patients with COPD in the development of self-management skills has shown to be complex and often unsuccessful. A substantial proportion of patients does not respond to self-management interventions, which might be explained by a 'one size fits all' and static approach regarding design, intensity and mode of delivery without a focus on individual exacerbation patterns and behaviors. There is a need for more comprehensive, dynamic and individualized strategies to improve exacerbationrelated self-management behavior. The use of mobile health (mHealth) has the potential to engage patients in managing their own health, to support them in gradually developing self-management skills over time and to change health behaviors. ${ }^{10-13}$

The aim of this thesis was twofold. In part one of this thesis, we aimed to generate a better understanding of self-management behavior of patients with COPD and explore whether the use of mHealth is promising to enhance exacerbation-related self-management. The studies of part one showed large room for improvement in patient self-management behaviors and positive findings regarding the use of mHealth for self-management support.

In part two of this thesis, we aimed to develop an evidence-driven, attractive and usable mHealth intervention to enhance exacerbation-related self-management in patients with COPD and to describe this development process transparently. An iterative user-centered design and development process resulted in the Copilot app, a mobile application for patients with COPD that targets early detection of exacerbations and performing prompt actions with a specific focus on developing self-management skills over time. Proof for the Copilot app was obtained by stepwise underpinning of the working mechanism. Patients and health care providers were involved throughout different stages of the intervention development to validate the outcomes and to enhance usability and feasibility of the intervention. 
In this final chapter, we will reflect on the main findings of this thesis and provide recommendations for clinical practice, research and education.

\section{Main findings}

Part 1: Self-management and the potential of mHealth in patients with COPD

- Only a minority of patients with COPD is activated for self-management, indicating great potential for improvement in self-management and subsequently in health outcomes (Chapter 2).

- Lower activation for self-management in patients with COPD is associated with increased anxiety, a more negative illness perception, increased BMI, increased age, increased disease severity, and less comorbidities (Chapter 2).

- Patients with COPD show different patterns in exacerbation-related selfmanagement behavior. These patterns are dynamic in nature and can change in individual patients over time due to variability in influencing factors and disease progression (Chapter 3).

- Acceptance of COPD, perceived severity of symptoms, knowledge of exacerbations, former experiences with exacerbations and social support are important generic factors influencing exacerbation-related self-management behavior (Chapter 3).

- To exert the highest magnitude of influence on the impact of exacerbations, it is important that patients with COPD perform specific self-management behaviors before, during and after an exacerbation. Based on expert consensus, a set of 17 self-management behaviors is considered to be relevant and feasible to influence, to reduce the impact of exacerbations (Chapter 4).

- Patient needs regarding self-management of exacerbations vary widely (Chapter 5).

- The use of mHealth for self-management of exacerbations is promising, although mHealth interventions should be complementary to regular care (Chapter 5).

- Patient willingness to use mHealth for self-management of exacerbations is driven by the perceived benefits and barriers of using mHealth (Chapter 5).

- $\quad$ Future mHealth interventions should be multi-component and tailored and should focus on developing self-management skills over time by providing adequate information, decision support and feedback on self-management behavior (Chapter 5). 
Part 2: A new mHealth intervention to enhance self-management in patients with COPD

- An evidence-driven and usable mHealth intervention was developed to enhance exacerbation-related self-management in patients with COPD: the Copilot app. The Copilot app meets patients' needs, preferences and capabilities, is likely to be used by patients and has a high potential to be effective in reducing exacerbation impact (Chapter 6).

- The unique user-centered design and development process of the Copilot app can be used by researchers and designers as general guidance for the development of future mHealth interventions (Chapter 6).

- The Copilot app is acceptable to use for self-management support in the health care providers' daily practice and is considered to fit the nurses role best (Chapter 7).

- The Copilot app is perceived to be feasible to integrate into the daily practice and existing care paths of Dutch primary, secondary and tertiary health care settings. Individual organizational factors should be taken into account when integrating the app in daily practice (Chapter 7).

\section{Reflections on self-management behavior of patients with COPD and the use of mHealth for self-management support}

\section{What do we know about self-management behavior in patients with COPD?}

Reflection on self-management behavior of patients with COPD is crucial to improve self-management support and to guide the development of selfmanagement interventions. Hereby, it is important to note that various definitions of self-management are used interchangeably in the literature and lead to confusion on what self-management entails. Self-management in this thesis was defined as "an individual's ability to detect and manage symptoms, treatment, physical and psychosocial consequences, and lifestyle changes inherent in living with a chronic condition". ${ }^{14}$

When starting this thesis, knowledge on self-management behavior of patients with COPD was limited. Our work has contributed to bridge this knowledge gap by providing insight into patient activation for self-management (Chapter 2). The finding that only a minority of patients with COPD was activated for selfmanagement, indicates great potential for improvement in self-management and 
stresses the need for more adequate self-management support. We also found that the level of activation for self-management was associated with several patient- and disease characteristics, which confirmed that future self-management support should not be one-size-fits-all. ${ }^{15}$ Furthermore, our conceptual model explaining factors influencing exacerbation-related self-management of patients with COPD has contributed to more in-depth understanding of self-management behavior (Chapter 3). Chapter 3 showed that patterns in self-management behavior are dynamic in nature and can change in individual patients over time due to variability in influencing factors and disease progression. The new insights from our conceptual model can be used to tailor self-management support.

To date, self-management interventions that aim to reduce the impact of exacerbations often focused on self-management behavior at specific moments in time, such as early detection of exacerbations and taking prompt actions solely or at self-management after exacerbations.8,16,17 The recently published definition of a COPD self-management intervention stresses the need for more comprehensive interventions by stating that interventions should be "structured but personalized and often multi-component, with goals of motivating, engaging and supporting the patients to positively adapt their health behavior(s) and develop skills to better manage their disease". ${ }^{18}$ Thus far, there was no clear focus on target behaviors that should be addressed to reduce the impact of exacerbations. To move towards more comprehensive and effective exacerbation-related selfmanagement interventions, we identified which self-management behaviors are most relevant to reduce exacerbation impact, have large room for improvement, and are feasible to influence (Chapter 4). Our exacerbation model showed that self-management of exacerbations requires various self-management behaviors at different points in time (chapter 4). Chapter 4 highlights that self-management interventions should focus on self-management behaviors before, during and after an exacerbation to exert the highest magnitude of influence on the impact of exacerbations and provides a new focus on target behaviors for future selfmanagement support.

\section{Is mHealth promising for self-management support in patients with COPD?}

The use of mobile health (mHealth) has potential for self-management support in patients with COPD. Mhealth creates opportunities to strongly individualize interventions and to provide tailored support anytime and anywhere using relevant behavior change techniques, which could stimulate the development of effective self-management skills and change health behaviors. ${ }^{10-13}$ Given the 
positive trends in mobile device use over the past decades and the potential of mHealth for self-management support, we explored in this thesis whether mHealth could be used to improve self-management support in patients with COPD and thereby reduce the impact of exacerbations. Currently, there are numerous health applications for COPD available in app stores and also used by patients with COPD, although for a large amount of these apps scientific evidence is unclear or not present at all. ${ }^{10,19}$ Recent literature showed promising results of mHealth in patients with COPD, ${ }^{11,20-23}$ but no firms conclusions could be drawn regarding the effectiveness of mHealth interventions on reducing exacerbation impact (chapter 6). To determine whether we should focus on mHealth to improve self-management support and thereby reduce the impact of exacerbations, we explored patient and health care provider perspectives towards the use of mHealth for self-management.

Chapter 5 showed that most patients with COPD and health care providers had a positive attitude towards mHealth and perceived many benefits of using mHealth for self-management. Both patients and health care providers were generally positive towards a multicomponent and tailored mHealth intervention that aims at developing self-management skills over time by providing adequate information, decision support and feedback on self-management behavior. Based on the insights from chapter 5 , we concluded that it is promising to use mHealth for exacerbation-related self-management. Chapter 5 also provided insight into barriers for the use of mHealth for self-management support, preferences regarding the content of an mHealth intervention and facilitators for engagement with mHealth (Chapter 5). A key finding was that mHealth should be used complementary to regular care as health care providers should continue to have an essential role in providing self-management support. This is in line with recent studies underlining that a good patient-health care provider relationship is important for patients to engage and take responsibility over their own care process.24-26 Furthermore, we found that mHealth interventions should be attractive, rewarding, safe and tailored to the patient's needs. Recent studies also focused on identifying patient and health care providers perspectives towards the use of mHealth, which increases our understanding of barriers and facilitators for the use of mHealth and provides important insights regarding features of mHealth interventions..$^{25,27,28}$ The knowledge on important features of mHealth interventions should be incorporated in the development of future mHealth interventions to increase the likelihood of developing effective and feasible interventions. To optimize successful implementation of mHealth interventions, the perceived facilitators and barriers of using mHealth should be considered. ${ }^{28}$ 
Although the use of mHealth is considered promising for self-management support in patients with COPD, it needs to be emphasized that, at least for the coming years, not all patients will be eligible for mHealth, especially for those with a more negative attitude towards mHealth and with low digital literacy. ${ }^{11,29}$ However, the rapid increase of smartphone and tablet use over the past few years, also in older populations, indicates that this will undoubtedly improve in the upcoming decades. ${ }^{30,31}$

\section{Reflections on a new mHealth intervention: The Copilot app}

Based on the findings of chapter 2,3,4 and 5, ideas for the content and the design of a new mHealth intervention were generated: The Copilot app. The Copilot app is a modular app that focuses specifically on developing self-management skills over time - learning by doing - and targets early detection of exacerbations through self-monitoring and performing self-management actions through individualized action planning (Chapter 6). A written action plan developed by Trappenburg et al. (2011) was used as a basis for the Copilot app due to its proven effectiveness in reducing exacerbation impact. ${ }^{32}$ The Copilot app includes a unique symptom monitoring module that was developed by our team to determine normal dayto-day variability in individual patients and to monitor symptom deterioration by patients themselves (chapter 6). The Copilot app requires a case manager role from health care providers as previous research has shown that ongoing case manager support is needed to achieve effective and safe self-management.8,16,18 More information about the Copilot app is provided in Appendix 1.

Our specific focus on developing self-management skills and changing health behaviors by using behavior change techniques differs from other mHealth initiatives for COPD. ${ }^{20-22,33-35}$ Current mHealth interventions often focus on providing COPD information only or on telemonitoring, ${ }^{19,36}$ which is substantially different from providing self-management support. Self-management requires an active role of patients and decision making by patients..$^{14,37}$ In line with the recent definition of a COPD self-management intervention, the Copilot app aims at engaging and supporting patients to positively adapt their behaviors and develop skills to better manage their COPD. ${ }^{18}$ With tele-monitoring information from the patient is used but the decision-making process is mostly professional based, ${ }^{21}$ which could even result in a more passive role of patients..$^{38}$ Recently, a new mHealth intervention with a similar focus as the Copilot app was developed 
and evaluated in the Netherlands by Boer et al. (2019). ${ }^{39}$ Similar to the Copilot app, this mHealth intervention has a specific focus on supporting patients with COPD in self-management and includes an action plan as well. Unfortunately, the RCT showed no positive effects on exacerbation-free time, health status, selfefficacy, self-management behavior, and health care utilization. ${ }^{39}$ However, Boer et al. (2019) concluded that mHealth may be a valuable alternative for patients with COPD who prefer a digital tool instead of a paper action plan as participants were positive about the mHealth tool and no negative effects were observed. Despite the absence of positive effects in the trial of Boer et al. (2019), ${ }_{19}^{39}$ positive effects can be expected for the Copilot app. The key focus of the Copilot app on exacerbation detection and decision making by patients differs from the mHealth tool of Boer et al. (2019) that detects exacerbations and provides automated, tailored self-management advice to patients based on a decision tree. ${ }^{39}$ The Copilot app relies more on improving self-management skills of patients and changing self-management behaviors, which might positively affect outcomes such as exacerbation-free time and health status. ${ }^{40}$

At this stage, the Copilot app is a minimum viable product (MVP) that needs further development over time. The usability of this MVP is considered to be good (Chapter 6) and based on the MVP, the Copilot app is perceived to be feasible in the health care providers' daily practice (Chapter 7). The current version of the Copilot app is most relevant for patients who have experienced one or more exacerbations in the past and are motivated to develop exacerbation-related selfmanagement skills using mHealth. The Copilot app can become more interesting for a wider range of patients if additional target behaviors would be added in the future, for example by placing more emphasis on exacerbation prevention. Also, in future versions of the app, taking comorbidities into account is important to make the intervention available for a wider population and to ensure patient safety. ${ }^{41,42}$

\section{Reflections on the development of mHealth interventions}

\section{How to develop mHealth interventions?}

The development of mHealth interventions is often driven by technological possibilities and initiated by commercial companies. Subsequently, mHealth interventions do not always fit with the needs and preferences of end-users, are often not based on scientific evidence and have limited focus on implementation 
in daily practice. 10,43,44 This increases the risk of developing mHealth interventions that are not successfully used in daily practice and subsequently have no impact on health outcomes. To create impact with mHealth interventions, it is important that mHealth interventions are effective, fit with end-user needs and preferences and are actually used in daily practice. ${ }^{12,43,45}$ The development of mHealth interventions should include activities to address these conditions. However, to date, there is limited guidance on how to do this. ${ }^{12,45}$

The literature does provide insight into how end-users should be involved in the development of mHealth interventions to match with their needs and preferences ${ }^{46,47}$ However, which activities should be performed to underpin how mHealth interventions will work is underexposed in the literature. When developing mHealth interventions that aim to change behaviors, it is important to understand how an intervention would change patient behaviors. Designing interventions to change health behaviors is however complex and needs theoretical grounding to increase the design's efficacy. ${ }^{48}$ In current thinking about the development of behavior change interventions, the importance of theory is clear, ${ }^{48-50}$ but the way in which theory should be incorporated in the design process is not. ${ }^{49,51,52}$ Also underexposed in the literature are activities that should be performed during the development of mHealth interventions to increase the likelihood of successful implementation in daily practice. With regards to mHealth interventions, implementation actually means bringing a product to the market. Common problems regarding implementation of mHealth interventions are related to the fit with infrastructures, funding, scalability and sustainability. It is important that these factors are considered during intervention development. ${ }^{53}$

Thus far, scientific publications mainly focus on evaluation of mHealth interventions. The development of evidence- and theory-driven mHealth interventions is rarely described transparently in scientific literature. More transparency in the development process of mHealth interventions is needed to strengthen the internal and external validity of interventions and to add value to health care research. ${ }^{54}$ In chapter 6 , we described the development of the Copilot app in detail to contribute to more transparency in the development of mHealth interventions.

\section{Development of the Copilot app: What are strengths?}

A major strength of our work was the systematic and thorough way of developing the Copilot app according to an iterative user-centered design (UCD) that was based on existing development models and diminished the chance of missing 
important steps..$^{54,55}$ The use of these models resulted in systematic investigation of evidence and incorporation of the views of end-users, continuous evaluation of prototypes and the use of persuasive design techniques to match user profiles and motivate patients to engage in self-management (Chapter 6). This unique approach of scientific engineering increased the likelihood of developing an mHealth intervention that will be effective, fits with the end-users needs, preferences and capabilities and is likely to be implemented and scaled up in COPD care (Figure 1). We will further reflect on this in the next paragraphs.

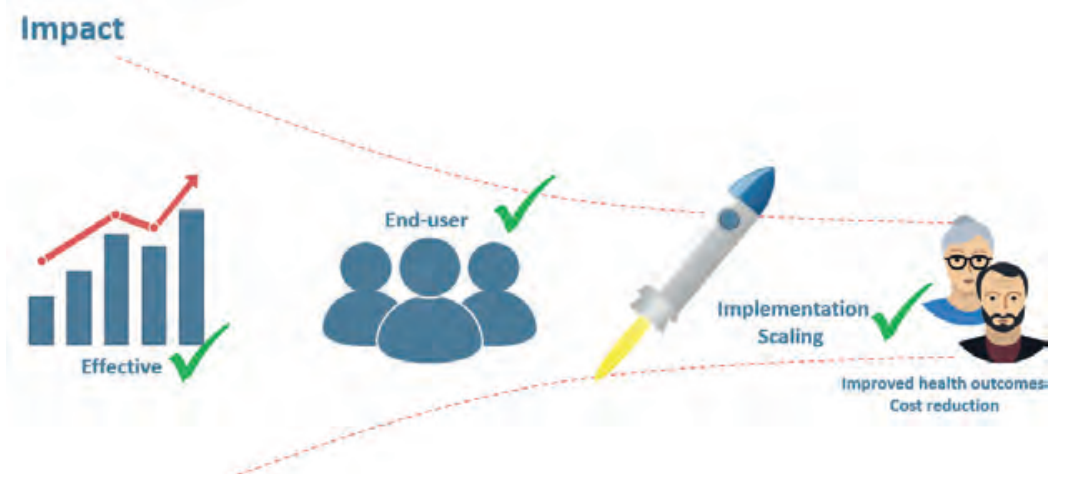

Figure 1 Guidance for the development of mHealth interventions

\section{Will the Copilot app be effective?}

As mHealth initiatives continue to proliferate with limited evidence for their effectiveness, we have put much effort into collecting proof for the working mechanism of the Copilot app. Recently, more value is being placed on optimizing the working mechanism of complex interventions during the development and less on the evaluation of interventions in trials..$^{54} \mathrm{~A}$ more clear focus on underpinning of the working mechanisms of interventions during intervention development is needed to increase the likelihood of developing effective interventions that will work within various contexts. ${ }^{54}$ The theory and evidence-driven development of the Copilot app increased the likelihood of developing an intervention that works and will be effective in reducing exacerbation impact. ${ }^{48}$ Proof for the Copilot app was obtained by stepwise underpinning of the working mechanism. This process consisted of thorough investigation of current evidence, a detailed analysis of target behaviors followed by a selection of relevant behavior change techniques and in-depth exploration of user needs and preferences. COPD patients and health care providers were involved throughout different stages of the intervention development to validate the outcomes (Chapter 6). 
To understand how interventions work, the causal mechanism of how interventions lead to short- and long-term outcomes should be illustrated. ${ }^{54,56}$ In recent years, the use of logic models to synthesize and describe the complex pathways within interventions is getting more attention. ${ }^{56-59}$ We used logic modelling to map out the potential working mechanism of the Copilot app by detailing all evidence and assumptions underpinning the pathway from the intervention to long-term impact on outcomes. ${ }^{13,56} \mathrm{Key}$ in this process was to understand which specific behaviors are important to address, what needs to change in patients' behavior, which techniques can change behavior and what could potentially influence behavior (Chapter 6). 60,61

Recently, more emphasis is being placed on the importance of understanding endusers behavior in the development of digital behavior change interventions. ${ }^{13,61,62}$ The Behavior Change Wheel, an increasingly used theoretical framework for the development of behavior change interventions, points out that systematic understanding of the behavior that needs to change is important and should be guided by using a new model of behavior change: the capability, opportunity and motivation generating behavior model (COM-B) ${ }^{61,63} \mathrm{~A}$ thorough analysis of target behaviors using COM-B is essential for the selection of relevant intervention functions that are likely to bring about change in behavior and selection of behavior change techniques (BCTs). A BCT refers to an 'active ingredient' and mechanism of change that is an observable and replicable component of behavior change interventions. ${ }^{60,63} \mathrm{~A}$ strength of our work was that we gained indepth understanding of the target behaviors and systematically selected relevant intervention functions and BCTs by following the Behavior Change Wheel, which was crucial to underpin the pathway towards behavior change. ${ }^{61,63} \mathrm{~A}$ strength in this process was the collaboration with a behavioral scientist and designers who helped us to translate theoretical intervention functions and BCTs into mHealth intervention components, taking into account what was possible from a creative perspective and with a focus on features that work to optimize engagement with mHealth. Based on their expertise, final decisions were made on the most important BCTs for the Copilot app.

\section{Does the Copilot app fit with end-user needs and preferences?}

A strength of our work was our bridging approach involving scientists, patients with COPD, health care providers, COPD experts, designers, behavioral scientists and software developers throughout the iterative development phases. The involvement of those experts was established at each development phase based on the specific expertise needed. This agile process has been a great advantage, 
as we were free to design a unique intervention based on evidence and input from patients, health care providers and experts. Continuous involvement of end-users in the design of interventions is nowadays considered to be key in intervention development frameworks. ${ }^{46,54,64}$ In the development of the Copilot app, the input of both patients and health care providers guided the design of the intervention. This resulted in a usable app that fits with the end-user needs and preferences and is also perceived to be feasible in the daily practice of Dutch health care providers (Chapter 6 \& 7).

\section{Is the Copilot app likely to be implemented and scaled up?}

The success of an mHealth intervention not only depends on the intervention itself, but also largely on the fit within current health care systems and the context in which it will be used..$^{65}$ For successful implementation in daily practice, it is highly important to explore how interventions relate to the context in which they will be used, to be able to understand how they will work and how different actors contribute to one or another. ${ }^{57,65,66} \mathrm{Implementation}$ of the Copilot app leads to a new process of care delivery within a chain of care and requires adequate positioning within the patient-health care provider relationship. ${ }^{44}$ Therefore, the context in which the Copilot app will be used was explored by investigating patients and health care providers perspectives on current self-management support and the added value of the intervention for COPD care (Chapter 3, 5 \& 6). Logic modelling helped us to incorporate contextual factors in the working mechanism of the intervention leading to a flexible intervention that can work within various contexts (Chapter 7).

Finally, an important strength of our work were the valorization activities performed throughout the development phases needed for successful implementation and future scaling of the Copilot app in COPD care. These activities were triggered by attending the Ureka Mega Challenge of the University Medical Center of Utrecht (The Copilot app was the winner of 2017). Within the context of this challenge, business modelling was performed. 53,67 We investigated the value proposition of the Copilot app with respect to other mHealth technologies and explored the best innovation and distribution routes and market opportunities. Business modelling helped us to identify critical success factors that will influence the sustainability and effectiveness of the app, which is often overlooked during the development process of eHealth and mHealth technologies. ${ }^{53}$ The impact of interventions is only partly attributable to the effectiveness of interventions, as no effect will be sorted without actual use of an intervention. Therefore, efforts to ensure valorization and implementation of interventions are key during intervention development and should not be an end-stage activity. ${ }^{53}$ 


\section{Development of the Copilot app: What are lessons learned?}

Our extensive and thorough way of developing the Copilot app from science also has its limitations. It could be argued that this development process, which took four years in total, is not feasible in daily practice. The four years of research were however needed to collect proof for the working mechanism of the app, not for the design and software development itself which took approximately a year. Pursuing the rules of science during the development process contributed to the process being this time consuming, as it required completing an empirical cycle at each development phase and often included extensive review of a study protocol by a medical ethics research committee. ${ }^{68}$ The time-consuming development increases the risk of a misfit with current market developments or that technology has moved on by the time of implementation. ${ }^{43,45,68}$ Therefore, the need for efficiency in the development of mHealth interventions is currently a highly discussed topic. ${ }^{43,45,69}$ Although systematic and thorough development of mHealth interventions is important, decisions have to be made about which phases and steps are relevant to the topic and should be included in the development process of future mHealth interventions. Based on our work, we believe that iterative development of mHealth interventions should at least include defining the exact problem, identifying evidence by literature review on similar interventions, evaluating end-user behaviors and their needs, examining current practice and context, mapping out the working mechanism of the intervention, usability testing and performing valorization activities. Taking time aspects into consideration, it is important to consider which steps can be based on previous research, which steps can be performed simultaneously and how thorough each individual step should be executed. For example, relevant target behaviors and end-user needs could also be investigated in a less in-depth way than we did.

Crucial for the implementation of the Copilot app is that the app will be successfully brought to the market and becomes available for COPD patients and their HCPs. At this point in time, the Copilot app is not on the market yet. Although various valorization activities were performed, including business modelling, we had no specific expertise in our team to bring the app to the market and create sustainable value with the Copilot app. The current landscape of mHealth in the Netherlands shows that the success of mHealth interventions largely depends on good entrepreneurship as exclusive agreements on reimbursement of mHealth have been made between mHealth providers and health care insurers. This emphasizes that intervention development should not start with a strict focus on the content but should have a continuous focus on market developments and business opportunities as well. Early collaboration with a business partner seems 
to be key in the success of mHealth interventions and could, in our case, have resulted in the app being already available for patients. Business partners are needed to guarantee further development, funding and marketing of mHealth interventions. The restricted budget for the development of the Copilot app was also a limitation and required us to focus on the development of a minimum viable product (MVP) that consists of a patient interface only. Development of a safe and compatible back-end for HCPs is however considered to be important for the use of the Copilot app in daily practice (Chapter 7).

A good match between scientists and business partners is essential for success, although establishing a collaboration can be complex as both parties have different interests. While improving patient outcomes can be a shared interest, scientists will have a focus on developing interventions with optimal content, while business partners also have to take into account profitability. Also, for scientists in particular, it can be difficult to estimate whether a business partner has the credibility to bring an mHealth intervention to the market. Therefore, we consider it is crucial to involve external expertise (such as a valorization officer or holding) from the start to monitor market developments and business opportunities and to provide assistance in finding a credible business partner.

With the current COVID-19 pandemic, a rapid increase of the availability of mHealth solutions is observed worldwide. Collaborations between private and public organizations are nowadays quickly established, extra budget for the development of mHealth is created, and new mHealth initiatives are developed within a short amount of time. ${ }^{70}$ This current crisis shows more than ever that early collaboration between private and public organizations, and sufficient budget, are key in making mHealth initiatives available quickly. It should however be noted that it is challenging to develop evidence-based and safe interventions in such a short amount of time.

\section{What should be the scientist's role in developing $m$ Health interventions?}

In the design and development process of the Copilot app we, as scientists, were in the lead. In this leading position, we were experts on the content, we coordinated the collaboration with all stakeholders and we were involved in the creative design and technical development of the app. We have experienced that developing mHealth interventions within the academy involves many challenges, mainly related to the technical development of the app and being the owner of the app. The complexity of developing mHealth interventions for scientists is also recognized in recent literature. ${ }^{43}$ An important question rising from our 
development process was, what should be the scientist's role in the development of mHealth interventions?

We think that scientists should have a significant role in the development and evaluation of mHealth interventions, since they have the expertise to develop evidence- and theory driven interventions that can solve patient-related problems, which is often underexposed when interventions are being developed by private parties. We do however believe that scientists ideally should not be the owner of an mHealth initiative. Unless scientists themselves have entrepreneurial skills and ambitions in owning an mHealth initiative, we think an mHealth initiative should have a corporate owner who is involved early in the development. This is also strengthened by the fact that granting programs nowadays require collaboration between public and private parties to increase the likelihood that new scientific knowledge is actually used in health care practice, compared to the more traditional separation between public and private funding. ${ }^{71}$

Based on our work, we believe that scientists should be part of a multidisciplinary team consisting of scientists, end-users, health care professionals, designers, software developers and business partners. The importance of multidisciplinary teams that work together throughout the entire project period is recognized to be important to produce mHealth interventions that are designed, deployed and adapted effectively. ${ }^{43,44,68}$ Within multidisciplinary teams, scientists should focus on building evidence for the content of an mHealth intervention and its fit with end-users, should have a leading role in iterative evaluations of the intervention and should be involved in the creative design and software development to safeguard the evidence base.

Currently, the role of scientists and the relevance of research for the society is debated by an initiative called Science in transition. An important statement of Science in transition is that future science should be more valued on its social relevance and should have less focus on scientific publications. ${ }^{72}$ Besides the scientific publications in this thesis, a practical tool for patients with COPD was developed that can change how self-management support will be provided in COPD care. This emphasizes that scientists having a prominent role in the development of mHealth interventions fits with current thoughts about the role of scientists. However, the development of an mHealth intervention as part of a PhD study also has its limitations. PhD studies traditionally focus on the performance of scientific research within a fixed time frame and result in a thesis that includes several scientific papers. With a thesis as final product, valorization is often 
not a key focus. This thesis points out that a focus on valorization is needed to create impact with research. Hereby, it is important to critically consider which valorization activities should be performed by scientists themselves and for which activities other expertise should be involved.

\section{The Copilot-app: What should be next steps?}

An essential next step for the Copilot app is to collaborate with a business partner and health care insurers to bring the app to the market. Hereby, it is important to ensure that the Copilot app will become freely available for patients and can be integrated into current systems used in COPD care. ${ }^{10,19}$ After establishing this collaboration, back-end software for health care providers should be developed before further evaluation of the Copilot app can be performed. Since we have put many efforts into collecting proof for the working mechanism of the intervention during the development process, we consider it important to focus on controlled implementation of the Copilot app and parallel to that, to continuously evaluate the intervention.

First, a longitudinal feasibility study should be conducted with both patients and health care providers on a small scale, to investigate the delivery and acceptability of the intervention, safety of the intervention, compliance to the intervention and limited efficacy. In a second step, the Copilot app can be implemented on a larger scale and be evaluated on its effectiveness. Evaluating effectiveness of mHealth interventions is a highly debated topic. Recent reviews about mHealth interventions for patients with COPD suggest the use of RCTs with adequately powered sample sizes to evaluate effectiveness. ${ }^{11,20}$ However, the time-consuming design of RCTs is not ideal for rapidly evolving mHealth technologies that can become outdated quickly. ${ }^{10,68}$ Using an RCT would imply two or more years of research, which means for the Copilot app that an intervention with high potential of effectiveness and no expected risk of harm, will not be available for COPD patients. Furthermore, an RCT only enables identifying whether a complex mHealth intervention as a whole works and the cost-effectiveness of it, without identifying which intervention components work in whom. The continuously evolving nature of $\mathrm{mHealth}$ interventions requires strategies that can continuously evaluate the efficacy of mHealth interventions as new versions and changes are introduced..$^{73} \mathrm{~A}$ proposed method is a trial of intervention principles that tests the theoretical concepts of a mHealth intervention and allows adapting the mHealth interventions during evaluation. ${ }^{74}$ Important in further evaluations of the Copilot app is an assessment on how context influences the effectiveness of the app. ${ }^{65}$ Realist evaluation could be used to investigate how the app works and for whom, 
what influences implementation success and failure, whether the app can be successfully adapted or scaled-up from one context to another and to what extent effects could be generalized to other contexts..$^{65}$ In future evaluations, selfmanagement skills and behavior change should be assessed as outcomes and clearly reported..$^{11,62,75}$

\section{Implications and recommendations}

\section{For clinical practice}

This thesis has provided more insight into self-management behavior of patients with COPD, which is an important step in future targeting and tailoring of selfmanagement support. Chapter 4 shows which self-management behaviors are important before, during and after an exacerbation to reduce the impact of exacerbations and provides a new focus on target behaviors for self-management support. This thesis emphasized that self-management support by health care providers should be dynamic over time, based on the patient's status and selfmanagement skills.

Thus far, managing exacerbations in COPD care is often reactive. The Copilot app developed in this thesis can contribute to more pro-active care by focusing on the development of self-management skills. With the Copilot app, patients can learn to better detect exacerbations and to take prompt self-management actions. The use of BCTs in the Copilot app is promising in changing the patients' selfmanagement behaviors and reducing exacerbation impact. The Copilot app can be used by health care providers to provide more evidence-based, structured and tailored self-management support and guide patient consultations. It is essential is that health care providers receive sufficient training in the use of the Copilot app, since working with the app requires behavior change from health care providers as well. This training should include relevant BCTs based on a thorough analysis of the health care providers motivation, capability and opportunities to use the Copilot app. ${ }^{61,76}$ Chapter 7 shows that the intervention can easily be adapted to a specific setting and context, which increases the likelihood of successful implementation in Dutch COPD care. Embedding of the Copilot app in both primary, secondary and tertiary care settings, could bridge the gap between these settings and contribute to providing integrated care. Longitudinal feasibility evaluation is needed before large-scale implementation of the Copilot app in daily practice. 


\section{Recommendations:}

- Self-management support in patients with COPD should be dynamic over time and focus on improving self-management behavior before, during and after an exacerbation. The conceptual exacerbation model and identified set of relevant and feasible self-management behaviors (Chapter 4) can be used for future targeting and tailoring of self-management support.

- The conceptual model explaining factors influencing exacerbation-related selfmanagement (Chapter 3) can be used to tailor self-management support.

\section{Specific recommendations for the Copilot app:}

- $\quad$ Further development of the Copilot app is needed before starting with controlled implementation and evaluation of the Copilot app in clinical practice.

- A training for health care providers about the use of the Copilot app should be developed.

- $\quad$ Future versions of the Copilot app should focus on the inclusion of comorbidities on the one hand and the inclusion of more target behaviors that are relevant prior to, during and after an exacerbation to maximize reduction of exacerbation impact on the other hand.

\section{For researchers focusing on the development of mHealth interventions}

This thesis addressed the importance of putting more efforts into collecting proof for the working mechanism of mHealth interventions during intervention development and less on the evaluation of mHealth interventions. The usercentered design and development of the Copilot app can be used as a general framework for the development of future mHealth interventions. Essential in the development of mHealth interventions is that they are grounded in theory and evidence and that user-needs and preferences are thoroughly investigated. Moreover, valorization and implementation activities should be regarded as continuous activities throughout the development process to ensure sustainable use in its intended practice. Furthermore, our work addressed the importance of developing mHealth interventions in multidisciplinary teams. The extensive reporting of the development of Copilot contributes to more transparency in the development of complex interventions in health care, which is needed to strengthen the internal and external validity of interventions and to add value to health care research. ${ }^{54}$ Our work contributes to the discussion on efficiency in the development of interventions by mapping out a state-of-the-art design and development process and showing how time consuming this is. Thorough user-centered and evidencedriven development of mHealth interventions is needed to increase the likelihood 
of developing interventions that work, fit with the end-users' needs and are used in daily practice. However, researchers and designers should be aware that time consuming development also introduces a vulnerability as it could result in a misfit with current technological and market developments. The knowledge and experiences gained from the user-centered design and development process of the Copilot app are already being used by The Health Care Innovation Center (THINC) of the University Medical Center Utrecht. THINC offers short cyclic services, related to science-driven development and evaluation of interventions, to companies that develop technological innovations. By offering short-cyclic services, and making choices in specific steps that are needed for an innovation, our work has been translated into a more pragmatic approach.

\section{Recommendations:}

- The development of Copilot can be used as an example for science-driven and user-centered engineering of future mHealth interventions. Decisions should be made on which steps are relevant to the topic and the thoroughness in executing these steps.

- Iterative development of future mHealth interventions should at least include defining the exact problem, identifying evidence by literature review on theory and similar interventions, evaluating end-user behaviors and their needs, examining current practice and context, underpinning of the working mechanism by logic modelling, usability testing and performing valorization activities.

- The development of future self-management interventions should include a thorough analysis of target behaviors and selection of relevant intervention functions and behavior change techniques (BCTs) to underpin the pathway towards behavior change.

- Future mHealth interventions focusing on self-management should be used complementary to regular care and be attractive, rewarding, safe and tailored to the patient's needs.

- mHealth interventions should be developed by a multidisciplinary team of scientists, end-users, health care professionals, designers, software developers and business partners. Early collaboration with business partners is needed to increase the likelihood of successful implementation in daily practice.

- The development of mHealth interventions should also focus on a back-end structure to enhance compatibility with current systems in daily practice.

- Ongoing evaluation of mHealth interventions is needed as mHealth interventions will be continuously improved. Evaluation of mHealth interventions should focus on evaluation of the working mechanism of interventions and take context into account. 


\section{For education}

The use of mHealth can no longer be ignored in health care. This thesis showed that health care providers, in particular nurses and physicians, have an important role in the integration of mHealth in daily practice. Thus far, the use of mHealth for self-management is not widely adopted in daily practice. Health care providers should become aware that the use of technology is nowadays an important part of their work and should develop new skills to be able to use mHealth. Hereby, it is important that health care providers are able to assess which mHealth interventions can be used for self-management support. However, the current lack of consensus on the concept of self-management leads to different perceptions of self-management among health care providers and, subsequently, hampers the selection of relevant self-management interventions. ${ }^{77}$ It is important that health care providers have a clear interpretation of the concept of self-management. Education plays major part in this. Self-management has already been given a more prominent place within the bachelor of nursing 2020 curriculum, but there is still room for improvement. Education of health care providers should focus on adequate positioning of the concept of self-management and on how health care providers can equip patients with skills to adequately manage their disease and support behavior change. Furthermore, education should contribute to the development of an open mind with regard the use of mHealth for selfmanagement support. In this process, it is important that health care providers learn to critically reflect on whether sufficient evidence for mHealth interventions is available. Therefore, health care providers should learn what the essential steps in intervention development are, to be able to identify whether sufficient efforts are undertaken to prove that an intervention will work and is both reliable and usable for the target population. The user-centered design and development of Copilot illustrates which steps are important in the development of evidencebased mHealth interventions and can be used as an example within education of health care providers.

\section{Recommendations:}

- Education of health care providers should focus on gaining a clear understanding of the concept of self-management and the impact of selfmanagement on their professional roles.

- Education of health care providers should draw attention to the potential of mHealth solutions for daily practice, focus on the development of essential skills needed to use mHealth and stimulate critical reflection on the evidence of mHealth interventions. 


\section{Conclusions}

This thesis started with a question: Can mobile health be used to enhance selfmanagement in patients with COPD and thereby reduce the impact of exacerbations?

This thesis showed that mHealth can be used to enhance self-management of exacerbations in patients with COPD, although the use of mHealth should always be complementary to regular care. This thesis has provided more in-depth insight into self-management behavior of patients with COPD and factors that should be taken into account when developing mHealth interventions to support self-management. The Copilot app developed in this thesis can learn patients with COPD to better detect exacerbations and to take prompt self-management actions. As a result of our user-centered design and development process, the Copilot app meets patients' needs, preferences and capabilities, is likely to be used by patients and has high potential to be effective in reducing exacerbation impact. The Copilot app is unique in the current field of mHealth due to its specific focus on developing self-management skills over time. The Copilot app is perceived to be feasible in Dutch COPD care and can contribute to more pro-active COPD care. The design and development of the Copilot app can be used as an example for science-driven and user-centered engineering of future mHealth interventions. 


\section{References}

1. Global Initiative for Chronic Obstructive Lung Disease (GOLD). Global strategy for the diagnosis, management, and prevention of chronic obstructive pulmonary disease [updated 2020]. Available from: https://goldcopd.org/wp-content/uploads/2019/11/GOLD-2020-REPORT-ver1.0wms.pdf. Accessed June 2, 2020.

2. Donaldson GC, Seemungal TA, Bhowmik A, Wedzicha JA. Relationship between exacerbation frequency and lung function decline in chronic obstructive pulmonary disease. Thorax. 2002;57(10):847-852.

3. Miravitlles $M$, Ferrer $M$, Pont $A$, et al. Effect of exacerbations on quality of life in patients with chronic obstructive pulmonary disease: A 2 year follow up study. Thorax. 2004;59(5):387-395.

4. Seemungal TA, Donaldson GC, Paul EA, Bestall JC, Jeffries DJ, Wedzicha JA. Effect of exacerbation on quality of life in patients with chronic obstructive pulmonary disease. Am J Respir Crit Care Med. 1998;157(5 Pt 1):1418-1422.

5. Toy EL, Gallagher KF, Stanley EL, Swensen AR, Duh MS. The economic impact of exacerbations of chronic obstructive pulmonary disease and exacerbation definition: A review. COPD. 2010;7(3):214-228.

6. Soler-Cataluna JJ, Martinez-Garcia MA, Roman Sanchez P, Salcedo E, Navarro M, Ochando R. Severe acute exacerbations and mortality in patients with chronic obstructive pulmonary disease. Thorax. 2005;60(11):925-931.

7. Zwerink M, Brusse-Keizer M, van der Valk, P D, et al. Self-management for patients with chronic obstructive pulmonary disease. Cochrane Database Syst Rev. 2014;3:CD002990.

8. Howcroft M, Walters EH, Wood-Baker R, Walters JA. Action plans with brief patient education for exacerbations in chronic obstructive pulmonary disease. Cochrane Database Syst Rev. 2016;12:CD005074.

9. Harrison SL, Goldstein R, Desveaux L, Tulloch V, Brooks D. Optimizing nonpharmacological management following an acute exacerbation of chronic obstructive pulmonary disease. Int J Chron Obstruct Pulmon Dis. 2014;9:1197-1205.

10. Kumar S, Nilsen WJ, Abernethy A, et al. Mobile health technology evaluation: The mHealth evidence workshop. Am J Prev Med. 2013;45(2):228-236.

11. McCabe C, McCann M, Brady AM. Computer and mobile technology interventions for self-management in chronic obstructive pulmonary disease. Cochrane Database Syst Rev. 2017;5:CD011425.

12. Schnall R, Rojas M, Bakken $\mathrm{S}$, et al. A user-centered model for designing consumer mobile health (mHealth) applications (apps). J Biomed Inform. 2016;60:243-251.

13. West R, Michie S. A guide to development and evaluation of digital behavior change interventions in health care. London: Silverback Publishing; 2016.

14. Barlow J, Wright C, Sheasby J, Turner A, Hainsworth J. Self-management approaches for people with chronic conditions: A review. Patient Educ Couns. 2002;48(2):177-187. di: 10.1016/s07383991(02)00032-0.

15. Trappenburg J, Jonkman N, Jaarsma T, et al. Self-management: One size does not fit all. Patient Educ Couns. 2013;92(1):134-137.

16. Lenferink A, Brusse-Keizer M, van der Valk, P D, et al. Self-management interventions including action plans for exacerbations versus usual care in patients with chronic obstructive pulmonary disease. Cochrane Database Syst Rev. 2017;8:CD011682.

17. Harrison SL, Janaudis-Ferreira T, Brooks D, Desveaux L, Goldstein RS. Self-management following an acute exacerbation of COPD: A systematic review. Chest. 2015;147(3):646-661. 
18. Effing TW, Vercoulen JH, Bourbeau J, et al. Definition of a COPD self-management intervention: International expert group consensus. Eur Respir J. 2016;48(1):46-54.

19. Hallensleben C, van Luenen S, Rolink E, Ossebaard HC, Chavannes NH. eHealth for people with COPD in the Netherlands: A scoping review. Int J Chron Obstruct Pulmon Dis. 2019;14:1681-1690.

20. Alwashmi M, Hawboldt J, Davis E, Marra C, Gamble JM, Abu Ashour W. The effect of smartphone interventions on patients with chronic obstructive pulmonary disease exacerbations: A systematic review and meta-analysis. JMIR Mhealth Uhealth. 2016;4(3):e105.

21. McLean S, Nurmatov U, Liu JL, Pagliari C, Car J, Sheikh A. Telehealthcare for chronic obstructive pulmonary disease: Cochrane review and meta-analysis. Br J Gen Pract. 2012;62(604):e739-49.

22. Goldstein RS, O'Hoski S. Telemedicine in COPD: Time to pause. Chest. 2014;145(5):945-949.

23. Yang F, Wang Y, Yang C, Hu H, Xiong Z. Mobile health applications in self-management of patients with chronic obstructive pulmonary disease: A systematic review and meta-analysis of their efficacy. BMC Pulm Med. 2018;18(1):147-018.

24. Luhr K, Holmefur M, Theander K, Eldh AC. Patient participation during and after a selfmanagement programme in primary healthcare - the experience of patients with chronic obstructive pulmonary disease or chronic heart failure. Patient Educ Couns. 2018;101(6):11371142.

25. Huygens MW, Vermeulen J, Swinkels IC, Friele RD, van Schayck OC, de Witte LP. Expectations and needs of patients with a chronic disease toward self-management and eHealth for selfmanagement purposes. BMC Health Serv Res. 2016;16:232-016.

26. Andersen IC, Thomsen TG, Bruun P, Bodtger U, Hounsgaard L. Between hope and hopelessness: COPD patients' and their family members' experiences of interacting with healthcare providers - a qualitative longitudinal study. Scand J Caring Sci. 2018;32(3):1197-1206.

27. Alwashmi MF, Fitzpatrick B, Davis E, Gamble JM, Farrell J, Hawboldt J. Perceptions of health care providers regarding a mobile health intervention to manage chronic obstructive pulmonary disease: Qualitative study. JMIR Mhealth Uhealth. 2019;7(6):e13950.

28. Alwashmi MF, Fitzpatrick B, Davis E, Farrell J, Gamble JM, Hawboldt J. Features of a mobile health intervention to manage chronic obstructive pulmonary disease: A qualitative study. Ther $A d v$ Respir Dis. 2020;14:1753466620951044.

29. Korpershoek YJG, Vervoort, S C J M, Trappenburg JCA, Schuurmans MJ. Perceptions of patients with chronic obstructive pulmonary disease and their health care providers towards using mHealth for self-management of exacerbations: A qualitative study. BMC Health Serv Res. 2018;18(1):757-018.

30. World Health Organisation. Mhealth. New horizons for health through mobile technologies. Available from: http://www.who.int/goe/publications/goe_mhealth_web.pdf. Updated 2011. Accessed August 3, 2018.

31. Centraal Bureau Statistiek. 75-plussers sterkst groeiende groep internetters. Available from: https:// www.cbs.nl/nl-nl/nieuws/2016/52/75-plussers-sterkst-groeiende-groep-internetters. Updated 2016. Accessed June 19, 2020.

32. Trappenburg JC, Monninkhof EM, Bourbeau J, et al. Effect of an action plan with ongoing support by a case manager on exacerbation-related outcome in patients with COPD: A multicentre randomised controlled trial. Thorax. 2011;66(11):977-984.

33. Sul AR, Lyu DH, Park DA. Effectiveness of telemonitoring versus usual care for chronic obstructive pulmonary disease: A systematic review and meta-analysis. J Telemed Telecare. 2020;26(4):189199. doi: $10.1177 / 1357633 \times 18811757$.

34. McKinstry B. The use of remote monitoring technologies in managing chronic obstructive pulmonary disease. QJM. 2013;106(10):883-885. 
35. Bolton CE, Waters CS, Peirce S, Elwyn G, EPSRC and MRC Grand Challenge Team. Insufficient evidence of benefit: A systematic review of home telemonitoring for COPD. J Eval Clin Pract. 2011;17(6):1216-1222.

36. Zorginstituut Nederland. Rapport digitale COPD zorg in Nederland. Available from: https://www. zorginstituutnederland.nl/publicaties/rapport/2019/06/03/zinnige-zorg---rapport-digitale-copdzorg-in-nederland. Updated 2019. Accessed September 14, 2020.

37. Lorig KR, Holman H. Self-management education: History, definition, outcomes, and mechanisms. Ann Behav Med. 2003;26(1):1-7.

38. Stamenova V, Yang R, Engel $K$, et al. Technology-enabled self-monitoring of chronic obstructive pulmonary disease with or without asynchronous remote monitoring: Protocol for a randomized controlled trial. JMIR Res Protoc. 2019;8(8):e13920.

39. Boer L, Bischoff $E$, van der Heijden $M$, et al. A smart mobile health tool versus a paper action plan to support self-management of chronic obstructive pulmonary disease exacerbations: Randomized controlled trial. JMIR Mhealth Uhealth. 2019;7(10):e14408.

40. Wang L, Guo Y, Wang M, Zhao Y. A mobile health application to support self-management in patients with chronic obstructive pulmonary disease: A randomised controlled trial. Clin Rehabil. 2020:269215520946931.

41. Lenferink $A$, Frith $P$, van der Valk $P$, et al. A self-management approach using self-initiated action plans for symptoms with ongoing nurse support in patients with chronic obstructive pulmonary disease (COPD) and comorbidities: The COPE-III study protocol. Contemp Clin Trials. 2013;36(1):8189.

42. Schrijver J, Effing TW, Brusse-Keizer M, van der Palen J, van der Valk P, Lenferink A. Predictors of patient adherence to COPD self-management exacerbation action plans. Patient Educ Couns. 2020. Jun 18;S0738-3991(20)30333-5.

43. Ben-Zeev D, Schueller SM, Begale M, DuffecyJ, Kane JM, Mohr DC. Strategies for mHealth research: Lessons from 3 mobile intervention studies. Adm Policy Ment Health. 2015;42(2):157-167.

44. van Gemert-Pijnen JE, Nijland N, van Limburg M, et al. A holistic framework to improve the uptake and impact of eHealth technologies. J Med Internet Res. 2011;13(4):e111.

45. Curtis KE, Lahiri S, Brown KE. Targeting parents for childhood weight management: Development of a theory-driven and user-centered healthy eating app. JMIR Mhealth Uhealth. 2015;3(2):e69.

46. Yardley L, Ainsworth B, Arden-Close E, Muller I. The person-based approach to enhancing the acceptability and feasibility of interventions. Pilot Feasibility Stud. 2015;1:37-015.

47. Sanders EB-, Stappers PJ. Co-creation and the new landscapes of design. CoDesign. 2008;4(1):518.

48. Glanz K, Bishop DB. The role of behavioral science theory in development and implementation of public health interventions. Annu Rev Public Health. 2010;31:399-418.

49. Hagger MS, Weed M. DEBATE: Do interventions based on behavioral theory work in the real world? Int J Behav Nutr Phys Act. 2019;16(1):36-019.

50. Michie S, Carey RN, Johnston M, et al. From theory-inspired to theory-based interventions: A protocol for developing and testing a methodology for linking behaviour change techniques to theoretical mechanisms of action. Ann Behav Med. 2018;52(6):501-512.

51. Conn VS, Hafdahl AR, Cooper PS, Brown LM, Lusk SL. Meta-analysis of workplace physical activity interventions. Am J Prev Med. 2009;37(4):330-339.

52. Prestwich A, Sniehotta FF, Whittington C, Dombrowski SU, Rogers L, Michie S. Does theory influence the effectiveness of health behavior interventions? meta-analysis. Health Psychol. 2014;33(5):465-474.

53. van Limburg M, van Gemert-Pijnen JE, Nijland N, Ossebaard HC, Hendrix RM, Seydel ER. Why business modeling is crucial in the development of eHealth technologies. J Med Internet Res. 2011;13(4):e124. 
54. Bleijenberg N, de Man-van Ginkel, J M, Trappenburg JCA, et al. Increasing value and reducing waste by optimizing the development of complex interventions: Enriching the development phase of the medical research council (MRC) framework. Int J Nurs Stud. 2018;79:86-93.

55. Johnston SK, Nguyen HQ, Wolpin S. Designing and testing a web-based interface for selfmonitoring of exercise and symptoms for older adults with chronic obstructive pulmonary disease. Comput Inform Nurs. 2009;27(3):166-174.

56. Baxter SK, Blank L, Woods HB, Payne N, Rimmer M, Goyder E. Using logic model methods in systematic review synthesis: Describing complex pathways in referral management interventions. BMC Med Res Methodol. 2014;14:62-2288.

57. Moore GF, Audrey S, Barker M, et al. Process evaluation of complex interventions: Medical research council guidance. BMJ. 2015;350:h1258.

58. Hawe P. Lessons from complex interventions to improve health. Annu Rev Public Health. 2015;36:307-323.

59. Band R, Bradbury K, Morton K, et al. Intervention planning for a digital intervention for selfmanagement of hypertension: A theory-, evidence- and person-based approach. Implement Sci. 2017;12(1):25-017.

60. Michie S, Richardson M, Johnston M, et al. The behavior change technique taxonomy ( $\mathrm{v} 1$ ) of 93 hierarchically clustered techniques: Building an international consensus for the reporting of behavior change interventions. Ann Behav Med. 2013;46(1):81-95.

61. Michie S, Atkins L, West R. The behaviour change wheel. A guide to designing interventions. Great Britain: Silverback Publishing; 2014.

62. Michie S, Yardley L, West R, Patrick K, Greaves F. Developing and evaluating digital interventions to promote behavior change in health and health care: Recommendations resulting from an international workshop. J Med Internet Res. 2017;19(6):e232.

63. Michie S, van Stralen MM, West R. The behaviour change wheel: A new method for characterising and designing behaviour change interventions. Implement Sci. 2011;6:42-5908.

64. Yardley L, Morrison L, Bradbury K, Muller I. The person-based approach to intervention development: Application to digital health-related behavior change interventions.J Med Internet Res. 2015;17(1):e30.

65. Craig P, Di Ruggiero E. Taking account of context in population health intervention research: Guidance for producers, users and funders of research. 2018. NIHR Journals Library; 2018 Apr.

66. Hekkert MP, Suurs RAA, Negro SO, Kuhlmann S, Smits, R E H M. Functions of innovation systems: A new approach for analysing technological change. Technological Forecasting and Social Change. 2007;74(4):413-432.

67. Ries E. The lean startup: How today's entrepreneurs use continuous innovation to create radically successful businesses. First ed. New York: Crown Business; 2011.

68. Riley WT, Glasgow RE, Etheredge L, Abernethy AP. Rapid, responsive, relevant (R3) research: A call for a rapid learning health research enterprise. Clin Trans/ Med. 2013;2(1):10-1326.

69. McCallum C, Rooksby J, Gray CM. Evaluating the impact of physical activity apps and wearables: Interdisciplinary review. JMIR Mhealth Uhealth. 2018;6(3):e58. doi: 10.2196/mhealth.9054.

70. Inspectie Gezondheidszorg en Jeugd. Coronavirus: Meer ruimte voor e-health. Available from: https://www.igj.nl/actueel/nieuws/2020/03/26/coronavirus-meer-ruimte-voor-e-health. Updated 2020. Accessed June 19, 2020.

71. ZonMw. ZonMw in the netherlands. Available from: https://www.zonmw.nl/en/about-zonmw/ zonmw-in-the-netherlands/. Updated 2020. Accessed June 19, 2020.

72. Dijstelbloem H, Miedema F, Huisman F, Mijnhardt W. Waarom de wetenschap niet werkt zoals het moet, en wat daar aan te doen is. Position paper. Available from: https://scienceintransition.nl/ app/uploads/2013/09/POSITION-PAPER-16-sep-2013.pdf. 2013. Accessed June 19, 2020. 
73. Mohr DC, Burns MN, Schueller SM, Clarke G, Klinkman M. Behavioral intervention technologies: Evidence review and recommendations for future research in mental health. Gen Hosp Psychiatry. Invalid date;35(4):332-338.

74. Mohr DC, Schueller SM, Riley WT, et al. Trials of intervention principles: Evaluation methods for evolving behavioral intervention technologies. J Med Internet Res. 2015;17(7):e166.

75. Effing TW, Bourbeau J, Vercoulen J, et al. Self-management programmes for COPD: Moving forward. Chron Respir Dis. 2012;9(1):27-35.

76. Feiring $E$, Friis T. Facilitators and barriers to clinicians' use of COPD action plans in selfmanagement support: A qualitative study. Patient Educ Couns. 2019.

77. Westland H, Schröder CD, de Wit J, Frings J, Trappenburg JCA, Schuurmans MJ. Self-management support in routine primary care by nurses. Br J Health Psychol. 2018;23(1):88-107. 


\section{Appendix 1}

\section{The Copilot app}

A mobile app to support patients with COPD in exacerbation-related self-management

The Copilot app is a modular app that focuses specifically on developing selfmanagement skills over time - learning by doing - and targets early detection of exacerbations and performing self-management actions.

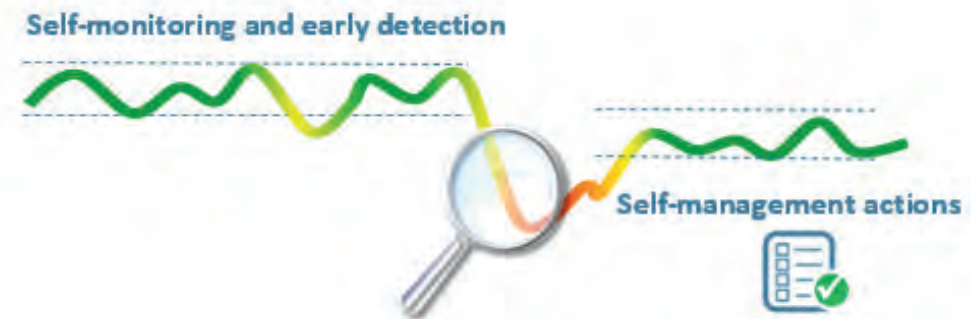

The Copilot app consists of 4 components:

- a personalized COPD action plan with five color zones;

- a symptom monitoring module;

- a calendar (overview of registered symptoms and self-management actions);

- an information module about COPD and self-management.

A conversational interface in the app guides the patient in the use of the Copilot app.

Action plan

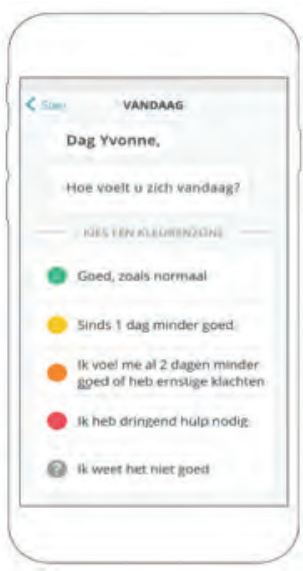

Symptom monitoring

Calendar

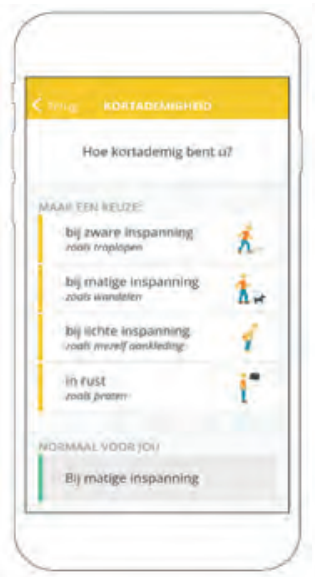

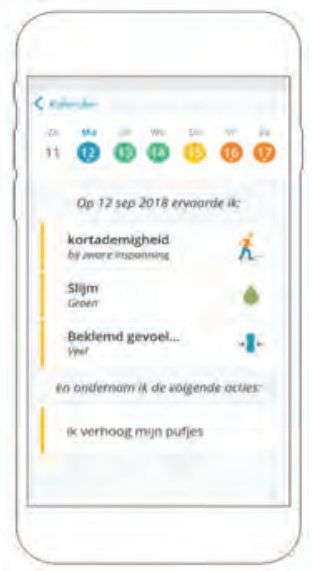

Conversation

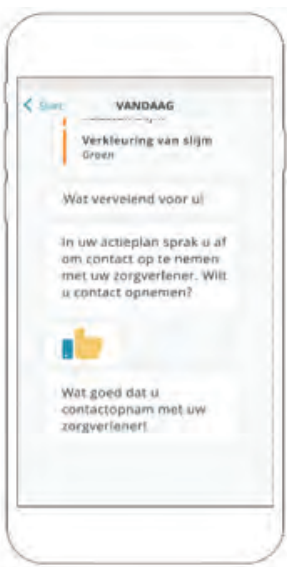


The 5 color zones in the Copilot app

$\begin{array}{ll}\text { Green } & \text { "I feel well' } \\ \text { Yellow } & \text { "I feel less well" } \\ \text { Orange } & \text { "I feel less well for } 2 \text { days or I have severe symptoms" } \\ \text { Red } & \text { "I need immediate help" } \\ \text { Gray } & \text { "I am doubting about how I feel" } \\ & \text { The app supports patients in selecting the correct color zone. }\end{array}$

\section{Scenario for use of the Copilot app in daily practice}

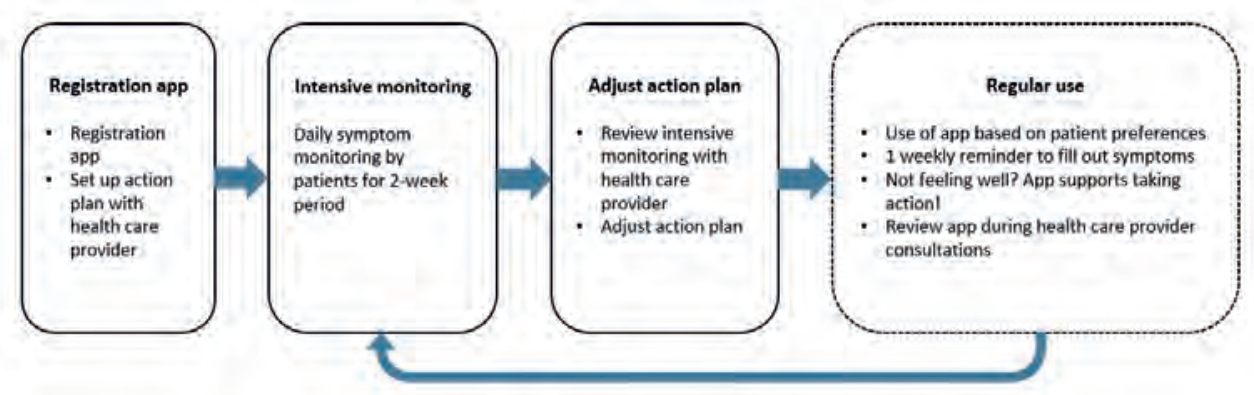


General Discussion 

Summary 
Worldwide, Chronic Obstructive Pulmonary Disease (COPD) is one of the most common chronic diseases and currently the fourth leading cause of mortality. The natural course of this progressive disease is interrupted by periods of symptom deterioration called exacerbations. Exacerbations accelerate the decline in lung function, negatively affect the quality of life, and lead to increased mortality and high socio-economic costs. Self-management is widely recognized to be important to reduce this negative impact on both patients and society. Patients are nowadays expected to have an active role and to take responsibility in decisions affecting their chronic disease. This includes managing symptoms, treatment, physical and psychosocial consequences of living with a chronic condition. However, self-management can be quite difficult for patients. Adequate self-management support is needed to equip patients with skills to actively participate in the management of their COPD and to change health behaviors. Thus far, patients with COPD do not always respond to self-management interventions. This might be explained by a 'one size fits all' and static approach regarding design, intensity and mode of delivery of interventions and the lack of focus on individual exacerbation patterns and behaviors. There is a need for more comprehensive, dynamic and individualized strategies to improve exacerbation-related selfmanagement behavior. The use of mobile health (mHealth) has potential to engage patients in managing their own health, to provide tailored support in developing self-management skills over time and to change health behaviors.

The aim of this thesis was twofold. In part one, we aimed to generate a better understanding of self-management behavior of patients with COPD and explore whether the use of mHealth is promising to enhance exacerbation-related selfmanagement. In part two, we aimed to develop an evidence-driven, attractive and usable mHealth intervention to enhance exacerbation-related self-management in patients with COPD. This resulted in the Copilot app, a mobile app for patients with COPD that targets early detection of exacerbations and performing prompt actions. In part two, we described the development of the Copilot app in detail. During the development, proof for the Copilot app was collected by stepwise scientific underpinning of the working mechanism and usability of the app. Finally, the feasibility of the Copilot app in the daily practice of health care providers was evaluated.

\section{Part 1: Self-management and the potential of mHealth in patients with COPD}

The first part of this thesis provides insight into current self-management behavior of patients with COPD and the potential of mHealth to enhance exacerbation- 
related self-management. In chapter $\mathbf{2}$ we explored how activated patients with COPD are for self-management and which patient and disease characteristics are associated with activation for self-management. Activation refers to the knowledge, skills and confidence of patients for self-management of their chronic condition. In this cross-sectional study, data were collected among 290 patients by means of a questionnaire and chart review. We found that only a minority of the participants (15\%) was activated for self-management. Increased anxiety, a more negative illness perception, increased BMI, increased age, increased disease severity and less comorbidities were associated with a decrease in activation for self-management. The regression model including these determinants had an explaining variance of $17 \%$. This knowledge enables health care professionals to identify patients at risk of inadequate self-management, which is a first step towards targeting and tailoring of self-management interventions.

In chapter $\mathbf{3}$ we explored the underlying process of exacerbation-related selfmanagement behavior in patients with COPD. To develop a grounded theory, 15 semistructured interviews with patients were conducted to understand their experiences and perceptions toward exacerbation-related self-management. By following a cyclic process in which data collection and data analysis alternated, several patterns in exacerbations related self-management behavior were identified and a conceptual model describing factors influencing exacerbationrelated self-management was developed. Important factors influencing exacerbation-related self-management were: acceptance of COPD, knowledge of exacerbations, experiences with exacerbations, perceived severity of symptoms and social support. In addition, specific factors influencing the ability to recognize an exacerbation or the performance of self-management actions were identified. Our conceptual model shows that patterns in self-management behavior are dynamic in nature and can change in individual patients over time due to variability in influencing factors and disease progression. The new insights from our conceptual model can be used to tailor self-management support.

Chapter 4 describes a Delphi study in which we aimed to reach expert consensus on the most relevant set of self-management behaviors that can be targeted and influenced to maximally reduce the impact of exacerbations. First, based on literature and expert opinion, a conceptual exacerbation model was developed. Potential relevant self-management behaviors were formulated by the research team for each of the five phases of this conceptual model. Second, by using online surveys, a total of 19 experts rated the relevance and feasibility of the self-management behaviors. After two Delphi rounds, consensus within the 
expert panel was reached on a set of 17 self-management behaviors that were perceived both relevant and feasible to target and influence. We concluded that self-management support in patients with COPD should be dynamic over time and focus on improving self-management behavior before, during and after an exacerbation. The conceptual exacerbation model and identified set of relevant and feasible self-management behaviors can be used for future targeting and tailoring of self-management support.

To determine whether the use of mHealth is promising for exacerbation-related self-management support, perceptions of patients and health care providers towards the use of mHealth for self-management were explored. Chapter $\mathbf{5}$ describes a qualitative study in which focus group interviews were held with patients with COPD $(n=13)$ and health care providers $(n=6)$. The data were analyzed by a thematic analysis. The study showed that that most patients and health care providers had a positive attitude towards mHealth and perceived many benefits of using mHealth for self-management. The willingness to use mHealth for self-management of exacerbations was driven by the perceived benefits and barriers of using mHealth. Both patients and health care providers strengthened the need for a multicomponent and tailored mHealth intervention that improves patients' exacerbation-related self-management by determining their health status and providing adequate information, decision support and feedback on self-management behavior. Based on this study, we concluded that the use of mHealth for self-management of exacerbations is promising, although mHealth should always be used complementary to regular care.

The chapters in the first part of this thesis provided building blocks for the development of a new evidence-driven mHealth intervention to enhance exacerbation-related self-management in patients with COPD: the Copilot app. The Copilot app is a mobile app for patients with COPD that targets early detection of exacerbations and performing prompt actions with a specific focus on developing self-management skills over time.

\section{Part 2: A new mHealth intervention to enhance self-management in patients with COPD}

The second part of this thesis describes the development and early-stage feasibility evaluation of the Copilot app. The full user-centered design and development process of the Copilot app is described in detail in chapter 6 . This process consisted of four iterative phases: (1) background analysis and design 
conceptualization, (2) alpha usability testing with paper prototypes, (3) iterative software development, and (4) field usability testing with the first version of the app. Patients with COPD, health care providers, COPD experts, designers, software developers, and a behavioral scientist were involved throughout the design and development process. The intervention was developed using the Behavior Change Wheel, a theoretically based approach for designing behavior change interventions, and logic modeling was used to map out the potential working mechanism of the intervention. Furthermore, the principles of design thinking were used for the creative design of the intervention. The iterative development resulted in an evidence-driven and usable mHealth intervention: The Copilot app. As a result of our user-centered design and development process, the Copilot app meets the needs, preferences and capabilities of patients with COPD, is likely to be used by patients with COPD, and has a high potential to be effective in reducing exacerbation impact. The unique user-centered design and development process of the Copilot app can be used by researchers and designers as general guidance for the development of future mHealth interventions.

In Chapter $\mathbf{7}$ the feasibility of the Copilot app in the daily practice of health care providers was investigated as health care providers have an important role in providing the app to patients, personalizing the app and evaluating the app during consultations. A multimethods study was used to investigate how health care providers experience working with the app and how they perceive the feasibility of the app in their daily practice. In total, 14 health care providers were observed while performing tasks in the app and asked to think aloud. The System Usability Scale was used to investigate the usability of the app and semistructured interviews were held to explore the perceived feasibility of the app. This study showed that health care providers were able to work with the app and found the app acceptable to use. The app especially fits within the available time and workflow of nurses. Several factors that can affect the use of the app were identified: the autonomy of the professional, the focus of the organization on eHealth, costs associated with the app, and compatibility with the current systems used. Most health care providers expressed that there are conditions that must be met to be able to use the app. The app was perceived feasible to integrate into the existing care paths of primary, secondary and tertiary health care settings in the Netherlands. We concluded that the Copilot app is feasible to use in the daily practice of Dutch health care providers and that personalizing and evaluating the app best fits the role of the nurse. With this study, a new approach to evaluate the perceived feasibility of mHealth interventions at an early stage is provided. 
In chapter 8 we discuss important outcomes of this thesis. We give reflections on current self-management behavior of patients with COPD, the promise of mHealth for self-management support and on the added value of the Copilot app for COPD care. Furthermore, we reflect on the user-centered design and development of the Copilot app, describe lessons learned from this process and reflect on the scientist's role in developing mHealth interventions. Finally, we provide recommendations for clinical practice, research and education.

In conclusion, this thesis shows that the use mHealth is promising to enhance self-management of exacerbations in patients with COPD. It is important that the use of mHealth is complementary to regular care. This thesis provides more in-depth insight into self-management behavior of patients with COPD and factors that should be considered when developing mHealth interventions. The Copilot app developed in this thesis can learn patients with COPD to better detect exacerbations and to take prompt self-management actions. The Copilot app meets patients' needs, preferences and capabilities, is likely to be used by patients and has high potential to be effective in reducing exacerbation impact. The Copilot app is unique in the current field of mHealth due to its specific focus on developing self-management skills over time, is perceived to be feasible in Dutch COPD care and can contribute to more pro-active COPD care. The design and development of the Copilot app can be used as an example for science-driven and user-centered engineering of future mHealth interventions. 

Samenvatting 
De chronische obstructieve longziekte COPD is wereldwijd een van de meest voorkomende chronische ziekten en de op vier na grootste oorzaak van overlijden. Deze progressieve ziekte kent plotselinge periodes van tijdelijke verergering, ook wel exacerbaties of longaanvallen genoemd. Exacerbaties versnellen de achteruitgang in longfunctie, hebben een negatieve invloed op de kwaliteit van leven van patiënten, vergroten de kans op overlijden en leiden tot hoge zorgkosten. Zelfmanagement is essentieel om deze negatieve invloed op zowel de patiënt als de maatschappij te verminderen. Bij zelfmanagement wordt er van patiënten verwacht dat zij een actieve rol aannemen en verantwoordelijkheid nemen bij beslissingen die van invloed zijn op de ziekte. Het gaat hierbij om het managen van symptomen, behandeling, fysieke en psychosociale consequenties van het leven met een chronische aandoening. Zelfmanagement kan voor patiënten echter heel lastig zijn. Goede ondersteuning bij zelfmanagement is belangrijk om patiënten toe te rusten met de juiste vaardigheden om deze actieve rol aan te kunnen nemen en om gedrag te kunnen veranderen. Tot op heden hebben zelfmanagement interventies niet altijd effect op patiënten. Dit komt mogelijk doordat zelfmanagement interventies meestal niet 'op maat' worden aangeboden en geen rekening houden met individuele patronen in exacerbaties en gedrag. Er is behoefte aan meer uitgebreide, dynamische en individuele oplossingen om zelfmanagement rondom exacerbaties te verbeteren. Het gebruik van mobile health, ook wel mHealth genoemd, heeft potentie om patiënten meer te betrekken bij het managen van hun aandoening, op maat ondersteuning te bieden in het ontwikkelen van zelfmanagement vaardigheden en om gedrag te veranderen.

Het doel van dit proefschrift was tweeledig. In het eerste deel van dit proefschrift beoogden we beter begrip te krijgen in zelfmanagement gedrag van patiënten met COPD. Daarnaast wilden we verkennen of het gebruik van mHealth kansrijk is om zelfmanagement rondom exacerbaties te verbeteren. In deel twee van dit proefschrift was het doel om een op wetenschappelijke kennis gebaseerde, aantrekkelijke en gebruiksvriendelijke mHealth interventie te ontwikkelen om zelfmanagement rondom exacerbaties te verbeteren. Dit heeft geresulteerd in de Copiloot app, een mobiele app voor patiënten met COPD die zich richt op vroegtijdige herkenning van exacerbaties en het nemen van de juiste acties op het juiste moment. In deel twee van dit proefschrift hebben we de ontwikkeling van de Copiloot app gedetailleerd beschreven. Tijdens de ontwikkeling is er stapsgewijs wetenschappelijk bewijs verzameld om het werkingsmechanisme van de app en de bruikbaarheid van de app te onderbouwen. Tot slot is de haalbaarheid van de Copiloot app in de dagelijkse praktijk van zorgverleners in kaart gebracht. 


\section{Deel 1: Zelfmanagement en de potentie van mHealth bij patiënten met COPD}

Het eerste deel van dit proefschrift geeft inzicht in het huidige zelfmanagement gedrag van patiënten met COPD en de potentie van mHealth om zelfmanagement rondom exacerbaties te verbeteren. In hoofdstuk 2 hebben we verkend hoe geactiveerd patiënten met COPD zijn voor zelfmanagement en welke patiënt- en ziekte karakteristieken geassocieerd zijn met activatie voor zelfmanagement. Met activatie voor zelfmanagement wordt bedoeld: de kennis, vaardigheden en het vertrouwen van patiënten in het kunnen managen van de chronische aandoening. In deze cross-sectionele studie zijn er door middel van vragenlijsten en dossieronderzoek gegevens verzameld van 290 patiënten. Hieruit bleek dat slechts een minderheid van de patiënten (15\%) geactiveerd was voor zelfmanagement. Verhoogde mate van angst, een meer negatieve ziekteperceptie, verhoogde BMI, oudere leeftijd, toegenomen ziekte ernst en minder co-morbiditeiten waren geassocieerd met een afname van activatie voor zelfmanagement. Het regressie model waarin deze factoren overbleven had een verklaarde variante van $17 \%$. De kennis uit dit onderzoek kan zorgverleners helpen om patiënten met een risico op inadequaat zelfmanagement te identificeren. Dit is een eerste stap naar het meer doelgericht en op maat aanbieden van zelfmanagement interventies.

In hoofdstuk $\mathbf{3}$ hebben we het onderliggende proces van exacerbatiegerelateerd zelfmanagement gedrag van patiënten met COPD verder verkend. Een 'grounded theory' (of gefundeerde theorie) studie werd uitgevoerd. Er zijn 15 semigestructureerde interviews gehouden met patiënten om inzicht te krijgen in hun ervaringen en percepties ten aanzien van zelfmanagement rondom exacerbaties. Aan de hand van een cyclisch proces, waarbij dataverzameling en data analyse elkaar afwisselden, zijn verschillende patronen in exacerbatie-gerelateerd zelfmanagement gedrag geïdentificeerd en is er een conceptueel model ontwikkeld dat factoren weergeeft die zelfmanagement gedrag beïnvloeden. Belangrijke factoren waren: acceptatie van COPD, kennis van exacerbaties, ervaringen met exacerbaties, ervaren ernst van symptomen en sociale steun. Daarnaast zijn er factoren geïdentificeerd die specifiek invloed hebben op het herkennen van exacerbaties of het nemen van zelfmanagement acties. Ons conceptuele model laat zien dat patronen in zelfmanagement gedrag dynamisch zijn en in de loop van de tijd kunnen veranderen in individuele patiënten, als gevolg van variabiliteit in factoren die van invloed zijn op zelfmanagement en ziekteprogressie. De nieuwe inzichten van ons conceptuele model kunnen gebruikt worden om meer op maat zelfmanagementondersteuning te bieden. 
Hoofdstuk 4 beschrijft een Delphi studie waarin we beoogden met experts overeenstemming te bereiken over de meest relevante en haalbare zelfmanagement gedragingen die beïnvloed kunnen worden om de impact van exacerbaties zoveel mogelijk te verminderen. In een eerste stap werd er op basis van de literatuur en de meningen van experts een conceptueel exacerbatie model ontwikkeld. Voor elk van de vijf fases van dit model werden door het onderzoeksteam potentieel relevante zelfmanagement gedragingen geformuleerd. In een tweede stap hebben in totaal 19 experts, door middel van online vragenlijsten, de relevantie en haalbaarheid van de vooraf bepaalde zelfmanagement gedragingen beoordeeld. Na twee Delphi rondes werd er binnen het expert panel consensus bereikt over een set van 17 zelfmanagement gedragingen die zowel relevant als haalbaar werden geacht om te beïnvloeden. We hebben geconcludeerd dat zelfmanagementondersteuning aan patiënten met COPD dynamisch zou moeten worden aangeboden in het verloop van de tijd en zich zou moeten focussen op het bevorderen van zelfmanagement gedrag zowel voor, tijdens als na een exacerbatie. Het conceptuele exacerbatie model en de geïdentificeerde set van relevante en haalbare zelfmanagement gedragingen kan gebruikt worden voor het meer doelgericht en op maat aanbieden van zelfmanagementondersteuning in de toekomst.

Om te bepalen of het gebruik van mHealth kansrijk is om exacerbatie-gerelateerde zelfmanagementondersteuning te bieden zijn de percepties van zowel patiënten als zorgverleners ten aanzien van het gebruik van mHealth verkend. Hoofdstuk 5 beschrijft een kwalitatieve studie waarbij focus groep interviews gehouden zijn met patiënten met COPD $(n=13)$ en zorgverleners $(n=6)$. De gegevens werden geanalyseerd door middel van een thematische analyse. De studie liet zien dat de meeste patiënten en zorgverleners een positieve houding hadden ten aanzien van mHealth en veel voordelen van het gebruik van mHealth verwachten. De bereidheid om mHealth te gebruiken voor zelfmanagement rondom exacerbaties werd beïnvloed door de verwachte voordelen en nadelen van het gebruik van mHealth. Zowel patiënten als zorgverleners benadrukten de behoefte aan een uitgebreide, en op maat aangeboden, mHealth interventie voor het verbeteren van zelfmanagement rondom exacerbaties. Het is wenselijk dat een mHealth interventie adequate informatie geeft, ondersteuning biedt in het bepalen van de gezondheidstoestand, hulp bij het nemen van beslissingen, en feedback geeft op zelfmanagent gedrag. Op basis van deze studie hebben we geconcludeerd dat het gebruik van mHealth voor zelfmanagement van exacerbaties kansrijk is, maar dat mHealth altijd als toevoeging op de reguliere zorg ingezet zou moeten worden. 
De hoofdstukken in het eerste deel van dit proefschrift vormden bouwstenen voor het ontwikkelen van een nieuwe, op wetenschappelijke kennis gebaseerde mHealth interventie om exacerbatie-gerelateerd zelfmanagement gedrag van patiënten met COPD te verbeteren: de Copiloot app. De Copiloot app focust zich op het aanleren van zelfmanagement vaardigheden over de tijd en richt zich specifiek op vroegtijdige herkenning van exacerbaties het nemen van de juiste acties op het juiste moment.

\section{Deel 2: Een nieuwe mHealth interventie om zelfmanagement van patiënten met COPD te verbeteren}

Het tweede deel van dit proefschrift beschrijft de ontwikkeling en vroegtijdige evaluatie van de haalbaarheid van de Copiloot app. Het volledige gebruikersgerichte ontwerp- en ontwikkelproces van de Copiloot app wordt gedetailleerd beschreven in hoofdstuk 6. Dit proces bestond uit vier iteratieve fases: (1) achtergrond analyse en conceptualisatie van het ontwerp, (2) testen van papieren prototypes met eindgebruikers, (3) iteratieve software ontwikkeling en (4) testen van de eerste versie van de app met eindgebruikers. Patiënten met COPD, zorgverleners, COPD experts, ontwerpers, software ontwikkelaars en een gedragswetenschapper waren betrokken bij het proces van ontwerpen en ontwikkelen van de app. De interventie werd ontwikkeld aan de hand van het Behavior Change Wheel, een theoretisch kader voor het ontwikkelen van gedragsveranderingsinterventies, en er is een model ontwikkeld om het potentiele werkingsmechanisme van de interventie in kaart te brengen. Verder werden de principes van design thinking gebruikt voor het creatieve ontwerp van de interventie. De iteratieve ontwikkeling heeft geresulteerd in een op wetenschappelijke kennis gebaseerde en bruikbare mHealth interventie: De Copiloot app. Het gebruikersgerichte ontwerp- en ontwikkelproces heeft ertoe geleid dat de app voldoet aan de behoeften en voorkeuren van patiënten met COPD, waarschijnlijk gebruikt gaat worden door patiënten en een grote kans heeft om effectief te zijn in het verminderen van de impact van exacerbaties. Het unieke gebruikersgerichte ontwerp- en ontwikkelproces van de Copiloot app kan gebruikt worden door onderzoekers en ontwerpers als een leidraad voor de ontwikkeling van toekomstige mHealth interventies.

In hoofdstuk $\mathbf{7}$ is de haalbaarheid van de Copiloot app in de dagelijkse praktijk van zorgverleners onderzocht omdat zij een belangrijke rol hebben in het verstrekken van de app aan patiënten, het personaliseren van de app en het evalueren van de app tijdens consulten. In deze studie werden in totaal 14 zorgverleners 
geobserveerd bij het uitvoeren van taken in de app en gevraagd om hierbij hardop te denken. De System Usability Scale werd gebruikt om de bruikbaarheid van de app in kaart te brengen en semigestructureerde interventies werden afgenomen om percepties ten aanzien van de haalbaarheid van de app te inventariseren. Deze studie liet zien dat zorgverleners goed met de app konden werken en deze acceptabel in gebruik vonden. De app past het beste in de beschikbare tijd en werkzaamheden van verpleegkundigen. Er zijn een aantal factoren geïdentificeerd die het gebruik van de app kunnen beïnvloeden: de autonomie van de professional, de focus van een organisatie op eHealth, kosten van de app en de compatibiliteit met huidige systemen die gebruikt worden. Daarnaast zijn er voorwaarden in kaart gebracht waar aan voldaan moet worden om de app te kunnen gebruiken in de praktijk. Zorgverleners schatten in dat integratie van de app in de huidige zorgpaden in zowel eerste, tweede als derdelijns zorginstellingen haalbaar is. Op basis van deze studie hebben we geconcludeerd dat het gebruik van de Copiloot haalbaar is in de dagelijkse praktijk van zorgverleners in Nederland en dat het personaliseren en evalueren van de app het beste past bij de rol van de verpleegkundige. Dit onderzoek toont een nieuwe werkwijze om vroegtijdig de haalbaarheid van mHealth interventies te evalueren.

In hoofdstuk 8 bediscussiëren we de belangrijkste bevindingen van dit proefschrift. We reflecteren op het huidige zelfmanagement gedrag van patiënten met COPD, de kansrijkheid van mHealth voor het ondersteunen van zelfmanagement en op de toegevoegde waarde van de Copiloot app voor de COPD zorg. Daarnaast reflecteren we op het gebruikersgerichte ontwerpen ontwikkelproces van de Copiloot app, beschrijven we de lessen die we hieruit geleerd hebben en reflecteren we op de rol van wetenschappers in het ontwikkelen van mHealth interventies. Tot slot geven we aanbevelingen voor de klinische praktijk, onderzoek en onderwijs.

Samengevat, dit proefschrift laat zien dat het gebruik van mHealth veelbelovend is om zelfmanagement rondom exacerbaties bij patiënten met COPD te bevorderen. Belangrijk is hierbij te noemen dat het gebruik van een mHealth interventie een toevoeging zou moeten zijn op de reguliere zorg. Dit proefschrift geeft meerdere diepgaande inzichten in zelfmanagement gedrag van patiënten met COPD en factoren waarmee rekening moet worden gehouden bij het ontwikkelen van mHealth interventies. De Copiloot app, die ontwikkeld is in het kader van dit proefschrift, kan patiënten met COPD helpen om beter exacerbaties te herkennen en op het juiste moment de juiste zelfmanagement acties te ondernemen. De Copiloot app voldoet aan de behoeften, voorkeuren en mogelijkheden van 
patiënten, gaat waarschijnlijk gebruikt worden door patiënten en heeft grote kans om effectief te zijn in het verminderen van de impact van exacerbaties. De Copiloot app is uniek in het huidige landschap van mHealth door de specifieke focus op het ontwikkelen van zelfmanagement vaardigheden over de tijd, wordt haalbaar geacht in de Nederlandse COPD zorg en kan daarmee bijdragen aan meer proactieve COPD zorg. Het ontwerp- en ontwikkel proces van de Copiloot app kan gebruikt worden als voorbeeld voor de ontwikkeling van op wetenschappelijke kennis gebaseerde en gebruikersgerichte mHealth interventies. 



\section{List of publications and presentations}




\section{Scientific publications}

Korpershoek YJG, Holtrop T, Vervoort SCJM, Schoonhoven L, Schuurmans MJ, Trappenburg JCA. Early-stage feasibility of a mobile health intervention (Copilot) to enhance exacerbation-related self-management in patients with chronic obstructive pulmonary disease: multimethods approach. JMIR Form Res. 2020;4(11);e21577. doi:10.2196/21577

Korpershoek YJG, Hermsen S, Schoonhoven L, Schuurmans MJ, Trappenburg JCA. User-centered design of a mobile health intervention to enhance exacerbationrelated self-management in patients with chronic obstructive pulmonary disease (Copilot): mixed methods study. J Med Internet Res. 2020;22(6);e15449. doi: 10.2196/15449.

Korpershoek YJG, Vervoort SCJM, Trappenburg JCA, Schuurmans MJ. Perceptions of patients with chronic obstructive pulmonary disease and their health care providers towards using mHealth for self-management of exacerbations: a qualitative study. BMC Health Serv Res. 2018;18(1):757. doi:10.1186/s12913-018-3545-4

Korpershoek YJ, Bruins Slot JC, Effing TW, Schuurmans MJ, Trappenburg JC. Selfmanagement behaviors to reduce exacerbation impact in COPD patients: a Delphi study. Int J Chron Obstruct Pulmon Dis. 2017;12:2735-2746. doi:10.2147/COPD. S138867

Korpershoek Y, Vervoort S, Nijssen L, Trappenburg J, Schuurmans MJ. Factors influencing exacerbation-related self-management in patients with COPD: a qualitative study. Int J Chron Obstruct Pulmon Dis. 2016;11:2977-2990. doi:10.2147/ COPD.S116196

Korpershoek Y, Bos-Touwen ID, de Man-van Ginkel JM, Lammers JW, Schuurmans MJ, Trappenburg J. Determinants of activation for self-management in patients with COPD. Int J Chron Obstruct Pulmon Dis. 2016;11:1757-1766. doi:10.2147/ COPD.S109016

Bos-Touwen I, Schuurmans M, Monninkhof EM, Korpershoek Y, Spruit-Bentvelzen L, Ertugrul-van der Graaf I, de Wit N, Trappenburg J. Patient and disease characteristics associated with activation for self-management in patients with diabetes, chronic obstructive pulmonary disease, chronic heart failure and chronic renal disease: a cross-sectional survey study. PLoS One. 2015;10(5):e0126400. doi: 10.1371/journal.pone.0126400. 


\section{Scientific presentations}

- User centered development of an mHealth intervention to enhance selfmanagement of exacerbations in patients with chronic obstructive pulmonary disease (COPD). Presentation at CBC conference 2018: Behaviour Change for Health, London, United Kingdom, 2018.

- Self-management behaviors to reduce exacerbation impact in COPD patients: a Delphi study. Poster presentation at American Thoracic Society, International Conference, Washington, California, 2017.

- User-centered development of a mobile action plan to enhance self-management including early detection of exacerbations in patients with chronic obstructive pulmonary disease. Presentation at European Nursing Conference, Rotterdam, The Netherlands, 2016 and at STTI European Conference, Utrecht, The Netherlands, 2016.

- Factors influencing exacerbation-related self-management in patients with chronic obstructive pulmonary disease (COPD): a qualitative study. Presentation at European Nursing Conference, Rotterdam, The Netherlands, 2016 and at STTI European Conference, Utrecht, The Netherlands, 2016.

- Determinants of self-management capacity of patients with COPD. Presentation at American Thoracic Society, International Conference, San Diego, California, 2014. Winner of the American Thoracic Society Abstract Scholarship Award, ATS Assembly on nursing.

\section{Practice presentations}

- mHealth voor het bevorderen van zelfmanagement bij COPD patiënten rondom een longaanval. Presentation at 'De week van de Iongen', Ermelo, The Netherlands, 2018.

- Zelfmanagement: 'Alles op afstand?' Kansen in de zorg voor longpatiënten en uitdagingen in de ontwikkeling van zelfmanagement interventies 'op afstand'. Seminar CIRO pulmonary rehabilitation, Horn, The Netherlands, 2018.

- $\quad m$ Health ter bevordering van zelfmanagement bij COPD exacerbaties: Stapsgewijze ontwikkeling van een interventie. Presentation at 'De week van de longen', Ermelo, The Netherlands, 2017.

- Zelfmanagement op maat: Uitdagingen voor de toekomst! Lecture at COPD network, Utrecht, The Netherlands, 2017.

- COPD Longaanval app. Pitch Ureka Mega Challenge, University Medical Center Utrecht, Utrecht, The Netherlands, 2017. Winner of Ureka Mega Challenge 2017. 
- Zelfmanagement op maat: Uitdagingen voor de toekomst! Lecture at 'Longdag AstraZeneca', Utrecht, The Netherlands, 2016.

- Zelfmanagement. Wat betekent dit voor de verpleegkundige praktijk? Lecture at St. Antonius Hospital, Utrecht, The Netherlands, 2015.

\section{Educational presentations}

- Van wetenschap tot valorisatie...uitdagingen voor een wetenschapper. Presentation at 'impact of research' workshop, Julius Center, University Medical Center Utrecht, Utrecht, The Netherlands, 2018.

- Zelfmanagement: Een uitdaging voor verpleegkundigen. Lecture at bachelor of Nursing, University of Applied Sciences, Utrecht, The Netherlands, 2018.

- Mhealth voor het bevorderen van zelfmanagement bij COPD exacerbaties: Ontwikkeling van een interventie. Presentation at Science and Nursing Practice course at premaster Clinical Health Sciences, Utrecht, The Netherlands, 2017.

- Mobile Action plan to enhance self-management and early detection of exacerbations in patients with COPD. Presentation at symposium Clinical Health Sciences, Utrecht, The Netherlands, 2016. 
List of publications and presentations 

Dankwoord 
Het is zover, mijn proefschrift is af! In de afgelopen jaren dat ik hieraan heb gewerkt heb ik vaak beseft hoe fijn het is dat mensen bereid waren om deel te nemen aan de onderzoeken, hoe leuk het is om hierbij met anderen samen te werken en hoe bijzonder het is dat er zoveel mensen met je meeleven. Graag wil ik stilstaan bij de mensen die direct of indirect hebben bijgedragen aan de totstandkoming van dit proefschrift.

Allereerst wil ik graag alle patiënten bedanken die hebben deelgenomen aan de onderzoeken in dit proefschrift. Dank u wel voor uw tijd, het delen van uw ervaringen en voor het meedenken over hoe we de Copiloot app zo goed mogelijk konden laten aansluiten bij de wensen van de eindgebruiker. Ook wil ik alle zorgverleners bedanken die hebben meegewerkt aan de onderzoeken en in verschillende fases een belangrijke bijdrage hebben geleverd aan de ontwikkeling van de Copiloot app.

Veel dank gaat uit naar mijn promotieteam dat werd gevormd door prof. dr. L. Schoonhoven, prof. dr. Marieke Schuurmans en dr. J.C.A. Trappenburg. Bedankt dat jullie mij de kans hebben geboden om aan dit onderzoek te werken! Beste Marieke, mede dankzij jou heb ik de keuze gemaakt om voor dit promotieonderzoek te gaan. Jij kunt als geen ander mensen inspireren en enthousiasmeren voor het verpleegkundig vak en wetenschappelijk onderzoek. Jouw kunde om de dingen in het juiste perspectief te plaatsen heeft mij enorm geholpen bij het nemen van beslissingen. Daar heb ik veel aan gehad en dat heb ik erg gewaardeerd. Bedankt voor je goede begeleiding, je scherpte en je persoonlijke interesse. Het was een voorrecht om met je te mogen samenwerken. Beste Lisette, op een later moment in mijn promotietraject werd jij mijn promotor. Dank je wel dat je vanaf dat moment zo betrokken was bij mijn onderzoek. Ik heb veel gehad aan jouw inbreng tijdens de promotie overleggen. Fijn dat je meedacht over eerder gemaakte keuzes en dat je de resultaten van mijn onderzoek wist te plaatsen in een breder perspectief. Zeker bij het afronden van dit proefschrift heb ik hier veel aan gehad. Beste Jaap, jij hebt mij geïntroduceerd in de 'wereld van de wetenschap'. Vanaf mijn afstudeeronderzoek bij de master Verplegingswetenschap tot nu heb jij een belangrijke rol gespeeld. Bedankt voor alle kansen die je me hebt geboden, voor jouw vertrouwen in mij en jouw positiviteit tijdens dit promotietraject. Ik heb van jou geleerd om altijd in mogelijkheden te denken en om successen te vieren. Wat was het een avontuur, het ontwikkelen van een app. Dank je wel voor alle energie die je daarin hebt gestoken. En wat was het bijzonder om samen met jou de Ureka Mega Challenge 2017 te winnen. Ik kijk er naar uit om de Copiloot app een stap verder te brengen! 
Graag wil ik de leden van de beoordelingscommissie prof. dr. F.E. Scheepers, prof. dr. J.E.W.C. van Gemert-Pijnen, prof. dr. M.L. Bouvy, prof. dr. N.H. Chavannes en prof. dr. T. Jaarsma hartelijk danken voor het lezen en beoordelen van mijn proefschrift.

Een aantal co-auteurs wil ik in het bijzonder bedanken. Sander Hermsen, wat heb ik veel gehad aan jouw expertise op het gebied van design en gedragswetenschappen bij het ontwikkelen van de Copiloot app. Jij hebt echt geholpen met het maken van de vertaalslag van theorie naar creatief design. Dank je wel dat je zo goed meedacht, voor jouw heldere kijk op zaken en voor je support in het maken van keuzes tijdens de ontwikkeling van de app.

Sigrid Vervoort, als expert op het gebied van kwalitatief onderzoek was jij bij drie onderzoeken betrokken. Bedankt dat ik zoveel van je heb mogen leren. Met jou was het sparren over analyses altijd gezellig!

Tanja Effing, jouw betrokkenheid en expertise bij het uitvoeren van de Delphi studie was heel waardevol. Ik kijk met veel plezier terug op onze samenwerking.

Ook gaat mijn bijzondere dank uit naar prof. dr. Jan-Willem Lammers. Bij de start van mijn promotieonderzoek waren we beiden nog werkzaam op de longafdeling in het UMC Utrecht en bent $u$ betrokken geweest bij één van de onderzoeken. Vandaag bent $u$ aanwezig als voorzitter van mijn verdediging. Bedankt voor uw steun en betrokkenheid.

En dan mijn TASTE-collega's: Nini Jonkman, Irene Bos-Touwen en Heleen Westland. Jullie zijn samen gestart met het onderzoek binnen de TASTE onderzoekslijn. Wat was het leuk om later bij jullie aan te mogen sluiten en met jullie ervaringen te kunnen delen. Door onze TASTE-overleggen én de gezellige koffie- en lunchmomenten vormden wij een (h)echt team. Nini, jij promoveerde al vrij snel. Bedankt dat je in de opstartfase van mijn onderzoek af en toe met me mee wilde denken. Irene, wat was het leuk om met jou samen te werken bij één van de onderzoeken en gezellig om later met jou op een kamer te zitten in het Julius Centrum. Heleen, de afgelopen jaren hebben wij veel met elkaar opgetrokken. Wat was het fijn om zoveel met elkaar te kunnen delen over werk maar ook privé. En het belangrijkste: om met elkaar te kunnen lachen. Ik ben heel blij dat jij vandaag mijn paranimf bent. 
Nienke Bleijenberg, wat ontzettend fijn dat ik met jou ervaringen kon uitwisselen en de stappen binnen mijn promotieonderzoek kon bespreken. Dit heb ik erg gewaardeerd. Ook wil ik je bedanken voor de kansen die er voor mij liggen binnen het lectoraat én de Academische Werkplaats Verpleegkunde in de wijk. Ik kijk uit naar onze verdere samenwerking.

Graag wil ik de studenten van de master Gezondheidswetenschappen, master Verplegingswetenschap en de bachelor Verpleegkunde bedanken die betrokken zijn geweest bij onderdelen van mijn promotieonderzoek. Een aantal studenten wil ik graag noemen: Lisa Nijssen, Joyce Bruins Slot en Tjitske Holtrop. Jullie hebben alle drie een belangrijke bijdrage geleverd aan het verzamelen van gegevens voor dit proefschrift. Dank voor jullie inzet! Ik vond het erg leuk dat jullie betrokken bleven om de onderzoeken uit te werken tot een publicatie.

Ook wil ik een aantal mensen bedanken die een belangrijke rol hebben gespeeld bij de ontwikkeling van de Copiloot app. Mario de Zeeuw, Jochem Wilson en Beatrijs Van Hoof van Panton BV, dank voor de fijne samenwerking bij het ontwerp van de Copiloot app en jullie introductie in 'de wereld van design'. Jullie expertise, betrokkenheid en positieve energie heb ik erg gewaardeerd. Jochem en Beatrijs, wat was het fijn om te merken dat jullie zo goed onze wetenschappelijke inzichten konden vertalen naar een creatief ontwerp. Beatrijs, jou wil ik in het bijzonder bedanken. Toen ik nadacht over de voorkant van mijn proefschrift, wist ik zeker dat jij goede ideeën zou hebben over een passend ontwerp. Ontzettend bedankt dat jij de cover van mijn proefschrift wilde ontwerpen, deze geeft voor mij weer waar het onderzoek in zijn totaliteit om draait.

Maurice Castagna en Rob Pando van Inspire BV, bedankt voor de fijne samenwerking bij de software ontwikkeling van de Copiloot app.

Walter van Litsenburg, dank je wel dat ik jou af en toe kon vragen om mee te denken over de Copiloot app. Ik heb veel aan jouw inzichten vanuit de praktijk gehad.

Saskia Weldam, fijn dat ik met jou ervaringen kon delen over COPD onderzoek en bedankt dat je moderator wilde zijn bij één van de focusgroep interviews.

Wendela de Lange, wat leuk dat we enkele jaren geleden nog samen op de longafdeling werkten als verpleegkundige en nu kunnen brainstormen over onderzoek naar technologische innovaties in de zorg. Dank je wel daarvoor! 
Carolien Verstraten, wij hebben veel gedeeld tijdens ons promotieonderzoek. Dank voor je betrokkenheid, het meedenken en je humor.

Mijn collega's en oud-collega's van het lectoraat Chronisch Zieken van de Hogeschool Utrecht (HU), wat is het fijn om onderdeel uit te maken van zo'n enthousiaste groep! Jullie interesse, jullie expertise, jullie meedenken en jullie gezelligheid hebben mij de afgelopen jaren veel gebracht. Sigrid Müller, Thóra Hafsteinsdottir, Roelof Ettema, Pieterbas Lalleman, Debbie ten Cate, Jeroen Dikken en Mariska van Dijk, jullie waren mijn collega's toen ik startte met promotieonderzoek. Of het nu ging om het wegwijs maken binnen de HU, brainstormen over onderzoeksmethoden of het maken van een filmpje over mijn onderzoek, ik kon altijd bij jullie terecht. Dank jullie wel daarvoor! Debbie, wij zijn ongeveer gelijktijdig gestart met ons promotieonderzoek. Heerlijk dat we de promotieperikelen met elkaar konden delen. Nienke Dijkstra, Linda Smit, Jessica Veldhuizen en Yvonne Jordens, jullie kwamen even later bij het lectoraat. Naast een frisse blik op onderzoek en veel enthousiasme brachten jullie ook veel initiatieven ter ontspanning. Super belangrijk! Ik ben blij met jullie als collega's. Janneke de Man, ik heb jou jaren geleden leren kennen toen ik als student verpleegkunde stage liep in het UMC Utrecht. Daarna hebben onze wegen zich vaak gekruist. Dank je wel voor je interesse en betrokkenheid door de jaren heen. En dan mijn collega's die in de afgelopen twee jaar het lectoraat zijn komen versterken: Dagmar van Nimwegen, Inge Wolbers, Anja Rieckert, Hugo Schalkwijk, Dieke Martini, Wietske Ham, Rixt Zuidema en Selma Wegkamp. Wat zijn jullie een mooie aanwinst voor het team. Ik kijk er naar uit om verder met jullie samen te werken. Tot slot, Ymkje Damsma, dank je wel voor je interesse en alle organisatorische steun door de jaren heen!

Ook wil ik mijn collega's van het Instituut Verpleegkundige Studies bedanken. Een paar mensen wil ik graag noemen. Carolien Sino, dank je wel voor je steun en betrokkenheid in de eerste jaren van mijn promotieonderzoek waarin je mijn leidinggevende was. Marleen Schultz, jij werd later mijn leidinggevende. Wat ontzettend fijn dat er in onze gesprekken altijd twee belangrijke, relativerende vragen waren: 'Weet je al welke jurk je gaat dragen bij je promotie?' en 'Hoe gaat de voorkant van je boekje eruit zien?' Dank je wel voor je interesse en de fijne samenwerking! Josien Engel, wat was het leuk om samen met jou een groep studenten te begeleiden bij hun afstudeeronderzoek en wat was je een goede moderator bij één van de focusgroep interviews, dank je wel daarvoor! Marlies Schrijvers en Mieke Brouwer, jullie waren eerst mijn collega's bij de premaster Verplegingswetenschap en later bij Verpleegkunde. Bedankt voor jullie interesse 
de afgelopen jaren. Fijn om af en toe even met jullie bij te kunnen praten! Thijs van Houwelingen, leuk dat onze onderzoeken raakvlakken hebben. Dank je wel voor het delen van recente ontwikkelingen rondom zorgtechnologie en het stellen van een kritische vraag op z'n tijd.

Verder wil ik graag de collega's van de onderzoeksgroep Verplegingswetenschap en de aanwezigen van de researchbesprekingen bedanken voor hun interesse en het meedenken over mijn onderzoek.

En dan mijn (oud) kamergenoten van het Julius Centrum (kamer 6.125). Wat was het fijn om een aantal dagen per week met jullie op een kamer te werken! Dank voor jullie gezelligheid, jullie luisterend oor en vooral voor jullie humor.

Uiteraard wil ik ook mijn voormalig collega's van de longafdeling bedanken. Ik vond het heel leuk om in de eerste jaren van mijn promotieonderzoek nog af en toe een dienst op de afdeling te werken. Ariane van Wamel en Frits Stricker, dank voor de fijne samenwerking en dat jullie verdere ontwikkeling altijd hebben gestimuleerd.

Graag wil ik mijn vrienden en familie bedanken die de afgelopen jaren zo hebben meegeleefd. Dank voor jullie steun en betrokkenheid, maar vooral voor alle gezelligheid naast het werkende leven! Een paar vriendinnen wil ik in het bijzonder noemen. Allereerst Josette, al vanaf groep 1 van de basisschool hebben wij veel belangrijke momenten in ons leven samen meegemaakt. Dank je wel dat je er altijd voor me bent, voor je interesse en voor alles wat we met elkaar delen. Wat ben ik blij dat je bij dit belangrijke moment naast mij staat als mijn paranimf. Inge, vanaf onze studententijd trekken wij veel samen op en zorg je voor zowel gezelligheid als sportiviteit. Ik ben blij met jou als vriendin. Esther en Joline, wat leuk dat we de laatste jaren zoveel van elkaars leven meekrijgen. Wat heerlijk en relativerend om alle mooie, grappige en uitdagende momenten met onze kleintjes te kunnen delen. Evelien, wij leerden elkaar kennen toen we beiden begonnen met werken als verpleegkundige. Nog altijd kunnen we volop over 'ons vak' kletsen, maar vooral ook over al het andere dat ons bezig houdt. Marieke, ontzettend bedankt voor alle koffiemomentjes in het UMCU of de HU waarbij we over ons onderzoek konden sparren maar vooral ook over andere belangrijke dingen in het leven. Wynke en Tessa, ondanks dat we elkaar niet wekelijks zien, zijn jullie er toch altijd. Dank voor jullie vriendschap. 
En dan mijn lieve schoonfamilie: Oma, Emmy, Sander, Sanne, Emma, Benjamin en Rolien. Bedankt dat jullie altijd zo meeleven en belangstellend zijn. Heerlijk dat er zoveel interesses en hobby's worden gedeeld, waardoor werk altijd naar de achtergrond verdwijnt. Tijdens zo'n promotietraject werk dat heel relativerend. Ik bof maar met jullie.

Mijn bijzondere dank gaat uit naar mijn ouders. Lieve pap en mam, jullie hebben me altijd alle mogelijkheden geboden om me verder te kunnen ontwikkelen en me het vertrouwen gegeven dat ik dit kon. Dank voor jullie onvoorwaardelijke steun, jullie belangstelling en vooral voor jullie goede zorgen. Ik ben blij met jullie! En dan mijn lieve zussen Sylvia en Marieke, wat fijn dat ik jullie zo vaak zie en dat we alles samen kunnen delen. Ik kan me geen betere zussen wensen. Syl, dank je wel dat je altijd zo belangstellend bent en dat je zo'n leuke tante bent. Mariek, het is fijn om met jou ook de interesse in de gezondheidszorg te delen. Maar vooral ben ik blij dat we zoveel van elkaars leven meekrijgen en dat onze kinderen zo heerlijk met elkaar kunnen spelen. Bart, ik vind het altijd heel verfrissend om even jouw Twentse, nuchtere, kijk op zaken te horen. Dank je wel daarvoor. Milou en Bram, wat is het leuk om jullie tante te zijn!

En dan tot slot, lieve Marc, wat is het heerlijk om zo'n relaxed en positief persoon naast me te hebben, zeker bij zo'n promotietraject. Dank je wel voor je steun, relativeringsvermogen, geduld en liefde. Wie had ooit gedacht dat ik dit proefschrift zou afschrijven ten tijde van de Covid-19 pandemie waarin we allebei vanuit huis werkten met de kinderen om ons heen? Daarbij heb je me echt goed geholpen. Vooral wil ik je bedanken voor alle mooie momenten de afgelopen jaren. Wat ben ik ongelooflijk blij met jou.

Lieve Olle en Fien, het allermooiste van de afgelopen jaren is dat jullie in deze periode geboren zijn. Wat brengen jullie veel geluk in mijn leven. Ik ben ontzettend trots op jullie! 



\section{Curriculum Vitae}


Yvonne Korpershoek was born on May 30 1986 in Veenendaal, the Netherlands. In 2006, she started with the Bachelor of Nursing at the University of Applied Sciences Utrecht. In 2010, she obtained both her Bachelor's degree in Nursing (with Honors) and at the same time finished her pre-master in Nursing Science at Utrecht University. After her graduation, she started working as a nurse at a surgical department of the University Medical Center Utrecht and she participated in the Nursing Convent of the University

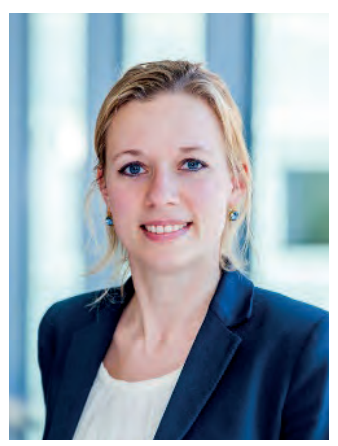
Medical Center Utrecht. In 2011, Yvonne started with the master in Nursing Science at Utrecht University. While attending this master study, she transferred to the lung department of the University Medical Center Utrecht to work as a senior nurse. Yvonne obtained her Master's degree (Cum Laude) in 2013. Her master thesis focusing on self-management in patients with COPD received an Abstract Scholarship Award from the American Thoracic Society in 2014. After her graduation, Yvonne continued working as a nurse and she started working as a lecturer at the premaster Nursing Science. In October 2014, Yvonne started her PhD project within the Tailored Self-management \& Ehealth (TASTE) research line at the research group Chronic Illnesses at the University of Applied Sciences Utrecht, in collaboration with the department of Nursing Science at the University Medical Center Utrecht. In the period 2014-2016, she combined her $\mathrm{PhD}$ project with her role as lecturer and nurse. In 2016, she continued working as a lecturer at the bachelor of Nursing. In 2017, Yvonne and her co-promotor Jaap Trappenburg won the Ureka Mega Challenge 2017, and received a grant of 50.000 euro for the development of the Copilot app for patients with COPD.

Yvonne continues her research activities at the University of Applied Sciences Utrecht and next to her research position, she started working as a linking pin between science, education and practice at the new Academic Nursing Practice in Primary Care Utrecht. 
Curriculum Vitae 
